\title{
A Multi-Year Plan for Research, Development, and Prototype Testing of Standard Modular Hydropower Technology
}

Approved for public release. Distribution is unlimited.
Brennan T. Smith Adam Witt Kevin M. Stewart Kyutae Lee Scott DeNeale Mark Bevelhimer et al.

February 2017 


\section{DOCUMENT AVAILABILITY}

Reports produced after January 1, 1996, are generally available free via US Department of Energy (DOE) SciTech Connect.

Website http://www.osti.gov/scitech/

Reports produced before January 1, 1996, may be purchased by members of the public from the following source:

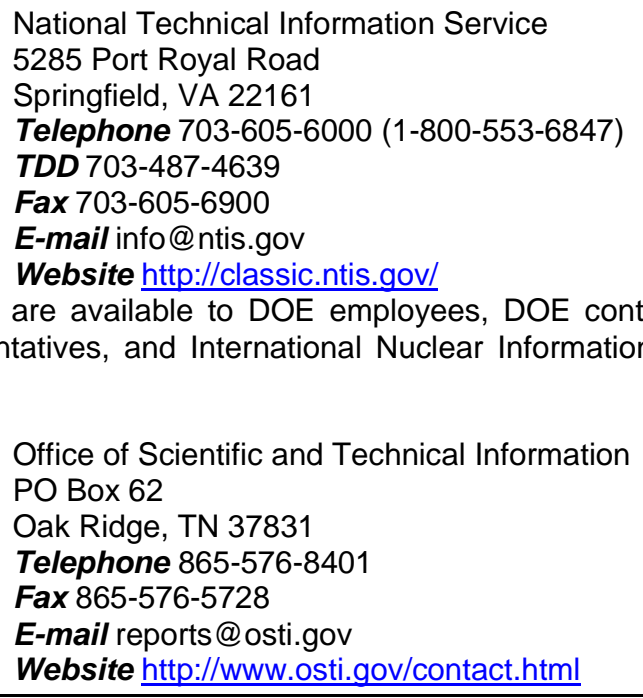

Office of Scientific and Technical Information

PO Box 62

Oak Ridge, TN 37831

Telephone 865-576-8401

Fax 865-576-5728

E-mail reports@osti.gov

Website http://www.osti.gov/contact.html

This report was prepared as an account of work sponsored by an agency of the United States Government. Neither the United States Government nor any agency thereof, nor any of their employees, makes any warranty, express or implied, or assumes any legal liability or responsibility for the accuracy, completeness, or usefulness of any information, apparatus, product, or process disclosed, or represents that its use would not infringe privately owned rights. Reference herein to any specific commercial product, process, or service by trade name, trademark, manufacturer, or otherwise, does not necessarily constitute or imply its endorsement, recommendation, or favoring by the United States Government or any agency thereof. The views and opinions of authors expressed herein do not necessarily state or reflect those of the United States Government or any agency thereof. 
Environmental Sciences Division

\title{
A MULTI-YEAR PLAN FOR RESEARCH, DEVELOPMENT, AND PROTOTYPE TESTING OF STANDARD MODULAR HYDROPOWER TECHNOLOGY
}

\author{
Oak Ridge National Laboratory \\ Brennan T. Smith \\ Adam Witt \\ Kevin M. Stewart \\ Kyutae Lee \\ Scott DeNeale \\ Mark Bevelhimer \\ Timothy A. Burress \\ Brenda Pracheil \\ Jason L. Pries \\ Patrick O'Connor \\ Rocio Uría-Martínez \\ Ryan McManamay \\ Shelaine Curd \\ Greg Zimmerman \\ The University of Tennessee-Knoxville \\ Kivanc Ekici Thanos Papanicolaou \\ Achilleas Tsakiris Benjamin Kutz

\section{Knight Piésold and Co.} \\ Norman Bishop

\section{McKeown and Associates LLC} \\ Alisha R. Fernandez \\ US Department of Energy \\ Timothy Welch \\ Daniel Rabon \\ Revision 1 \\ Date Published: February 2017 \\ Prepared by \\ OAK RIDGE NATIONAL LABORATORY \\ Oak Ridge, TN 37831-6283 \\ managed by \\ UT-BATTELLE, LLC \\ for the \\ US DEPARTMENT OF ENERGY \\ Contract DE-AC05-00OR22725
}





\section{CONTENTS}

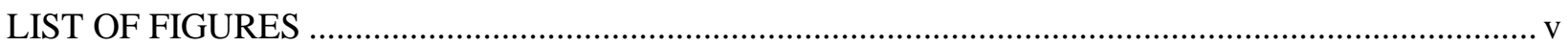

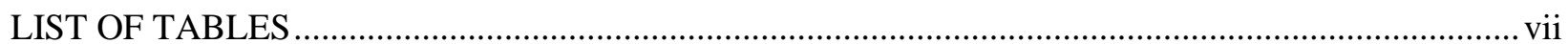

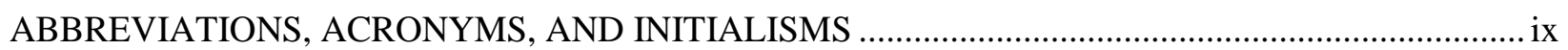

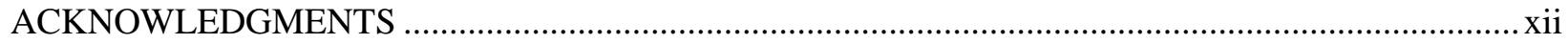

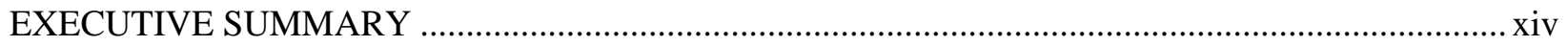

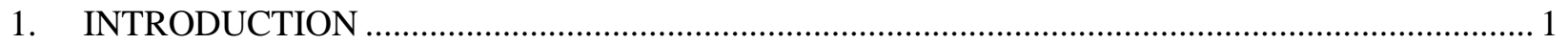

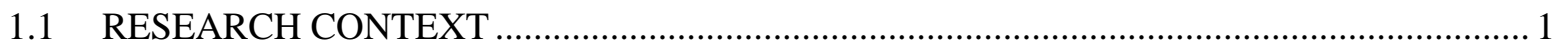

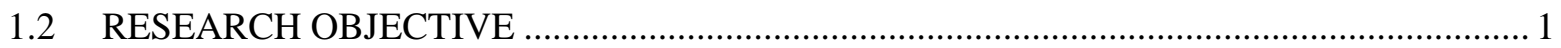

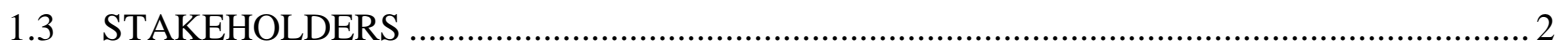

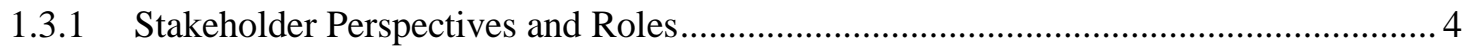

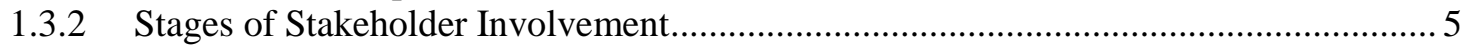

1.3.3 Mechanisms for Research Collaboration and Technology Transfer ............................. 6

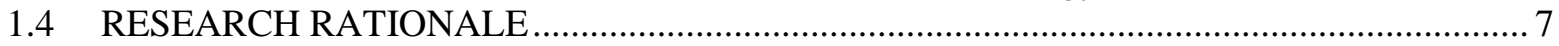

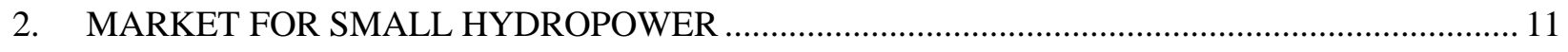

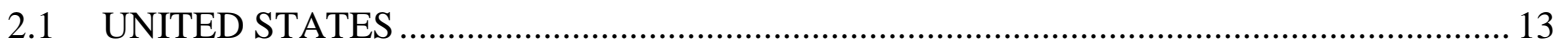

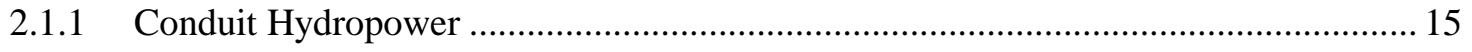

2.1.2 Non-Powered Dam Hydropower ...................................................................... 15

2.1.3 Opportunities for Efficient Minimum Flow Provision................................................ 16

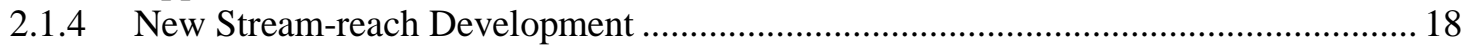

2.2 GLOBAL MARKET FOR SMALL HYDROPOWER TECHNOLOGY ............................. 19

2.2.1 Small Hydropower for Rural Electrification ............................................................ 19

2.2.2 Small Hydropower for Remote Systems and Microgrids ........................................ 20

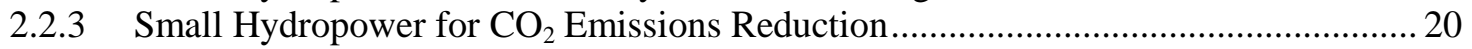

3. SMALL HYDROPOWER TECHNOLOGY STATUS, ADVANCES, AND CHALLENGES ........ 21

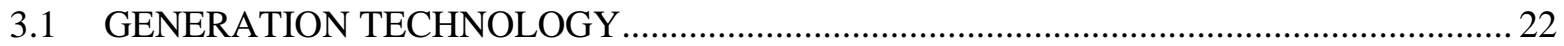

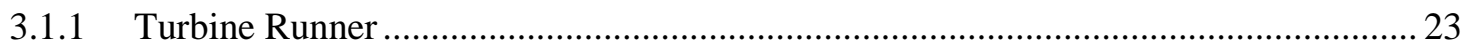

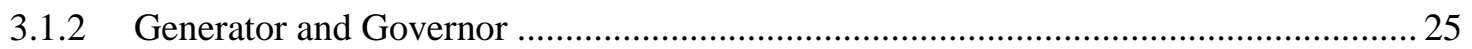

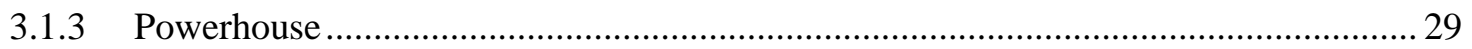

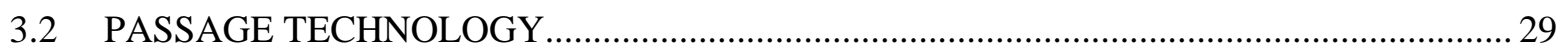

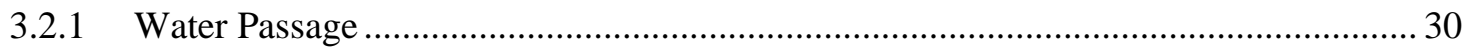

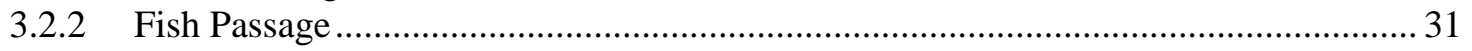

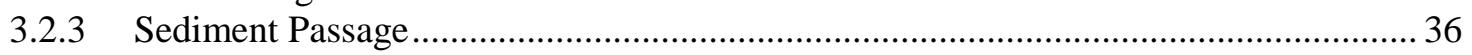

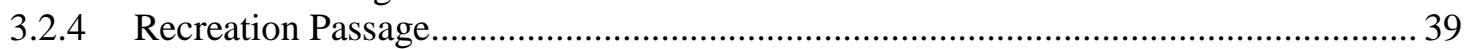

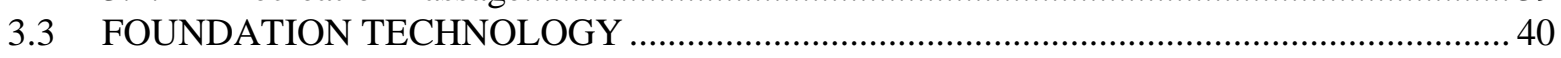

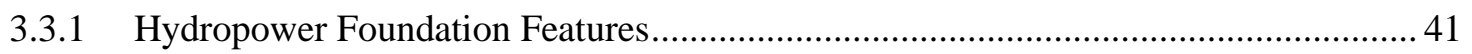

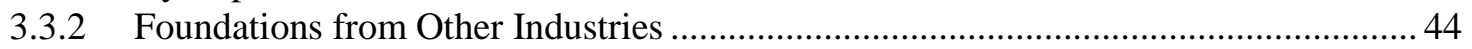

3.4 MONITORING AND CONTROL TECHNOLOGY ….................................................... 45

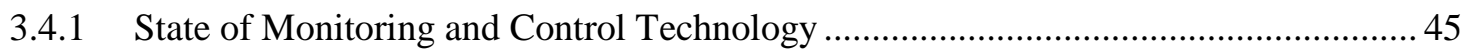

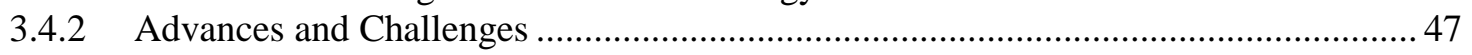

3.5 INTERCONNECTION TECHNOLOGY AND PARADIGMS .......................................... 47

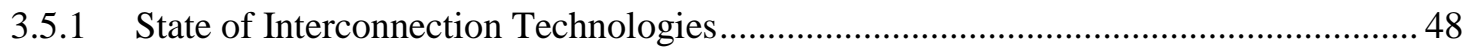

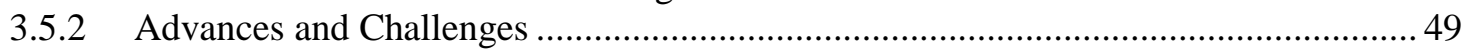

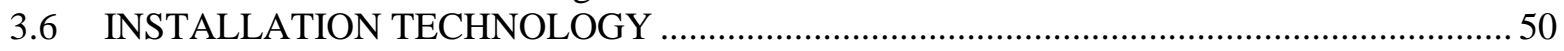

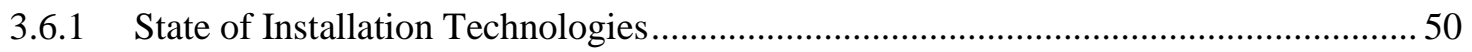

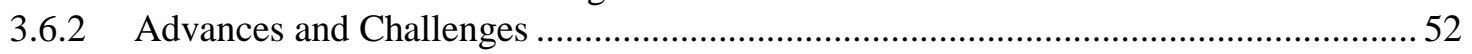

3.7 OPERATIONS AND MAINTENANCE TECHNOLOGY AND PARADIGMS .................. 53

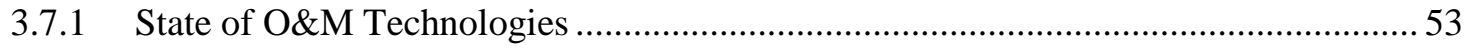

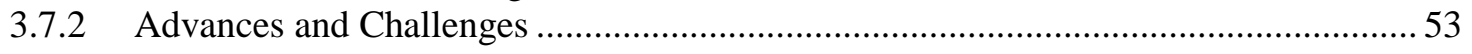


4. SMALL HYDROPOWER PROJECT DEVELOPMENT CONSIDERATIONS ...........................55

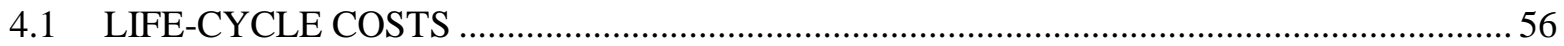

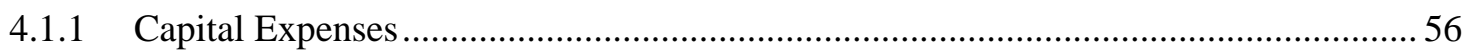

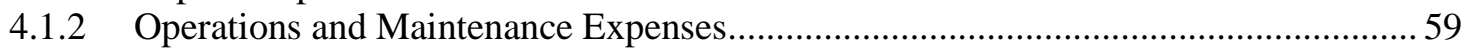

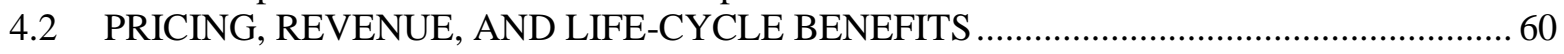

4.3 ENVIRONMENTAL IMPACT, ACCEPTANCE, AND SUSTAINABILITY .................... 61

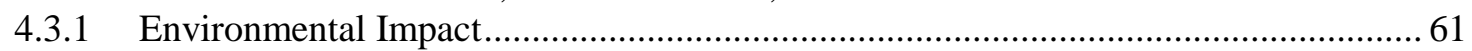

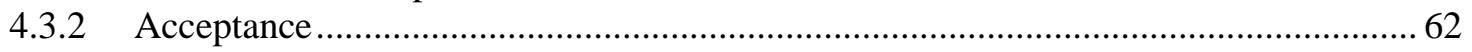

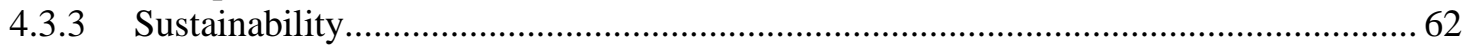

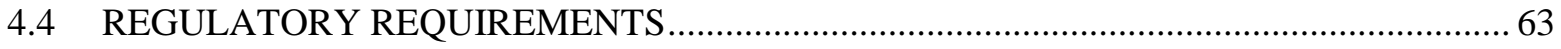

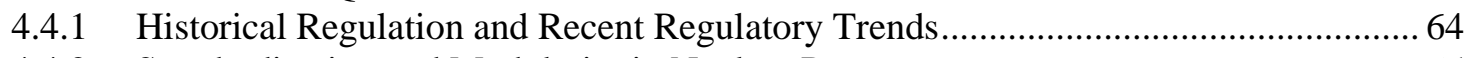

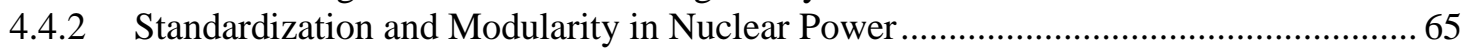

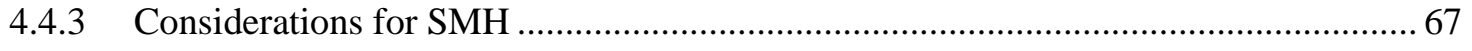

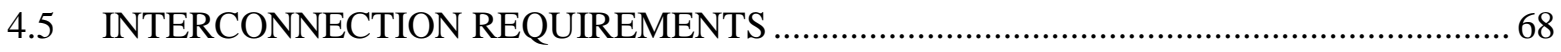

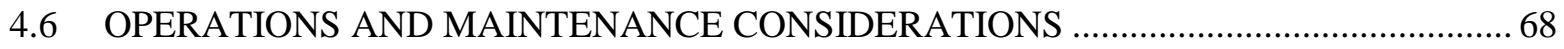

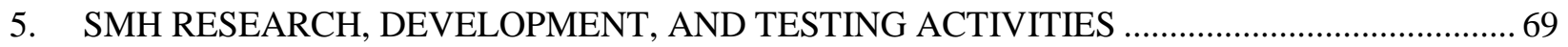

5.1 SMH EXEMPLARY DESIGN ENVELOPE SPECIFICATION ….................................. 71

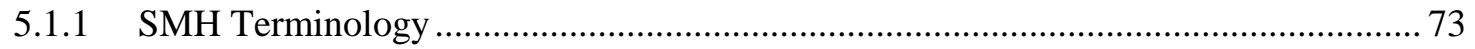

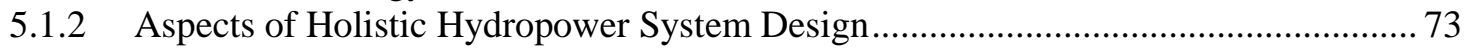

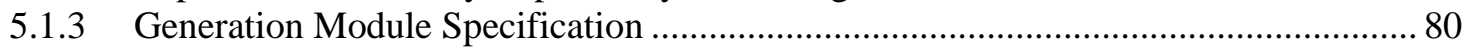

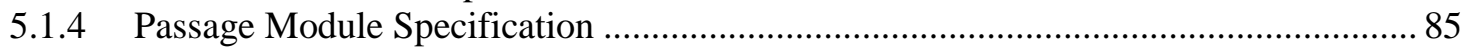

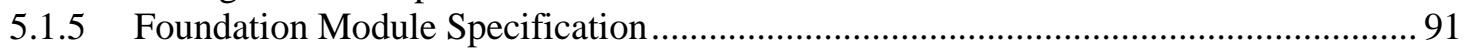

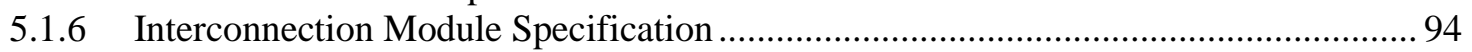

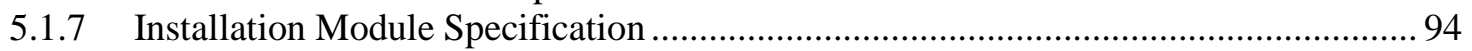

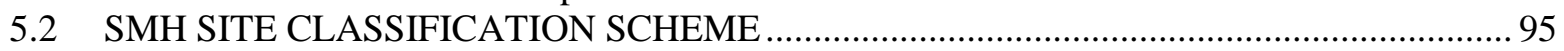

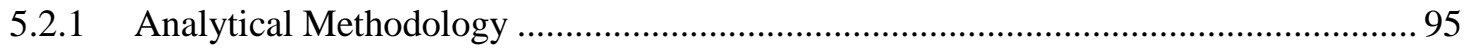

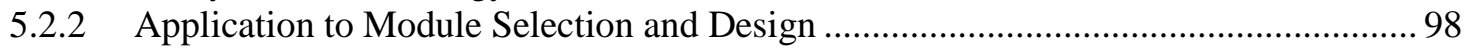

5.3 SMH SIMULATION AND MODELING CAPABILITY ............................................... 98

5.3.1 Criteria for Simulation and Modeling Efficacy .................................................... 99

5.3.2 Scale and Structure of Simulation and Modeling .................................................. 101

5.3.3 Integrated Simulation for Optimized Impacts and Trade-offs .................................. 106

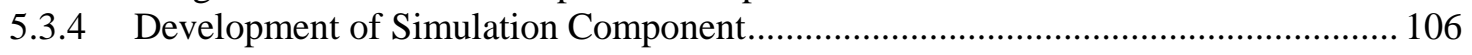

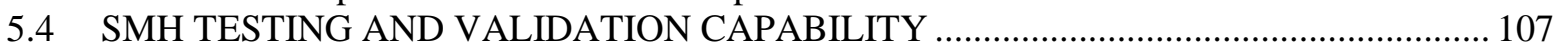

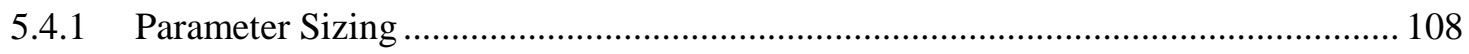

5.4.2 Development of SMH Testing and Validation Capability Needs Matrix .................. 108

5.4.3 Identification of Testing Methods and Instrumentation ............................................ 110

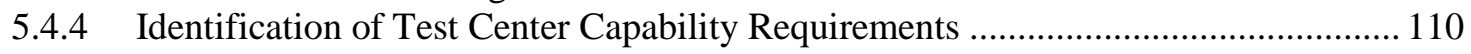

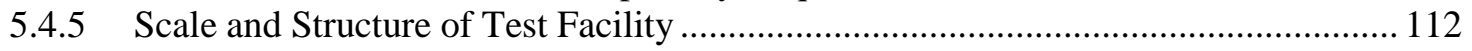

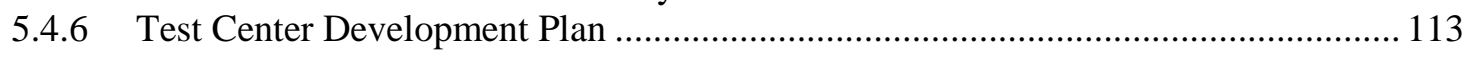

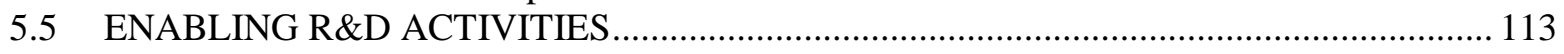

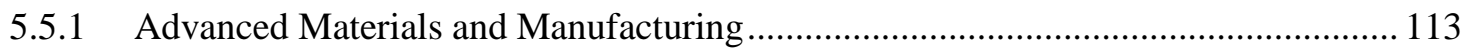

5.5.2 Sensors, Control, Monitoring, and Telemetry Technology Research ........................ 114

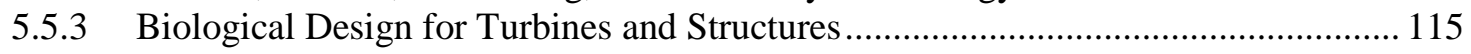

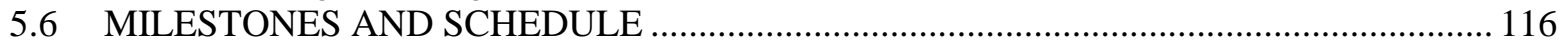

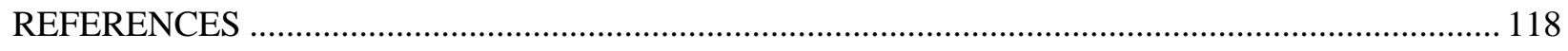

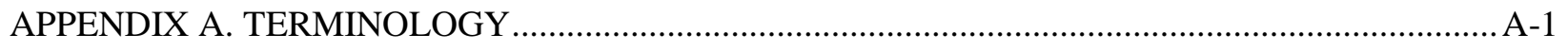

APPENDIX B. RECENT AND ONGOING DOE WATER POWER PROGRAM R\&D

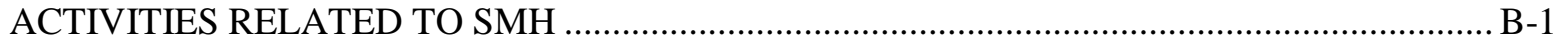




\section{LIST OF FIGURES}

Figure 1. Hydropower development stakeholders.

Figure 2. Overview of the relationship between stakeholders, SMH research pillars, and desired outcomes of the SMH research effort.

Figure 3. Global installed capacity and development potential for small hydropower plants with installed capacities of less than $10 \mathrm{MW}$.

Figure 4. Cumulative NPD potential capacity by state (for projects with estimated capacity between 1 and $10 \mathrm{MW}$ ).

Figure 5. Cumulative NSD potential capacity by state (sites with $<10 \mathrm{MW}$ of potential capacity).......... 18

Figure 6. Major components of a hydropower plant........................................................................... 21

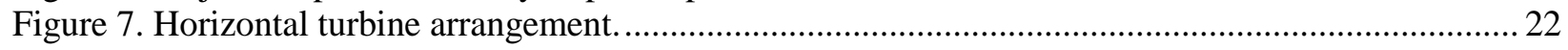

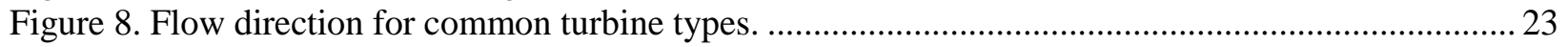

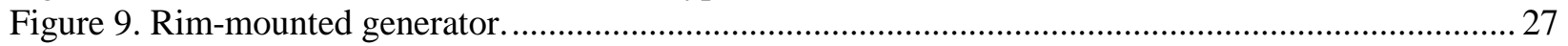

Figure 10. StreamDiver turbine module with permanent magnet generator encased in a bulb. ...............28

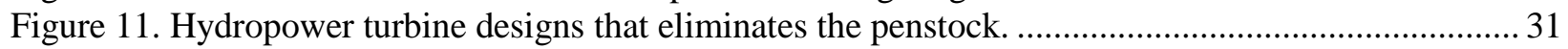

Figure 12. Inflatable rubber weir with steel gate (left) and without (right). ......................................... 31

Figure 13. Classification of the current technologies for fish passage at hydropower facilities................. 32

Figure 14. Top: pool and weir type fish ladder.............................................................................. 33

Figure 15. Locations and mechanisms within a hydropower plant that can lead to severe fish

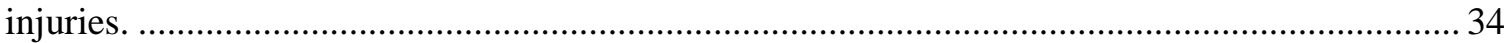

Figure 16. Top: a conventional Kaplan runner (left); a minimum-gap runner designed to decrease fish impingement (right) (Cada 2001); bottom: hydrocombine structure (Skalski et al. 1996; () Canadian Science Publishing or its licensors). .................................................................. 35

Figure 17. Top: high-level gates for sluicing (left); low-level gates for flushing (right)........................ 37

Figure 18. Gravel Gertie machine schematic (left) and photograph (right) for cleaning sediment

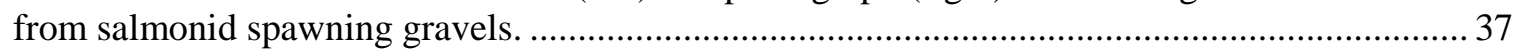

Figure 19. Shaft hydropower concept for normal fish and sediment passage....................................... 38

Figure 20. Combined fish passage and canoe chute on River Medway, Kent, United Kingdom

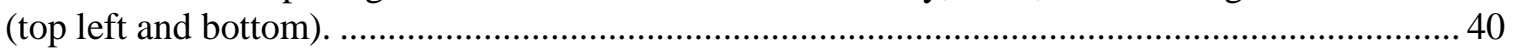

Figure 21. Common vertical and horizontal loads on a concrete dam and foundation............................ 43

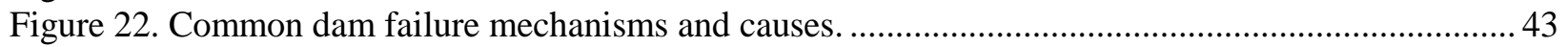

Figure 23. Excavation and construction of a stepped spillway for a low-head dam................................ 44

Figure 24. Monitoring and control process diagram for a typical hydroelectric power plant..................... 46

Figure 25. Major and auxiliary equipment components of a typical hydroelectric unit. ......................... 47

Figure 26. Top: direct power grid connection with generator stator coupled to grid............................... 49

Figure 27. Time from construction startup to operation for a sample of hydropower projects built

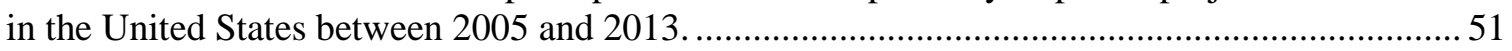

Figure 28. Moveable hydroelectric power plant installation in Germany.............................................. 52

Figure 29. VLH installation diagram showing turbine in operating position (top) and maintenance

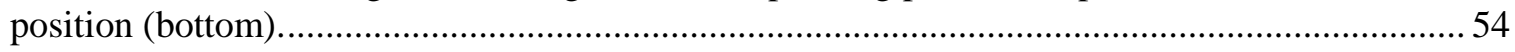

Figure 30. Conventional small hydropower development timeline showing project risk and costs throughout development and steps for which SMH development may offer benefits.................. 55

Figure 31. Costs of recently developed hydropower projects........................................................... 57

Figure 32. Distribution of hydropower capital costs by major component category................................58

Figure 33. Economies of scale in hydropower operations and maintenance. ......................................... 59

Figure 34. Conventional small hydropower development timeline showing project risk and costs throughout development and steps for which SMH development may offer benefits.................. 70

Figure 35. Conceptual diagram of SMH Exemplary Design Envelope Specification. .............................. 72

Figure 36. Holistic approach in SMH development............................................................................ 75 
Figure 37. A distribution of the number of new stream-reach development sites for a given average gross head, colored by $\mathrm{Q}_{30}$ (left), and for a given potential capacity, colored by average gross head (right).

Figure 38. Holistic context of stream function, modularity, and standardization in modular design. ........ 77

Figure 39. Number of $<10$ MW capacity NSD sites that exhibit known environmental attributes............ 78

Figure 40. Methodology and inputs for generation module Exemplary Design Envelope Specification.

Figure 41. Determining the modular trade-off between passage and generation modules will balance optimization of capital expenditures and projected energy yield against passage needs and impacts.

Figure 42. Methodology and inputs for passage module Exemplary Design Envelope Specification.

Figure 43. Methodology and inputs for foundation module Exemplary Design Envelope Specification. 91

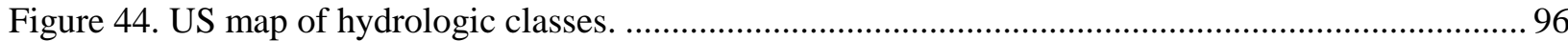

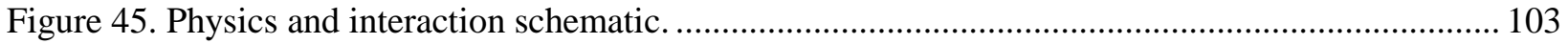

Figure 46. SMH Simulation and Modeling Capability structure of modeling aspects. ........................... 105

Figure 47. Two-tiered effort for the Simulation and Modeling Capability............................................. 105

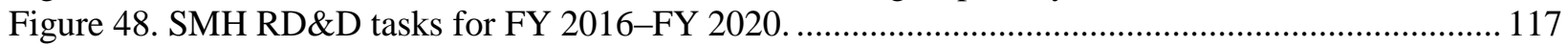




\section{LIST OF TABLES}

Table 1. Pathways and activities outlined for Goal 2 of the EERE 2016-2020 Strategic Plan

Table 2. Frequency distribution of minimum flow mitigation measures for plants (less than

$10 \mathrm{MW}$ ) that were issued FERC hydropower licenses from 1998 through 2013.

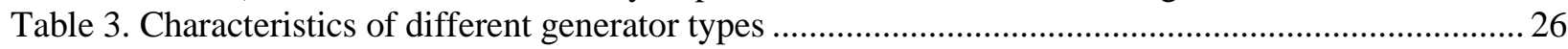

Table 4. Summary of interconnection technology trade-offs......................................................... 48

Table 5. Types of information (indicated by X's) that can be used in site classification to inform module need and design.

Table 6. Summary of high-level operational physics requiring simulation and modeling ...................... 100

Table 7. Preliminary testing needs matrix 



\section{ABBREVIATIONS, ACRONYMS, AND INITIALISMS}

\begin{tabular}{|c|c|}
\hline AHS & Archimedes Hydrodynamic Screw \\
\hline BioDE & BioDesign Project \\
\hline BioPA & Biological Performance Assessment \\
\hline CFD & computational fluid dynamics \\
\hline cfs & cubic feet per second \\
\hline $\mathrm{COL}$ & combined license \\
\hline $\mathrm{CP}$ & construction permit \\
\hline CRADA & Cooperative Research and Development Agreement \\
\hline DOE & US Department of Energy \\
\hline EDES & Exemplary Design Envelope Specification \\
\hline EERE & Office of Energy Efficiency and Renewable Energy \\
\hline EPA & Environmental Protection Agency \\
\hline EPRI & Electric Power Research Institute \\
\hline ESP & Early Site Permit \\
\hline EU & European Union \\
\hline FERC & Federal Energy Regulatory Commission \\
\hline FM & foundation module \\
\hline FOA & Funding Opportunity Announcement \\
\hline FPA & Federal Power Act \\
\hline GEIS & generic environmental impact statement \\
\hline GM & generation module \\
\hline HREA & Hydropower Regulatory Efficiency Act \\
\hline IAA & Interagency Agreement \\
\hline IEA & International Energy Agency \\
\hline INDC & Intended Nationally Determined Contribution \\
\hline IPP & independent power producers \\
\hline ITA & International Trade Administration \\
\hline LCOE & levelized cost of electricity \\
\hline LOPP & lease of power privilege \\
\hline MOU & Memoranda of Understanding \\
\hline MYRP & $\begin{array}{l}\text { Multi-Year Plan for Research, Development, and Prototype Testing of Standard Modular } \\
\text { Hydropower Technology }\end{array}$ \\
\hline NEPA & National Environmental Policy Act \\
\hline NPD & non-power dam \\
\hline NRC & US Nuclear Regulatory Commission \\
\hline NSD & new stream-reach development \\
\hline O\&M & operations and maintenance \\
\hline OL & operating license \\
\hline ORNL & Oak Ridge National Laboratory \\
\hline PM & passage module \\
\hline PMG & permanent magnet generator \\
\hline PPA & power purchase agreement \\
\hline PPE & plant parameter envelope \\
\hline PURPA & Public Utility Regulatory Policies Act \\
\hline R\&D & research and development \\
\hline $\mathrm{RD} \& \mathrm{D}$ & research, development, and demonstration \\
\hline REC & renewable energy credit \\
\hline SBIR & Small Business Innovation Research \\
\hline
\end{tabular}


SCADA Supervisory Control and Data Acquisition

SHP small hydropower plant

SMH standard modular hydropower

TRL Technology Readiness Level

TVA Tennessee Valley Authority

USACE US Army Corps of Engineers

UK

United Kingdom

USBR US Bureau of Reclamation 



\section{ACKNOWLEDGMENTS}

The authors would like to acknowledge and express their appreciation to all the following individuals and programs for their review, comments, and support of this report and support of Standard Modular Hydropower research efforts.

\section{Oak Ridge National Laboratory}

- Deborah Counce, Technical Writer/Editor

- Kathy Jones, Electronic Media Specialist

- Rose Raney, Technical Writer/Editor

- Priscilla Henson, Publications Manager

- Andy Sproles, Graphic Artist

- Douglas Edwardson, Web Developer

- Shih-Chieh Kao, Statistical Hydrologist

- Nicole Samu, Geospatial Data Coordinator/Cartographer

- Christopher DeRolph, GIS Analyst and Aquatic Ecologist

- Missy Miller, Administrative Assistant

- David Watson, Hydrogeologist

\section{New Mexico Institute of Mining and Technology}

- Rebecca Brink, Science Undergraduate Laboratory Intern

\section{University of Minnesota}

- The authors extend their gratitude to Professor John Gulliver of the Civil, Environmental, and Geo- Engineering Department at the University of Minnesota for his meaningful insights and detailed review of this report.

\section{Small Hydropower Stakeholders}

The authors would like to thank the many stakeholders with whom we have engaged to elicit feedback on the opportunities and challenges associated with developing and deploying standard modular hydropower technologies. Ongoing engagement with these technology innovators, commercial service/equipment providers, project developers, and environmental stewards has yielded insight into the myriad perspectives and experiences that shape the current hydropower landscape and inform standard modular hydropower research.

\section{Copyright Holders}

In addition, the authors would like to thank the many publishers, organizations, and individuals who have granted Oak Ridge National Laboratory permission to reuse various figures, graphics, and information that aid in communicating and illustrating key research concepts. 



\section{EXECUTIVE SUMMARY}

The Multi-Year Plan for Research, Development, and Prototype Testing of Standard Modular Hydropower Technology (MYRP) presents a strategy for specifying, designing, testing, and demonstrating the efficacy of standard modular hydropower (SMH) as an environmentally compatible and cost-optimized renewable electricity generation technology. The MYRP provides the context, background, and vision for testing the SMH hypothesis: if standardization, modularity, and preservation of stream functionality become essential and fully realized features of hydropower technology, project design, and regulatory processes, they will enable previously unrealized levels of new project development with increased acceptance, reduced costs, increased predictability of outcomes, and increased value to stakeholders. To achieve success in this effort, the MYRP outlines a framework of stakeholder-validated criteria, models, design tools, testing facilities, and assessment protocols that will facilitate the development of next-generation hydropower technologies.

Consistent with the Strategic Plan of the US Department of Energy's (DOE) Office of Energy Efficiency and Renewable Energy, and the Final Rule of the US Environmental Protection Agency's Clean Power Plan, SMH technology will provide electric power generation from a renewable energy resource while lowering up-front costs associated with project development, permitting, and siting. Recent DOE-funded hydropower resource assessments identify significant room to expand hydropower deployment in the United States at both undeveloped locations and existing infrastructure; however, development of this largely low-head resource using conventional hydropower practices is a significant economic and environmental challenge. Unlike other renewable energy resources, traditional hydropower often incorporates custom equipment and structures based on site-specific design and assessment. Advances in hydro powertrain design, additive materials and manufacturing, power electronics, and modular design offer great potential to reduce costs and procurement/installation timelines through standardization of hydropower components. Yet to realize broader opportunities, a holistic approach must simultaneously optimize costs and ensure the environmental compatibility of all structures and machines across the facility.

The MYRP proposes future SMH facilities that maintain the natural functionality of streams and watersheds through standardization and modularity at the onset, and through every stage, of project development. With standardized structures and machines, predictable characterization of localized hydrodynamic, limnological, and fluvial effects can be achieved through environmental design and performance testing during the technology development phase. Such characterization would minimize the site-specific needs for assessment of some localized impacts and reduce the stakeholder burden. Ultimately, SMH research will yield methods, tools, and technologies capable of increasing small hydropower cost competitiveness and enabling widespread deployment.

As envisioned, an SMH facility consists of a series of independent and interdependent modules that may provide individual, dedicated functions or serve multiple functions. Fundamentally, SMH modules are classified as generation, passage, foundation, interconnection, or installation modules, although additional, function-specific modules are possible and may be desired. Continued research will identify, classify, and quantify SMH design, modeling, and testing objectives, needs, and challenges through a stakeholder-validated framework.

This MYRP outlines the context, objective, framework, and rationale for SMH research, development, and demonstration priorities for the 2016-2020 timeframe:

- Section 1 explores the research context for innovative small hydropower technologies, outlines the research objectives for $\mathrm{SMH}$, describes a framework for facilitating and infusing stakeholder 
engagement into the research process, and highlights the rationale and structure envisioned for SMH research activities.

- Section 2 summarizes the domestic and global markets for new small hydropower development across various resources while describing important market considerations such as efficient minimum flow provisions, rural electrification, remote electric systems, and $\mathrm{CO}_{2}$ emissions.

- Section 3 catalogues the status, advances, and challenges associated with small hydropower technologies, including generation, passage, foundation, monitoring and control, interconnection, installation, and operations and maintenance technologies. The summaries contained therein stem from literature review and industry knowledge, with an emphasis on emerging standard and modular traits.

- Section 4 provides insight into some of the most critical project development considerations influencing small hydropower development and assesses how the SMH paradigm may reduce project cost and risk while ensuring environmental compatibility. The project development considerations described include life-cycle costs, life-cycle benefits, environmental impact, acceptance, sustainability, regulatory requirements, interconnection requirements, and operations and maintenance considerations.

- Section 5 outlines the four Research Pillars that make up the SMH research, development, and testing plan: Exemplary Design Envelope Specification, Site Classification Scheme, Simulation and Modeling Capability, and Testing and Validation Capability. Information on other research and development activities important to SMH development is provided (advanced materials and manufacturing, sensors, controls, monitoring, and telemetry technology, and biological design for turbines and structures), and a timeline for research, development, and demonstration activities is presented.

- Appendix A summarizes key terminology and Appendix B reports recent and ongoing DOE Water Power Program activities related to SMH.

This document represents Revision 1 of the SMH Multi-Year Research Plan and will be updated periodically.

Further discussion and development of a scientific consensus among stakeholder groups will ensure standardized and modularized designs yield acceptable and predicable environmental outcomes for resident and migratory populations, ecological communities, and systemic stream health. The success of SMH will depend upon the effectiveness of those discussions and subsequent research activities as evidenced by the demonstration of new standardized environmental assessment templates, standardized permitting processes, and standardized licensing processes for a finite number of stream types, machine modules, and structure modules within the SMH paradigm. To engage further in this research venture, please visit http://hydropower.ornl.gov/smh/modular/. 


\section{INTRODUCTION}

\subsection{RESEARCH CONTEXT}

This Multi-Year Plan for Research, Development, and Prototype Testing of Standard Modular Hydropower Technology (MYRP; Smith et al. 2016) supports Goal 2 of the US Department of Energy's (DOE) Office of Energy Efficiency and Renewable Energy (EERE) 2016-2020 Strategic Plan and Implementing Framework: Increase the generation of electric power from renewable resources (DOE 2016a). Therefore, the research and development (R\&D) contemplated herein resides within the broader context and scope of the renewable power portfolio outlined in the EERE Strategic Plan:

EERE will seek to address ... opportunities and challenges to make solar, wind, water, and geothermal power generation technologies directly cost competitive with conventional sources of electricity, and address the wide range of related market issues to facilitate their widespread deployment across the country. This will include approaches to address up-front capital, finance, projected operations and maintenance, and other "soft costs" associated with permitting and siting renewable power projects.

The standard modular hydropower (SMH) research described in this plan is also aligned with the Environmental Protection Agency's (EPA) final rule for the President's Clean Power Plan (EPA 2015). The proposed rule indicates that "consistent with other types of [renewable energy], new hydroelectric power generating capacity installed after 2012 is eligible for use in adjusting a $\mathrm{CO}_{2}$ emission rate" for existing carbon-emitting power plants. Consistent with this notion, the President's FY 2017 budget proposes a doubling of US funding in clean energy from $\$ 6.4$ billion to $\$ 12.8$ billion over 5 years, including funding for hydropower technology R\&D. More specifically, this multi-year plan identifies the research, development, and demonstration (RD\&D) priorities for SMH for the 2016-2020 timeframe.

The hierarchy, dependency, and phasing of R\&D in the EERE Strategic Plan are generally applicable across solar, geothermal, wind, and water power technologies; and the electric power interconnection context is common to all generation technologies. However, renewable electric power technologies evolve within unique development and deployment histories and contexts that include innovation through industry and public RD\&D investments, regulatory and financial incentive structures, public acceptance, and complex spatial distributions and temporal variabilities of renewable resources. Multi-year specifics of RD\&D pathways and activities will therefore differ among renewable power technologies. The remainder of this introductory section details the unique characteristics of hydropower (more specifically, $\mathrm{SMH})$ that demand attention in establishing technology R\&D plans.

\subsection{RESEARCH OBJECTIVE}

There are three overall achievements that will signal success for the SMH paradigm: (a) cost reduction through standardization and modularity, (b) ecological compatibility through eco-functional design, and (c) stakeholder acceptance. These achievements are contingent on the hypothesis that if stream functionality, standardization, and modularity become essential and fully realized features of hydropower technology, project design, and regulatory processes, they will enable previously unrealized levels of new project development with increased acceptance, reduced costs, increased predictability of outcomes, and increased value to stakeholders. The envisioned end-state of the R\&D described in this report is a stakeholder-validated framework, including criteria, models, design tools, testing facilities, and assessment protocols for specifying, designing, simulating, testing, and demonstrating the efficacy of $\mathrm{SMH}$ as an environmentally compatible renewable electricity generation technology. 
This hypothesis regarding the enabling effects of stream functionality, standardization, and modularity applies throughout the project development life cycle, from concept to commissioning and beyond to operations, maintenance, and eventual decommissioning. It is not difficult to envision the prospects for reducing unit design costs and increasing value by engineering, testing, and refining a finite set of hydraulic machine and structure modules for installation at many sites. Even the localized hydrodynamic, limnological, and fluvial effects of deploying such standardized structures and machines can be well characterized through environmental design and performance testing during the technology development phase. This characterization would minimize, for all stakeholders, the burden of site-specific assessment of some localized impacts. However, the prospects for those standardized and modularized designs, either singularly or cumulatively deployed, to consistently yield acceptable, predictable environmental outcomes for resident and migratory populations, for ecological communities, or for systemic stream health will likely require further discussion and development of a scientific consensus among stakeholder groups.

The success of SMH technology deployment will depend upon the effectiveness of those discussions and subsequent research activities as evidenced by the demonstration of new standardized environmental assessment templates, standardized permitting processes, and standardized licensing processes for a finite number of stream types, machine modules, and structure modules within the SMH paradigm. These new regulatory and stewardship templates will provide an envelope of design (Section 5.1) that ensures environmentally compatible project development and operations, balanced water use by a range of stakeholders, more predictability in decision-making and outcomes, and grid-competitive hydropower energy production costs. Significant development of new hydropower generating assets is unlikely to occur without the creation, validation, and widespread acceptance of these new regulatory and stewardship templates.

\subsection{STAKEHOLDERS}

Hydropower development stakeholders (Figure 1) bring multiple perspectives to the project development process. Those perspectives are an amalgamation of stakeholders' experiences, values, objectives, authorities, missions, and constraints. The concerns of these stakeholders are diverse and include but are not limited to concepts of aesthetics, availability, competing and complementary uses, environmental disturbance, legality, innovation, feasibility, risk, profitability, reliability, predictability, uncertainty, and resiliency. The absence of any one of these concerns or perspectives in the creation and refinement of the SMH framework will diminish the likelihood of success (i.e., new project development with increased acceptance, reduced costs, increased predictability of outcomes, and increased value to stakeholders). Stakeholders must be engaged from the very beginning of the effort to influence the design objectives, constraints, and rubrics for the technology. They must also participate in the development of tools and practices that implement these objectives, constraints, and rubrics. Stakeholder knowledge and experience will be vital; the benefits and challenges of more than a century of hydropower technology deployment and impacts reside in discerning and establishing a consensus of best practices from the successes and failures of that history.

The focus on a stakeholder-validated framework for SMH technology development means that neither this MYRP nor the concurrent Exemplary Design Envelope Specification for Standard Modular Hydropower Technology (Witt et al. 2017) (Section 5.1) details specific machine, hydraulic structure, or facility designs as candidates for testing, demonstration, or commercialized deployment. Specific technology innovation will be primarily an industry role, with enabling research support from DOE and research institutions. The framework will be formed with input from stakeholders to define and justify the types of modules and requirements that will be developed (e.g., a passage module with defined discharge versus head behavior), the functionality of modules (e.g. capability to pass kayakers safely), and the constraints on footprint and impacts (e.g., a generation module fully submerged at a defined low-flow threshold). The framework will enable DOE to partner with stakeholders to solicit and incentivize 
members of the hydropower community and industry to innovate and take risks to develop and validate specific designs that satisfy these module requirements. Those stakeholder-driven, market-driven designs will fully realize and integrate stream functionality, standardization, and modularity as a pathway to success.

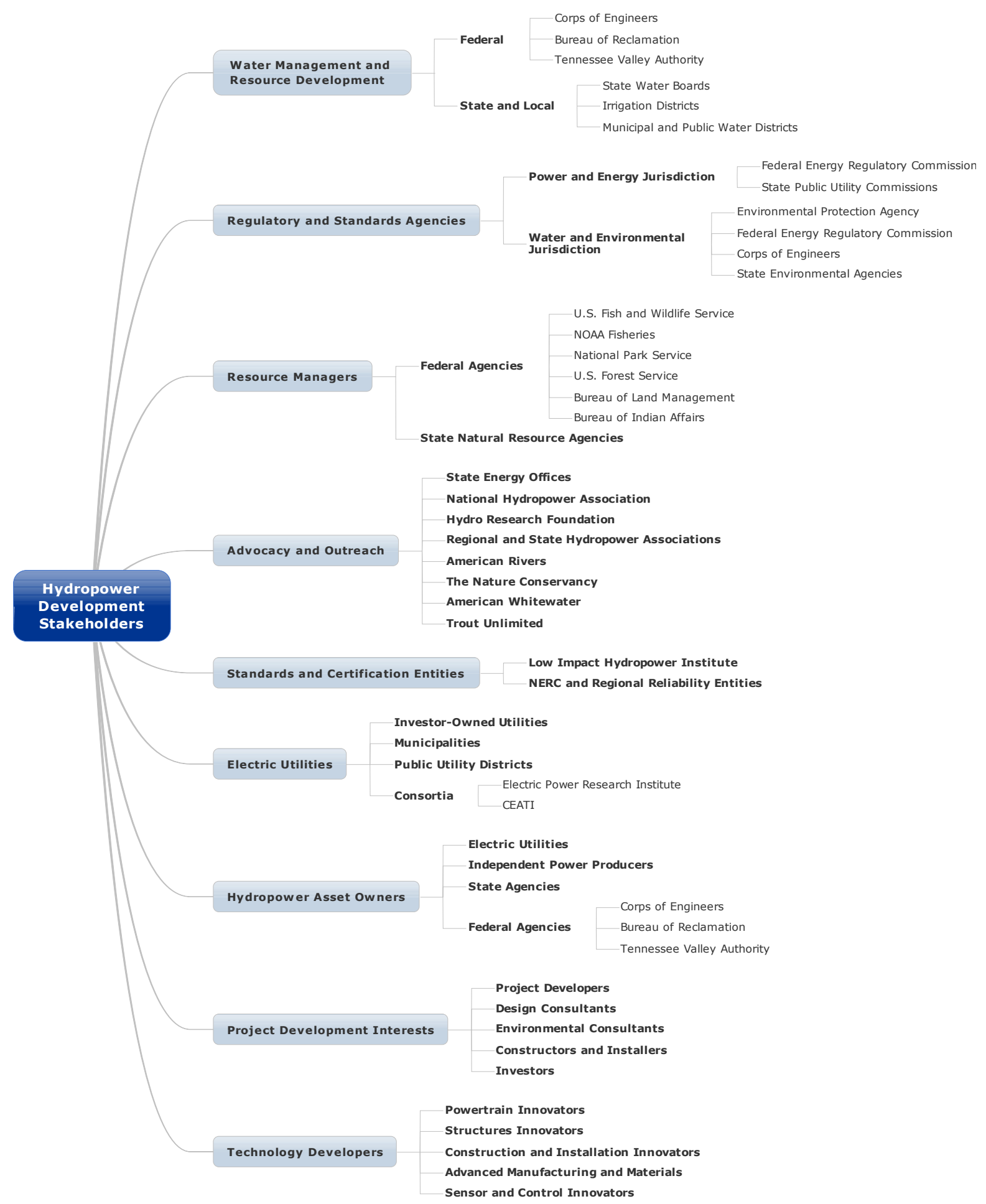

Figure 1. Hydropower development stakeholders. 


\subsubsection{Stakeholder Perspectives and Roles}

The R\&D phases promote involved communication with a variety of stakeholders (Figure 1). (For more information on technology readiness levels [TRLs], see DOE 2011.) Each of the stakeholders possesses different value propositions that reflect their concerns and potential roles in the SMH R\&D process. Certain stakeholders have broad missions in the hydropower community and may participate in multiple areas related to selecting and developing the $\mathrm{SMH}$ functional requirements and design constraints. This framework will provide a greater understanding of what each hydropower development stakeholder's objectives are, and how the Oak Ridge National Laboratory (ORNL) team, with the support of DOE, may realize these concerns from the inception to the finished product. The SMH MYRP consists of 3 years of proposed RD\&D that will require consistent engagement to reach each fiscal year's milestones.

Water management and resource development stakeholders are concerned not only with maintaining waterways for water use and consumption but also with how SMH technology incorporates environmental constraints, potential facility fit, operation and performance requirements, and endemic impacts to water resources they own. Discussion with these stakeholders, including the US Army Corps of Engineers (USACE), the US Bureau of Reclamation (USBR), and the Tennessee Valley Authority (TVA), will provide pertinent and necessary input during the Exemplary Design Envelope Specification phase for conceptualizing, selecting, and analyzing individual module designs (generation, passage, and foundation). Further input from federal water control agencies and state resource boards on cost-effective development strategies in the early design and development phases for the modular configuration (Exemplary Design Envelope Specification) and modeling (Simulation and Modeling Capability) will be important for assessing many objective scenarios, such as reducing costs and licensing time while ensuring reliable generation. Stakeholder feedback from these agencies will be highly valuable for understanding multiple trade-offs (e.g., performance, cost, and functionality) for the individual, intermodule, and intra-module configurations, facilitating the standardization process.

Designing and developing the standardized modules will also require engagement from regulatory and standards agencies and resource managers. These stakeholders cover a diverse range of regulations and standards and distinct concerns within the hydropower development community. The design criteria will need to comply with both federal and state regulations and standards requirements so that SMH technology provides safe, efficient, and reliable energy services at economical rates. ORNL will seek engagement from these agencies to help guide SMH development in a manner that meets federal and state environmental and water quality regulations and achieves a functional design with minimized impacts on the local ecology.

The ORNL team will seek collaboration with resource managers and with advocacy and outreach stakeholders so that the SMH Exemplary Design Envelope Specification and overall framework encompass concerns related to, but not limited to, water quality standards and policies, surrounding riparian conditions, and instream habitats for migratory fish species. Nongovernmental environmental agencies (e.g., American Rivers, Union of Concerned Scientists, The Nature Conservancy, and the National Resources Defense Council) and manufacturing companies may also provide input to further assess the environmental impact of SMH technology on vital river functions, potentially identifying ways to minimize impacts and restore functions.

As part of the effort to improve societal acceptance of SMH, it may be appropriate to consider how primary and secondary school students perceive hydropower development and how exposure to SMH concepts may encourage greater engagement and understanding of environmentally compatible energy development. As future SMH developers and stakeholders, these students may benefit from exposure to a design approach that begins with sustainability concepts, avoids unwarranted and unmitigated environmental impacts, and yields module and facility designs that are feasible and profitable. The 
present effort could engage students through classroom presentations of general SMH concepts; student visits to SMH testing facilities and demonstration sites; and hands-on projects that involve students in module innovation, development, and visualization of model and field data. As the SMH paradigm comes into focus with ongoing research, these activities might form the core of an entire secondary school curriculum for SMH development.

Communication with regulatory bodies (e.g., the Federal Energy Regulatory Commission [FERC]), hydropower asset owners, project developers, and electric utilities will be essential to determine pathways for reducing costs in the design phase and minimizing the time and complexity involved in licensing, installation, and interconnection. The framework will focus on identifying the standards and regulations that must be met for operational purposes, as well as on strategizing how to design an environmentally compatible, cost-optimized standard module. Working closely with an agency like FERC will provide guidance with regard to meeting current federal regulations and identifying future policy barriers, potentially improving permit/licensing time and costs for SMH technology and for the small hydro market as a whole.

Asset owners and project developers may provide key insights into developing innovative designs while maintaining reliable and flexible generation. The design criteria and functional requirements for such stakeholders may include assessing costs from the owner perspective, and identifying possible risks (i.e., electrical reliability, financial profitability) to investing in SMH technology, in light of the projected revenue streams, from the perspective of parties involved in the construction, water management, or power marketing roles.

The test facility portion of the MYRP will require close engagement with a host of stakeholders, as detailed in Figure 1, to first understand and second agree upon specifications and potential development. The design specifications defined in the early research phase will shape the site selection process, as will the type of test facility that is chosen (e.g., existing federal infrastructure with established permitting and licensing versus a new facility). Depending upon the chosen sites, ORNL will coordinate with the relevant regulatory and investing companies for business model development and construction of the test facility. The validation testing involves a highly iterative process that will involve a combination of government bodies (FERC and water control agencies), funding entities, scientific institutions, investors, and manufacturers with a keen perspective on ensuring the performance of an economical prototype.

Researchers will use the MYRP as a reference for establishing baseline concepts, identifying target markets and resource potential, and setting RD\&D goals. A framework will be developed with these various stakeholders to define SMH concepts and terminology, incorporate the public and private perspective, and promote stakeholder roles in SMH RD\&D so that the technology may be more readily adopted for future use as a reliable, flexible generation asset.

The expected outcomes from collaborating with the stakeholders over a 3-year period will focus on defining the SMH design concept and criteria, developing the appropriate modeling tools for simulating and testing the standardized modules, and developing a test facility plan and site for future testing and demonstration. The prospective goal beyond these phases targets actual deployment to be led by the hydropower industry. This framework will allow DOE to work with a diverse group of stakeholders at each of the crucial research steps and to develop SMH technology in a manner that considers how it will impact these stakeholders as well as incorporate their individual needs.

\subsubsection{Stages of Stakeholder Involvement}

The planning, execution, and successful completion of SMH R\&D will require stakeholder engagement throughout the duration of the effort. Acceptable and validated module and facility designs will not be 
possible without such engagement. Extensive stakeholder participation and influence will occur during Exemplary Design Envelope Specification development, with additional input and influence in the Simulation and Modeling Capability and Testing and Validation Capability development efforts. In each of these efforts, the measure of completeness will be the extent to which the functional requirements and design constraints of all stakeholders are expressed, clarified, and considered in the planning and execution of the design, simulation, and testing efforts. The research activities commissioned by DOE must address these functional requirements and design constraints and must enable stakeholders to simulate designs that meet requirements and validate the designs and functionality at partial or full scales in the field. To this end, stakeholder communication will occur in the form of webinars, document review and comment, workshops, and conference presentations throughout the duration of the SMH effort. Aspects of the research that require scientific validation will be reported, reviewed, and disseminated to technical stakeholders in science and engineering publications.

\subsubsection{Mechanisms for Research Collaboration and Technology Transfer}

During the life-cycle of SMH R\&D, DOE may provide opportunities for stakeholders to participate, with and without public funding, in RD\&D of SMH technology. Decisions about which research collaboration and technology transfer mechanisms are offered, and when, may be affected by the public review, comment, and revision process for this MYRP and related documents. DOE may also decide to issue one or more requests for information to solicit public input subsequent to the publication of this document. Mechanisms for research collaboration and technology transfer include the following.

- Funding Opportunity Announcements (FOAs) in which DOE may competitively award grants to a limited number of applicants. Specific eligibility and evaluation criteria typically engender proposals from technology and project developers to accomplish particular stages of SMH technology development and deployment, but they may also focus on the development of SMH simulation and testing capabilities by institutions.

- Cooperative Research and Development Agreements (CRADAs) in which DOE may support the research efforts of its national laboratories working specifically and cooperatively with third-party technology developers to address particular challenges and solutions jointly recognized by participating entities in the development pathway to deployment. A CRADA will specify those challenges, the roles of each entity in researching solutions, and the requirements for reporting joint research progress to DOE. A CRADA will also establish the disposition of intellectual property that is jointly developed by these collaborating entities.

- Memoranda of Understanding (MOUs) and Interagency Agreements (IAAs). DOE currently has an MOU for hydropower research in place with the Department of Interior and the Department of the Army; USBR and the USACE, respectively, serve as primary agencies representing those departments in MOU activities. SMH technology development is not an explicit activity within that MOU scope but may be addressed when the MOU is updated. Bilateral and multilateral MOUs may also be established among other federal, state, and local agencies to address SMH RD\&D (see, for example, the FERC MOU with the State of Colorado ${ }^{1}$ ). MOUs typically signal the intent of agencies to coordinate research, development, or regulatory efforts toward mutually desirable outcomes rather than commit specific resources (funding and personnel) to specific tasks. If agencies need to establish financial and legal commitments among themselves for specific deliverables, they will establish IAAs to do so.

\footnotetext{
${ }^{1}$ https://www.ferc.gov/legal/mou/mou-co.pdf
} 


\subsection{RESEARCH RATIONALE}

The breakpoints that define hydropower projects as small-scale or large-scale in terms of capacity, size, or total cost are objective and dependent on context and stakeholder perspective. An important delineation to consider is that the site-specific customized design optimization and related intensive environmental and regulatory assessments inherent to large-scale hydropower projects are less feasible (economically) at smaller scales. The projected revenue streams from some smaller types of development opportunities are insufficient to amortize such large site-specific initial costs. This does not mean that these small projects can or should be developed without safeguards for the environment and for public and worker health and safety. Rather, for these types of projects, standardization and modularity may enable such assurance at reduced costs. Undertaking research to enable these outcomes through new designs employing advanced materials, modeling, and manufacturing is a focus of this multi-year plan. The answer to the important question "what is small?" in hydropower project development will emerge from this research, wherein validated designs and demonstrations of specific SMH designs will provide assurance of desirable financial, environmental, and safety outcomes for specific types and size ranges of hydropower project development.

The RD\&D rationale presented in this report includes standardization and modularity as essential principles for hydropower technology cost reduction, more so than for hydropower performance improvement. This is because state-of-the-art hydropower turbine technology is presently able to produce energy reliably with nearly ideal performance with efficiencies greater than $95 \%$. Optimized performance and reliability are expected and vital for the competitiveness of large-scale hydropower. The present unfulfilled need is for powertrain, structural, environmental, and installation technologies that can garner regulatory approval, public acceptance, financial investment, and deployment at smaller scales. These projects would deploy in either small undeveloped streams or at small non-powered dams (NPDs), with an acceptable low impact environmental footprint, and be "directly cost competitive with conventional sources of electricity" as envisioned in the EERE Strategic Plan. The relative abundance of small project development opportunities and the dearth of large project opportunities within the undeveloped hydropower potential of the United States is a testament to the present difficulties and risks of small project development that the hydropower standardization and modularity RD\&D proposed herein will address.

The hierarchy of research proposed herein rests upon three complementary constructs:

- Renewable Power RD\&D Focus Areas and Activities. These focus areas are identified for Goal 2 (Renewable Power) in the EERE Strategic Plan and are referred to collectively herein as the Renewable Power RD\&D Focus Areas. The focus areas include (1) Cost Reduction, (2) Validation, and (3) Acceptance; however, this shorthand terminology should not be construed as diminishing the scope of each focus area as discussed in the EERE Strategic Plan and replicated in this report as Table 1. Each focus area has multiple activities defined within the EERE Strategic Plan. They are typically complementary and iteratively linked within an RD\&D program. These linkages are profound in the case of SMH technology RD\&D, with a historical context of more than 100 years of hydropower technology evolution and perspectives on deployment impacts. That history has engendered a diverse and sophisticated stakeholder community and a complex set of objectives and constraints for hydropower project development and technology deployment.

- SMH Research Pillars. These pillars define the SMH-specific RD\&D activities proposed in this report and focus them into coordinated research paths. They are intended to inform the inter-annual and intra-annual planning and execution of the SMH research scope by the DOE Water Power Program and its industry, academic, and national laboratory research partners and stakeholders. The four pillars are the Exemplary Design Envelope Specification, the Simulation and Modeling 
Capability, the Testing and Validation Capability, and the Site Classification Scheme. Each of the first three pillars emphasizes attention to stakeholder-expressed functional requirements and design constraints for SMH technology and deployment. The Exemplary Design Envelope Specification must incorporate stakeholder concerns (for example, physical disturbance and kayak passage) as design constraints or functional requirements at the conceptual stage. The Simulation and Modeling Capability must provide means to predict the effectiveness of designs that address those concerns and simulate the performance trade-offs between effectiveness and cost that result. The Testing and Validation Capability must provide the means to validate the effectiveness of designs at partial or full scale. The Site Classification Scheme will include a set of attributes, potential impacts, and classification schemes that will determine which components of a standardized assessment scheme are invoked during development and which technology modules are necessary and compatible with development of a site. The Site Classification Scheme will be scoped and developed via elicitation and participation from the stakeholder communities identified in Figure 1.

- SMH Module Specifications. The SMH module specifications and guidance for their use, in combination and singularly, are the products that will become available as the RD\&D proposed in this report is completed over a multi-year period. The products of initial DOE-commissioned research activities under the SMH effort are not actual instances of specific modules. The initial products are the robust technical, environmental, and economic specifications for modules that will promote the feasibility and acceptance of new hydropower development. Thus, the SMH effort will produce specifications for a generation module (GM), passage module (PM), foundation module (FM), installation module, and interconnection module, with others added to the scope as additional opportunities or needs for standardization and modularity become apparent in project development life-cycles. The actual innovation, engineering design, manufacturing, testing, and demonstration of specific module designs will be primarily the role of third-party technology development stakeholders, which will reference and implement the module specifications with assistance from DOE and research partners. These modules may be assembled from several physical components (for example, the GM may include turbine and generator components or an integrated turbine generator component). Each of these modules must eventually be defined, developed, demonstrated, and validated within the Exemplary Design Envelope Specification, Simulation and Modeling Capability, and Testing and Validation Capability research pillars. The modules are defined in greater detail in Chapter 5 within the Exemplary Design Envelope Specification description.

The relationships and hierarchy of these constructs are depicted in and Table 1 and Figure 2. 
Table 1. Pathways and activities outlined for Goal 2 of the EERE 2016-2020 Strategic Plan

EERE Strategic Goal 2: Increase the generation of electric power from renewable resources

\section{Pathway 1: Cost reduction and performance improvement}

Activity 1.1-Develop innovative materials and components to reduce hardware costs Activity 1.2-Improve system efficiencies and performance

Activity 1.3-Accelerate understanding of reliability issues and failure modes to reduce operation and maintenance costs

Activity 1.4-Improve resource characterization and forecasting to enable optimized siting and plant operation

\section{Pathway 2: Technology validation and risk reduction}

Activity 2.1-Provide testing and simulation capabilities to speed component and systems development

Activity 2.2 - Support pilots and first-of-a-kind demonstrations to validate the performance of new technologies

\section{Pathway 3: Reducing market barriers}

Activity 3.1-Streamline financing for renewable power projects

Activity 3.2-Optimize and streamline regulatory and permitting processes at the federal, state, and local levels

Activity 3.3-Provide analysis and resources to identify and mitigate environmental and other key barriers to the deployment of renewable power at scale

Activity 3.4-Support the development and improvement of codes and standards, test methods, certification programs, and best practices

Activity 3.5-Help prepare the renewable power workforce 


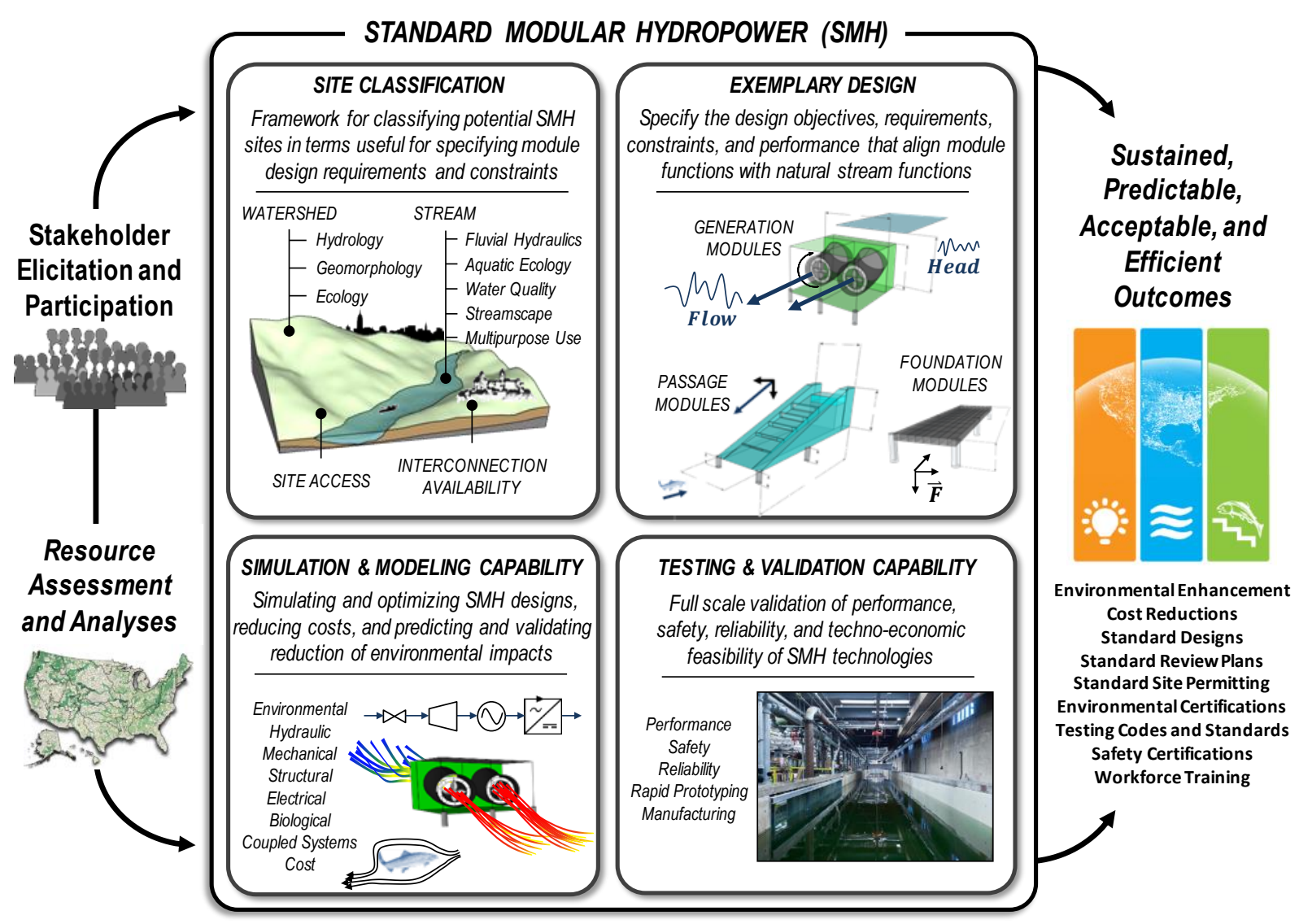

Figure 2. Overview of the relationship between stakeholders, SMH research pillars, and desired outcomes of the SMH research effort. 


\section{MARKET FOR SMALL HYDROPOWER}

In many respects, the emerging market for SMH parallels the existing market for small hydropower throughout the world. This section will provide an analysis of the global small hydropower market and, where available, the hydraulic parameters of the resource potential.

A recent comprehensive analysis of worldwide small hydropower potential and development for plants of less than 10 MW (UNIDO and ICSHP 2013) estimates a global installed capacity of 75 GW distributed among 148 countries and territories (Figure 3). A global resource potential of $173 \mathrm{GW}$, obtained from a variety of sources with varying degrees of data integrity, is made up of significant contributions from Eastern Asia, where China estimates nearly $65 \mathrm{GW}$ of undeveloped small hydropower. Only North America and Europe represent mature markets in which small hydropower is well developed and the potential capacity is less than the installed capacity. The undeveloped potential on both continents, while significant, largely consists of sites that are marginally difficult or expensive to develop. The coupling of this challenge to the historical success of small hydro development means these markets offer a broad spectrum of knowledge and expertise from which SMH technologies can be readily adapted and advanced.

The undeveloped small hydro potential in South America, Africa, Asia, and Europe represents the bulk of global potential. The spread of geospatial and topographical distributions encompasses both high- and low-head sites with various flow magnitudes. A small group of countries report significant high-head development, including Turkey (95\% of installed capacity is greater than $15 \mathrm{~m}$ ) and the Dominican Republic (nearly one-third of small hydro is generated at a head greater than $90 \mathrm{~m}$ ). Some countries report that, while attractive, high-head sites are located in remote areas where site access is a challenge and development is unlikely. Most countries report a significant low-head hydro potential (loosely defined as less than $15 \mathrm{~m}$ ), including the United States, Canada, Uruguay, Ireland, South Korea, Laos, and Bangladesh. This includes greenfield development potential as well as adding generation capability to agricultural waterways, existing dams, and water distribution facilities.

Impediments to building out small hydro potential vary significantly by region. For example, scarcity of water, lack of hydrologic data, and electricity access are significant barriers to overcome in Africa, requiring innovation beyond equipment and civil structures. Several developing countries report a shortage of water resources management experience and water power manufacturing expertise as notable barriers. On the other hand, lack of financing, limited access to capital, and the absence of government incentives compared with other renewables are cited as the principal barriers to development in South America. In Western Europe, opposition to small hydropower development has arisen from governments, nongovernmental organizations, and environmental groups because of ecological and fish mortality concerns. Similar sentiments are found in the United States, where regulatory timelines, licensing difficulties, and limited development incentives have slowed the growth of small hydro installed capacity.

Most global development potential comprises small hydropower sites with unique financial and engineering challenges and impediments. The US government, ${ }^{2}$ the international hydropower industry (Bishop et al. 2015), and numerous international organizations (IEA 2000; TN SHP 2005; ICPDR 2013) have proposed standardized and modular hydropower equipment and design practices as critical RD\&D priorities to help overcome these impediments. The US DOE recently awarded seven industry partners a total of $\$ 6.5$ million to develop hydropower drivetrains and structural foundations that incorporate elements of standardization and modularity. The International Energy Agency (IEA) has identified

\footnotetext{
${ }^{2}$ http://energy.gov/eere/articles/energy-department-awards-65-million-advance-low-environmental-impacthydropower
} 


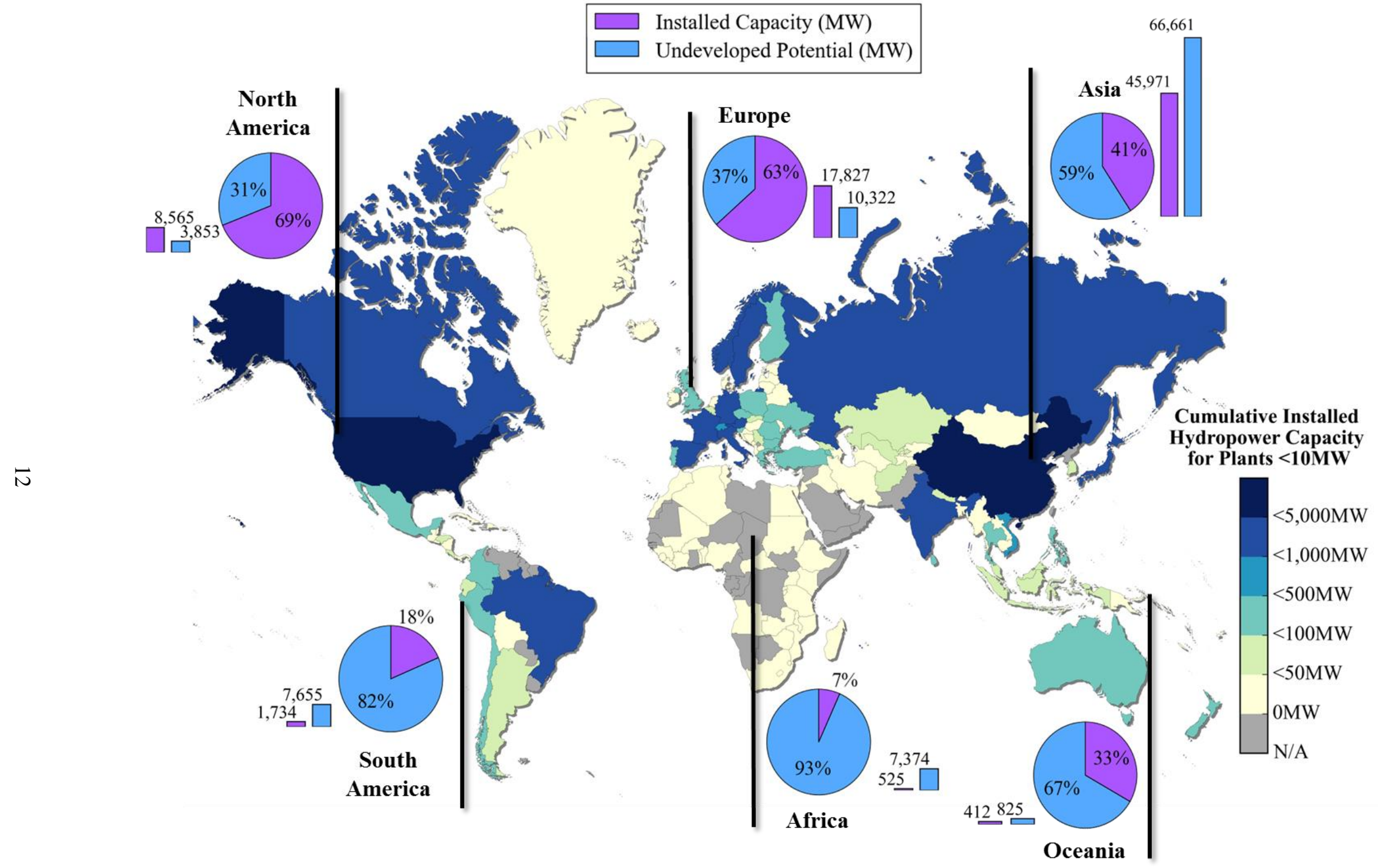

Figure 3. Global installed capacity and development potential for small hydropower plants with installed capacities of less than 10 MW. Numbers are presented as point estimates obtained from (UNIDO and ICSHP 2013), although data integrity is not guaranteed for all countries. 
standardization of design procedures, component modularity, and the integration of broad functionality into a single hydropower system as key R\&D Recommendations.

A cohort of European manufacturers, financiers, research institutions, national energy authorities, and European Union (EU) institutions suggests that systemization of a small hydropower design that meets technical, economic, and environmental targets should be the basis of a European small hydropower RD\&D strategy. These efforts from DOE and the international community would help facilitate standardized and modularized technology development and propose strategies to address market and policy barriers with the intention of supporting long-term, sustainable growth of small hydropower globally.

\subsection{UNITED STATES}

Of the 2,198 hydropower plants currently operating in the United States, 1,426 have nameplate capacities in the small hydropower range $(0.1-10 \mathrm{MW})$. The median size within the small hydropower fleet is 1.41 MW. For individual turbine-generator units, the median size across the entire US hydropower fleet is 1.6 MW, and only $25 \%$ of all installed units have a nameplate capacity of greater than $10 \mathrm{MW}$ (UríaMartinez et al. 2015).

All small hydropower projects combined add up to $3.5 \mathrm{GW}$, which is only $4.4 \%$ of installed hydropower capacity in the United States. Two regions contain $60 \%$ of the small hydropower fleet: the Northeast (492 plants) and the Southwest (371 plants). While approximately $75 \%$ of all installed hydropower capacity in the United States is owned by public entities, only $35 \%$ of small hydropower is owned by public entities. The two largest ownership categories for small hydropower in the United States are private non-utilities and investor-owned utilities. The small hydropower segment is the one accounting for most of the approximately 200 transfer licenses approved by FERC in the last decade, indicating that there is an active market for the installed base of hydropower plants. Exemption transfers do not need approval by FERC and are more difficult to track (Uría-Martinez et al. 2015).

The first hydropower plants installed in the United States in the late 19th century were small, and they continued contributing non-negligible fractions of total installed capacity in the next few decades. However, small hydropower development slowed down markedly between 1930 and the end of the 1970s. Those were the decades in which development focused on building large dams and large hydropower projects. By the late 1970s, the best sites for large dam construction were taken, and the permitting process for installing new large dams had become lengthier and more complex because of the environmental legislation enacted in the late 1960s and early 1970s (Wild and Scenic Rivers Act, National Environmental Policy Act, Clean Water Act, Endangered Species Act). Small hydropower made a remarkable comeback in the 1980s, which remains to date the most active decade in terms of number of hydropower projects (419) installed in the United States. Facilities in the 0.1 to $10 \mathrm{MW}$ capacity range accounted for 289 projects.

One policy program and one piece of legislation can be cited as key drivers for the strong pace of development of small hydropower sites in the 1980s. First, DOE started the National Small Hydropower Program in 1977 to promote the development of small hydropower facilities at NPDs and other sites through R\&D, cooperative agreements to help developers defer the costs of feasibility studies, and loans for the feasibility and licensing stages of project development. As part of this program, 160 loans and 76 cooperative agreements were approved at a total cost of \$36.9 million for DOE (EPRI 1985).

Second, Congress passed the Public Utility Regulatory Policy Act (PURPA) in 1978 to, among other objectives, accelerate the development of small hydropower facilities at existing dams. PURPA required electric utilities to purchase electricity from independent power producers (IPPs) developing small 
hydropower facilities (and other renewables). The rate to be paid by the utility to the IPP would reflect the utility's avoided cost (i.e., the cost of developing or acquiring that incremental capacity and energy if the utility did not have the option of purchasing it from the IPP).

New hydropower development is largely composed of three types of projects: development on existing conduits, the addition of turbines to existing non-powered dams (NPDs), and new stream-reach development (NSD) at undeveloped sites. Small projects continue dominating the hydropower development landscape today. As of December 31,2014, 75\% of projects at any stage of the development pipeline had a proposed capacity of $\leq 10 \mathrm{MW}$. The median sizes of proposed projects were $0.42 \mathrm{MW}, 4.8$ MW, and 6 MW for conduits, NPD sites, and NSD sites, respectively.

Recent changes to the federal permitting process have targeted small hydropower projects for which the existing pathways to obtaining a FERC license or exemption are particularly onerous on a $\$$ /kilowatt basis. Section 4.4.1 discusses those changes in detail. However, federal permitting is not the only challenging portion of the development process for small hydropower projects. Bishop et al. (2015) present a list of barriers to hydropower development, all of which apply to small projects. The list mentions the following issues:

- the high costs associated with the initial site assessment owing to the lack of a centralized, publicly available database

- the need for costly, site-specific project designs

- the uncertainty and risk involved in arranging financing and power purchase agreements (PPAs)

The resource assessments conducted by DOE national laboratories and other federal agencies are a step toward addressing the first of those barriers. These assessments have catalogued the technical potential for NPD and NSD and identified sets of sites that would warrant further feasibility studies (USBR 2011; Hadjerioua et al. 2012; USACE 2013; Kao et al. 2014). For conduits, no national-level resource assessment has yet been conducted; but Reclamation has published a resource assessment that addresses hydropower production potential in the conduit network it owns (USBR 2012). The work on standardization and modularity of small hydropower project components proposed in this research plan directly addresses the second item on the list. Options that could be pursued for financing and PPAs include learning from recent successful projects, ensuring that financing institutions and other potential investors understand hydropower's cost and value streams, and investigating the potential for standardization of PPAs.

With regard to the role of the United States as a manufacturer of hydropower equipment, Uría-Martínez et al. (2015) identified at least 172 companies with manufacturing plants in the United States that produce at least 1 of 6 key electromechanical or civil components (turbines, generators, penstocks, gates, turbines, and valves). The US International Trade Administration (ITA) evaluated the top markets for exports of US-manufactured hydropower equipment. The ITA report concluded that the United States is more competitive in the small hydropower segment than in the large hydropower segment, which is dominated by five companies (three in Europe and two in China), particularly for projects constructed close to the United States. ${ }^{3}$ Similarly, the US Trade and Development Agency, which "helps companies create U.S. jobs through the exports of U.S. goods and services for priority development projects in emerging economies," found that US-manufactured turbines and generators do not appear to be competitive relative to those produced in the nearest manufacturing locations for hydropower projects in Africa, Asia, and Latin America (Personal communication between R. Uría-Martínez, Oak Ridge National Laboratory, and D. Ross, US Trade and Development Agency, May, 1, 2015).

\footnotetext{
${ }^{3}$ http://export.gov/build/groups/public/@eg_main/@reee/documents/webcontent/eg_main_070688.pdf (page 61)
} 


\subsubsection{Conduit Hydropower}

The development of existing canal and conduit infrastructure for hydropower generation is being recognized as an emerging opportunity for new hydropower development. Recent bipartisan US legislation authorizes new conduit hydropower development, with provisions to streamline the regulatory process and reduce administrative costs (HREA 2013). Conduit hydropower projects are built on existing man-made water-conveyance structures that have already incurred the burden of civil works construction and environmental review. Although most water-conveyance systems were designed for non-power purposes (e.g., irrigation, municipal water delivery), hydropower facilities can be assimilated into conduit infrastructure without constructing new dams or weirs, and with minimal impact on the original authorized conduit purpose. Unlike conventional hydropower facilities, conduit hydropower does not require ecological and biological impact mitigation, as these projects are not situated on natural waterways.

Conduit hydropower generation is carried out through two mechanisms: (1) the exploitation of existing head or pressure differentials within the conduit system where the energy exceeds baseline operational requirements, and (2) conversion of the kinetic energy of moving water into mechanical energy. Both mechanisms must maintain the integrity of existing infrastructure while meeting the delivery and priority expectations of stakeholders. These design limitations are creating a market opportunity for small and low-head hydropower generation technologies that can demonstrate efficient, reliable performance at low cost. While both new and traditional technologies are being developed and marketed to meet this need, the high sensitivity of project costs, coupled with the relative similarity of conduit geometries, is driving innovation toward designs that incorporate elements of standardization and modularity.

A determination of the applicability of SMH GMs to conduit hydropower is premature at this time. However, three noteworthy observations can serve as food for thought. First, the functional requirements of the SMH GM outlined in Section 5.1.3 will be site-independent, lending credence to the prospect of future SMH conduit designs. Second, the resource potential for conduit hydropower has not been determined with a consistent approach on a national level. The results of existing assessments, although they use different methodologies and data sources, indicate the magnitude of conduit hydropower potential is significantly less than the potential for NSD. Although this does not preclude the consideration of conduit sites, the current research effort is focused on the functional requirements and technical specifications necessary to address the known hydropower potential in the United States. Third, since 2013, only one FERC-approved conduit hydropower project has been placed into service; and as of October of 2015, no conduit exemptions had been filed or issued with FERC (FERC 2015b). In contrast, five conventional small hydro projects were licensed in 2015. Although an apparent trend cannot be derived from a single year, the relative immaturity of the conduit hydropower market remains a challenge from a regulatory perspective.

\subsubsection{Non-Powered Dam Hydropower}

Within the United States, roughly 2,500 dams provide over $78 \mathrm{GW}$ of conventional hydropower, while more than 80,000 dams do not produce electricity (NPDs). Analogous to conduit hydropower, much of the civil works costs and environmental impact assessments of NPDs were incurred upon their construction. In most cases, the addition of hydroelectric equipment could be carried out at a lower cost, in a shorter timeframe, and with less risk than would be incurred in constructing a new dam. Even in such cases, however, SMH designs may reduce costs and environmental footprints compared to traditional design and construction practices. A recent resource assessment of NPD potential in the United States identified 597 sites with greater than $1 \mathrm{MW}$ of potential capacity and a national cumulative potential capacity of $10.9 \mathrm{GW}$. The top $100 \mathrm{NPD}$ sites represent $73 \%$ of the potential capacity $(8 \mathrm{GW})$, each site having a potential capacity greater than $20 \mathrm{MW}$. 
A total of 441 sites with $1.25 \mathrm{GW}$ of cumulative capacity, or $69 \%$ of all potential NPD sites and $10 \%$ of all potential NPS capacity, could be developed with installed capacity of between $1 \mathrm{MW}$ and $10 \mathrm{MW}$ (Figure 4).

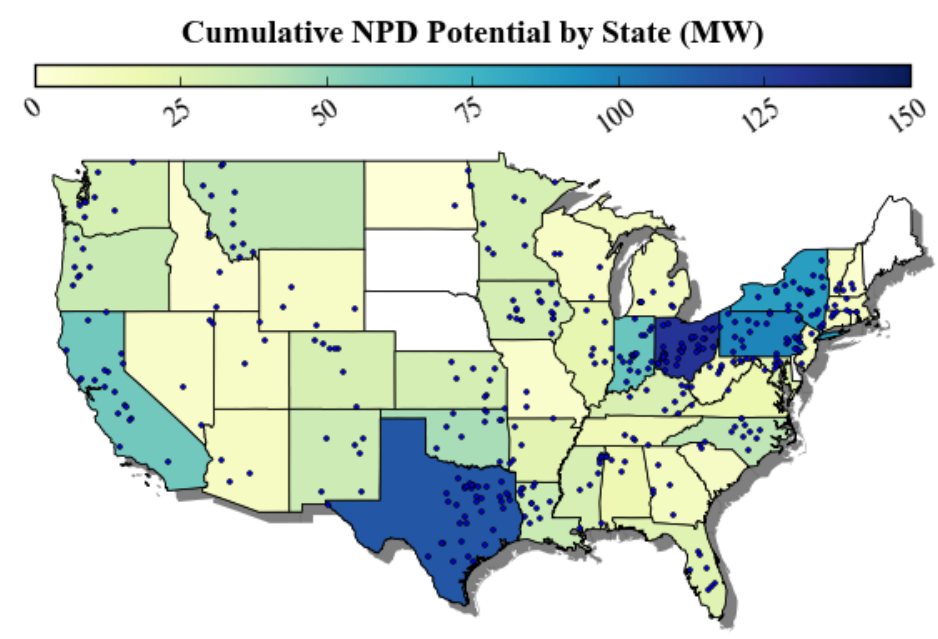

Figure 4. Cumulative NPD potential capacity by state (for projects with estimated capacity between 1 and 10 MW). Developed using data from the National Hydropower Asset Assessment Program database. ${ }^{4}$

Most of the ten small NPD projects that started operation in the United States during the last decade under FERC licenses have been on dams owned and operated by USACE, although instances of development at dams owned by Reclamation and municipal agencies are also present. For those ten projects, the median time spent in pre-licensing activities was 36 months, the median time elapsed from FERC license application to FERC license issuance was 23 months, and the median time from license issuance to start of construction was 45.5 months. Not only did that latter step typically take the longest, but also it was the one for which the largest variability across projects can be observed. Activities performed during that part of the development process include obtaining Section 408 permits from USACE and any other necessary permits, as well as the negotiation of PPAs and financing. Recent small NPD projects have shown pronounced variability not only in the length of the development process but also in construction costs. Construction costs have ranged between $\$ 2,000 / \mathrm{kW}$ and $\$ 6,000 / \mathrm{kW}$.

More than 200 NPD projects were in the development pipeline at the end of 2014. Most of them are at the earlier stage of the process in which the developers have received a preliminary permit from FERC and are still conducting feasibility studies. Approximately $80 \%$ of the projects are being pursued by private developers. Some of these developers are filing for clusters of preliminary permits in a given region. By sharing the costs of engaging regional stakeholders and of some of the feasibility studies across multiple sites, this strategy may help in managing risk and containing pre-licensing expenditures per kilowatt of capacity eventually developed (Uría-Martinez et al. 2015).

\subsubsection{Opportunities for Efficient Minimum Flow Provision}

Most hydropower facility licenses or exemptions require that a minimum or environmental flow be maintained at all times or during pre-specified seasons. These minimum flow requirements are designed to sustain downstream fish populations and habitat while protecting recreational, scenic, and environmental resources (FERC 2015a). Minimum flows help to ensure the wetted perimeter downstream is consistently maintained within an acceptable range that minimizes disturbances to aquatic and riparian

\footnotetext{
${ }^{4}$ http://nhaap.ornl.gov/content/non-powered-dam-potential
} 
environments. Deviations in project discharge below the minimum flow requirement could negatively affect downstream water temperature, quality, quantity, and habitat by withholding a continuous stream of nutrients, dilutive capacity, and important environmental indicators embedded in the flow. The license often contains a monitoring and reporting provision that requires project owners to record and submit minimum flow measurements. If the owner is found to be noncompliant with the terms of the license, an explanation and proposed corrective action are required.

As an example of minimum flow mitigation measures that may be required for new development, Table 2 lists the minimum flow mitigation measures for projects of less than $10 \mathrm{MW}$ capacity that were issued FERC hydropower licenses from 1998 through 2013. The most frequent mitigation category is a yearround bypass, or a conveyance around the hydropower facility dedicated to providing a year-round minimum flow. More than $10 \%$ of projects required a minimum flow in the tailrace year-round, and nearly the same percentage of facilities required a seasonal minimum flow in the tailrace. A total of 171 projects, or more than two-thirds of licenses issued to plants of less than $10 \mathrm{MW}$, required some level of minimum flow. This trend remains largely unchanged from the 1980s, when instream minimum flow requirements were the most common FERC-mandated mitigation measure (Sale et al. 1991).

Table 2. Frequency distribution of minimum flow mitigation measures for plants (less than $10 \mathrm{MW}$ ) that were issued FERC hydropower licenses from 1998 through 2013. Data from Bevelhimer et al. (2015). Many, if not most, of these projects are relicensed projects that have been in operation for decades

\begin{tabular}{|c|c|c|c|}
\hline $\begin{array}{c}\text { Minimum flow mitigation } \\
\text { measure }\end{array}$ & $\begin{array}{l}\text { Number of } \\
\text { plants } \\
<10 \mathrm{MW}\end{array}$ & $\begin{array}{l}\text { Percentage of } \\
\text { plants }<10 \\
\text { MW }\end{array}$ & Mitigation measure description \\
\hline Year-round bypass & 68 & 27.4 & $\begin{array}{l}\text { Bypass section requires a year-round } \\
\text { minimum flow }\end{array}$ \\
\hline Seasonal bypass & 44 & 17.7 & $\begin{array}{l}\text { Bypass section requires a predetermined } \\
\text { minimum flow based on time of year }\end{array}$ \\
\hline Seasonal tailrace & 28 & 11.3 & $\begin{array}{l}\text { The tailrace requires a predetermined } \\
\text { minimum flow based on time of year }\end{array}$ \\
\hline Year-round tailrace & 27 & 10.9 & $\begin{array}{l}\text { The tailrace requires a year-round static } \\
\text { minimum flow }\end{array}$ \\
\hline Seasonal and time of year bypass & 3 & 1.2 & $\begin{array}{l}\text { The tailrace requires a predetermined } \\
\text { minimum flow based on time of year and } \\
\text { water availability criteria }\end{array}$ \\
\hline Seasonal and time of year tailrace & 1 & 0.4 & $\begin{array}{l}\text { The tailrace requires a predetermined } \\
\text { minimum flow based on time of year and } \\
\text { water availability criteria }\end{array}$ \\
\hline Total & 171 & 69.0 & \\
\hline
\end{tabular}

The trend in FERC licenses for small hydropower plants (SHPs) to require some seasonal minimum flow indicates there may be a market for modular and standardized generating units that accommodate minimum flows for existing facilities or those nearing the relicensing process. A custom solution is nearly always applied, and the costs of retrofitting an existing structure are often substantial compared with the small amount of energy generation potential, especially when a subsidy is not available. SMH has the potential to mitigate some of these costs if a module with known performance criteria can be designed to meet similar minimum flow requirements across multiple sites. The installation of many cost-competitive smaller modular units may also provide additional flexibility to meet minimum flows in new stream reaches, where flow pulsing or shaping across modules could ensure a large wetted perimeter is maintained at all times downstream. 


\subsubsection{New Stream-reach Development}

A recent resource assessment of NSD technical potential in the United States used a combination of datasets for watershed boundaries, river geometry, existing dams, topography, flow measurements, and flood zones to identify streams with enough energy production potential to support run-of-river hydropower development (Kao et al. 2014). ${ }^{5}$ The assessment identified a technical potential of $84.7 \mathrm{GW}$, of which approximately $40 \%$ is at low-energy-density ( $<1 \mathrm{MW}$ ) stream-reaches (Figure 5$)$. The regions with the highest potentials are the Pacific Northwest; the Missouri hydrologic region, which contains parts of Missouri, Kansas, Colorado, Wyoming, North Dakota, South Dakota, Minnesota, and Iowa and all of Nebraska and Montana; and California. The study acknowledges that energy production potential is just one of the many attributes that need to be considered in selecting a site for further feasibility studies. For instance, 19.2 GW of the total potential corresponds to sites located in national parks, on wild and scenic rivers, and in wilderness areas where hydropower development is highly unlikely. In addition, the assessment examines the overlap between potential NSD sites and a variety of other attributes that could reveal environmental concerns (e.g., presence of Endangered Species Act-listed fish species, critical habitats) or challenges to development due to geopolitical considerations or competing water uses.
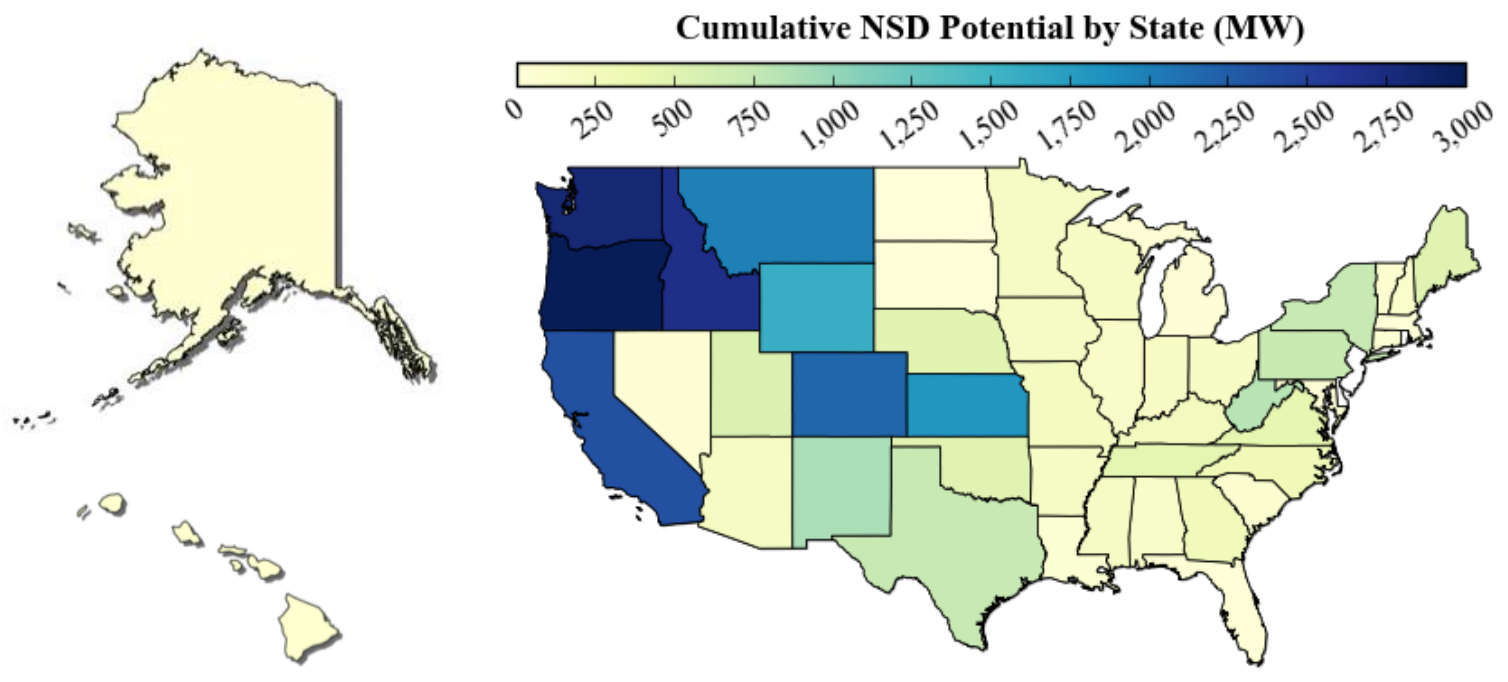

Figure 5. Cumulative NSD potential capacity by state (sites with $<10 \mathrm{MW}$ of potential capacity). Developed using data from the National Hydropower Asset Assessment Program. ${ }^{6}$

The fraction of the estimated technical potential that can feasibly be developed depends on market conditions and on available technologies. For instance, the assessment found undeveloped NSD capacity of $2.07 \mathrm{GW}$ in the Lower Mississippi region, which is more than $400 \%$ of the existing installed nameplate capacity in that region. But the stream-reaches in the Lower Mississippi tend to be high-flow and lowhead, for which the most common turbine types are not well suited. Thus, efficiency improvements and/or cost reductions in low-head generation technologies could significantly impact the fraction of the technical potential that is economically attractive to develop in that region.

\footnotetext{
${ }^{5}$ The stream population considered to produce estimates of NSD technical potential excluded flowlines with estimated annual mean flow of less than $35 \mathrm{ft}^{3}$ per second, as well as those in which water flow is already regulated by existing dams.

${ }^{6}$ http://nhaap.ornl.gov/
} 
The wealth of NSD potential contrasts sharply with a dearth of NSD plants starting operation in the United States during the last decade. Three NSD plants with capacities greater than $1 \mathrm{MW}$ have gone into service in the last decade: Kasidaya Creek (AK), Lake Dorothy (AK), and Youngs Creek (WA). Looking toward future development based on the FERC hydropower licensing pipeline as of the end of 2014, only 35 NSD projects were represented. The median size of those projects is small, and half of them fall under the category of diversion projects that would not involve significant dam construction. Two-thirds of these projects are being pursued by private developers, mostly private non-utility companies, and the remaining one-third by cooperatives, municipalities, state agencies, or other political subdivisions (UríaMartinez et al. 2015).

The potential for SMH to play a role in future NSD is apparent. Most potential NSD capacity, and over $80 \%$ of potential NSD sites, exhibit hydropower potential of less than $10 \mathrm{MW}$. Future development of these resources will require a unique approach to technology development not only at the generation level, where efficient low-head and low-power turbines will be used, but also at the facility level, where innovation is necessary to reduce overall costs, shorten development timelines, and address environmental impact mitigation early in the design phase.

\subsection{GLOBAL MARKET FOR SMALL HYDROPOWER TECHNOLOGY}

The supply side of the global market for SMH is largely determined by a mixture of physical characteristics (topography and hydrology) and technology. For instance, very low-head projects were largely determined not to be economically feasible in the feasibility studies conducted in the United States as part of the DOE National Small Hydropower Program in the late 1970s and early 1980s. Recent technological advances in turbine-generator units for very low-head projects might change the results of feasibility studies conducted at the same sites considered infeasible a few decades ago.

Global market demand for small hydropower derives from the global demand for electricity and depends on how small hydropower compares in terms of levelized cost of electricity (LCOE) and other attributes (e.g., environmental impact, reliability, social acceptance) with other electric generation technologies (REN21 2015). ${ }^{7}$ In addition, the global demand for small hydropower relates to the demand for other services like water supply and irrigation because, in some cases, the canals, conduits, and pipelines built for those other purposes can offer a low-cost option for adding electricity generation.

\subsubsection{Small Hydropower for Rural Electrification}

According to the World Bank, 1.3 billion people lack access to electricity; $84 \%$ of them are in rural areas. ${ }^{8}$ The Alliance for Rural Electrification discusses the reasons why small hydropower is an ideal technology for rural electrification. First, the fuel used in hydroelectricity production (i.e., water) is locally available. Second, SHPs have low distribution and labor costs. Third, SHPs have a longer life than most other electricity generation technologies. Fourth, small hydropower has a high energy payback ratio (i.e., the ratio of energy produced to energy spent in building, operating, and maintaining the plant). Rural electrification efforts using small hydropower have provided crucial energy services in various geographic locations globally (Paish 2002). ${ }^{9}$

\footnotetext{
7 The REN21 2015 Global Status Report estimates that, in 2014, global investment in new small hydropower (defined in the report as being less than $50 \mathrm{MW}$ ) was \$1 billion in developed countries and \$4 billion in developing countries. This total was $17 \%$ lower than in the previous year.

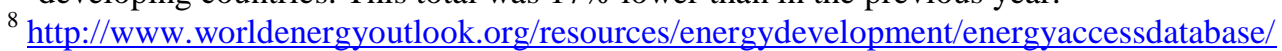

${ }_{9}$ Paish (2002) offers a review of the use of small and micro hydropower systems for rural electrification.
} 
In China, small hydropower has played an important role in the process of rural electrification. According to data from the China Electricity Yearbook, in the year 2000, 95\% of the counties (mostly rural) that were not connected to a regional or national grid used small hydropower for their local electricity supply (Peng and Pan 2006). Nepal also relies heavily on off-grid small hydropower systems to power isolated villages (Palit and Chaurey 2011). In Equatorial Africa, hydropower alone cannot reliably supply electricity all year long, but it can be successfully combined with other renewables like solar photovoltaics (Kenfack et al. 2009). For these projects to be economical, they must be used to satisfy not only residential loads, which are concentrated in the evening hours, but also income-generating activities (e.g., agriculture, fisheries, manufacturing). The Indian government in April 2015 launched the National Mission on Small Hydropower, focused on projects of up to $25 \mathrm{MW}$. This program aims to install $5 \mathrm{GW}$ of small hydropower over a 5-year period by adding generation to existing facilities through upgrades, rehabilitation, and development of new hydropower on existing infrastructure such as canal drops and dam outlets. This program will additionally focus on developing micro hydropower in mountainous regions (Poindexter 2015). Standard designs are one of the options to minimize development costs for new small hydropower. The Indian national government encourages participation from all the state governments in the program and provides a policy framework that incentivizes private developers to contribute to the target.

\subsubsection{Small Hydropower for Remote Systems and Microgrids}

The reasons cited that make small hydropower suitable for rural electrification in developing countries also make it an attractive option for use in electric systems on islands; in remote locations; or in systems that - although connected to a centralized electric grid - want the option to become "islands" for reliability or other purposes by establishing a microgrid. For instance, in 2015, a remote microgrid bill was introduced to the US Senate concerning remote communities in Alaska, Hawaii, and US territories that still rely heavily on diesel generators for reliability. These communities could benefit from hybrid microgrid technologies, including micro hydro and/or other renewables, which would lower their electricity costs over time.

\subsubsection{Small Hydropower for $\mathrm{CO}_{2}$ Emissions Reduction}

Small hydropower is one of the technologies that can help the 195 countries that submitted Intended Nationally Determined Contributions (INDCs) to craft the COP21 agreement reach those $\mathrm{CO}_{2}$ emissions reduction targets. The extent to which small hydropower will be chosen over other low-emissions or renewable electricity generation technologies will largely depend on its cost relative to those other technologies and its actual (and perceived) environmental impact. 


\section{SMALL HYDROPOWER TECHNOLOGY STATUS, ADVANCES, AND CHALLENGES}

The fundamental goal of a hydropower project is to convey flowing water through a turbine at the highest possible pressure difference across the turbine. The approximate equation for power is

$$
P=\frac{Q H \eta}{11.8}
$$

where $P$ is turbine output power in $\mathrm{kW}, Q$ is discharge through the turbine in $\mathrm{ft}^{3} / \mathrm{s}, H$ is hydraulic head in $\mathrm{ft}, \eta$ is the efficiency of the turbine, and 11.8 is a conversion constant for English units. This equation indicates a decrease in available head must correspond to an increase in flow to generate a similar amount of power.

A hydropower system contains electromechanical equipment and controls that enable the conversion of hydraulic input energy to mechanical energy and ultimately electrical energy for interconnection to electric power delivery systems. SHPs are able to accomplish this task through a variety of equipment and civil structure configurations designed for specific stream resources.

For the purposes of this document, SHPs are classified into four categories: (1) water diversion, (2) damtoe, (3) run-of-river, or (4) canal-/conduit-based. Within these four categories, SHPs generally contain some combination of several major equipment and civil structure categories, each of which may require permanent or semi-permanent placement of civil works, equipment, and electrical interconnection systems. An SHP design life can range from 30 to beyond 100 years when sustained with periodic replacement and renovation and regular maintenance. An illustration of the major components of a conventional hydropower project is provided in Figure 6, and additional terminology is defined in Appendix A.

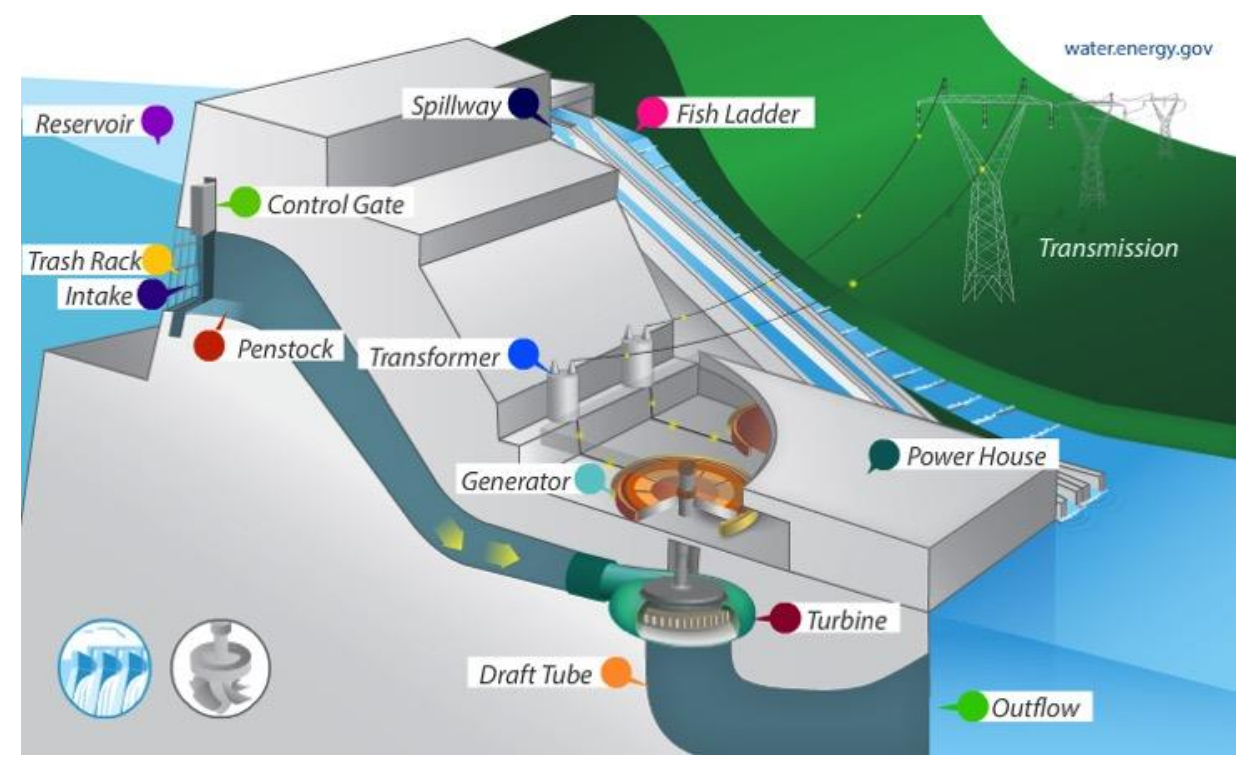

Figure 6. Major components of a hydropower plant. (Source: US Department of Energy. Used by permission.) 
Many comprehensive overviews of SHP technologies, plant arrangements, and equipment options are widely available, ${ }^{10}$ and the reader is referred to these exhaustive resources for specific technical detail. The remainder of Section 3 further sheds light on the purpose, function, advances, and challenges of current SHP technologies while identifying those ${ }^{11}$ that display aspects of standardization and modularity. To do so in an informative way that aligns with the goals of SMH technology development, this section is structured based on seven categories: generation, passage, foundation, controls and monitoring, installation, interconnection, and operations and maintenance (O\&M). Emphasis is placed on low-head SHPs, which make up the majority of NSD sites in the United States. A detailed discussion of how these categories represent the SMH concept is found in Section 5.1.

\subsection{GENERATION TECHNOLOGY}

Generation technology enables energy production, the primary source of revenue for a hydropower project. A significant number of components comprise generation technology (Figure 7). As outlined in this section, generation technology most fundamentally consists of a turbine runner, generator and governor, and powerhouse. Since the financial success of a hydropower facility depends directly on the performance of the generation technology, these components have been refined and matured by over 100 years of hydropower innovation. Still, given the dearth of small hydropower in the United States and the lack of recent, major innovations, new technologies focusing on low-head hydropower application may offer many opportunities. For additional information on generation technology, see Leyland (2014), Colorado (2010), ESHA (2004), and various other hydropower references.

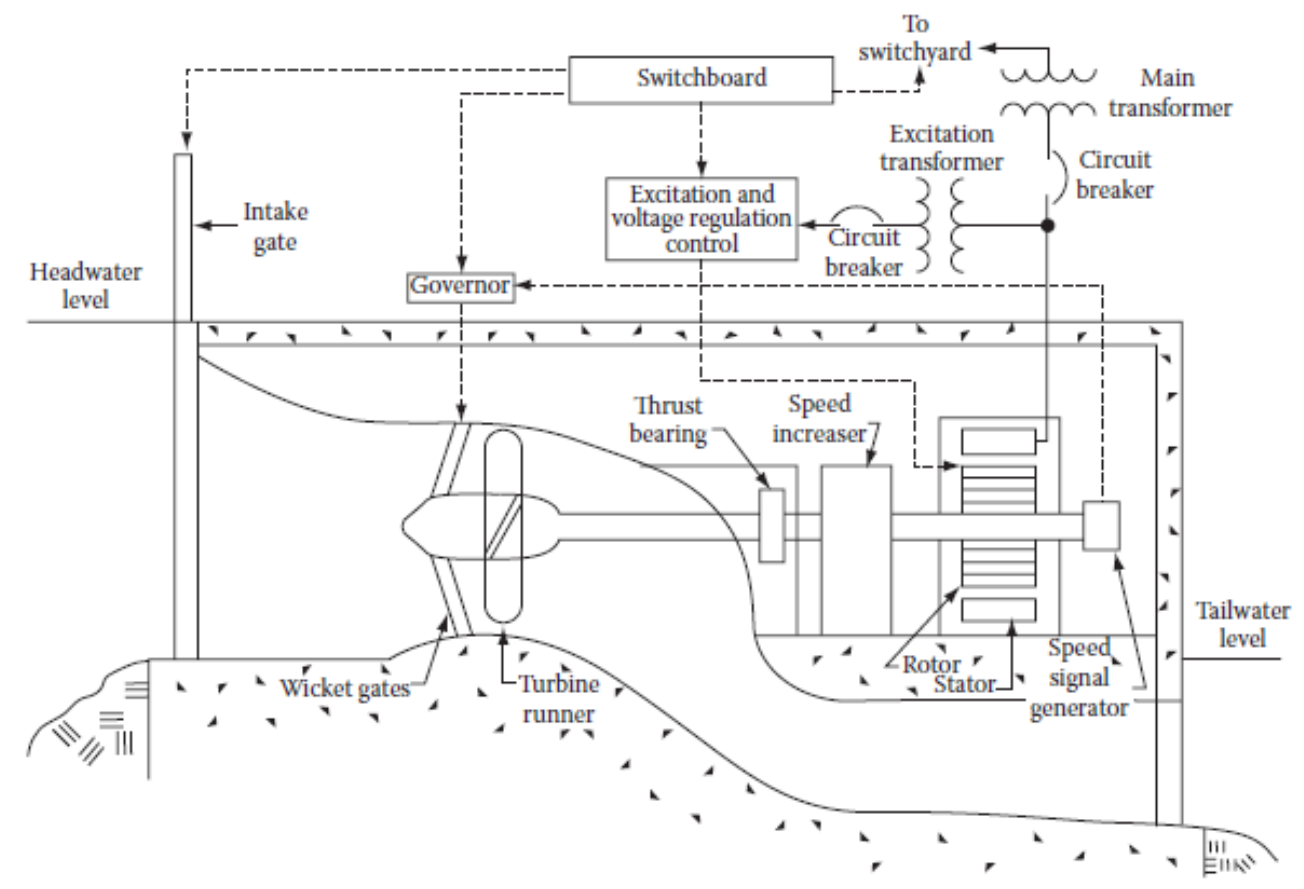

Figure 7. Horizontal turbine arrangement. Reprinted with permission from IEEE. Copyright IEEE (1988). All rights reserved.

\footnotetext{
${ }^{10}$ General references include USACE (1978), ASME (1996), Gulliver and Arndt (1991), Gordon (2003), ESHA (2004), Colorado (2010), Oregon (2012), Hatch (2014), and Leyland (2014).

${ }^{11}$ In some cases, multiple technologies are available that exhibit SMH qualities. The specific images and references in this section are included for illustration purposes only.
} 


\subsubsection{Turbine Runner}

The turbine runner is the prime mover in the hydropower scheme, converting hydraulic energy into mechanical energy via blades or buckets. While a form of the turbine runner has been used in mechanical applications for millennia, the first application of a hydroelectric turbine runner began in the late 19th century. ${ }^{12}$ Since that time, the runner has evolved into a practical, highly efficient, highly optimized spinning machine.

\subsubsection{Turbine Runner Characteristics}

\section{Turbine runner classification}

Hydropower turbine runners can be classified as either impulse or reaction based on their means of converting the pressure and velocity of moving water into energy. Most turbine runners are further classified as tangential, axial, or mixed flow (a combination of axial and radial flow) based on the primary direction of the flow of the working fluid (Figure 8).

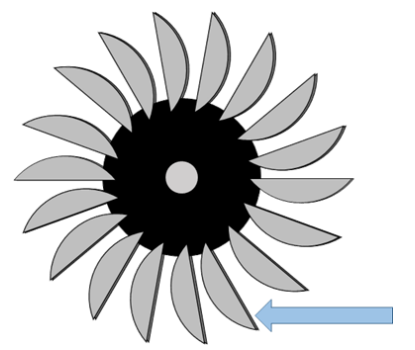

Tangential

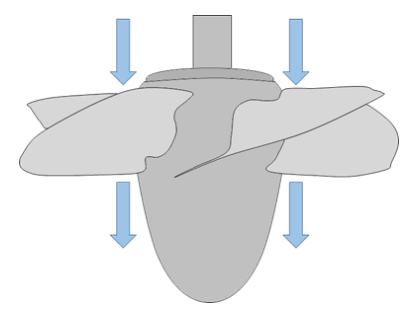

Axial

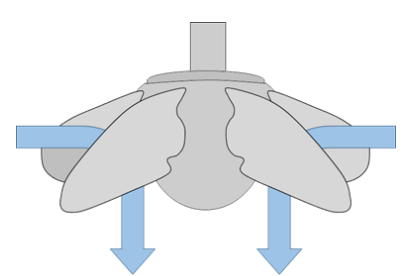

Radial

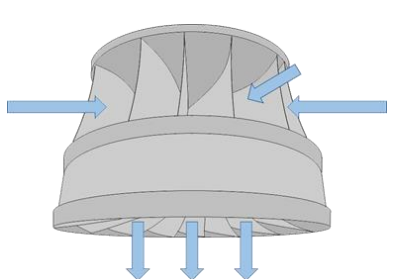

Mixed

Figure 8. Flow direction for common turbine types.

\section{Turbine runner design considerations}

Turbine efficiency is generally high for most current generation technologies, although the shape of the efficiency curve is dependent on the specific turbine configuration. ${ }^{13}$

Impulse turbines can maintain a broad, flat efficiency curve from approximately 30 to $125 \%$ of full load as a result of precise control of inlet flow rates. Reaction turbines are designed with varying degrees of operational control and may include adjustable inlet gates and turbine blades to extend the range of peak performance.

A double-regulated reaction turbine consists of adjustable inlet gates and turbine blades, giving an extended range of peak performance. The gate opening is adjusted to control inflow, and the blade pitch is synchronized to the gate opening to ensure the angle of attack is optimum at all cross sections within the turbine. Double-regulated reaction turbines exhibit high efficiencies at partial load under varying heads and flows. Single-regulated turbines (either the gates or blades are adjustable) can match the peak efficiency of double-regulated turbines, but they are less efficient at partial load and varying heads and flows. Turbines with no regulation (i.e., with fixed blades and gates) have very steep efficiency curves at a given head and flow, and partial loading causes poor performance that can lead to accelerated component degradation. A reaction turbine may require a draft tube that diffuses the flow and slows the

\footnotetext{
${ }_{12}^{12} \mathrm{http} / / /$ energy.gov/eere/water/history-hydropower

${ }^{13}$ https://www.renewablesfirst.co.uk/hydropower/hydropower-learning-centre/kaplan-turbines/
} 
discharge velocity to recover residual kinetic energy. By reducing the exit velocity, the draft tube effectively creates a higher head, which increases the power output of the turbine. Efficiency is also improved by providing a smooth exit with reduced turbulence.

In addition to efficiency, turbine speed plays an important role in the turbine sizing and hence the cost of the machine. There are two concepts associated with turbines and speed: rotational speed and specific speed. "Rotational speed" refers to the number of revolutions per minute the runner will make under given inflow conditions. The rotational speed of the runner is proportional to head and flow and must be synchronized (either directly by mechanical means or indirectly through power electronics) to the frequency of the grid, which is $60 \mathrm{~Hz}$ in the United States. "Specific speed" refers to the nondimensional number used to classify turbines based on their performance and proportions. The mathematical representations of specific speed incorporate some combination of head, rotational speed, diameter, and either flow or power output. Engineering experience has proved that different shapes and orientations of runner blades will result in optimum performance at particular specific speeds.

\section{Turbine runner summary}

The speed and diameter of a turbine runner are intrinsically linked and are closely associated with the head and flow at a given site. In other words, the forces and material costs inherent in a turbine design are closely linked with the revenue-generating capability of a particular site. These relationships are exploited early in the feasibility stage of development to develop, compute, and successively refine a power output estimate and subsequent power benefit stream. The final runner design will generally balance low installed cost and high efficiency with other site-specific considerations that lead to the most favorable project arrangement.

\subsubsection{Advances and Challenges}

\section{Standardized turbine runners}

At SHPs, reductions in project cost are often obtained through a standardized package, consisting of some combination of off-the-shelf, readily available components; components that have a standard design but await an order for fabrication; and if necessary, components that must be procured for the specific job. Engineering design and fabrication or machining redundancies are reduced significantly if a common size of turbine runner is used across multiple projects. Standardized turbine runner designs have been optimized through model studies to accommodate a representative cross-section of heads, flows, power potentials, and spatial and cost limitations. Many manufacturers will provide a head and flow turbine application chart overlaid with identified regions that accommodate a standard turbine size. Small efficiency losses due to non-custom design may be offset by component cost reductions that prove economically attractive over the lifetime of the turbine.

\section{Modular generating units}

A concept used in many other energy sectors, modularity has, until recently, been mostly underutilized in the hydropower industry. Standardized turbine runners offered with a pre-determined power output may be combined in a modular fashion to increase the installed capacity at a site. In most cases, modular extension is carried out in parallel, with runners operating adjacent to one another in the same hydraulic passage or with individual penstocks. The complex civil works, electrical connections, and hydraulic challenges may be offset by cost reductions from volume orders of standardized turbines. To date, this strategy has been employed mainly at NPDs or locks where the need for civil works has been minimized. 


\section{Unconventional runner designs}

Most small hydro worldwide has been developed using the three conventional runner types: Pelton for high heads (tangential in Figure 8), Francis for high to medium heads (not shown in Figure 8), and Kaplan variations for low heads (axial and radial in Figure 8). Recently, several unconventional runner designs that exhibit acceptable performance characteristics have gained acceptance, particularly for lowhead sites. These include the Natel SLH HydroEngine, ${ }^{14}$ the VA Tech Hydro ECOBulb, ${ }^{15}$ and the Archimedean screw, among others.

\section{Advanced materials}

Whereas metals have been used in the hydropower industry with great success for over 100 years, composite materials have not seen significant uptake in powertrain components. Some major turbine equipment manufacturers have investigated lightweight materials, although they have not been widely adopted (DOE 2014). The decreased cost and reliable performance of composites in other industrial sectors are gradually leading to hydropower industry acceptance, particularly the use of fiber-reinforced composite materials in small hydropower turbines. The rise of additive manufacturing (i.e., 3D printing) offers numerous opportunities for innovation in the hydropower industry. The use of advanced materials and manufacturing techniques in hydropower design represents an area in which future R\&D could greatly benefit the hydropower industry (see Section 5.5.1).

\section{Advanced simulation capabilities}

Traditional runner design techniques based on empirical relationships or simplified computational fluid dynamics (CFD) models have been popular because of their low cost and simplicity in modeling turbomachinery flows. However, most simplifying assumptions inherent in these techniques (e.g., flow and turbulence averaging) result in decreased prediction accuracy. More recently, improvements in computer and algorithm technologies have enabled the simulation of highly unsteady flows. In general, these models are still very expensive (typically two orders of magnitude more expensive than steady solvers) in terms of both computational time and memory storage. For example, unlike steady-state computations that typically require modeling of a single, fixed turbine runner blade, time-accurate computations require modeling of the entire rotor, significantly increasing the computational cost and memory storage. These requirements put increased pressure on both the industry and academic communities; therefore, much more efficient computational techniques are needed for the design of future turbine technology.

\subsubsection{Generator and Governor}

The generator is responsible for converting the mechanical power of the runner into electrical power for distribution. All modern hydropower plants use AC generators (ESHA 2004). Standard generators consist of two components, a stator and a rotor. The rotor is a spinning component attached to the runner. The stator is the stationary component that supplies electrical power to the grid. The rotor carries a magnetic field as it rotates, creating a time-varying magnetic field in the stator. The time-varying magnetic field induces electric fields in the stator windings, creating the currents that couple the stator to the grid.

\footnotetext{
${ }^{14}$ http://www.natelenergy.com/

15 http://www.andritz.com/hydro/hy-small-hydropower-standard.htm
} 


\subsubsection{Generator Characteristics}

\section{Classification}

There are two main categories of generators based on the type of rotor-stator interaction: synchronous and asynchronous. Since the induction generator is the only type of asynchronous generator used in hydropower applications, and most induction generators operate at a non-synchronous speed, the terms "asynchronous" and "induction" are often used interchangeably. In addition to synchronicity, generators are operated in either fixed-speed or variable-speed mode depending on whether the stator field frequency matches the grid frequency. In the case of a variable-speed generator, power electronics are often required to perform AC-to-AC conversion.

The terms "synchronous" and "asynchronous" as used in this document refer to the relationship between the rotor speed and the frequency of the excitation in the stator. In a power generation context, they may also refer to the relationship between the stator frequency and the grid frequency. When the stator frequency is the same as the grid frequency (synchronous power generation), the stator may be directly connected to the power grid. When the stator frequency is different from the grid frequency (asynchronous power generation), the stator must be indirectly coupled to the grid through power electronics. Table 3 summarizes the relationships among rotor topology, generator speed range, and grid connection method.

Table 3. Characteristics of different generator types

\begin{tabular}{|c|c|c|c|}
\hline & & \multicolumn{2}{|c|}{ Power grid connection } \\
\hline & & Direct & Indirect \\
\hline \multirow{3}{*}{$\begin{array}{c}\text { Speed } \\
\text { range }\end{array}$} & Fixed & $\begin{array}{l}\text { All synchronous generators } \\
\text { - Require mechanical regulation of speed } \\
\text { for normal operation } \\
\text { Singly fed induction generators } \\
\text { - Require mechanical regulation of speed } \\
\quad \text { for optimal operation }\end{array}$ & $\begin{array}{l}\text { Although it is possible to operate a } \\
\text { generator with power electronics at a fixed } \\
\text { speed, it typically can be operated as a } \\
\text { variable-speed drive. Therefore, this is } \\
\text { likely not an optimal configuration for } \\
\text { synchronous or induction generators }\end{array}$ \\
\hline & \multirow[t]{2}{*}{ Variable } & $\begin{array}{l}\text { Doubly fed induction generators } \\
\text { - Power electronics supply variable- } \\
\text { frequency power to the rotor through slip } \\
\text { rings }\end{array}$ & $\begin{array}{l}\text { All synchronous generators and singly } \\
\text { fed induction generators } \\
\text { - Peak power/efficiency is obtained } \\
\text { over a wide speed range }\end{array}$ \\
\hline & & $\begin{array}{l}\text { Singly fed induction generators } \\
\text { - Peak power/efficiency is obtained only in } \\
\text { a narrow speed range }\end{array}$ & \\
\hline
\end{tabular}

\section{Generator design considerations}

To maintain proper performance, several key generator design considerations must be addressed. The way the turbine and generator are coupled plays an important role in the overall system performance and operation. In most traditional arrangements, a shaft couples the turbine runner directly to the generator, providing the necessary torque to spin the generator rotor. A generator can be coupled to the turbine runner along a vertical or horizontal axis, depending on the desired hydropower scheme and runner design. In many low-head schemes, the rotational speed of the turbine is low, and belts or gears are incorporated into the coupling mechanism to step up the rotational speed of the generator to match the grid frequency (Figure 9). This may lead to additional gear losses, vibration and noise, and lifetime 
maintenance requirements and costs. Designs that incorporate the generator rotor directly onto the turbine blades and eliminate the need for a shaft and speed increasers have also been deployed.

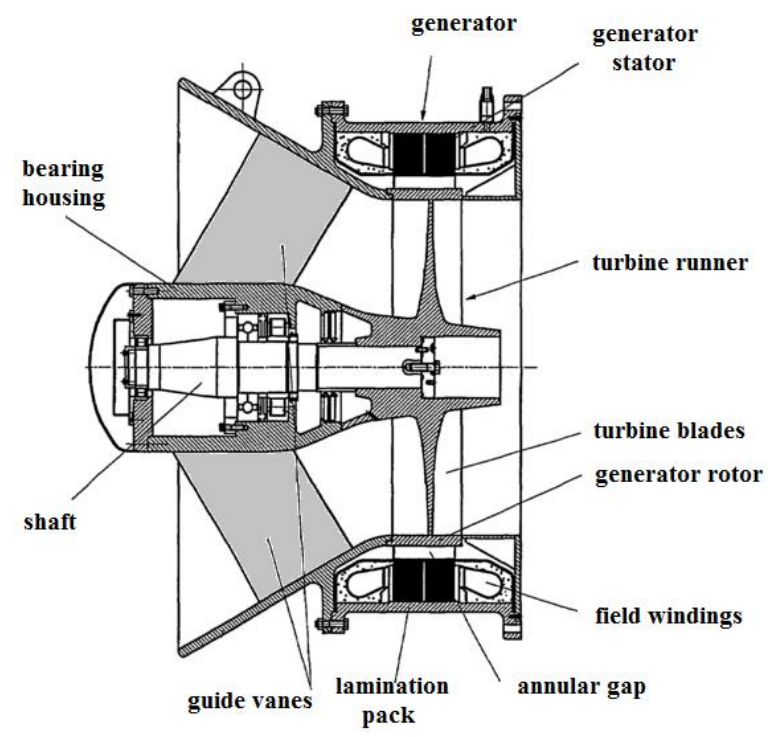

Figure 9. Rim-mounted generator. (Source: ANDRITZ HYDRO GmbH. Used by permission.)

Another essential design consideration, speed control, plays a major role in dictating output voltage; and operational procedures should be established to ensure maximum efficiency and avoid runaway speed. Many small hydropower generators operate at a fixed speed, and adjustments to the flow rate must be made when head fluctuates to maintain the proper system speed. This can result in efficiency losses, because the best efficiency point of the unit does not always align with the synchronization speed. The main role of the governor is to balance the water flowing through the system with the power requirements of the grid. The governing mechanism can take the form of mechanically actuated gates that change the flow through the turbine based on head-discharge-frequency relationships, and/or of power electronics that regulate the voltage and frequency of the generator output to match the grid requirements. The latter approach is referred to as a variable-speed system, as it allows the turbine to operate at the best efficiency point for the given head and flow independent of system speed requirements. Variable-speed systems may be attractive at low-head sites where regulating gates require significant expense and design complexity. In these cases, multiple parallel fixed-blade turbines would be of value. The number of units operating would be determined primarily by the discharge, and the speed would be determined primarily by the head available, which could change over time.

In addition to synchronous speed, the maximum runaway speed of the runner must be a design consideration. Under total load rejection at full head and flow, the runner may rotate at two to three times the design speed, creating significant mechanical forces that can damage equipment and electrical connections.

Owing to heat production during operation, generators require a cooling system to transfer heat away from electrical components and conductors. For small generators of less than 3 MVA ( $3 \mathrm{MW})$, direct air-cooling is suggested (Leyland 2014), whereas larger generators require cooling water systems. In either case, intakes for the cooling fluid must be placed in locations where debris, bugs, or dust will not enter the system; and filters or strainers must be sized and maintained to ensure fluid flow is not restricted. 
Additional auxiliary equipment necessary for successful generator operation may include lighting and electrical surge protection systems, fire protection systems, neutral earthing equipment, monitoring equipment, ventilation systems, compressed air systems, and lubrication handling systems. Additional generator equipment considerations include guide and thrust bearings, lubrication pumps, flywheels to increase generator inertia, brake rings, excitation systems, and instrument transformers.

\title{
3.1.2.2 Advances and Challenges
}

\section{Permanent magnet generators}

Both the rise of wind power and the large proportion of low-head sites among undeveloped potential sites have increased interest in the use of permanent magnet generators (PMGs) for hydropower generation. A PMG eliminates the need for complex external excitation by using spinning rare earth magnets on the generator rotor rather than electromagnets, resulting in mechanical design simplification, fewer mechanical and excitation losses (i.e., higher system efficiency), and improved system reliability. Highperformance magnets do not require active rotor cooling, so the need for external cooling systems also is eliminated. A PMG still requires a mechanism to regulate output voltage and runner speed, although reduced electrical and mechanical complexity can lead to cost savings. Limited PMG adoption to date within the hydro industry has led to interconnection difficulties and limited regulator acceptance in some regions. Many conceptual designs and pilot projects with variable-speed PMGs have been proposed or are under development (Bard et al. 2006; All-Energy 2013; Sobczyk et al. 2010), yet large-scale adoption has not occurred because of the traditionally high cost of the rare earth metals used to manufacture the magnets and uncertainty regarding PMG grid interconnection requirements (Hatch 2008). One application of this technology is the Voith StreamDiver (Figure 10).

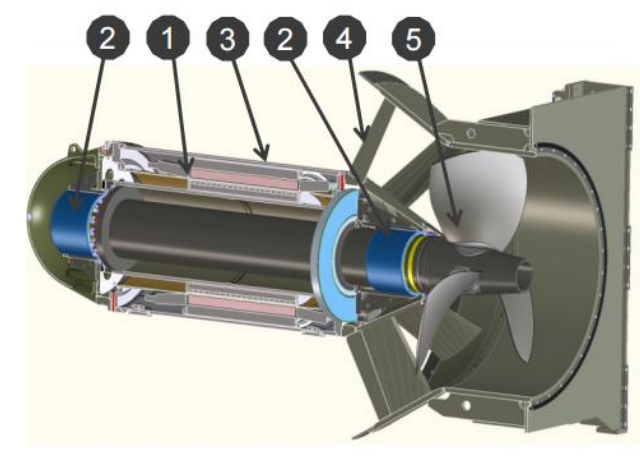

\author{
1 Permanent magnet generator \\ - Water-floated \\ 2 Thrust and guide bearings \\ - Water-lubricated \\ 3 Turbine bulb \\ - Water-filled \\ - No dynamic seals \\ 4 Turbine housing with fixed \\ guide vanes \\ 5 Propeller runner
}

Figure 10. StreamDiver turbine module with permanent magnet generator encased in a bulb. (Source: Voith GmbH. Used by permission)

\section{Variable-speed electronics}

The use of variable-speed electronics, an emerging generation technology, achieves high operational efficiency with fixed-gate, fixed-blade turbines through the use of power electronics and eliminates the need for servomotors. A variable-frequency drive has the ability to set a system speed that corresponds to the best efficiency point for a given head, allowing the turbine to maintain high efficiency over a broad range of heads. Optimum system efficiency is more easily attained, and component life is prolonged, by limiting the vibrations, hydraulic losses, and mechanical stresses that result from off-design operation. A recent retrofit at an existing site showed that equipment and installation costs were cheaper than for an equivalent synchronous system (DOE 2014). The incorporation of complex power electronics may require additional programmable logic controllers, modified governor and excitation systems, and 
additional electric circuitry; and additional loads associated with equipment modifications can be expected.

\section{Embedded generator design}

In the current paradigm, traditional low-head hydropower projects suffer from disproporionately high costs due to the relatively larger size of the electromechanical equipment and, hence, civil works needed to meet the high flows associated with a given power output. To mitigate this constraint, generation technology designs for low-head sites are trending toward standardized, compact, axial-flow type turbines with limited physical footprints and embedded generators. Axial-flow turbines can operate in a straight hydraulic passage from upstream to downstream. This configuration passes greater flows than a curved passage; has fewer efficiency losses, as friction-inducing elbows and bends are eliminated; and results in reduced lateral bulk compared with radial-type turbines that require scroll cases. The axial-flow orientation enables compact designs that incorporate the generator into a bulb-type nose on the upstream face of the runner or on the outer diameter of the runner.

\subsubsection{Powerhouse}

A conventional powerhouse encloses the turbine runner, generator, water conveyance, and electrical systems to protect them from external hazards. It can be structurally connected to the dam, or it can serve as a stand-alone structure hydraulically connected to a stream through a water conveyance system. Powerhouse design is dictated largely by the electrical and mechanical equipment layout; ease and safety of installation, operation, and maintenance; required runner elevation setting with respect to the tailwater; site-specific geologic or topographical constraints; integration into the local landscape; and cost.

The powerhouse has been an area of intense focus for recent hydropower development, with many innovative solutions achieved. Among the key advances and challenges, SHP development may benefit from precast modular designs, elimination of the powerhouse, and integration into the surrounding landscape.

\subsection{PASSAGE TECHNOLOGY}

The use of a dam, weir, or diversion structure is common to most hydropower projects. These structures allow for improved control of flood flows while creating hydraulic head to drive the turbine. However, they typically create disruptions in the exchange pathways among water, aquatic life, sediment, and other beneficial users of the stream. In the context of hydropower development, any effect on water distribution, water quality, recreation, stream aesthetics, fish and wildlife habitat, and other natural resources must be thoroughly understood in the development phase. Decisions regarding the need for potential mitigation technologies must be based on the perceived or measured impacts of hydropower operation on the riverine environment.

Passage technologies at a hydropower plant can be explored in a myriad of ways from a perspective of function, design, and need. In this section, passage technologies are categorized in terms of function into four groups: water, fish, sediment, and recreation. Each function is briefly described, followed by a discussion of current strategies, techniques, and designs that seek to maintain upstream and downstream connectivity while achieving economic feasibility. 


\subsubsection{Water Passage}

Essential to a hydropower facility's function, water passage may be accomplished in a variety of ways. Proper flow allocation is an essential design consideration and an important early-phase project development consideration.

\subsubsection{Water Passage Characteristics}

A hydropower facility must pass minimum, normal, flood, and probable maximum flood flows consistently and safely downstream. This is generally accomplished by using a power conveyance, such as a penstock, to pass generating flows through the turbines, and a diversion structure, including weirs and spillway outlets, to pass nongenerating flows around the turbines. Water is passed toward and around the turbines by use of a weir, spillway, bypass canal, or other structure, the construction and configuration of which will depend on the type of hydropower scheme. These are generally classified as fixed or mobile (ESHA 2004), where fixed structures are built onto the streambed and hydraulically optimized to increase the water level and pass flows over the crest, and mobile structures can regulate water levels via gates or other outlet structures.

\subsubsection{Advances and Challenges}

Partitioning of the total flow into generating and nongenerating flows remains a challenging feat, as competing demands on the same resource need to be reconciled. Nongenerating flows represent a loss of energy - more power is generated if the entire flow is passed through the turbines. However, nongenerating flows are often required for passing fish and sediment downstream (as discussed in detail in Sections 3.2.2 and 3.2.3) to mitigate stream connectivity disruptions caused by the hydropower facility (Richter et al. 2007; Ziv et al. 2012). Furthermore, nongenerating flows may provide water for irrigation, recreation, and adequate environmental flow conditions to enable and sustain fish habitat and prevent stream degradation downstream of the facility (Richter et al. 2007). This challenge is particularly acute for large reservoirs, where optimization of dam operation has received significant attention via advanced algorithm development (Chatterjee et al. 1998; Debnath et al. 2014). However, key prerequisites for successful optimization of generating and nongenerating flow management at any scale are (1) a priori knowledge of the primary linkage relationships or equivalent functionalities among the variables describing generation and passage characteristics and (2) the establishment of appropriate indices that allow the quantification of process and optimization goals (Richter et al. 2007; Ziv et al. 2012; Debnath et al. 2014).

Alongside the development of hydropower optimization algorithms, two strategies are emerging to drive cost reductions in water conveyance infrastructure: fabrication using alternative materials, and elimination of the penstock and powerhouse altogether. Alternative material penstocks have been developed and implemented at small hydro sites (Minott and Delisser 1983), although further R\&D into lightweight, high-strength materials to reduce installation and construction costs is commonly suggested (Zhang et al. 2012; Bishop et al. 2015). Design standards, codes, and industry-approved best practices are not fully developed for these materials, leading to hesitancy among some developers. Elimination of the penstock has been accomplished by using turbines designed to deploy at very low-head sites (Fraser et al. 2007) and at NPDs or locks with existing civil infrastructure (ANDRITZ 2014) (Figure 11). A trade-off must be achieved between the loss of pressurized delivery, cost, and runner size. 

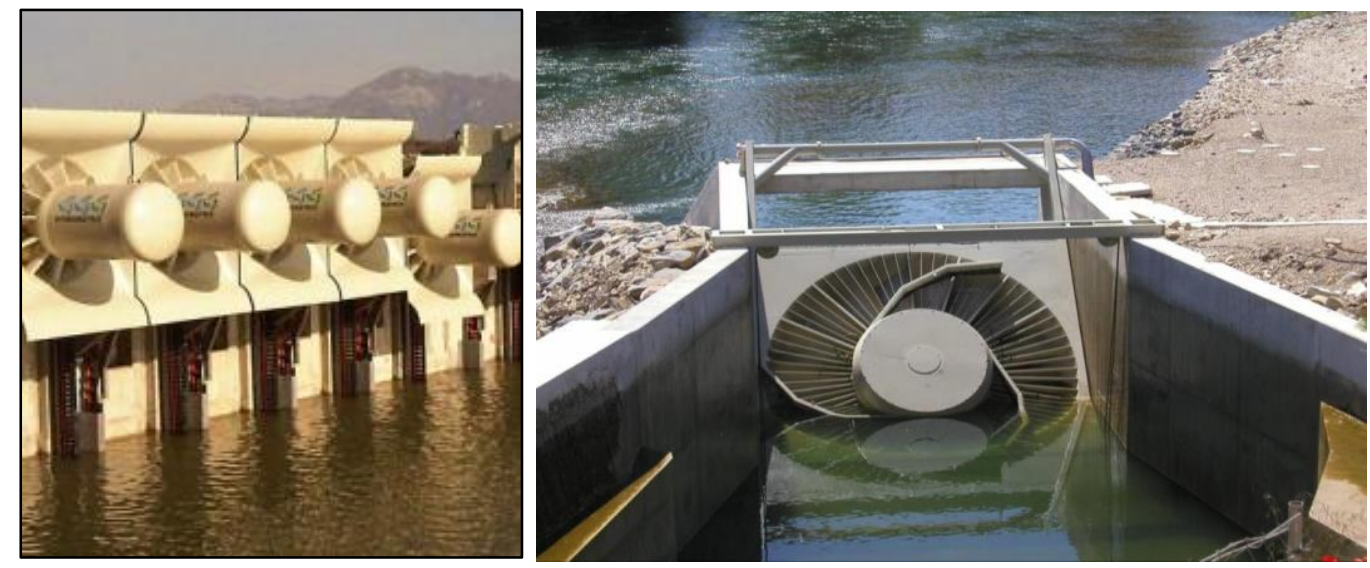

Figure 11. Hydropower turbine designs that eliminates the penstock. The HydroMatrix turbine module (left) is loaded on a guide rack that slides onto the face of a dam (ANDRITZ HYDRO GmbH. Used by permission.); the VLH turbine (right) spans the width of the intake works. (Source: MJ2 Technologies North America. Used by permission.)

Most diversion structures consist of a substantial volume of concrete, an inherent disadvantage to a modular construction approach. On-site, systematic construction of the entire structure is often necessary. Strategies to reduce the size and need for reinforced concrete in diversion structures are being explored that could lead to material and labor cost savings. A new approach currently under development is the offsite manufacturing of precast modular concrete segments that interface with interlocking connectors. The segments are delivered and connected on-site, where installation times may be decreased four-fold and civil costs reduced by up to $60 \%$ compared with traditional concrete installation (French Development Enterprises LLC 2015). The use of an inflatable weir to increase head without using additional concrete is also gaining attention as a low-initial-cost and flexible diversion structure. A reinforced rubber bladder is inflated and deflated with an air compressor, based on upstream water levels. It may operate as a standalone rubber bladder or with steel gate panels (Figure 12).
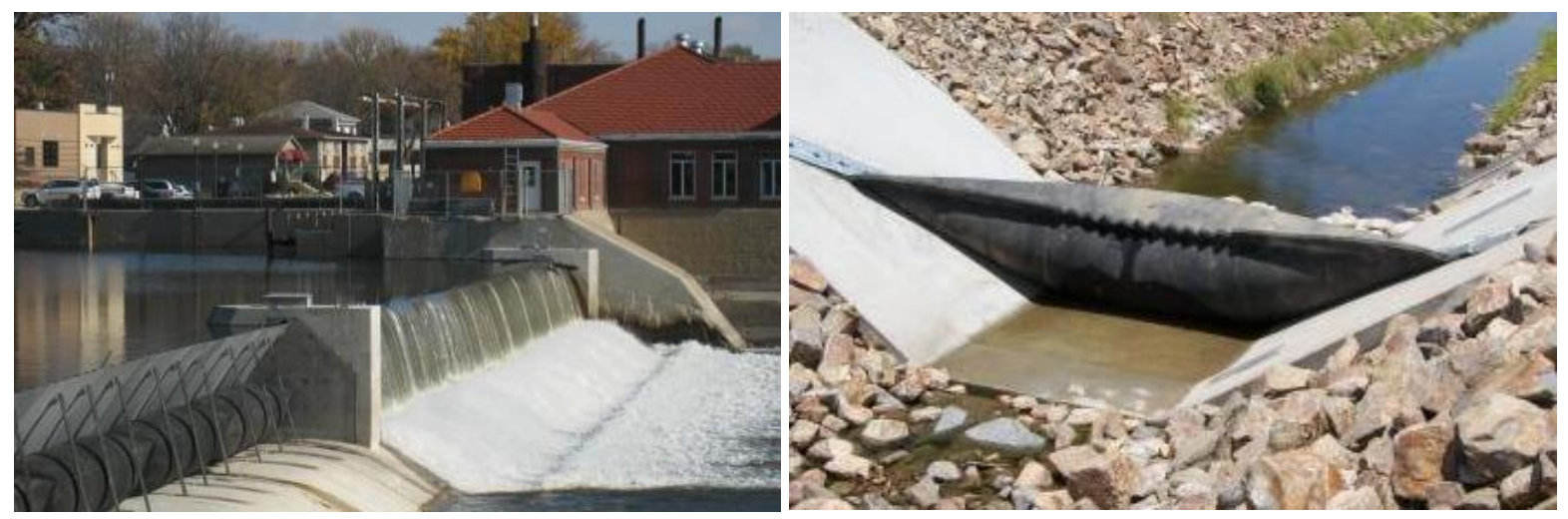

Figure 12. Inflatable rubber weir with steel gate (left) and without (right). (Source: Obermeyer Hydro, Inc.)

\subsubsection{Fish Passage}

Numerous technologies and approaches are applied to pass fish through, over, or around a hydropower facility (Figure 13). The technology selection process and design approach are generally informed by site and stream resource information, as well as the biological needs of the target fish species. Passage technologies can be broadly categorized as upstream, downstream, or experimental. General references for this section include Katopodis (1992); OTA (1995); Schilt (2007); Brownell et al. (2012); Noonan et al. (2012); Pracheil et al. (2016); and CNRA (2013). 


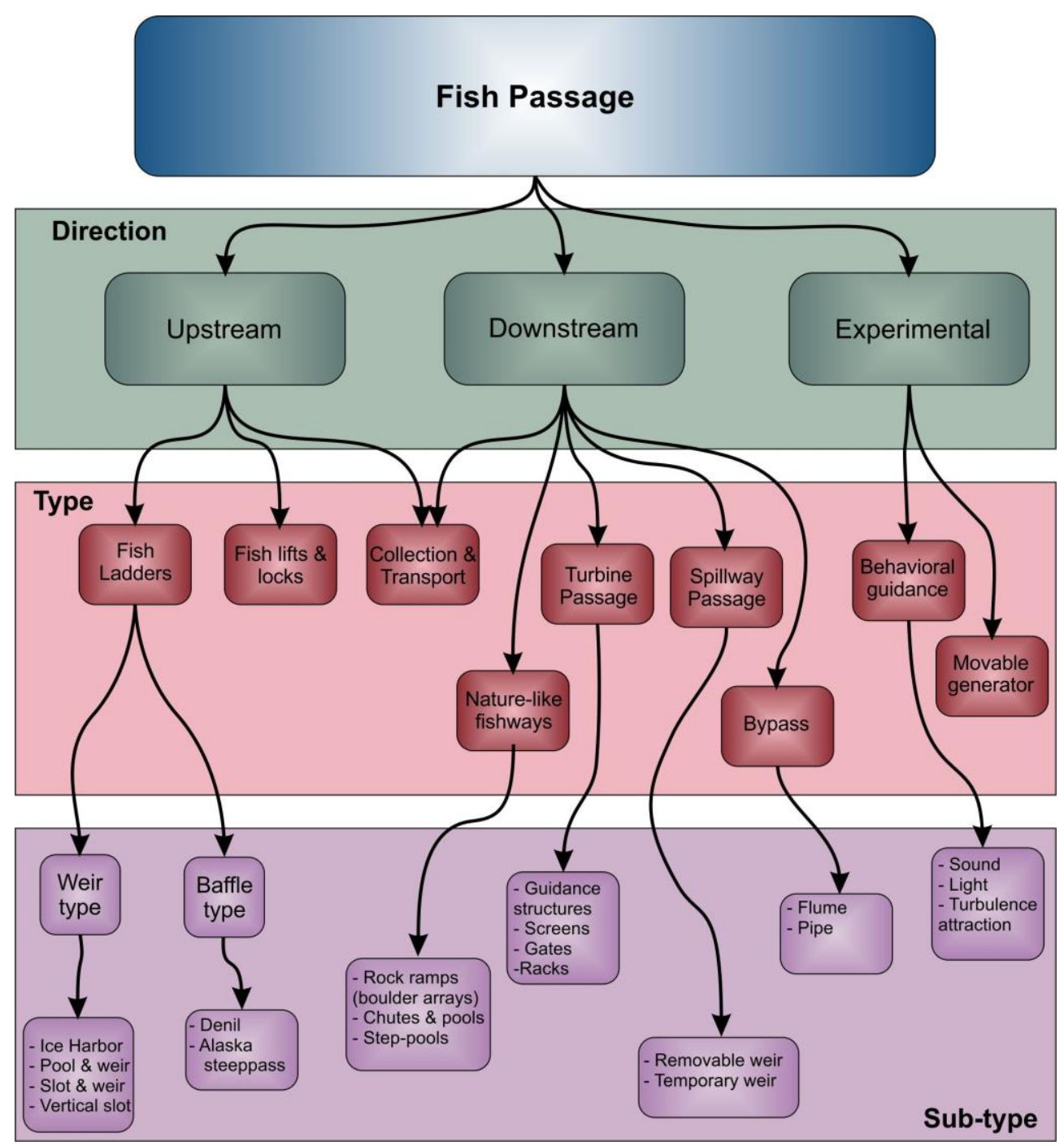

Figure 13. Classification of the current technologies for fish passage at hydropower facilities.

\subsubsection{Upstream Fish Passage}

Upstream fish passage is typically accomplished with a physical structure, such as a fish ladder or lift. Fish ladders are classified by hydraulic profile and function and are generally either pool and weir type fishways or baffled fishways (e.g., vertical slot, steeppass, Denil) (Figure 14). Fish ladder selection and design are dependent on appropriate attraction flow, fish swimming behavior, flow magnitude to be passed, controls necessary to achieve a certain flow regime in the ladder, velocities and pressures to be experienced by fish, slope, and baffle configuration. A fish lift captures fish in a hopper located downstream and raises them vertically to the upstream side of the structure. This design is preferred at high-head dams where fish ladders would require a substantial construction effort. Design considerations include whether the lift is mechanical or automated, the technique necessary to attract fish into the lift entrance, and the level of handling necessary to ensure targeted species achieve passage. Upstream passage technologies have been developed mostly for anadromous species, including salmon and trout; fewer designs are targeted at other riverine species of less commercial interest. 

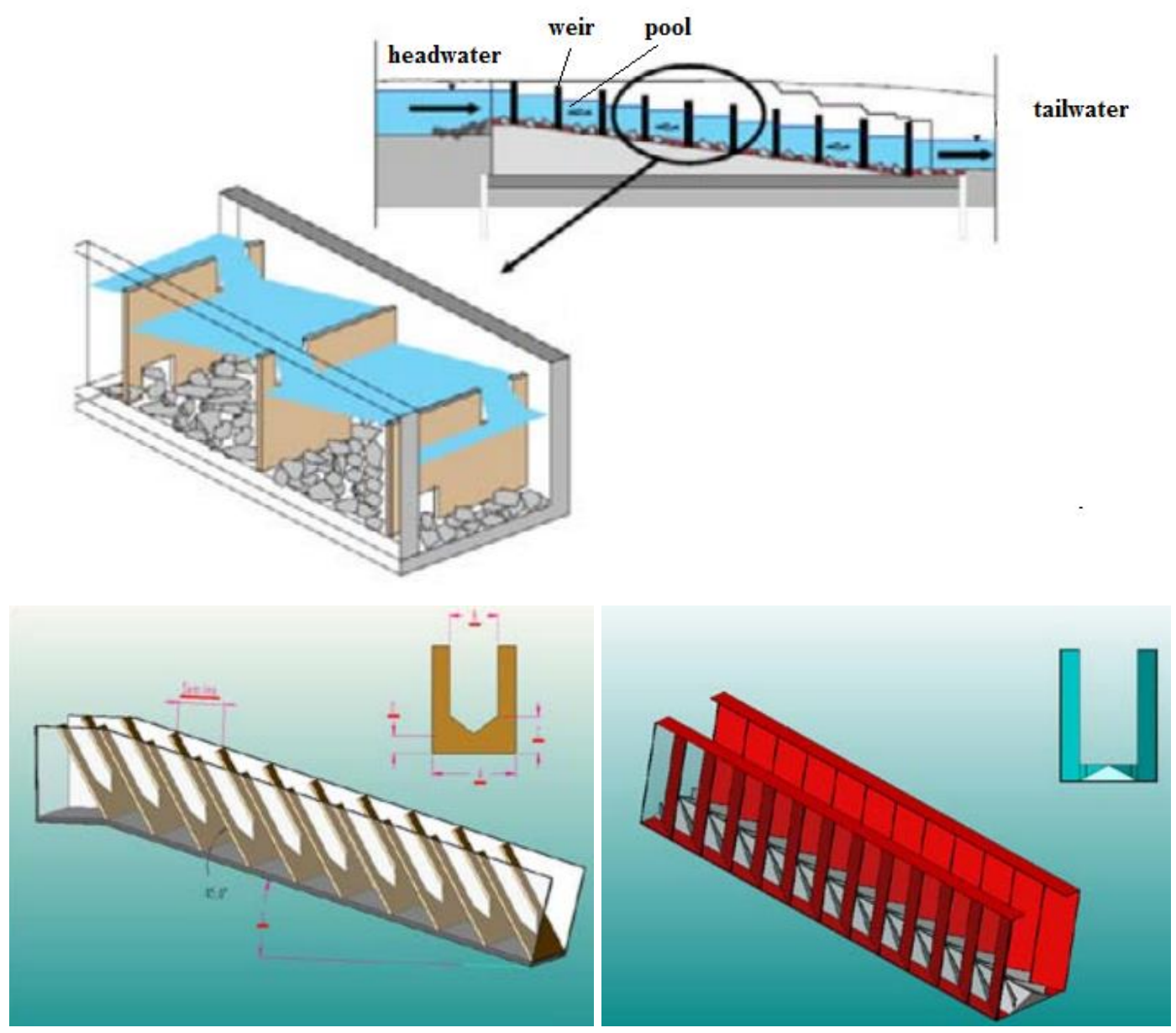

Figure 14. Top: pool and weir type fish ladder. Bottom: baffled structures including Denil (left) and Alaska steeppass (right). (Brownell et al. 2012)

\subsubsection{Downstream Fish Passage}

The goal of downstream passage is to transport fish around or through the hydraulic structure and prevent fish mortality in the water conveyance system to the GM (Figure 15). Downstream fish passage is commonly accomplished with bypass facilities, specially designed weirs, conduits, sluiceways, or fishfriendly turbines (Pracheil et al. 2016). Because fish passing through the turbine are exposed to significant pressure, shear, and turbulent stresses, which may cause fish mortality, special turbine design and operational techniques that improve fish survival have been developed (Cada 2001). Entrainment of fish into the turbines is typically limited by placing structural barriers that physically exclude fish based on size, such as guidance structures, screens, gates, or racks. Other techniques include increasing spillway flows, which may increase exposure to supersaturated water and cause gas bubble disease, and surface collection techniques that trap fish and transport them downstream in trucks or barges. Effective structural designs require knowledge of the target species, including population size, preferred swimming depth within the water column, swimming ability, fish jumping height and other behavioral criteria. 


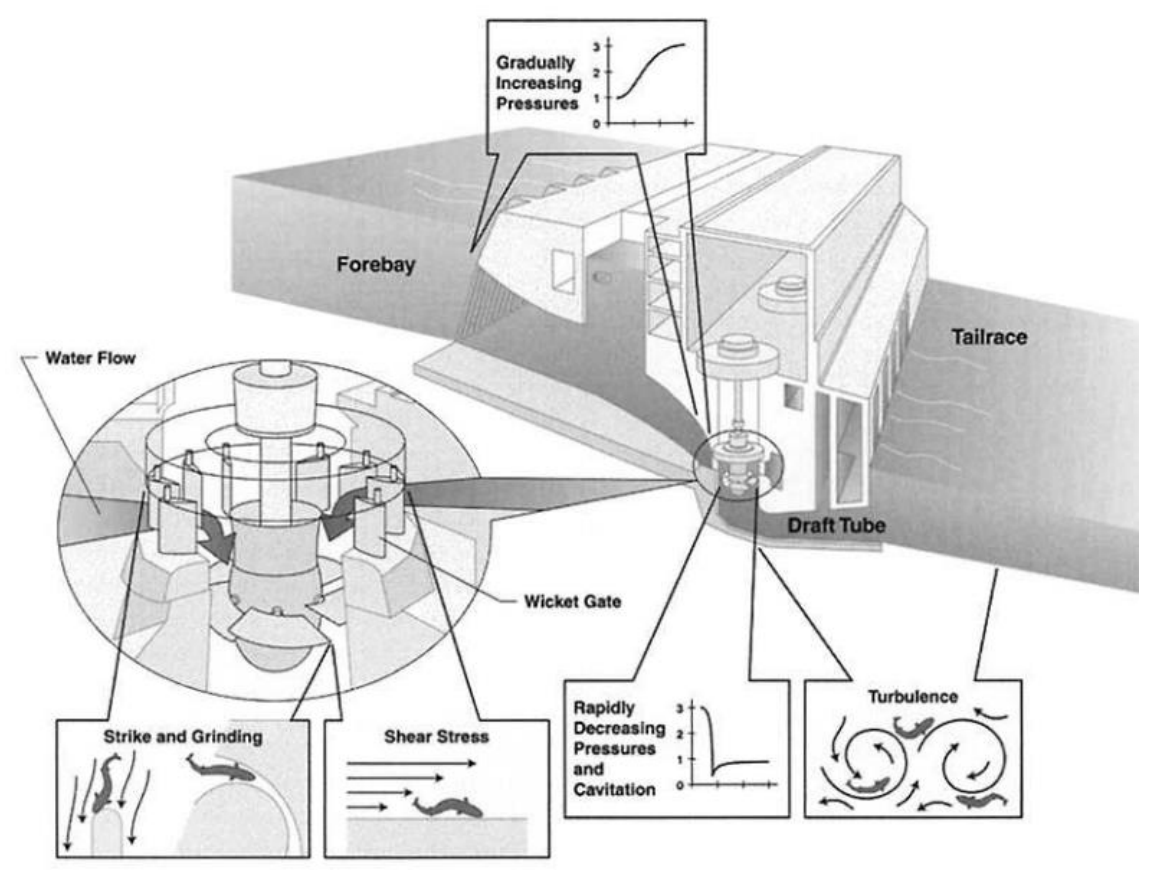

Figure 15. Locations and mechanisms within a hydropower plant that can lead to severe fish injuries. (Cada 2001)

\subsubsection{Experimental Fish Passage Techniques}

The need for inexpensive, effective, and standardized passage facilities has led to the investigation of alternative passage technologies that are not yet universally accepted. Experimental passage techniques include "behavioral guidance" devices such as sound, light, turbulence attracting (Coutant 1998), and electrical barriers; these are predominantly used to guide fish either away from the turbine inlet into the downstream passage structures, or to the inlet of the upstream passage structures. To date, only a handful of behavioral techniques at specific locations have been used to satisfy resource agency passage criteria (OTA 1995), and standardization may not be possible because of species-dependent responses. An emerging trend in downstream passage is the use of nature-like fish channels, which incorporate natural riverine features such as riffles, stones, natural substrates, pools, and rapids into complex bathymetries with space for internal habitat development (Aadland 2010; Schweiger et al. 2011, Gebler 2012).

\subsubsection{Advances and Challenges}

Reviews of upstream fish passage technologies and structures show significant knowledge gaps in the understanding of fish attraction and fishway performance (FERC 2004; Bunt et al. 2012). A consistent observation methodology is not applied across passage assessment studies; most field studies are species and location dependent; and results vary significantly. In addition, many structures are designed for sitespecific conditions and objectives that are not easily transferable to different projects. Several stakeholders have called for standardized fishway and fish passage structural component evaluations and inventories to help developers identify mitigation techniques early in the design and development phase (TN SHP 2005; Bunt et al. 2012; Bishop et al. 2015). This call for developing a standardized framework for fish passage design, along with the site-specificity of current fish passage technologies, underlines a critical need to develop and adopt a holistic approach that considers the interplay and feedbacks among hydraulics, operation, and module design (Dermisis and Papanicolaou 2009; Thomas et al. 2011) to move toward the development of quantifiable fish passage goals. The combination of fish and other passage 
needs into a single civil structure may be an opportunity to reduce costs and meet multiple stakeholder needs through a standardized approach.

Techniques to reduce costs and standardize downstream passage outcomes have largely focused on turbine passage and integrating passage structures into the hydro facility. Significant research and experimental effort has gone into developing fish-friendly turbines for downstream passage (Cada 2001; Cooke et al. 2011; Carlson and Richmond 2011). These technologies seek to decrease fish mortality by minimizing gaps in the turbine runner ${ }^{16,17}$ or operating at slower speeds and higher minimum pressures than those of typical turbines (Figure 16). ${ }^{18}$ Achieving passage through turbines may eliminate the material, labor, and O\&M costs associated with fish passage structures. The integration of passage facilities into the hydropower structure has occurred on a large scale at Wells Dam, where a spillway intake located directly above the turbine intake has been equipped with a bypass system with a vertical slot barrier. The bypass creates an attraction flow for fish, which are then passed over the spillway (where mortality tends to be lower) rather than forced through a turbine or fish passage intake.
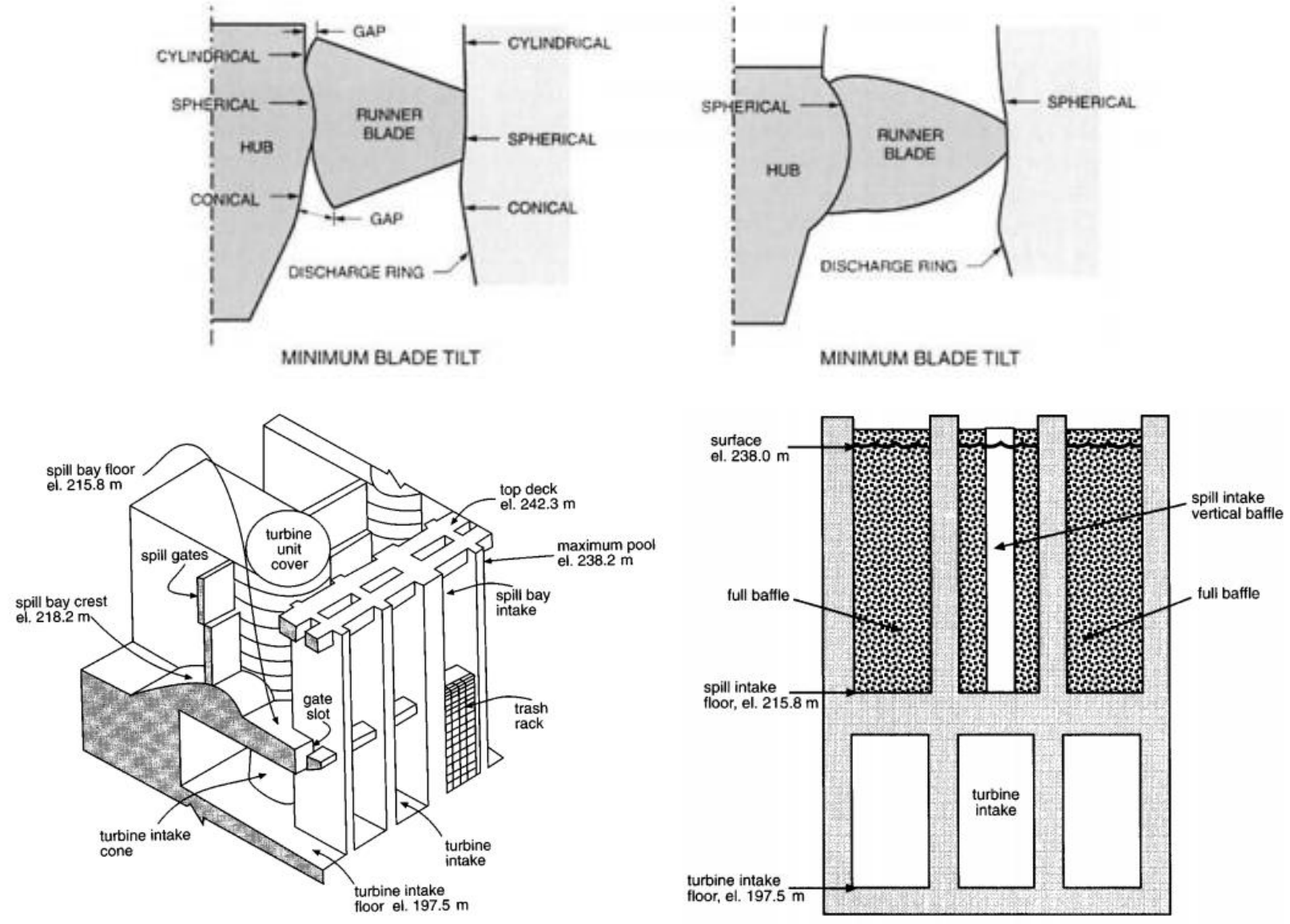

Figure 16. Top: a conventional Kaplan runner (left); a minimum-gap runner designed to decrease fish impingement (right) (Cada 2001); bottom: hydrocombine structure (Skalski et al. 1996; @ Canadian Science Publishing or its licensors).

\footnotetext{
${ }^{16}$ http://www.voith.com/en/products-services/hydro-power/environmentally-friendly-hydro-products/minimum-gaprunner-876.html

17 http://www.aldenlab.com/Fish-Passage

${ }_{18}$ http://www.vlh-turbine.com/fish
} 


\subsubsection{Sediment Passage}

Sediment transport throughout a riverine system is essential for channel formation and maintenance of suitable aquatic habitat. Both coarse and fine sediments have distinct environmental roles and pronounced effects on hydropower operations. Coarse sediments (i.e., gravel and sand) form the underlying structure of most riverbeds, banks, and bars. They serve an important role in creating riffles and spawning sites critical for aquatic biota, and continuous coarse sediment loads help decrease downstream channel incision (Kondolf et al. 2014). Fine sediments contribute to the formation of some riverine structures; the downstream transport of nutrients, contaminants, and other organic particles; and the productivity of downstream and coastal zones.

Sediment passage at a hydropower facility should be managed to minimize anthropogenic disruptions of the environment. It is also important for two operational reasons: to avoid sedimentation entrapment and accumulation in the forebay, which results in a decrease in storage volume, and to avoid fine particle discharge through the water conveyance into the turbine, where sediment can quickly erode the turbine runner. Strategies and technologies for sediment management can be classified as minimization of sediment inflow, sediment routing, and sediment removal (Annandale 2013). General references for this section include Shen (1999); ESHA (2004); Andaroodi (2006); Annandale (2013); Kondolf et al. (2014); and Wild et al. (2015).

\subsubsection{Minimization of Sediment Inflow}

Sediment inflows can be managed by controlling the upstream generation of sediment in the catchment region. This strategy relies on knowledge of sediment production and is subject to significant uncertainty and many unknowns. Techniques include catchment erosion control, such as reforestation and sedimentconscious agricultural practices; strategically placed checkdams that capture sediment before it can travel downstream; and warping, or the diversion of sediment-rich flows onto local farmland to improve soil fertility (Kondolf et al. 2014).

\subsubsection{Sediment Routing}

Designated bypass facilities, gates, or outlets may be incorporated into a hydropower project to assist in passing sediment (Kondolf et al. 2014; Andaroodi 2006) (Figure 17). Sediment bypasses route sedimentladen waters offstream around the dam to avoid sedimentation and reconnect sediment passage with the river downstream of the dam. Such a facility requires a steep gradient to drive sediment through the bypass tunnel or channel. High-level gates can be used for sediment sluicing. When opened, the gates pass high discharges, which carry sediment at velocities that hinder sedimentation. Low-level gates are designed for drawdown flushing. Complete drawdown of the reservoir creates large discharges, which scour and re-suspend sediment, which is then flushed through the gates downstream. Sediment traps may also be designed upstream of the hydropower intake to slow incoming velocities and allow sediment to settle. Traps may be designed with desanding gates, or they may allow sediment to accumulate in the channel before low-level flushing gates are opened. Low-level gates can also be designed to vent turbidity currents - dense, sediment-laden flows that flow along the reservoir floor. 

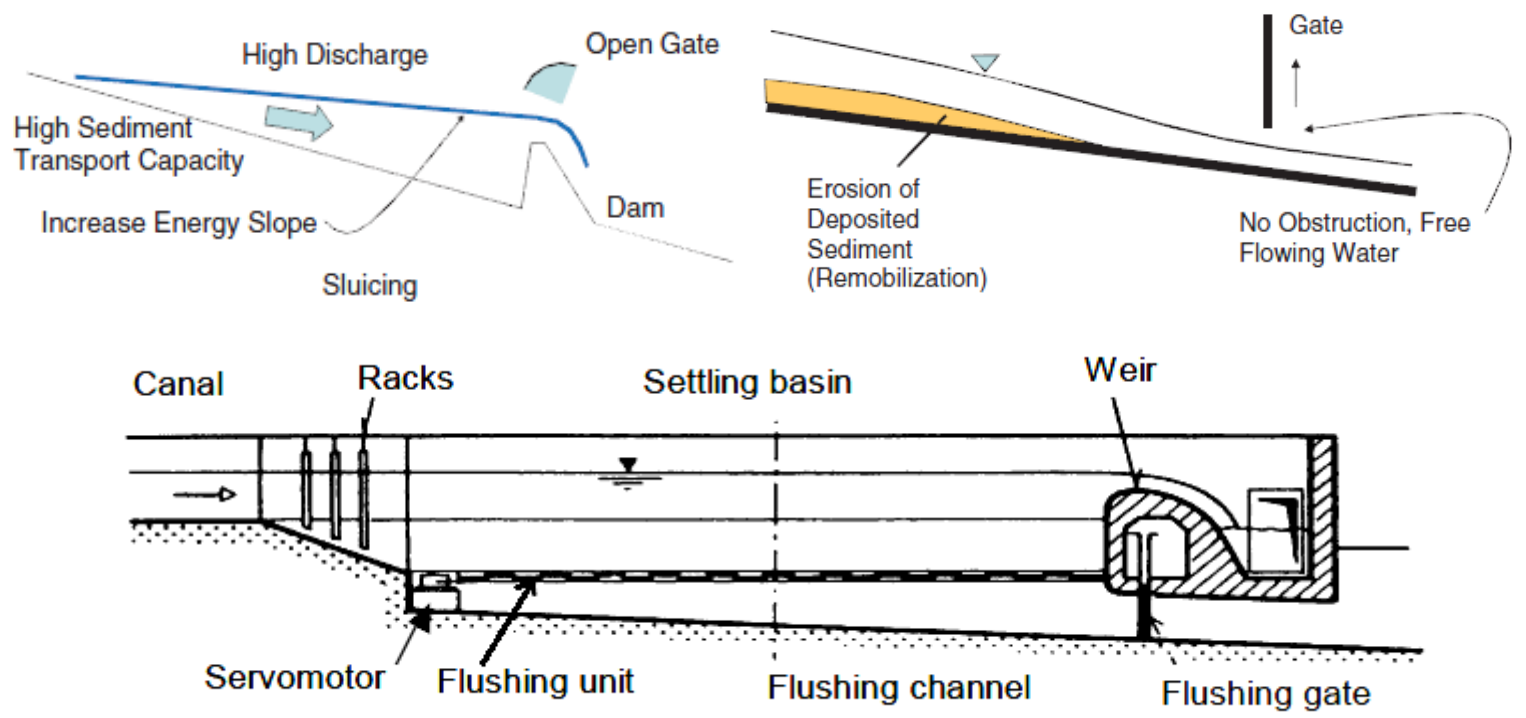

Figure 17. Top: high-level gates for sluicing (left); low-level gates for flushing (right). (Kondolf et al. 2014). Bottom: sediment trap with low-level flushing gate (Andaroodi 2006).

\subsubsection{Sediment Removal}

The physical removal of deposited sediments can be achieved mechanically by using hydraulic suction pumps, siphons, scrapers, or other heavy equipment. Mechanical removal may require the transport of sediment off-site for disposal, which can add significant expense. It may also require a complete drawdown of the reservoir, which could take the facility offline. Hydraulic dredging is generally more expensive than mechanical removal and is thus carried out selectively, typically near the water conveyance intake (Kondolf et al. 2014). Bates and Johnson (1986) describe and illustrate the machine "Gravel Gertie" (Figure 18) and report on field tests carried out in the Pacific Northwest. The efficiency of the removal of fines reached up to $78 \%$ in small to medium-size channels with small to medium-size hydraulic structures located nearby. Understanding how these structures interact with sediment is especially important for addressing the interdependencies and need for multiple sediment removal strategies. For example, mechanical sediment removal may be required if dam flushing has created a temporary increase in suspended sediment and settlement of fines. The vitality and health of stream invertebrate populations is tied closely to the particle sizes of streambed sediments, and techniques such as the Gravel Gertie or the fire hose proposed by Mih (1978) can prevent the suffocation of fish eggs and lessen the need for dredging.
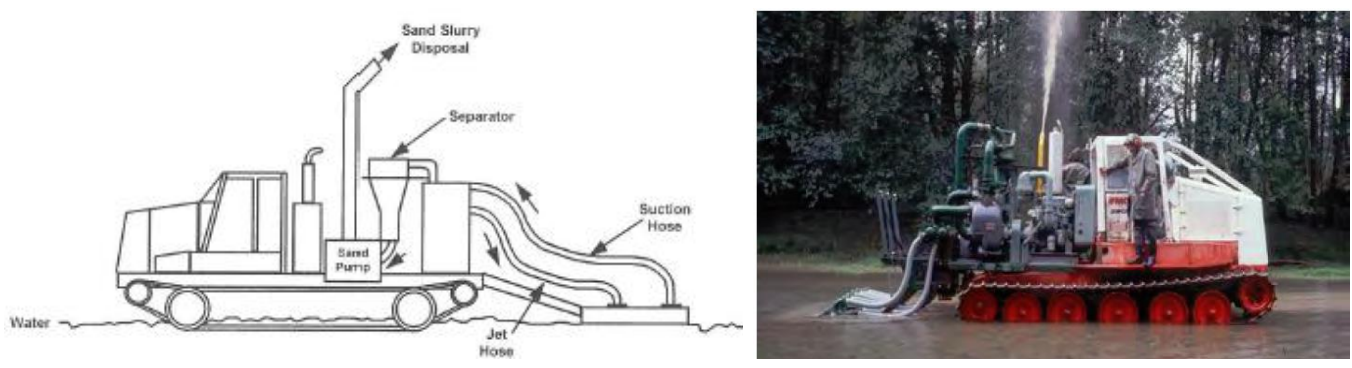

Figure 18. Gravel Gertie machine schematic (left) and photograph (right) for cleaning sediment from salmonid spawning gravels. The machine shoots vertical jets of water into the streambed and a suction system removes the resulting fine suspended sediment. (Bates and Johnson 1986; WOU 2004) 


\subsubsection{Advances and Challenges}

The variety of sediment passage and management techniques reflects the diversity of stream types, catchment basins, and alluvial characteristics of streams and rivers that support hydroelectric production. One attempt at standardization of sediment traps for high-head mountain streams takes the maximum excluded grain size as the primary design input, from which a target settling velocity informs the dimensions of the settling trap (Andaroodi 2006). Another approach suggests the sediment management technique should be chosen after a calculation of the long-term equilibrium river profile, or the profile achieved once initial sedimentation is complete and incoming and outgoing sediment are generally balanced (Kondolf et al. 2014). Technologies for long-term sediment management should anticipate future needs and be designed to accommodate those needs. Several authors (Annandale 2013; Kondolf et al. 2014 and references within; Wild et al. 2015 and references within) suggest that low-level gates for drawdown flushing, which have been implemented worldwide with relative success, may produce the best sediment management outcomes. The challenge articulated by Kondolf et al. (2014) is that no standard location or placement is suggested, as each location, dam type, and sediment management strategy will entail a distinct design.

A new overflow hydropower prototype and demonstration plant with built-in ecological protections and sediment passage mechanisms has recently been developed and patented in Germany (Figure 19). ${ }^{19}$ The concept uses submersible StreamDiver turbine-generators beneath a horizontal trash rack that excludes bed load, large debris, and fish. A portion of the flow spills over the top of the generating units into the tailrace to enable downstream fish passage and to flush bed loads and sediments that have accumulated on the trash rack.

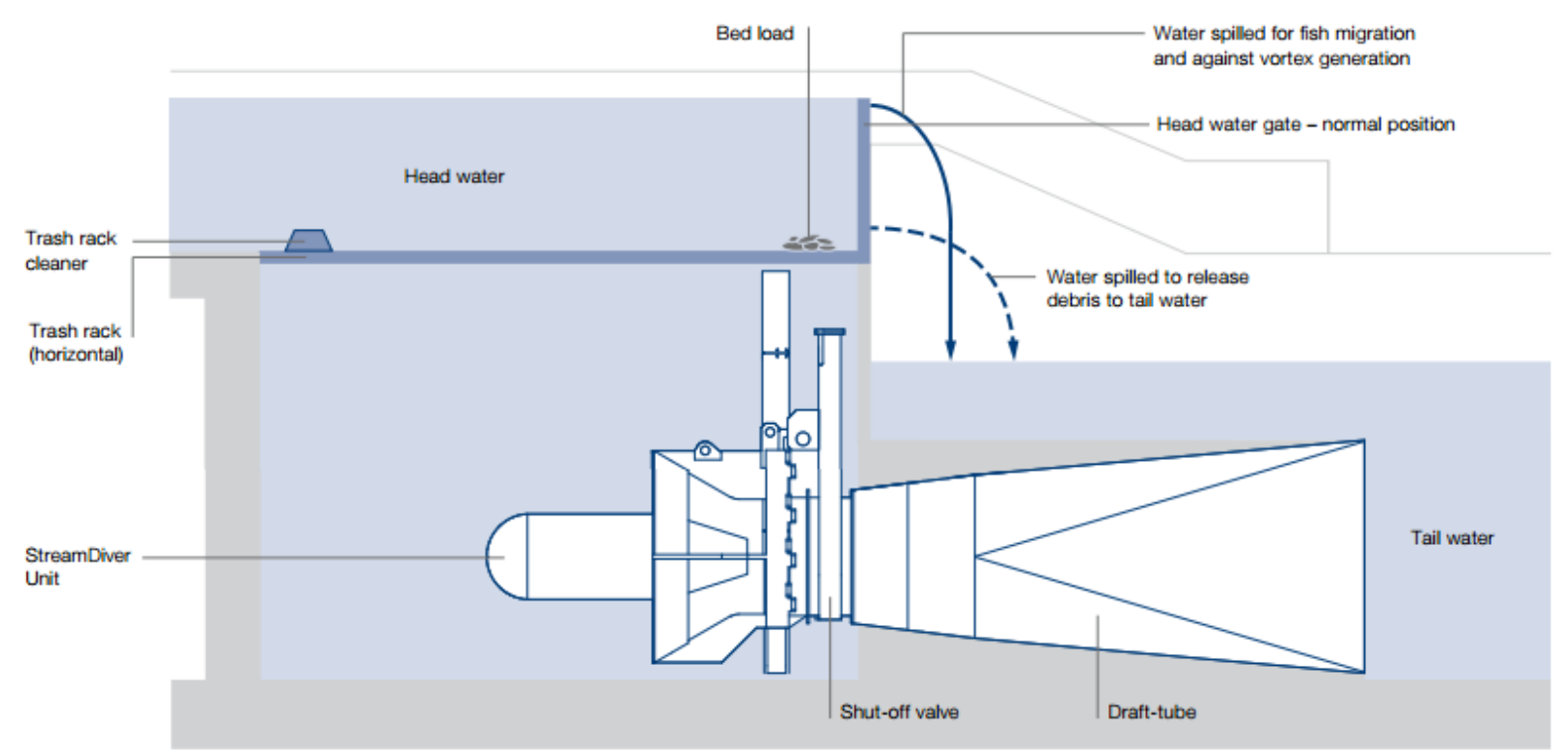

Figure 19. Shaft hydropower concept for normal fish and sediment passage. Shaft power plant concept developed and patented by the Technical University of Munich, Germany. (Source: Voith GmbH. Used by permission.)

${ }^{19}$ http://www.voith.com/en/t3408_e_StreamDiver_2015-08-19.pdf 


\subsubsection{Recreation Passage}

Hydropower facilities provide a variety of recreation benefits that are tremendously important to the economy (Bonnet et al. 2015). They can also have significant adverse impact on recreational pursuits in two distinct ways: (1) Low flows may inhibit instream recreation opportunities, including boating, whitewater rafting, and fishing, and near-stream activities, including camping, hiking, and aesthetic enjoyment. (2) The dam structure itself may block the passage of small recreational craft or create hazardous recirculating flows. This section will focus on technologies aimed at passing small personal recreational craft instream. General references for this section include Caisley et al. (1999); Caisley and Garcia (1999); and Whittaker et al. (2005).

\subsubsection{Recreation Passage Facilities}

Many designs exist for boat chutes that accommodate canoes or whitewater craft at low-head dams (Caisley et al. 1999; Newman and Munslow 2010). Canoe pass facilities are generally shallow with small, continuous gradients that allow smooth passage of a rigid canoe hull. They must be optimized to a length that is cost-effective yet creates safe flow conditions. Additional design criteria include maximum hydraulic drop, width of structure, features to identify locations of passage, energy dissipation mechanisms, length and characteristics of the recovery region, and emergency devices (Colorado 2008). Whitewater and kayak passage facilities can be dam enhancements and tend to have a complex structure of pools and drops that create an increased degree of difficulty for recreationists who tend to prefer more challenging terrains.

\subsubsection{Recreation Passage Safety}

The human element of recreation passage entails safety as the primary design consideration. An abrupt drop is a defining characteristic of hydropower facilities; and under certain circumstances, this condition leads to unstable, hazardous recirculating flows that can fatally trap unaware or unprepared recreationists. ${ }^{20}$ Recreation passage must limit strongly recirculating flows (i.e., hydraulic jump), the entrapment of extremities, and the potential pinning of bodies and craft against unseen or hidden obtrusions. Significant research has gone into understanding and mitigating these conditions (Caisley and Garcia 1999 and references within). Hydropower projects generally require safety devices or measures to reduce public exposure to hazards, which may include educating and informing the public, visual and audible warnings, physical restraining devices, escape devices, or procedures for safe operation (FERC 1992).

\subsubsection{Advances and Challenges}

A few dual-use recreation and fish passage facilities have emerged that capitalize on the mutual need for low-gradient passage. At least six canoe fish passages have been constructed on the River Medway in Kent, UK (Environment Agency 2013) (Figure 20). A handful of combined facilities have been constructed in the United States, although these are generally located at small, non-powered weirs. ${ }^{21}$

\footnotetext{
${ }^{20}$ http://krcproject.groups.et.byu.net/index.php

${ }^{21} \mathrm{See}$ http://www.acewater.com/wp-content/uploads/2011/03/cofc9809-color-power-plant-dam-proj-desc.pdf and http://www.illinoisfloods.org/documents/2011_IAFSM_Conference/2\%20Wednesday/3A_Testing\%20the\%20Gle n\%20D.\%20Palmer\%20Dam\%20(Yorkville\%20Dam)\%20Bypass\%20Cha.pdf
} 

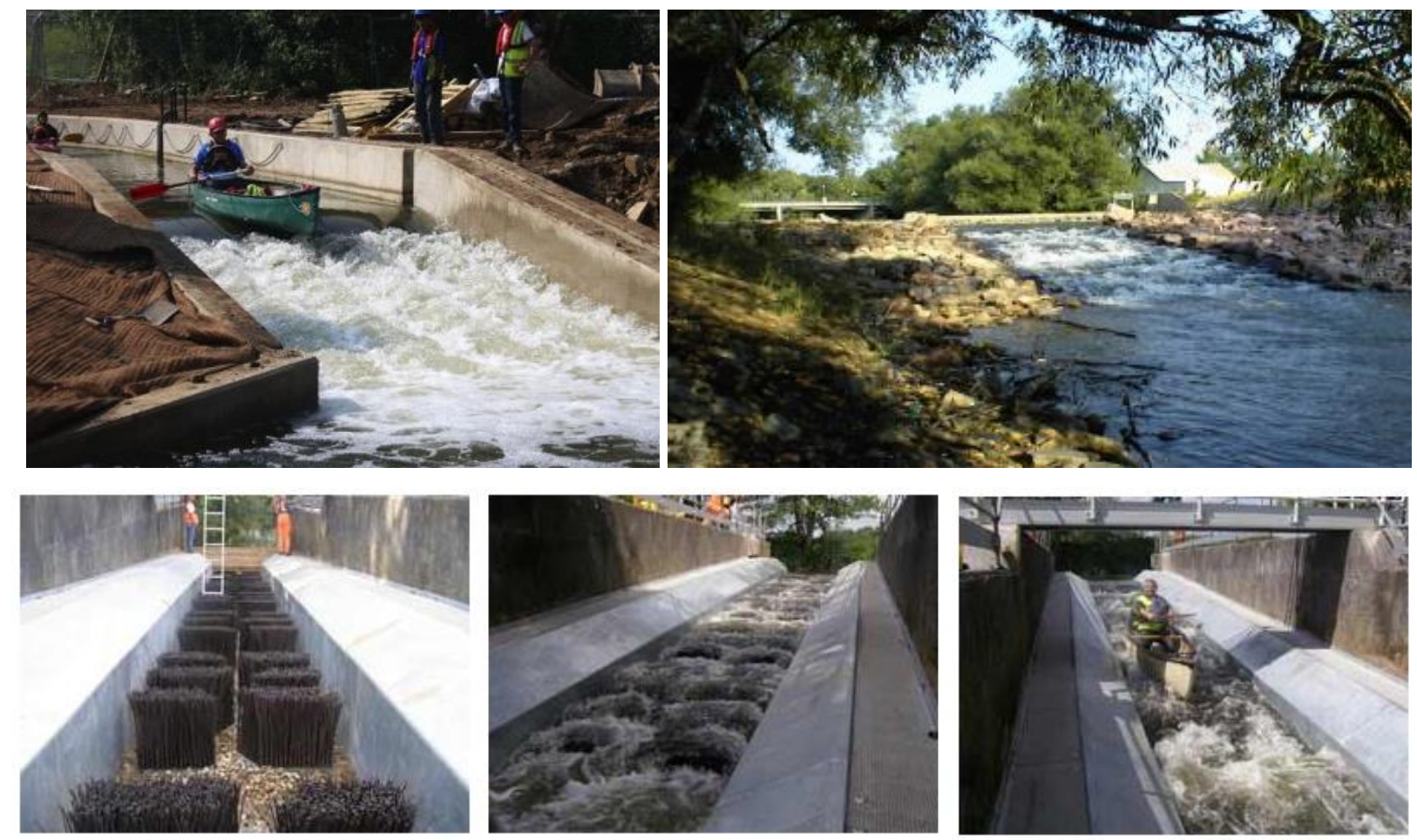

Figure 20. Combined fish passage and canoe chute on River Medway, ${ }^{22}$ Kent, United Kingdom (top left ${ }^{23}$ and bottom $^{24}$ ). Cache La Poudre River power plant dam/boat chute in Colorado (top right ${ }^{25}$ ).

A significant challenge to recreation passage is cost because recreation passage facilities can exhibit large footprints with multiple drops and instream habitat features, and significant design effort is necessary to safely accommodate novice recreationists. This has led some projects to forego recreation passage facilities in favor of portages or boat landings upstream and downstream of the hydropower facility. The treatment of an instream drop as a clear and avoidable hazard may be preferred to the liability associated with the real and perceived dangers of passage at low-head dams. ${ }^{26}$

\subsection{FOUNDATION TECHNOLOGY}

Within small hydropower dam design, the term "foundation" generally refers to the stream floor and abutments (USBR 1987). The foundation is treated to accommodate a variety of dam designs, which may have features that extend into the foundation. The conventional approach to hydropower development is to construct a massive, durable, permanent dam with appurtenant civil works that require extensive foundation preparation, analysis, design, treatment, and monitoring. When a site with strong hydropower potential has a foundation consisting of a soil type that is potentially unstable or pervious, significant difficulties, delays, and costs can be incurred to prepare the foundation if development is pursued. However, the reliability of hydropower as a renewable resource has been demonstrated and proved by the durability and long useful life of structures supported by strong foundations.

\footnotetext{
${ }^{22}$ A video of a series of canoe chutes can be found at https://www.youtube.com/watch? $=$ GfuAjXEHifc

${ }^{23}$ Source: UK Environment Agency. Used by permission.

${ }^{24}$ Source: British Canoeing. Used by permission.

${ }^{25}$ Source: Anderson Consulting Engineers, Inc. Used by permission.

${ }^{26} \mathrm{http}: / / \mathrm{www} . c 0 l u m b u s m o n t h l y . c o m / c o n t e n t /$ stories/2015/10/low-head-dams-danger-below.html.
} 
A variety of excellent resources are available describing the classification and subclassification of dams, materials, and construction considerations. General references for this section include USACE (1978); USBR (1987); and ESHA (2004). Within the context of SMH, the FM is conceived as being a structural interface that secures the PM and GM to the stream floor. With this in mind, Section 3.3 will discuss common foundation features and design considerations with respect to small hydropower development and will provide a brief overview of foundation technologies found in other industries. A list of recent federally funded proposals related to hydropower foundation research is also presented. Section 5.1.5 outlines FM considerations for SMH.

\subsubsection{Hydropower Foundation Features}

\subsubsection{Dam Foundation}

Globally, most small dams are constructed as embankment dams, which offer adaptability to a variety of different foundations (ESHA 2004). An embankment dam is constructed by placing and compacting layers of soil, rock, clay, and/or sand. Since these materials are often available and sourced locally, embankment dams typically offer low construction costs. For small embankment dams, it is generally economical to establish the foundation based on empirical relationships using large safety factors rather than precise designs informed by subsurface measurements, field tests, and complex theoretical models (USBR 1987). At a minimum, foundation treatment should consist of open excavation to remove sod and topsoil, followed by construction of a trench with impermeable materials or geomembranes to limit leakage under the dam. At some sites, compacted sand, gravel, or silty soil is laid with or without a trench. Rock foundations are generally preferred over soil foundations, as they are hard and resist erosion. In some cases, pervious zones in rock foundations may require treatment with cement grouting or other methods beneath and upstream of the dam to minimize leakage and provide stability. Compared with rock foundations, sand and gravel foundations are more pervious and present challenges from underseepage and seepage forces. Construction of trench-type cutoffs, sheet pilings, or concrete or cement walls under the dam may help mitigate underseepage risks.

Concrete dams are suitable for a wide range of underlying topographies, are generally able to prevent seepage and erosion, offer more resistance to overtopping than earth embankment dams, and are constructed through a highly mechanized process. Stability is achieved through a large mass; a triangular, wide-bottomed shape that distributes stresses across the foundation; and a level or slightly sloping upstream profile (USBR 1987). The underlying foundation must be analyzed for potential deformations based on the load from the dam and resistance to shear at the bond between the foundation and the concrete.

\subsubsection{Powerhouse Foundation}

Most small hydropower schemes house generation technology in a powerhouse located either in or adjacent to the streambed. Like the dam structure, the powerhouse structure must be placed on sufficiently sound material to prevent shear and sliding forces. The powerhouse may be constructed in or as a part of an existing dam or structure and thus may require minimal foundation work. Another possible scenario entails construction of a new dam or structure in which the powerhouse is integrated with the impoundment structure. Such an arrangement requires significant foundation work to ensure structural stability from the many forces impacting the structure. A third arrangement includes separation of the powerhouse from the dam via an enclosed conveyance, which enables optimal selection of powerhouse location to avoid costly foundation work. Regardless of the arrangement, most schemes will require some excavation work to properly set the turbine elevation. In the absence of sound material, additional excavation may be required to obtain suitable stability (INEL 1979). The powerhouse foundation design 
must be sufficiently robust to support the significant weight of a traditional powerhouse and the hydroelectric, maintenance, and control equipment housed within the structure.

\subsubsection{Water Conveyance Foundation}

A penstock is typically used to transfer water through an impoundment or divert water around the natural streambed. When the penstock is integrally built into an impoundment structure, the forces anticipated from its operation should be considered in designing the foundation. For cases in which water diversion or other requirements dictate the use of a stand-alone penstock (either above or below ground), foundation features such as anchors and thrust blocks are needed to eliminate movement caused by the operating forces, particularly at locations of penstock direction change (Colorado 2010).

In most schemes using a reaction turbine, the water conveyance system will require a tailrace to discharge powerhouse flows away from the structure while ensuring the turbine draws proper downstream suction. Typical designs integrate the tailrace as a part of the powerhouse foundation, which reduces construction cost and spacing needs (Colorado 2010).

\subsubsection{Foundation Design Considerations}

The classification of topography, underlying soil, underlying geology, and landforms is critical to foundation treatment design. In the feasibility stage, it is necessary to conduct subsurface sampling where all potential structures will be located to determine the depth to bedrock; character of the bedrock and underlying soils; present and future permeability; and relationship of the geologic conditions to future stability, landslide risk, and seismic risk. Inadequate foundation investigation can lead to significant construction difficulties in small and large structures. Level foundations without stability problems are preferred, and the quality and quantity of material applied to the foundation must be appropriate to support massive civil structures against various horizontal and vertical loads.

The dam structure and foundation must resist the forces and loads that create stresses and alter structural stability. Forces that must be addressed and estimated include external water pressure, silt pressure, ice pressure, debris pressure, structural weight, internal water pressure and uplift, temperature, and seismic loading (USBR 1987). These forces can be classified and analyzed as vertical or horizontal loads, and their magnitudes must be understood and accounted for during both normal operation and severe conditions from flooding or seismic scenarios.

Figure 21 illustrates some of the most common vertical and horizontal forces impacting a dam and foundation. Additional consideration should be given to loads stemming from water conveyance conditions and powerhouse operation. Whether arranged as separate components or as an integrated system, the foundation and structure should be capable of withstanding the full range of forces expected.

Additional deteriorative forces must be considered to preclude failure. In its catalogue of hydropower civil works best practices (CEA n.d.), the Central Electricity Authority of India provides a succinct summary of common dam failure mechanisms and causes, which are summarized in Figure 22.

The foundation design may need to be extended to avoid extreme water velocities, which could lead to scour or erosion. A concrete apron or other rock protection may be laid. The tailwater elevation under low, normal, and flood conditions must also be considered, as high levels can interfere with the turbine outflow and low levels can create conditions favorable to the onset of cavitation. 


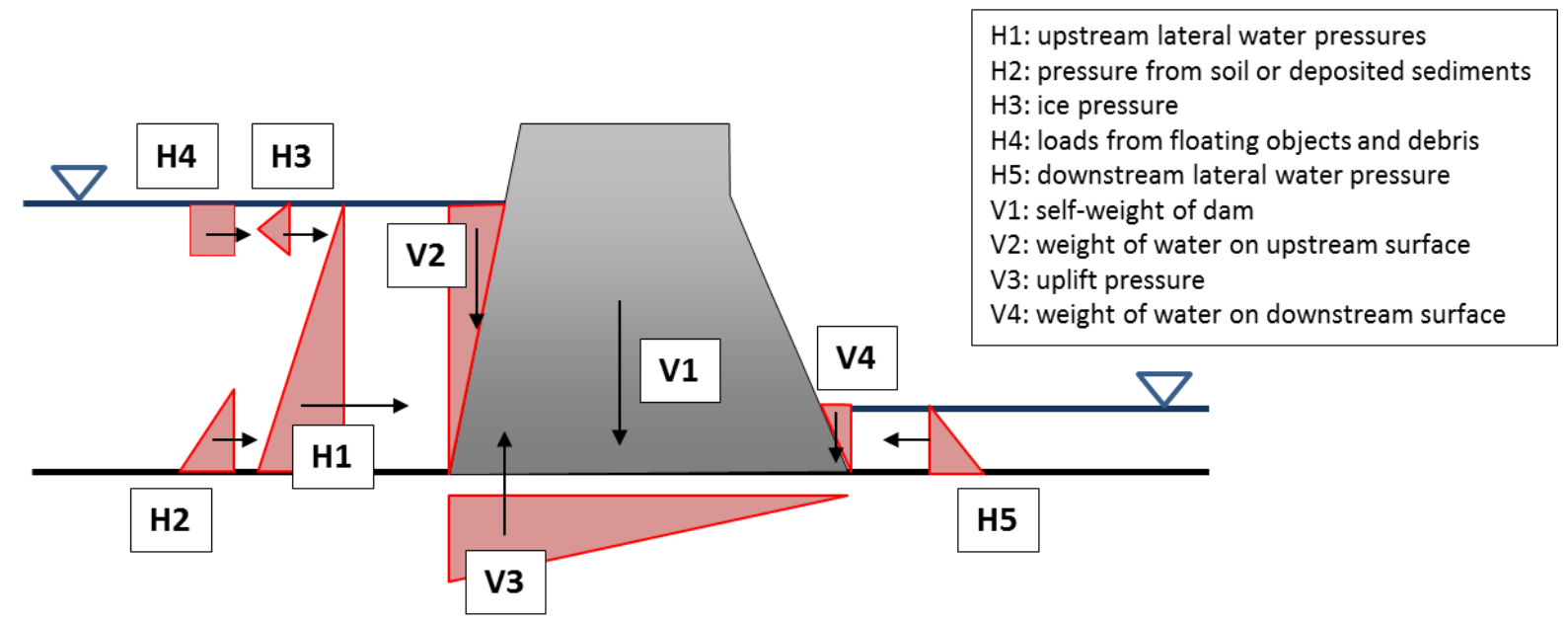

Figure 21. Common vertical and horizontal loads on a concrete dam and foundation. Red triangles represent vertical and horizontal load distributions impacting the dam. [Adapted from (ESHA 2004)]

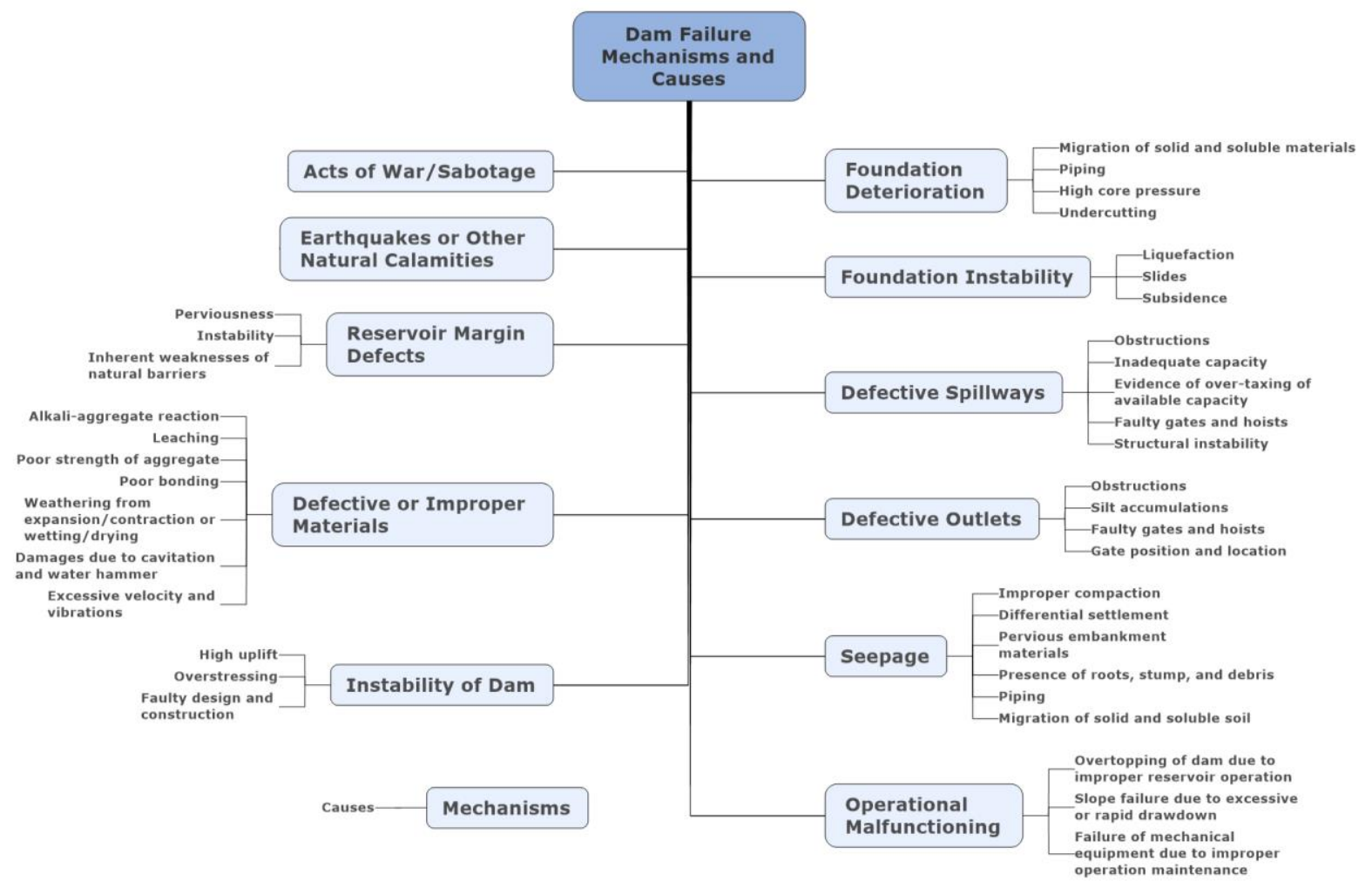

Figure 22. Common dam failure mechanisms and causes. (Adapted from CEA n.d.)

\subsubsection{Advances and Challenges}

Because of the critical role of the foundation and the high risk associated with failure, few cost reduction technologies or strategies have been developed. Constraints resulting from site-specific conditions and the availability of local materials may lead to actual designs that cost 10 to $20 \%$ more than the ideal design (Berga 2008). Some smaller dams have been constructed with roller-compacted concrete, which has 
reduced the footprint required for a foundation. However, as of 2008, no hydropower dams in the United States had been constructed of roller-compacted concrete (Hansen 2008); and limited but successful implementations had been carried out at non-hydro sites (Scott et al. 2008) and outside the United States (Linard and Hansen 2013). A vision for future hydropower systems with pre-constructed foundations has been presented as a potential research strategy (Bishop et al. 2015), but it has not seen significant uptake at new hydropower development sites. One acute challenge is the substantial volume of material required for the supporting superstructure. Even at low-head dams of less than $10 \mathrm{ft}$, a generous excavation is required to support the structure (Figure 23).
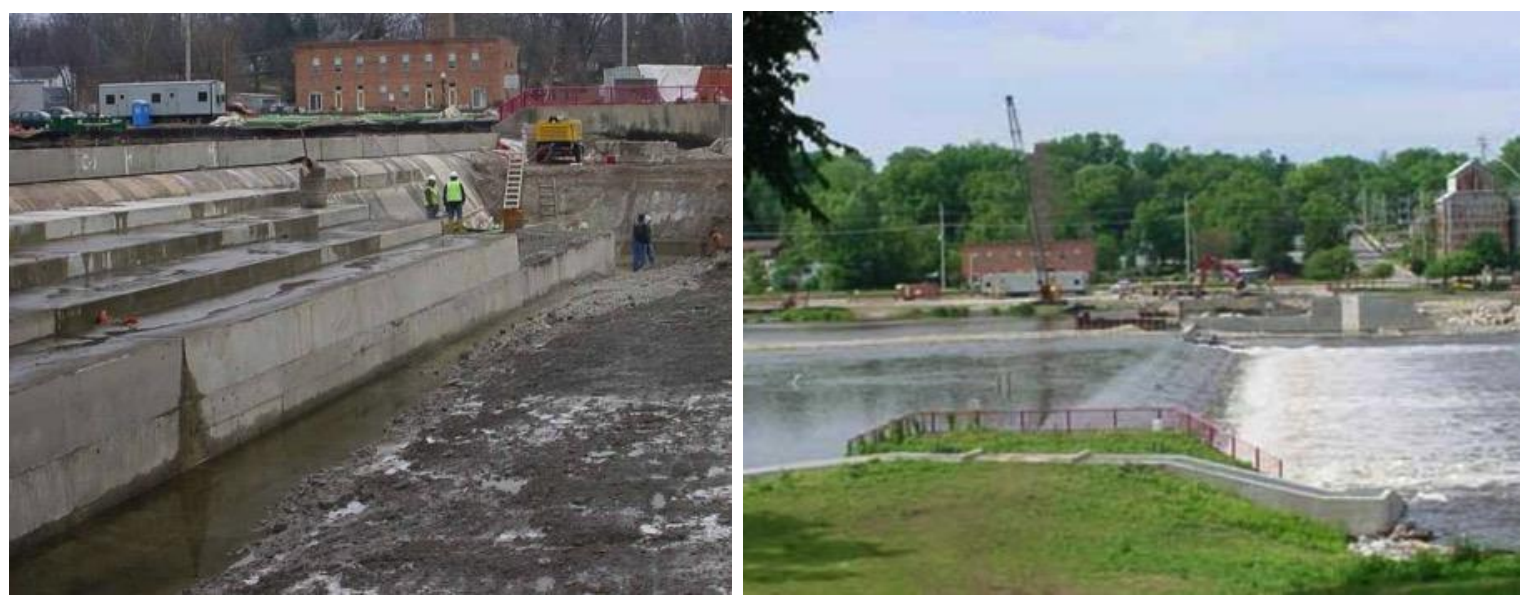

Figure 23. Excavation and construction of a stepped spillway for a low-head dam. (Source: Illinois Department of Natural Resources. Used by permission.)

\subsubsection{Foundations from Other Industries}

Although they are not seen in traditional small hydropower schemes, foundation technologies used in other industries offer insight into how engineers have struck a balance between physical demands, environmental and safety considerations, and cost implications. One such application is in offshore platforms used for oceanic extraction of oil and gas or for strategic placement of wind turbines or other infrastructure. Compared with small hydropower development, these platforms are significantly different in size and configuration from a typical dam or powerhouse, yet the design forces are similar in nature. Both are subject to significant bulk weight and are subject to overtopping forces from fluid motion, via both water and air flow. In addition, instream hydropower and offshore platform designs must withstand numerous dead and live loads, including those from environmental forces.

For oil and gas platforms targeting low to medium water depth, a fixed platform may be used. These often consist of a framed structure with tubular members and piled foundations. For platforms targeting deep seabed locations, recent developments have enabled the use of floating structures tied to the seabed via tethers. Common components for platform connection include moorings and anchors made of steel chain, steel wire rope, or synthetic fiber robe. Foundations require soil investigation at the desired location, with both in situ and laboratory testing. Typical depths of pile foundations range from 30 to 100 meters. $^{27}$

Soil nailing is a technique used in the construction industry as a retaining wall alternative for either permanent or temporary construction. Compared with traditional retaining walls, soil nailing offers multiple advantages, including the elimination of excavation and backfill, reduced material and cost

${ }^{27}$ http://www.slideshare.net/surya3303/offshore-structures-presentation 
requirements, smaller footprint and right-of-way requirements, and improved safety. Soil nailing is often applied in naturally high-slope areas to improve resistance to destabilizing and sliding forces. A typical application includes installing steel tendons into the ground at a near-horizontal angle and encapsulating the tendons in cement to resist corrosion and increase load transfer. The soil nailing system exists in tension, thus providing resistance to overturning instabilities (FHWA 1999).

Another foundation technology, the precast foundation, is more commonly used in residential and commercial building applications; however, some hydropower schemes have employed precast concrete, typically to provide powerhouse superstructures. Precast concrete construction offers a unique way to design and engineer foundation structures at off-site locations to reduce the time and cost associated with installation while enabling rapid procurement. Structural floors, roofs, walls, beams, columns, and piles are commonly designed using precast concrete techniques. Precast concrete modular components have long been used as prison cell modules, and the technique has more recently been used for school and hotel rooms and other applications. Various organizations, including the Precast/Prestressed Concrete Institute, ${ }^{28}$ provide manufacturing and installation certification based on following industry standards.

\subsection{MONITORING AND CONTROL TECHNOLOGY}

Monitoring and control technology is essential to the performance and operation of a hydropower facility throughout its life cycle. Whereas early hydropower plants relied on manual operation to adjust performance and configurations, the rise of digital and wireless technologies has automated the process and enabled precise and near-instantaneous feedback.

\subsubsection{State of Monitoring and Control Technology}

Small hydroelectric facilities consist of numerous hydroelectric-mechanical components, many of which require consistent monitoring and control for efficient and safe plant operation. Considering that site characteristics influence the selection of those components, additional complexities may exist across various assortments of hardware and controls. For example, site-specific head and flow conditions govern operational requirements of the plant and, subsequently, determine the power plant capacity, major and auxiliary equipment needs, and monitoring and control system specifications. The turbine and generator type required also influences the determination of the type and arrangement of monitoring and control technology used. In addition, the overall size of the facility may dictate the affordability of and requirements to maintain staff on-site during regular operation. This section summarizes the monitoring and control processes, major and auxiliary equipment, and monitoring and control requirements applicable to the small hydropower industry.

\subsubsection{Monitoring and Control Process}

Monitoring and control systems require varying degrees of architectural and functional complexity to ensure adequate hydropower plant operation. Considerations include the number, sizes, and types of turbine-generator units; type of plant (i.e., conventional or pumped-storage); types of auxiliary systems; and nature of operation (i.e., manned or unmanned). However, regardless of these complications, the basic processes shown in Figure 24 are common among typical hydropower plants. Monitoring and control involves gathering process information, controlling the process, monitoring process information, and supervising the process (IEEE 2006).

\footnotetext{
${ }^{28}$ http://www.pci.org/
} 


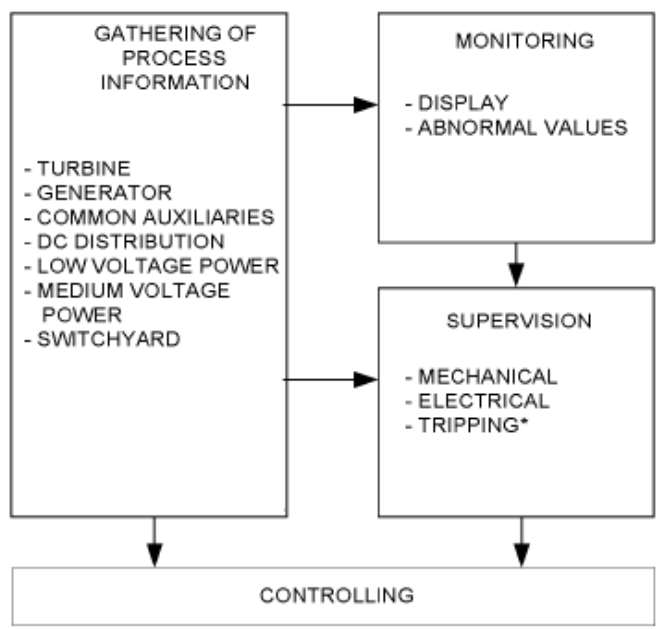

Figure 24. Monitoring and control process diagram for a typical hydroelectric power plant. Reprinted with permission from IEEE. Copyright IEEE 2006. All rights reserved. (IEEE 2006)

\subsubsection{Major and Auxiliary Equipment}

A review of the major and auxiliary equipment is important to determining the requirements for proper plant monitoring and control. The monitoring and control system provides processed information necessary to start, operate, and stop the hydropower units. If the information inputs detect abnormal conditions, the system should prevent startup or provide other protection measures, such as alarms and/or tripping, if units are already online.

IEEE Standard 1010 (2006) is used in this report to demonstrate the equipment of a typical hydropower plant, although the classification and components may vary depending on the reference guide used and the plant type. The equipment for a typical hydropower plant can be divided into two classes: major and auxiliary. Major equipment is the equipment directly associated with the production and transmission of power, and auxiliary equipment supports the major equipment for power production operation, protection, and service. A typical schematic (Figure 25) is excerpted from IEEE 1010 (2006).

\subsubsection{Monitoring and Control Requirements}

Many monitoring and control requirements exist because of the complex equipment that makes up a hydropower plant system. For example, a governor should have a control system capable of regulating water flow through the turbine to start and stop the unit and to control the speed and power output of the turbine generator. Similarly, accurate water level measurements are needed, as they directly and indirectly affect other plant control functions such as reservoir level control, net head calculations, pumping unit control, spillway gate control, power generation control, minimum water release control, and collection of statistical data. Environmental monitoring of dissolved oxygen, temperature, and sediment, among other water constituents, is also required for many hydropower facilities. 


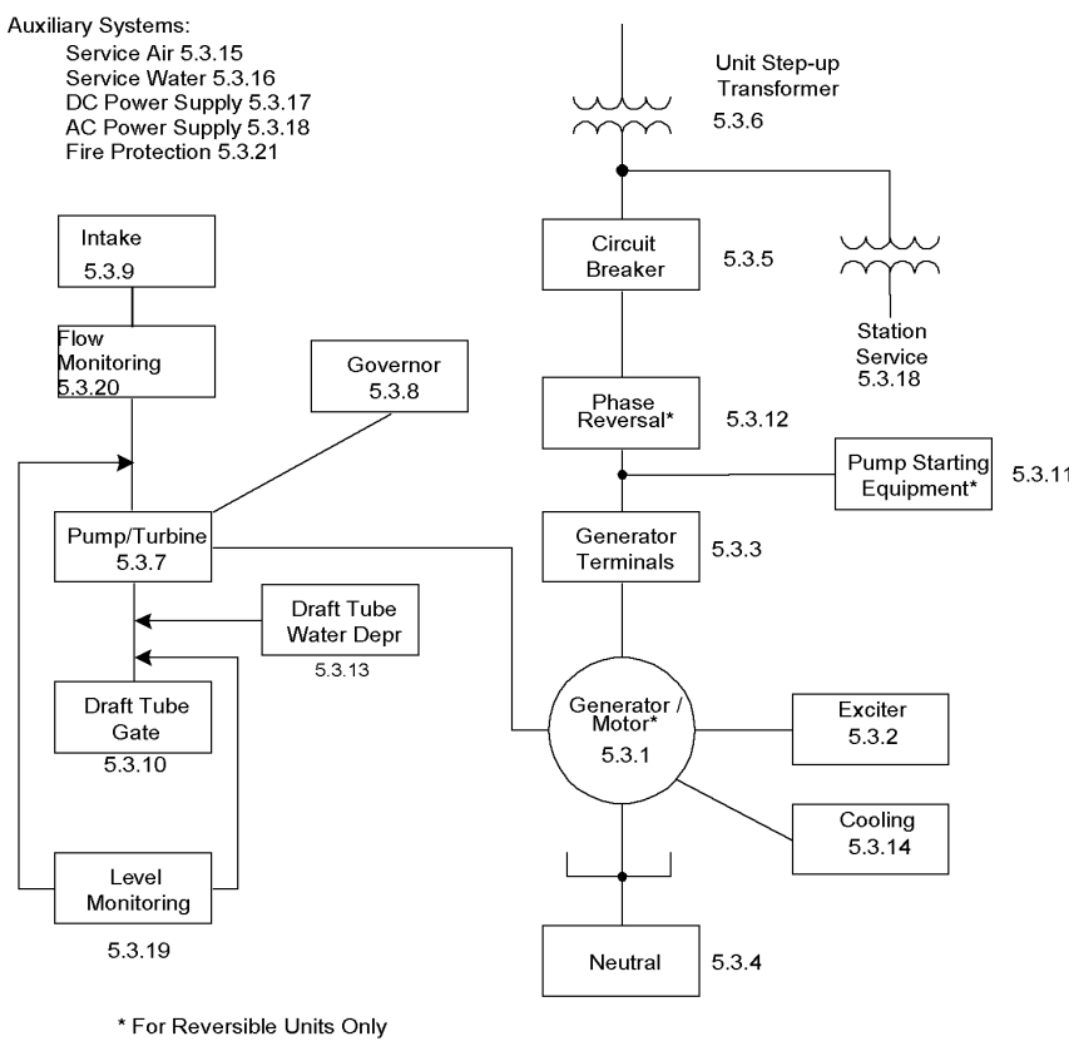

Figure 25. Major and auxiliary equipment components of a typical hydroelectric unit. Reprinted with permission from IEEE. Copyright IEEE 2006. All rights reserved. (IEEE 2006)

\subsubsection{Advances and Challenges}

Unfortunately, the reduced scale of an SHP does not necessarily reduce the required functionalities compared with a conventional large hydropower plant. Using the same design concepts as conventional equipment and control systems poses an economic challenge for the small hydropower industry. So it is necessary to use standardized rather than customized designs, integrate functionalities into single compact units, and modulate designs to enable scaling of the components. For example, voltage and current signals used by one unit can be designed to be available to the control system without the need for additional wiring (Stranne et al. 2005). Simplicity can be obtained through design integration to keep the cost of installation, maintenance, repair, and testing at an economical level. Moreover, a simpler system is generally more reliable than a complex one. Standardization and modulation of the system components also may mean replacement parts will be available over a longer period because of consistent demand, enabling ease of service.

\subsection{INTERCONNECTION TECHNOLOGY AND PARADIGMS}

Interconnection technology enables the transfer of electrical energy produced from electromechanical equipment to the electrical grid or the desired end-user. The interconnection technology used requires knowledge of the generation technology housed at the hydropower facility and of the electric power network targeted. 


\subsubsection{State of Interconnection Technologies}

Interconnection technologies and procedures for current hydropower facilities are well established, and the electrical equipment is listed under the National Electric Code. ${ }^{29}$ Current technologies and their uses are specific to the scale and nature of production. Conventional hydropower interconnection methods used to deliver power to the electric grid rely on several aspects of the scale and status of the power generation at the facility and the delivery of power to the grid system. For large-scale generating systems, power is first transmitted to a substation and then distributed to customers. The quantity of power dictates the transformer and distribution lines.

"Distributed energy" refers to the energy provided by smaller-scale and modular-type devices that provide electricity to consumers in vicinities close to the device locations. Microgrids are typically used to support electricity delivery. Microgrids can easily disconnect from the traditional grid (used by utilities) and act to alleviate disturbances in traditional grids to improve overall grid efficiency.

There are two primary interconnection approaches for small hydropower facilities: directly coupled generators and indirectly coupled generators (see Table 4 and Figure 26). Each approach requires a unique set of interconnection technologies, systems, and equipment with varying degrees of cost, complexity, and regulatory requirements. A direct connection uses gears, belts, or mechanical control to ensure the generator is directly coupled to the grid frequency. An indirect connection utilizes power electronics to couple the generator to the grid. Electrical interconnections are frequently cited as a major hidden cost driver for small hydro. This does not necessarily reflect the specific interconnection technologies and hardware to be procured and installed at a hydropower facility, but rather what is often an onerous process to obtain approval to connect to the grid or to a local utility.

Table 4. Summary of interconnection technology trade-offs (Applegate Group 2011)

\begin{tabular}{|c|c|c|}
\hline Attribute & Power electronics & Direct connection \\
\hline \multirow{2}{*}{$\begin{array}{l}\text { Interconnect } \\
\text { protection } \\
\text { equipment }\end{array}$} & Protection generally included in inverter/drive system & Requires auxiliary protection equipment \\
\hline & $\begin{array}{l}\text { Turbine speed control not required for grid } \\
\text { synchronization }\end{array}$ & $\begin{array}{l}\text { Grid synchronization requires speed control } \\
\text { turbine speed control }\end{array}$ \\
\hline \multirow{3}{*}{ Fault current } & Low & High \\
\hline & Delta typically, but Wye connect is okay & $\begin{array}{l}\text { Typically requires delta-wye connection with } \\
\text { grounded neutral }\end{array}$ \\
\hline & Nominal interrupt rating on breakers. & High interrupt rating on breakers \\
\hline $\begin{array}{l}\text { Efficiency at } \\
\text { rated }\end{array}$ & $85-90 \%$ typical & $>95 \%$ typical \\
\hline $\begin{array}{l}\text { Efficiency for } \\
\text { flows } \\
\text { above/below } \\
\text { design capacity }\end{array}$ & $\begin{array}{l}\text { Variable speed improves turbine efficiency for some } \\
\text { turbine types, but power electronic losses may increase } \\
\text { operation away from rated capacity }\end{array}$ & $\begin{array}{l}\text { Turbine efficiency may drop off at flows } \\
\text { above/below design flows }\end{array}$ \\
\hline \multirow{2}{*}{ Harmonics } & \multirow{2}{*}{$\begin{array}{l}\text { Filter required. May or may not be bundled into the } \\
\text { drive system }\end{array}$} & Minimal filtering required \\
\hline & & May require a resistor on neutral connection \\
\hline $\begin{array}{l}\text { Protection } \\
\text { systems }\end{array}$ & Included in inverter/drive & $\begin{array}{l}\text { Separate, utility-approved, control relay } \\
\text { required }\end{array}$ \\
\hline Utility preference & Preferred for small systems & Preferred for large systems \\
\hline
\end{tabular}

${ }^{29}$ http://www.nfpa.org/ 

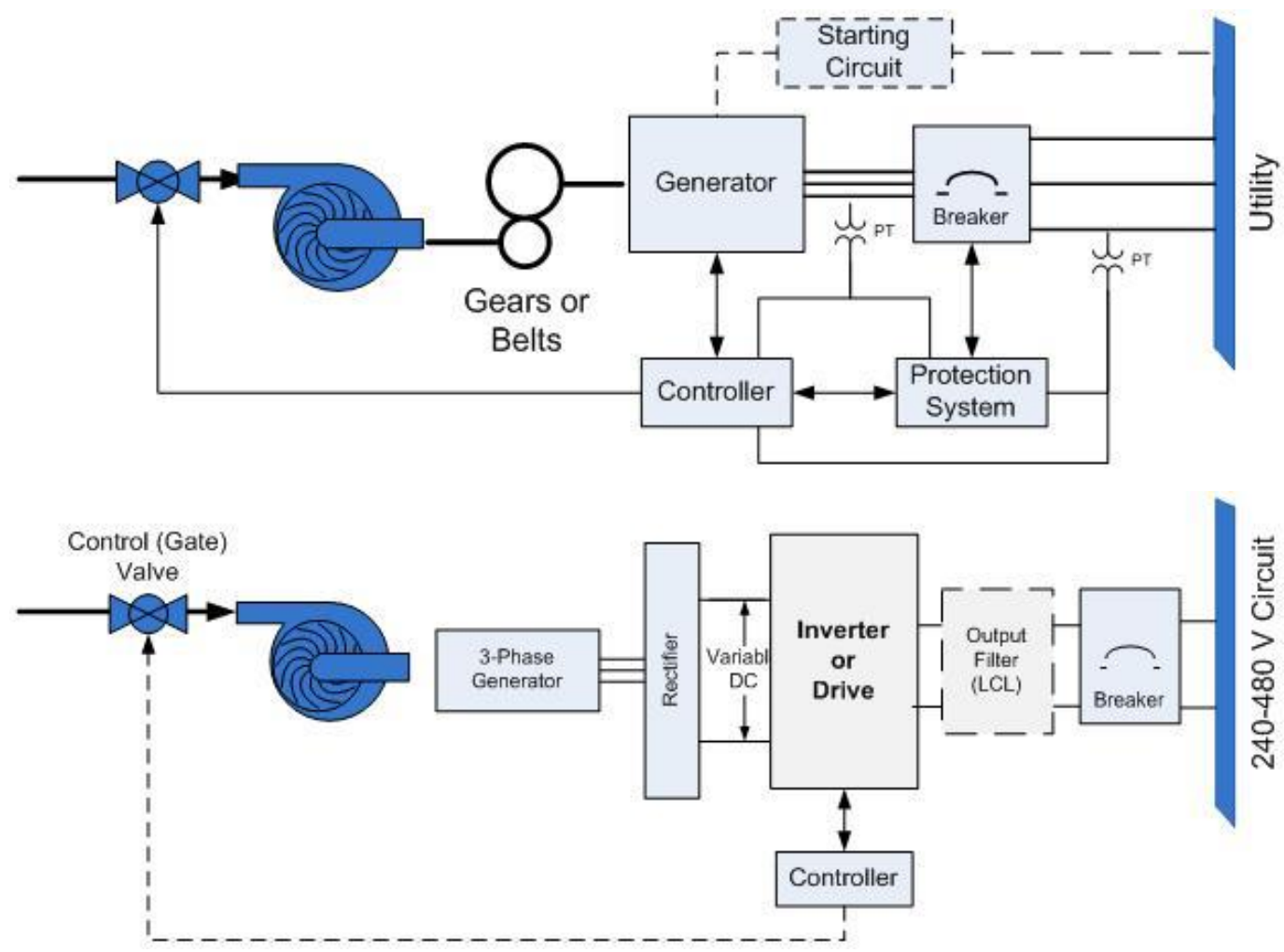

Figure 26. Top: direct power grid connection with generator stator coupled to grid. Bottom: indirect power grid connection, where the generator stator is coupled to the grid via power electronics. (Applegate Group 2011)

\subsubsection{Advances and Challenges}

Limitations and challenges associated with interconnection technologies, especially in the context of the use of small hydro in a distributed network, include the following:

- Technical challenges with reverse power flows causing possible malfunctions of voltage regulators, switched capacitors, and protection relays.

- Possible interference of feeder voltage control when the distributed system is located downstream of a voltage regulator.

- Difficulty in maintaining harmonized functionality for all potential load/generation operating scenarios using proper set points between the distributed grid and the voltage regulator.

- Operation of systems on distributed grids located in different locations using voltage set points may not be suitable nor ideal for all operating scenarios.

These challenges associated with connecting small hydro to the grid must be considered in the design of the components and equipment, as well as the operation and expectations for power production and system efficiencies. Table 4 provides a summary of the trade-offs associated with using indirectly coupled generators (i.e., power electronics) and directly coupled generators. 


\subsection{INSTALLATION TECHNOLOGY}

Installation involves the placement of components or systems into a fixed or semi-fixed position. Along with construction, installation of a hydropower facility constitutes a major cost and time resource. In a traditional sense, installation of many hydropower components and systems is accomplished through construction, and these terms are used herein to describe similar processes. Modular approaches to installation and construction could offer multiple benefits, though barriers to entry currently exist. This section describes some of the key characteristics of current installation technologies and documents advances and challenges.

\subsubsection{State of Installation Technologies}

The technologies used to construct and install hydropower facilities and equipment vary significantly across projects based on installed capacity, project type, location, generation technology, and access and within single projects based on civil works required, electromechanical equipment used, interconnection needs, and environmental mitigation requirements. In general, civil works construction and installation accounts for the largest percentage of the costs associated with hydropower development, making up 75 to $80 \%$ of the project construction cost (O'Connor, et. al 2015). The logistics associated with civil works construction and installation necessitates a detailed and comprehensive schedule to coordinate the activities between all parties; these may be developed, to some degree, based on site-specific characteristics such as site topography, geotechnical aspects, and location. As a result, the time from initial construction and installation activities to operation can be on the order of several years for traditional hydropower (Figure 27). The construction timelines are shorter for unconventional hydropower projects, such as conduit-based generation and prefabricated structures. The differences in construction effort and associated costs between these hydro-generation approaches encourage the increasing acceptance of hydro designs and approaches that incorporate aspects of modularity and standardized technologies.

To prepare a hydropower system for installation, components may be constructed on-site or manufactured, fabricated, and assembled off-site. Construction activities are typically carried out by a contractor working directly for a power plant owner (i.e., a utility, municipality, private developer, or other entity). An engineer, typically working for the owner, contractor, or both, carries out technical assessments of the construction requirements and offers a design following either a design-bid-build, design-build, or design-build-operate delivery method. Once the design contract has been finalized, construction may begin.

The traditional approach to in-stream dam, hydropower, and waterway construction is to build cofferdams, temporary dams that allow portions of the stream or river to be dried out using large pumps to enable excavation and foundation work. Once the foundation is formed, a hydraulic structure or dam made of concrete, engineered soil, or rock is built. Equipment is then installed and substations are constructed. Once the permanent civil structures are constructed, the equipment is fully assembled, tested, and commissioned. These construction activities often require execution in series, with each activity dependent upon the success of the preceding activity and sequencing physically from the ground up and from side to side. 


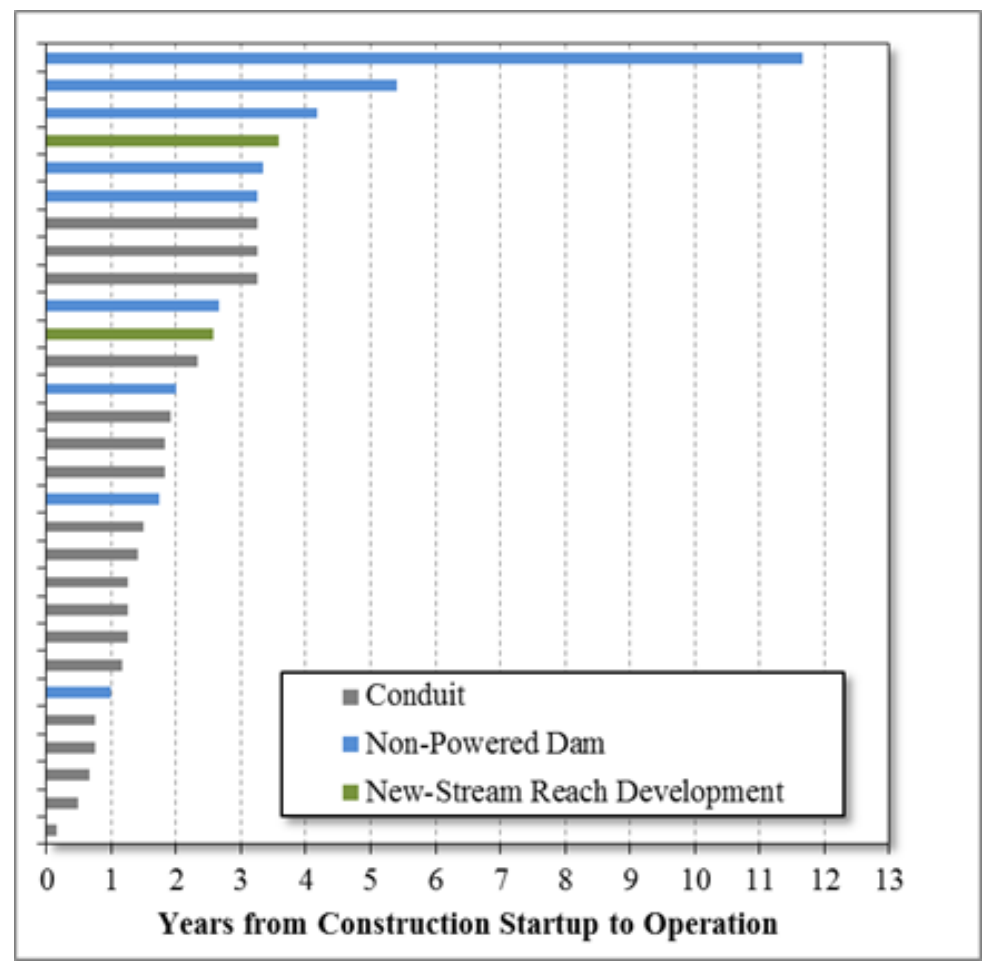

Figure 27. Time from construction startup to operation for a sample of hydropower projects built in the United States between 2005 and 2013. (Adapted from data in Uria-Martinez et al. 2015)

Cofferdams are expensive, built in multiple phases, and typically partially or totally removed once the permanent civil structures are completed. Often constructed from sand bags, sheet piles, wood, soil, rock, concrete, or other construction material, they must often remain in place for a construction period spanning multiple years. Since they are not constructed to withstand significant floods (often built to the 20 -year flood height), cofferdams are prone to overtopping, causing significant delay and impacts to construction because the cofferdam must often be repaired and dewatered and remediation of other structures also may be required.

Excavation and filling represent significant hydropower development efforts and costs that depend on various factors, including the excavation size and method, project phasing, geotechnical concerns, and groundwater issues. Structural stability of the soil and adjacent geological conditions must be ensured to maintain a safe construction site during construction and under a variety of anticipated conditions. To adequately support deep excavations, several methods may be employed, including using retaining walls, diaphragm walls, or cofferdams.

In addition to these technologies used for excavation, other techniques are used to facilitate construction processes, such as temporary diversion of water and modular, pre-built temporary and permanent structural systems for cofferdams and other structures.

Electromechanical design and installation is largely site-dependent and is closely aligned with the respective head and flow at the site. Most turbines and electromechanical supporting equipment are built according to the specified design performance for a range of heads and flows and are delivered to the site for installation. Both low-head and high-head turbines are typically installed using permanent crane systems installed within a powerhouse facility. 


\subsubsection{Advances and Challenges}

Currently, civil works methods for the construction and installation of traditional hydropower facilities have been slow to change. Designs are typically conceived as one-of-a-kind projects, with little thought given to whether modularity may be appropriate. However, concepts borrowed from commercial and even residential construction techniques, such as pre-built, pre-fabricated, and pre-assembled construction components, are proving to be effective at reducing labor with respect to labor costs and scheduling.

The most significant challenge to hydropower construction and installation is the uncertainty associated with cost and scheduling. Site conditions typically dictate the methods used at a site, and innovation in the development of installation technologies is lacking. Limitations associated with existing methods and technologies are accompanied by a lack of competition for streamlining the construction process. However, modular approaches widely used in other applications and infrequently applied to hydropower could offer opportunities to improve hydropower construction and installation techniques.

Many facets of construction may be accomplished through modular approaches. In construction terms, modularity is the process of breaking down a complete project into a series of smaller modules, constructed either off-site or adjacent to the site, with the objective to reduce on-site construction related to foundation work and module assembly. The process of modularization seeks to establish modules for each system element while identifying tasks that may be reduced or eliminated.

Modularity in the construction industry may offer reduced construction time, increased labor productivity and safety, improved manufacturing quality, decreased weather-related delays, reduced environmental and social disturbance, minimized site congestion, lower uncertainty, and higher efficiency. Some disadvantages also exist, including transportation restrictions, reduced flexibility (once modules are fabricated), and higher initial design cost. Constructing components in an off-site manufacturing location leverages a production-oriented environment, including overhead cranes, existing plant equipment, and skilled workers that can be supplemented as needed. Off-site construction may also enable fabrication using diverse materials, which may be difficult or impossible in an on-site environment. Often, mechanical equipment is preinstalled within the module before delivery to the site (Figure 28).
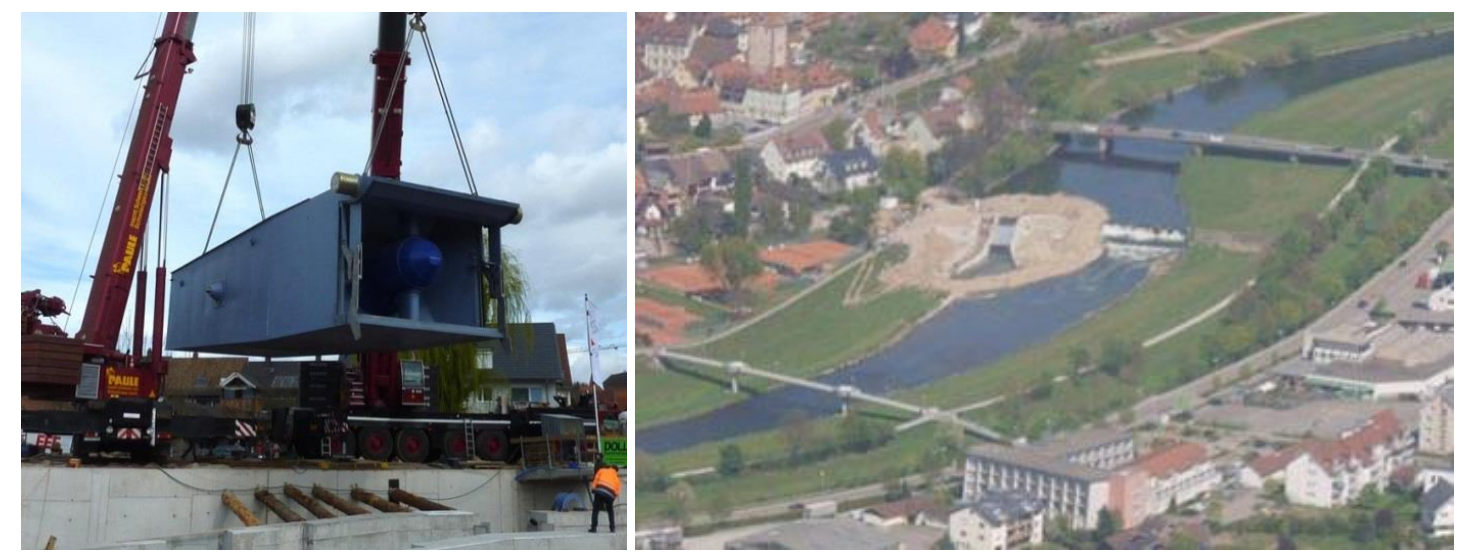

Figure 28. Moveable hydroelectric power plant installation in Germany. (Source: Hydro-Energie Roth GmbH, Karlsruhe, Germany. Used by permission. ${ }^{30}$

Although most contractors are familiar with traditional construction techniques, only those experienced in modular-centric industries are likely to be familiar with modularization. Contractors may be hesitant to

${ }^{30} \mathrm{http} / / / \mathrm{www}$. moveable-hepp.com/ 
accept modular approaches without evidence of successful application. However, as modularization represents an increasing share of construction activity, more contractors are becoming aware of its benefits; and financiers are recognizing the reduced financial risk it may offer. Research into modular installation technologies should focus on establishing the parameters for changing work methods through modular approaches.

To achieve widespread deployment and reduce construction and development timelines and costs, small hydropower technologies should be easy and quick to install. Standardized designs as envisioned for SMH technology could achieve these goals through variety of ways. The New Pathways to Hydropower industry report (Bishop et al. 2015), documents recent advances in composite materials which have led to lightweight, easy-to-move generation technology and water conveyance structures. Such advancements enable quick installation and reduce development timelines. The New Pathways to Hydropower report also outlined a need for establishing suitable test sites for prototype installations. Further research into standard installation modules which fit the SMH paradigm will be investigated starting in 2017.

\subsection{OPERATIONS AND MAINTENANCE TECHNOLOGY AND PARADIGMS}

Although hydropower facilities are typically designed to last for many decades, longevity is ensured only through proper O\&M. Over time, component performance may deteriorate and require adjustment, cleaning, modification, or replacement. Accommodation for permanent or temporary O\&M technologies should be made, and innovative solutions to eliminate traditional O\&M requirements could provide numerous benefits.

\subsubsection{State of O\&M Technologies}

O\&M technologies are traditionally project-specific and dependent upon the maintenance philosophy of the project owner. O\&M cost represents the second-highest contributor to LCOE, with the per-kilowatt cost increasing for smaller plants (O'Connor et al. 2015). Major factors contributing to O\&M include facility age, personnel requirements, operation mode, operational philosophy, equipment type, and fixed vs. variable costs (USACE 2009).

The development of an O\&M scheme is generally a developer responsibility (Bishop et al. 2015) and is typically not addressed until late in the project development cycle. In some cases, communication between equipment suppliers and developers is inadequate, leading to increased costs. Oftentimes, complex or aged equipment may result in more specialized maintenance needs or increased offline time and hence higher maintenance costs.

Typical O\&M practices for large-scale civil works, such as those used in hydropower projects, do not include O\&M costs in determining the plant's return on investment; therefore, funding is often inadequate. This may result in long-term and difficult outages complicated by very specialized maintenance or replacement procedures.

\subsubsection{Advances and Challenges}

Traditionally, the inspection, rehabilitation, or replacement of generating equipment requires significant labor and time resources, resulting in a major financial hurdle to the owner. The manufacturers of some equipment 
(e.g., ANDRITZ's HydroMatrix ${ }^{31}$ and the VLH Turbine ${ }^{32}$ ) have employed novel approaches to facilitate quick and efficient access to such equipment (Figure 29).

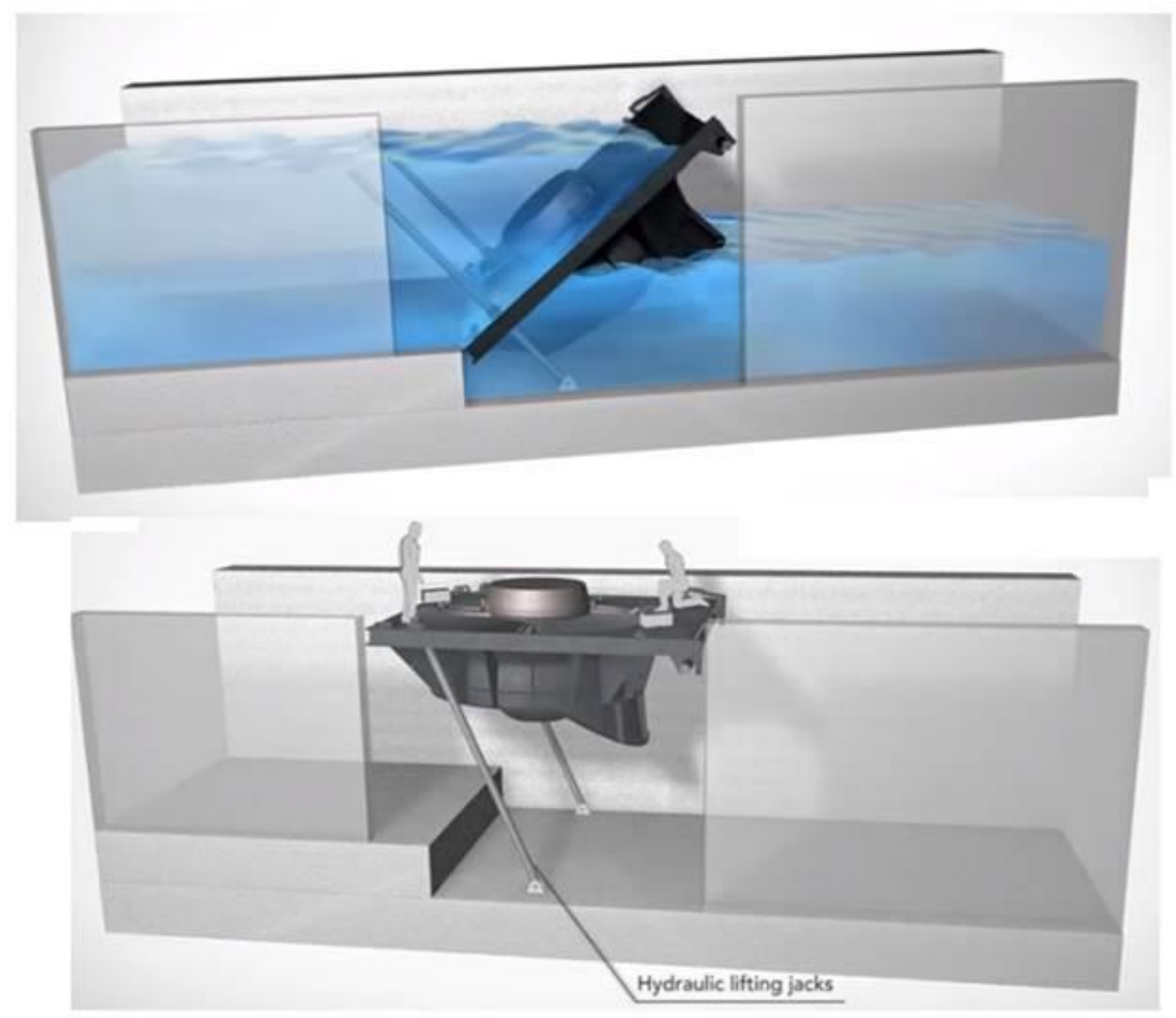

Figure 29. VLH installation diagram showing turbine in operating position (top) and maintenance position (bottom). (Source: MJ2 Technologies North America. Used by permission.)

${ }^{31} \mathrm{https}: / / \mathrm{www} \cdot$ andritz.com/hy-hydromatrix-en.pdf

32 http://www.vlh-turbine.com/ 


\section{SMALL HYDROPOWER PROJECT DEVELOPMENT CONSIDERATIONS}

The development, deployment, and, ultimately, commercial operation of a hydropower project is the culmination of a series of complex decisions and uncertain outcomes occurring across a multi-decadal timeline. As a key premise of SMH RD\&D, standardization and modularity of small hydropower may offer many cost, time, and risk reduction opportunities. Figure 30 outlines typical steps in the project development, construction, and ultimately operation of a conventional hydropower plant, as itemized in Bishop et al. (2015), which documents best practices across the various phases of hydropower project development. Each step in this process carries with it burdens of cost, time, and risk that combine to influence economic viability; thus both a generalized representation of cost and an illustrative magnitude of risk are shown.

\section{Conventional Small Hydropower Development Timeline, Risk, and Cost}

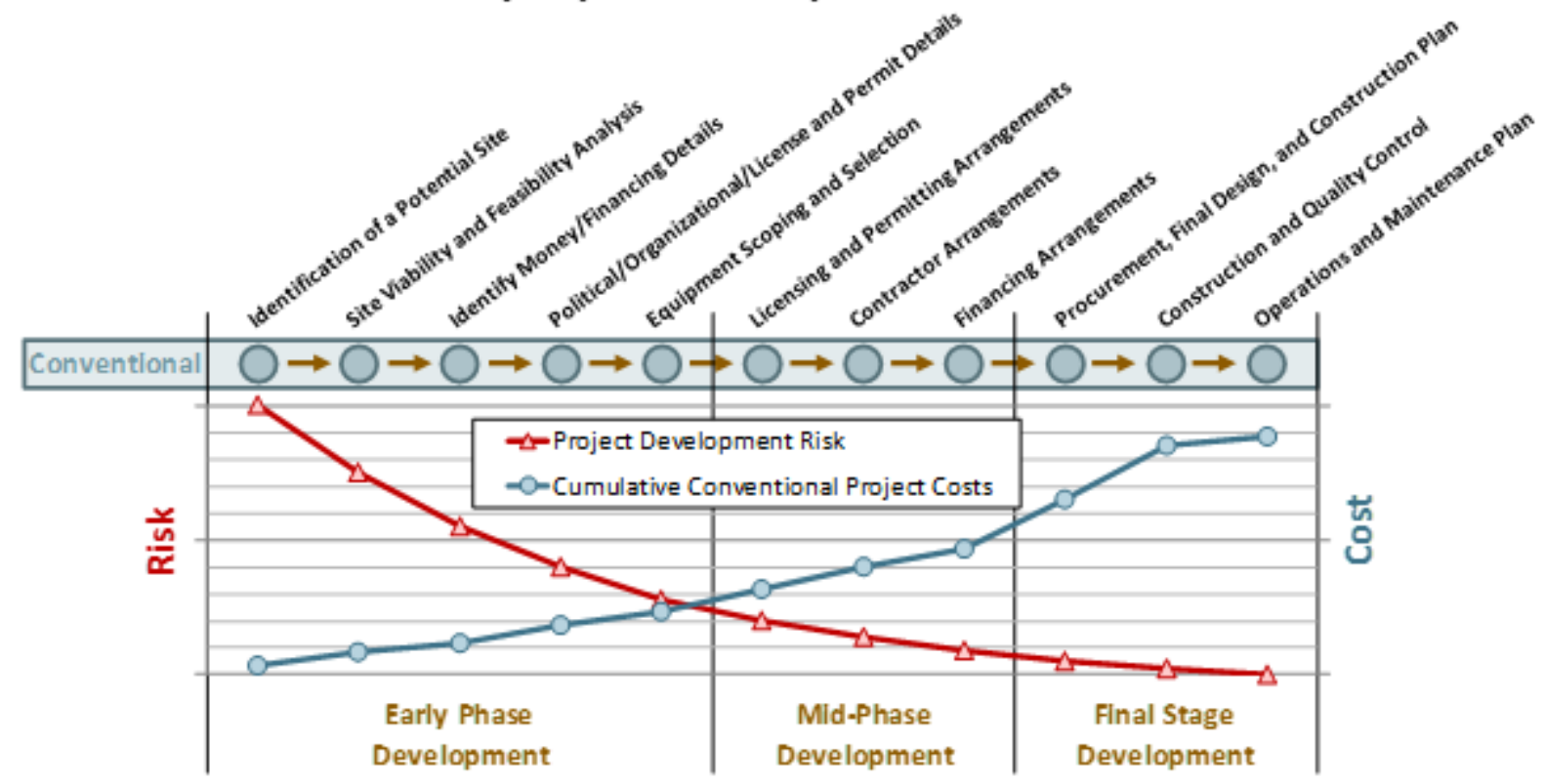

Figure 30. Conventional small hydropower development timeline showing project risk and costs throughout development and steps for which SMH development may offer benefits. Note that the figures presented are for demonstration purposes only and are not derived from analysis.

Section 4 of this MYRP documents the magnitude of costs and the major considerations across the full project development and operational life cycle of a small hydropower project, explicitly addressing lifecycle costs (Section 4.1); pricing, revenue, and life-cycle benefits (Section 4.2); environmental impact, acceptance, and sustainability (Section 4.3); regulatory requirements (Section 4.4); interconnection requirements (Section 4.5); and operations and maintenance considerations (Section 4.6). RD\&D activities related to specific, technology-centric development considerations are addressed in Section 5 of this MYRP. Additional development considerations, while important, are outside the scope of a federal RD\&D effort and are therefore not included in this document.

The goal of this section is to discuss the current state of hydropower project development. Although each successive section deals with the subject matter in more detail, one broad observation can be made: the current hydropower development paradigm focuses on maximizing revenue opportunity and project lifetime. To achieve feasibility, the useful output and working life of a facility are optimized to the greatest extent possible. Optimization of output requires detailed site-specific reconnaissance, analysis, and design, and customized equipment, which can create long and uncertain construction timelines, high 
initial capital costs, and unknown regulatory review outcomes. To achieve a long project useful life, traditional hydropower thinking is to construct a significant structure (e.g., dam, powerhouse, spillway) with significant foundation works that will be a visible engineering and construction achievement for generations. The high-stakes and uncertain economic dynamics of hydropower development are offset by a risk aversion strategy that includes large permanent structures with economies of scale.

SMH research is intended to catalyze several distinct benefits in the direct reduction of cost and risk throughout the development process. These benefits will be addressed in more detail in Section 5.

\subsection{LIFE-CYCLE COSTS}

Conventional hydropower projects are multi-decadal investments with distinct phases of expenditures through the project life cycle. As is documented in Figure 30, a project begins incurring costs well before it even begins construction, as owners begin to investigate site feasibility and work through the complex permitting and regulatory processes applicable to hydropower. Costs continue to mount after all necessary regulatory approvals are acquired, as final aspects of project development, such as negotiation of financing and power purchase arrangements, are completed. The largest expenditures occur in the construction and installation of the project itself; projects then continue to incur costs over their lifetimes, as both civil structures and generating equipment must be maintained and periodically overhauled throughout the life of a project. This section address each of these major life-cycle expenses in turn.

\subsubsection{Capital Expenses}

\section{Project development costs}

The development of a hydropower project from initial site identification and evaluation to groundbreaking on construction is a long, risky process. The median successful project subject to FERC licensing ${ }^{33}$ from the last decade has taken over 10 years to begin generating electricity (Uría-Martinez et al. 2015), and costs are incurred throughout this process to explore site feasibility and obtain all necessary regulatory approvals.

Generally, hydropower projects benefit from economies of scale with regard to the required expenditures during the development phase. Regulatory studies and initial engineering estimates do not necessarily scale linearly with project size; thus, larger projects may have many more megawatts (potential revenue) across which to spread these early expenditures. As an order-of- magnitude estimate, the total cost to license and develop a project, from initial permitting to financial close, can approach $\$ 800,000$ for a 1 MW NSD project and $\$ 4,000,000$ for a $10 \mathrm{MW}$ NSD project. ${ }^{34}$ Site-specific costs are highly variable based on the requirement for additional studies, such as those concerning environmental, recreational, or historical and archaeological impacts, necessary for FERC to make a licensing determination.

In addition to the direct costs of the project development process, these site-specific study costs also weigh relatively heavily in determining economic viability. As project outcomes during early-phase development are highly uncertain (that is, the project is highly risky), private developers must rely on their own funds (or those of their equity investors) to finance the requisite permitting and licensing costs, as well as preliminary engineering expenses. The rates of return sought on these equity outlays during this

\footnotetext{
${ }^{33}$ This duration is not necessarily a result of the FERC regulatory process itself, but instead is an emergent feature for larger projects facing the USACE addition 408 permitting process or simply is reflective of major delays in signing PPAs, attaining financing, and satisfying interconnection requirements.

${ }^{34}$ See the licensing cost equations in O'Connor et al. 2015. There are major uncertainties around the cost of project development, and it is possible that licensing and project development costs could be much higher.
} 
risky portion of the project are typically much higher than those for financing a project with a firm license and PPA, increasing the amount of revenues needed to make a new project feasible. In addition, a project may not begin commercial operation until many years after early-phase development has been initiated, increasing the relative weight of project development expenditures in any project feasibility calculation.

\section{Construction and equipment costs}

Once a project is adequately licensed and permitted, its construction will require a substantial amount of up-front capital. Under conventional hydropower design paradigms, most new developments entail the application of customized, site-specific civil and electromechanical equipment designs. Turbines are engineered to site-specific characteristics of water availability and head variation. These are then typically housed inside custom-designed powerhouses, most often made of concrete poured on-site. Hydropower applications requiring the construction of new impoundment structures, such as diversion weirs or dams, also require custom design and costly civil engineering. The net effect of the customary development approach involving site customization and large civil structures is to make the up-front capital costs of hydropower considerably higher than those for most other power generation technologies. Figure 31 illustrates the capital costs for different classes of hydropower development across the last 30 years, with NPDs classified as either low-head (below $30 \mathrm{ft}$ of head) or high-head (above $30 \mathrm{ft}$ of head).
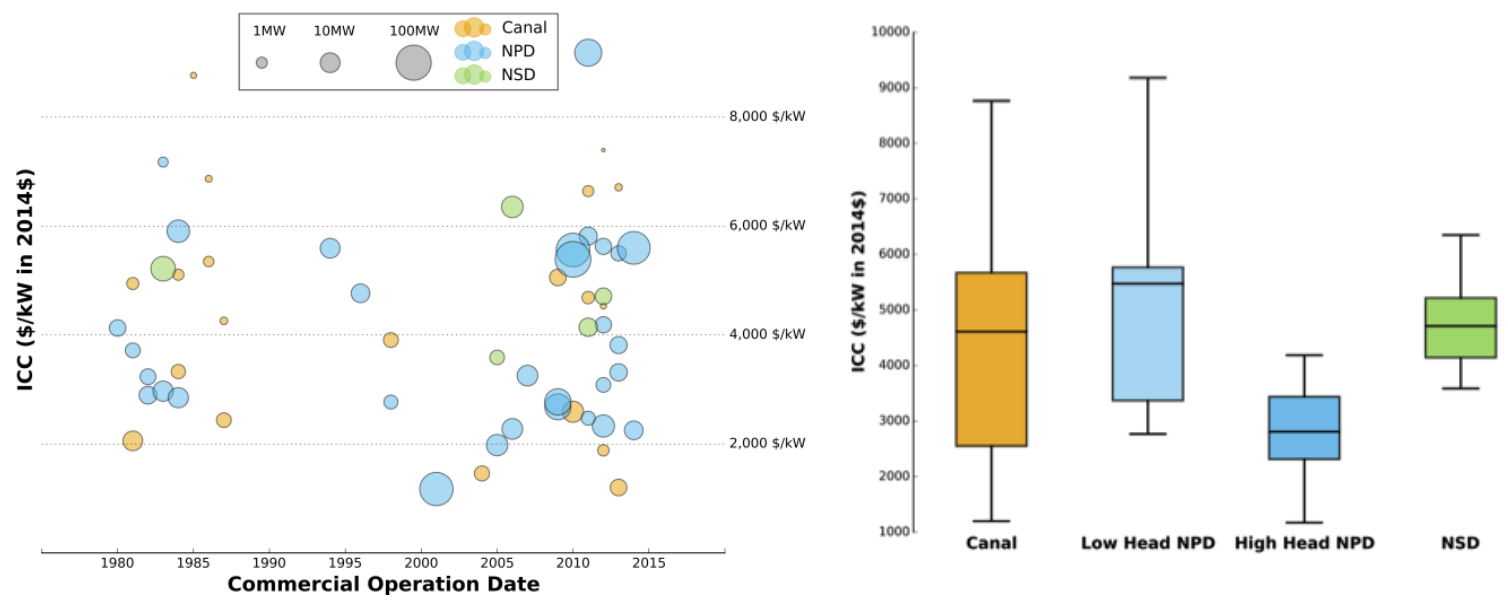

Figure 31. Costs of recently developed hydropower projects. (O'Connor et al. 2015)

As the industry's approach to designing and constructing hydropower projects has remained unchanged for the last 30 years, so too has the cost of development, generally ranging between $\$ 2,000$ and $\$ 6,000$ per kilowatt, depending on site features. ${ }^{35}$ Projects on existing water resource infrastructures, such as canals, conduits, or NPDs, will generally experience lower costs than an equivalent NSD facility.

Beyond the major cost savings attributable to existing infrastructure, variation in costs among projects is driven by many factors:

- Hydropower projects experience significant economies of scale with respect to plant head (INL 2003; EPRI 2011; O'Connor et al. 2015). For the same amount of capacity, a higher-head plant will have smaller units. Smaller units are directly less expensive; require a smaller physical footprint (and

\footnotetext{
${ }^{35}$ It is important to note that these costs are based on projects that have successfully reached commercial operation; that is, projects that were considered economically feasible to be constructed.
} 
associated civil structures) than lower-head counterparts; and generally operate at higher speeds, resulting in lower generator costs.

- Hydropower projects appear to have weak but statistically significant economies of scale with respect to project capacity (O’Connor et al. 2015).

- A plant with multiple units is generally more expensive than one with a single unit, although practical engineering considerations or physical limitations on turbine unit physical size (e.g., large low-head units) can mean that multi-unit designs are less expensive (Gordon 1983).

However, all types of hydropower projects share the same primary cost centers-electromechanical equipment and civil costs, along with civil structures (and associated engineering needs) comprise a plurality of costs for all hydropower development types (Figure 32). The economies of scale associated with design head are also evident in the contrast between low- and high-head NPD projects (defined as either below or above $30 \mathrm{ft}$ of head).

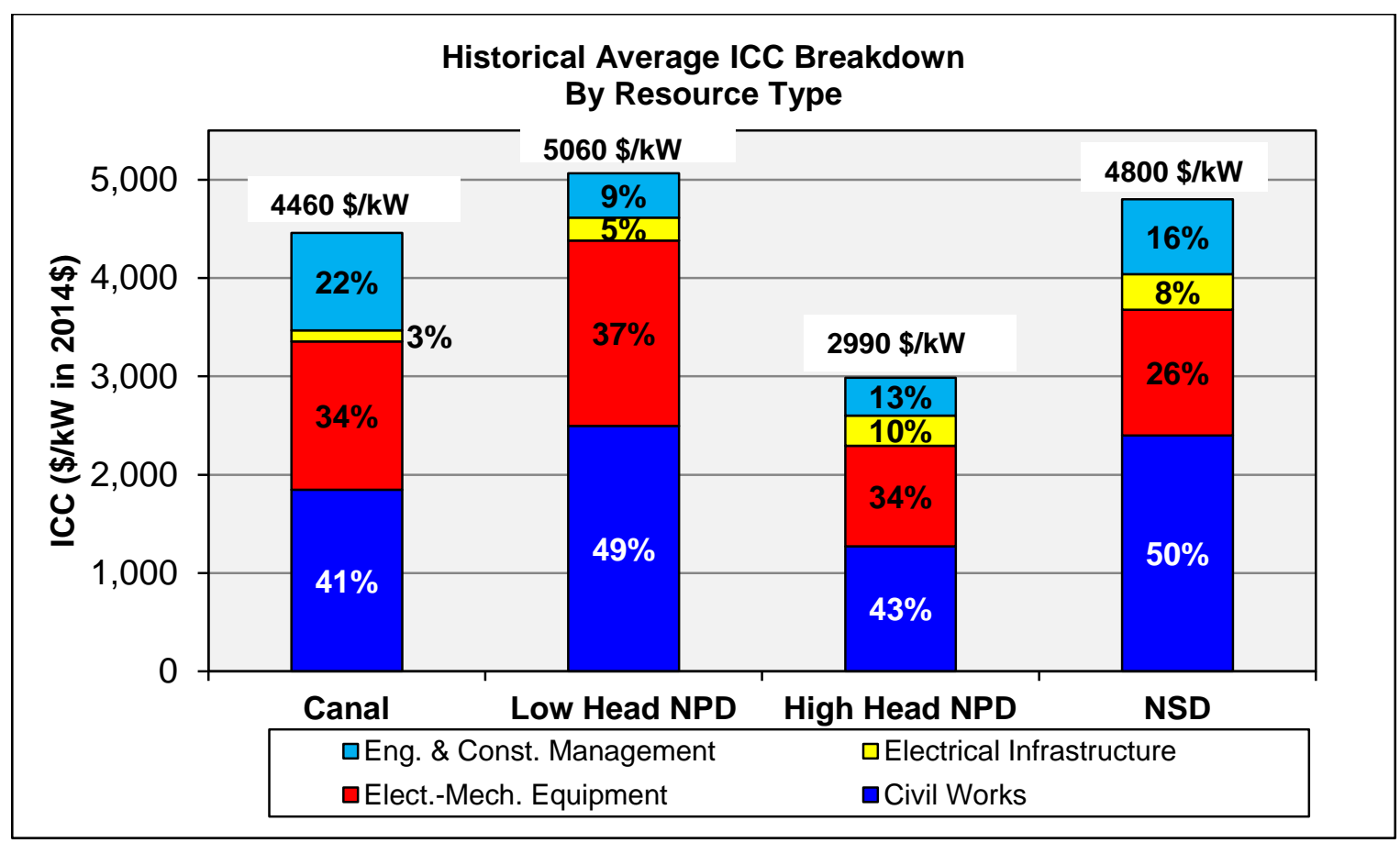

Figure 32. Distribution of hydropower capital costs by major component category. (O'Connor et al. 2015)

The civil construction-heavy nature of hydropower project design also introduces a major source of uncertainty into the ultimate project cost. At the beginning of project development, i.e. at "reconnaissance" stages of cost estimating, the typical uncertainty associated with an estimated cost can be as high as $100 \%$; that is, costs may be half of, or double, the original estimate (AACE 2013). In constructing new, permanent impoundments or large concrete powerhouses, site geologic uncertainties (e.g., foundation stability) and hydrologic uncertainties (e.g., flooding likelihood and the need for large cofferdams during construction) may require major expenditures, which may dramatically increase the cost of constructing new projects. Project developers may shepherd new construction through many years of development only to find that when civil construction uncertainties resolve, project economics have deteriorated. 
Recent turbine technology advances have attempted to mitigate some of the heavy costs and overall uncertainty related to civil construction. As an example, the use of modular turbine units at a proposed new development may reduce overall project costs by over $40 \%$ (O'Connor et al. 2015). The successful implementation of modular projects requires further research to understand the trade-off between equipment survivability, performance, and lifecycle costs. For example, if lower-cost turbines are designed to last 20 years, rather than the 50 year or greater life of conventional equipment, will the total lifecycle cost of replacement offset initial capital cost reductions?

Traditional development also entails some limited trade-offs between survivability, durability, and cost. In the development of present-day hydropower projects, this trade-off is most often seen in the choice and quality of equipment suppliers. There are multiple tiers of equipment that can be purchased, ranging from utility-scale offerings ${ }^{36}$ with proven, decades-long reliability to much less expensive but much more uncertain products that may require more frequent repair, overhaul, and replacement. However, despite these risks, the use of equipment perceived to be of lower quality is often necessary for small hydropower projects to be considered economically competitive in contemporary power markets. Other trade-offs between capital costs and reliability are possible but less common. One example is the conscious decision to allow a project's units to cavitate and incur the requisite repair costs to save on up-front construction by setting units at a higher elevation relative to the tailwater (requiring less excavation).

\subsubsection{Operations and Maintenance Expenses}

Similar to capital costs, the expenses associated with operating and maintaining hydropower facilities are highly site-specific, driven by economies (and diseconomies) of scale based on various design attributes. Plant or unit capacity is the largest driver, with higher capacities resulting in lower relative (that is, kilowatt per year) costs than lower capacities. Figure 33 illustrates this relationship.

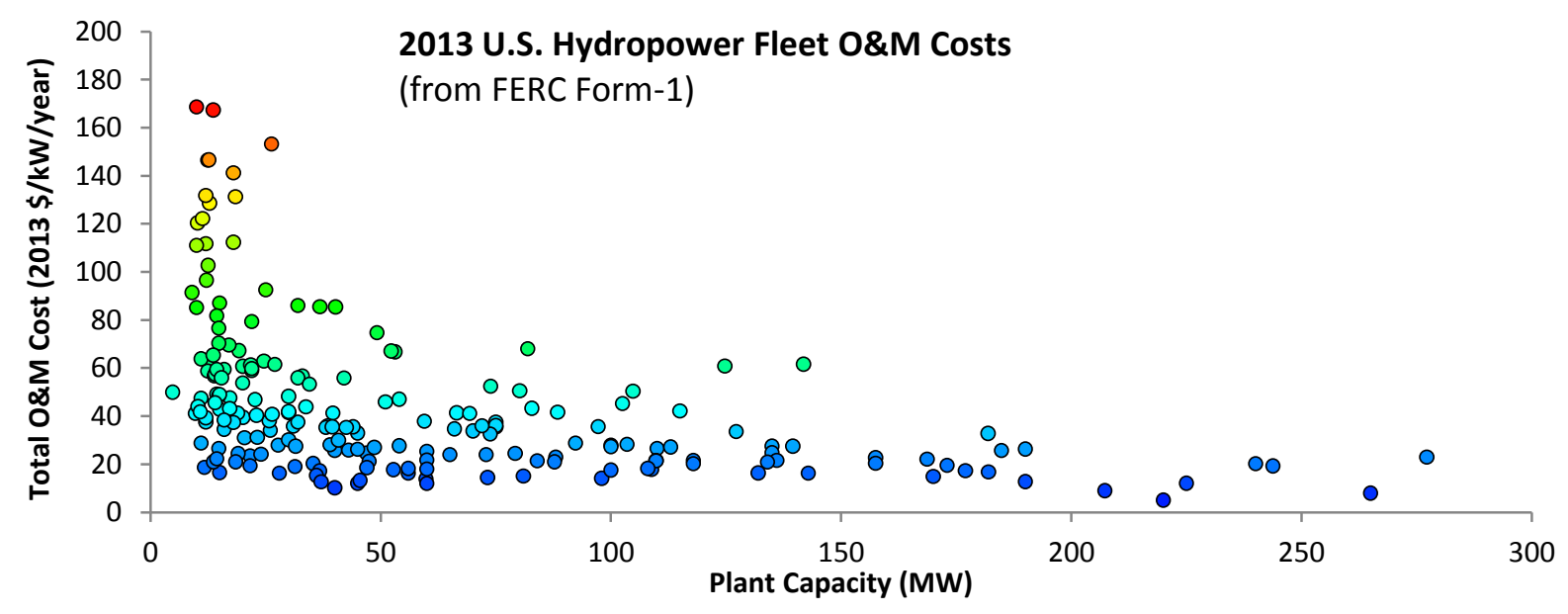

Figure 33. Economies of scale in hydropower operations and maintenance. (Adapted from O’Connor et al. 2015)

Larger projects are simply capable of spreading many of the fixed costs of hydropower O\&M across more megawatts; a maintenance visit by a technician will cost the same regardless of plant size. However, there are certain operational, maintenance, and administrative strategies that can reduce the costs of small hydropower. For example, industry has noted that automation and remote operation of facilities can

\footnotetext{
${ }^{36}$ These utility-class providers are generally global corporations headquartered in European countries, most notably Voith (Germany), Andritz (Austria), and Alstom (France).
} 
reduce costs between plants with similar technical characteristics by $50 \%$ or more (O'Connor et al. 2015). However, new design and O\&M strategies will be necessary to drive down the cost of running SMH projects.

In addition to economies of scale based on plant capacity, the numbers and types of generating units in use at a particular facility have cost implications. More units proportionally require more maintenance, and it is generally accepted that turbine technologies with more moving parts (e.g., double-regulated Kaplan or bulb units) are more expensive to maintain than their fixed-blade counterparts (e.g., propeller or Francis turbines). Project developers may opt for the minor up-front cost savings and reduced O\&M requirements over the potential increase in efficiency from the use of more versatile turbine technologies.

Beyond day-to-day O\&M activities, each major component of a hydropower project has a useful life, after which it may become prudent to explore replacement or rehabilitation to extend life, increase generation, and maintain reliability. Major unit components, such as turbine runners or generators, have very long expected lives of 50 years with the potential to run for longer (WAPA and USBR 2005). Rehabilitating these components is significantly less costly than their initial purchase and installation. For example, the average recent cost of rewinding a generator was only $\$ 116 / \mathrm{kW}$; although, as capital costs scale with project capacity and attributes, so too do overhaul and replacement (O'Connor et al. 2015).

\subsection{PRICING, REVENUE, AND LIFE-CYCLE BENEFITS}

Once constructed, a hydropower project has access to a number of different revenue streams from power markets, government incentives, and environmental value streams (e.g., Renewable Portfolio Standards).

In power markets, hydropower projects can be paid for their contributions to energy supply (generation), flexibility to respond to power system uncertainty (ancillary services), and availability during times of high need (capacity). The ancillary service and capacity values of a hydropower project are highly dependent on the amount of flexibility and storage available, which depends on site and design considerations. For run-of-river hydropower with little to no flexibility owing to design or regulatory considerations, revenues from generation are the primary value stream in electricity markets.

SMH-style designs will lack the capability to provide many traditional ancillary services, limiting the value of the capacity from these projects. In conventional designs, turbine governors respond automatically to power system signals, changing the output by varying the amount of water passing through the generating units to provide short-term energy services (frequency regulation or spinning reserve). Beyond ancillary services, the value of capacity from a project is its ability to generate as necessary during times of peak demand. Given that the ability to generate electricity at an SMH project is wholly contingent on real-time fluctuations in water availability, the relative amount of dependable capacity from these projects will be lower; and in a market context, this significantly reduces the capacity value. However, frequency and voltage regulation could be possible, albeit for a price, through the use of on-site batteries or implementation of advanced power electronic designs, which would allow an SMH facility to regulate while still using the same amount of water.

Beyond contributions in power markets, hydropower can also derive revenue from its environmental attributes, such as the sale of renewable energy credits (RECs) or participation in greenhouse gas markets. Prices in current REC markets vary from miniscule (such as \$1/MWh in "voluntary markets") to lucrative (such as \$50/MWh in select Northeastern states) (Marex Spectron 2015). The eligibility of hydropower to participate in these types of markets is highly variable, with restrictions based on the size, age, and type (e.g., NPD vs NSD) of project (Uria-Martinez et al. 2015). Under current rules, it is likely that very few NSD applications of SMH technology would be eligible in most REC markets. 
Ultimately, for a traditional hydropower development to make sense economically, its investors must have very long-term perspectives on development, as well as access to inexpensive capital to usher a project through the development pipeline and finance its construction at economically satisfactory rates. For this reason, historically (and even currently), most hydropower capacity (and overwhelmingly the largest projects) are developed by entities with an investment in long-term public welfare, including the federal government, municipalities, public utility districts, and other entities with decades-long planning horizons and access to public financing (for recent development trends see Uria-Martinez et al. (2015); for a more detailed exploration of the role of low-cost financing in facilitating the deployment of hydropower, see the Hydropower Vision, DOE [2016b]).

Moving forward, SMH designs can either take a similar, long-term value approach to conventional hydropower, or rethink the cost-value-lifetime trade-off for hydropower projects and explore the economics of shorter-lived but less expensive installations. However, it is important to keep in mind that, as SMH revenue opportunities are expected to be limited owing to connectivity and run-of-river operational realities, cost is the primary mechanism by which to improve the economics of these new designs.

\subsection{ENVIRONMENTAL IMPACT, ACCEPTANCE, AND SUSTAINABILITY}

Environmental regulation is one of the obstacles, if not the key obstacle, hindering SMH development. This section discusses the primary environmental impacts associated with hydropower, specifically SMH and the path toward sustainability and societal acceptance of hydropower.

\subsubsection{Environmental Impact}

Hydropower affects three categories of riverine properties that trigger environmental concerns: water quantity, water quality, and connectivity. SMH will rely on small, mostly run-of-river facilities that will potentially alter fewer of these characteristics or alter them to a lesser degree than conventional hydropower facilities. In this way, expansion of hydropower using SMH facilities may lead to lessened environmental impacts and greater acceptance of hydropower by the public and regulators.

Many conventional hydropower systems create water quantity issues by changing the flow regime (e.g., the magnitude, frequency, duration, timing, and rate of change of river flows [Poff et al. 1997]) as a result of the timed storage of water. Whereas water was historically most abundant in the winter or spring months associated with periods of increased precipitation or snowmelt, and least abundant in summer months, construction of hydropower dams allows for the storage of high flows to retain water for the generation of electricity in the summer months with high power demands but naturally lower flows. Water storage has thus led to changes in river flow below dams that impact river-dependent biota. Runof-river facilities integral to the expansion of SMH can be less disruptive to the natural flow regime itself, thereby creating hydropower with lower environmental impacts (Jager and Bevelhimer 2007; Pracheil et al. 2009).

Water quality issues, such as changes in thermal, dissolved oxygen, nutrient, sediment, and dissolved gas regimes, are also commonly associated with hydropower facilities; but they may be somewhat mitigated in SMH systems. Changes in the thermal regime, for example, can be caused by water intakes drawing from a single layer of the water column, for example, water intakes that draw from the bottom of a reservoir. These can result in cold water releases downstream of the hydropower facility even in the summer when water temperatures are warm. Such water temperature changes have been linked to delays in fish spawning, disruptions in insect emergence, and elimination of thermally sensitive fish species (Bunn and Arthington 2002). The lower heads associated with SMH may not alter thermal regimes as drastically as do larger conventional hydropower plants and thus may reduce thermal impacts. Similarly, 
SMH systems may have fewer dissolved oxygen issues because they avoid the reservoir stratification that creates anoxic conditions in the deepest portions of larger conventional hydropower reservoirs. The lower heads and near-constant movement of water characteristic of run-of-river SMH facilities are not favorable for reservoir stratification, so water releases are more well mixed and have higher dissolved oxygen concentrations.

Sediment and nutrient regimes are also altered by hydropower systems as a result of increased deposition in river-reservoir transition areas upstream of dams. Sediment deposition in reservoirs leads to sedimentand nutrient-starved water releases downstream of the dam (Ward and Stanford 1983), which in turn cause bank erosion, channel degradation (Ligon et al. 1995). SMH projects may be able to circumvent some of these ecological impacts because they are not designed for storing large volumes of water; therefore, they cause less slowing of water and concomitant deposition of sediments in the river-reservoir transition zone. Releases of dissolved gases, particularly the greenhouse gases methane and carbon dioxide that form as inundated upland vegetation decomposes (Beaulieu et al. 2014), will likely be lower in SMH facilities relative to conventional hydropower.

\subsubsection{Acceptance}

The history of hydropower in the United States is not without controversies. They range from large-scale expropriation of lands of native peoples and farmers across the country, to the decline of natural and tribal resources such as salmon, American shad, and American eel due to construction of massive hydropower projects in the coastal United States that block spawning migrations. As a result, a sector of the American public is wary of hydropower development. Learning from the lessons of past eras of hydropower development and working to bring this reticent sector of the population toward acceptance of hydropower is critical to the expansion of SMH and other hydropower technologies.

Many previous issues with societal acceptance of hydropower were tied to large conventional hydropower facilities that inundated large tracts of land, requiring wholesale buyout, expropriation, or relocation of entire communities. Principles of sustainability that will be used in planning SMH expansion may help to overcome some of these acceptance issues. Using SMH technologies as a critical component of hydropower expansion may get around some problems with societal acceptance because the low-head, run-of-river nature of SMH projects will inundate much smaller areas. Also, SMH facilities will incorporate passage, water quality, and other environmental mitigation modules that may encourage acceptance by those with environmental concerns. Because of the long history of hydropower in some regions of this country, an uneven distribution of natural resources that may be impacted by hydropower, and geographically variant socioeconomic forces, some geographic regions may be more accepting of or resistant to hydropower expansion than others. Gaining an understanding, before the planning effort begins, of which regions are most accepting of hydropower and have the fewest environmental barriers to hydropower expansion through SMH may help to lower the regulatory burden and resistance to hydropower expansion.

\subsubsection{Sustainability}

While "sustainability" can refer to economic or mechanical sustainability of operations, the economics of power production, or other considerations, in this report, unless otherwise noted, it will refer to environmental sustainability. Environmentally sustainable hydropower projects are those that are sited, built, and operated so as to strike a balance between ecological considerations (such as species diversity, water quality, recreation, and physical processes within the ecosystem), the needs of society to generate renewable energy, and the needs of hydropower producers to generate power at a profit. However, it is critical to note that environmental concerns are the primary limitation to new hydropower development, and thus any new development must be keenly aware of environmental requirements. Because of the 
importance of the environmental concerns to new development, SMH projects must be aligned with sustainability needs; therefore, fish and recreational passage, water quality, entrainment prevention, and other environmental mitigation modules will be essential pieces of all SMH development. Different environmental barriers to hydropower occur during both the licensing and relicensing phases, so different approaches to sustainable hydropower development must be used in each case. Both of those paths to sustainability are outlined in this section.

The path to new, sustainable SMH development that is capable of overcoming environmental barriers is through systematic, basin-scale approaches to siting facilities that explicitly examine trade-offs between power production and biodiversity or other environmental goods (Jager et al. 2015; McManamay et al. 2015). More specifically, as Jager et al. (2015) states, "making spatial decisions about hydropower development at the extent of large river basins and the resolution of smaller watersheds as planning units will produce solutions with higher ecological value that accommodate sustainable hydropower development." Using optimization approaches is integral to the preservation of ecological and power production values, because smaller, more numerous hydropower facilities do not necessarily yield lower impact or higher power production. For instance, (Ziv et al. 2012) show that putting more dams on smaller rivers with lower hydropower capacity not only jeopardized more fish species but also reduced net power production potential.

SMH expansion will also need to look to the future, when existing plants need to be relicensed and there will again be a need to evaluate and ensure the environmental sustainability of a project. Environmental regulations are becoming increasingly strict; and even small run-of-river facilities will be asked to lower their impacts during this process (potentially through adding water quality or fish passage mitigation) or evaluate optimal generation schemes to better benefit natural components of the ecosystem, such as biodiversity (Jager and Smith 2008). To better evaluate hydropower environmental impacts and to facilitate an understanding of how a particular facility fits among others in a sustainability spectrum, ORNL is developing a suite of sustainability metrics and guidelines for the hydropower industry that can aid hydropower facility compliance with environmental requirements. These metrics will be particularly important during the relicensing process but also are helpful in understanding likely environmental impacts and necessary mitigations during the project planning phase. These metrics will use existing frameworks in sustainability science, such as those developed for bioenergy production (Dale et al. 2013), and will include evaluation of flow regime (Richter et al. 1996), water quality (including greenhouse gases) (Boehlert et al. 2015; Bevelhimer et al. 2016), fish passage (Brown et al. 2013), and recreational impacts (Hooker 2014).

\subsection{REGULATORY REQUIREMENTS}

Among the challenges facing a proposed hydropower project is the myriad of regulatory requirements, permits, licenses, and approvals that must be obtained from state, local, and federal authorities. These requirements may include project reviews by the USACE (regarding potential effects on wetlands and/or on navigable waterways), the US Fish and Wildlife Service (regarding the effects on threatened and endangered species and their habitats), and the National Marine Fisheries Service (regarding effects on anadromous fish) and, ultimately, licensing approval from FERC. These regulatory requirements directly affect the design and cost of hydropower projects, since each such project requires extensive review of the design/technology being proposed, as well as of the environmental impacts of installing that particular project at a specified location. These issues would also apply to the installation and operation of SMH projects. This section discusses historical regulation, recent regulatory trends, examples of standardization and modularity in nuclear power, and regulatory considerations for SMH. 


\subsubsection{Historical Regulation and Recent Regulatory Trends}

The Federal Power Act (FPA) of 1920 created the Federal Power Commission (reorganized as FERC in 1977) and gave it the authority to license the vast majority of nonfederal hydropower projects. Since then, the licensing process has experienced multiple revisions. From the 1920s to the 1960s, dam construction flourished and installed hydropower capacity followed a rapidly increasing trend. But in 1969, the enactment of the National Environmental Policy Act (NEPA) substantially increased the complexity of the licensing process. NEPA required FERC to give equal consideration to the power and non-power implications of hydropower projects. This requirement translated into an increase in the number of studies, which are costly and often lengthy, needed to evaluate each license application to identify all the potential environmental impacts and request appropriate mitigations as part of the terms of the license. Except for pumped-storage hydropower projects, hydropower development slowed down dramatically after the implementation of NEPA and other environmental legislation (e.g., Wild and Scenic Rivers Act of 1968, Endangered Species Act of 1973). FERC introduced the alternative and integrated licensing processes in 1998 and 2003, aimed at increasing communication among the agencies involved in the licensing process and improving its overall efficiency.

Regulators have long recognized that the potential environmental impact of a hydropower project varies substantially across project types, and they have made some types eligible for more streamlined and expedited processes. Size is just one of the several attributes considered in gauging the potential environmental impact of a hydropower project and deciding on the level of scrutiny it must undergo. Exemptions from licensing for certain types of conduit hydropower projects have been available since the issuance of the FPA. Because they are not located on waterways, conduits typically have the least environmental impact, making them the ideal first candidates for an expedited exemption process. On the other hand, the $5 \mathrm{MW}$ exemption to small hydropower projects built on existing nonfederal dams or taking advantage of natural water features (e.g., natural lakes, waterfalls) was not authorized until the issuance of the PURPA of $1978 .{ }^{37}$ Unlike conduit-based projects, these small hydropower developments are not categorically exempt from NEPA and need to prepare environmental documents.

Starting in 2007, FERC staff have observed a markedly increasing trend in the number of submitted preliminary permit applications for small hydropower development. This renewed interest in small hydropower relates to the implementation of state-level renewable portfolio standards and other federal and state-level renewable energy incentives. To cope with the influx of applications, FERC stepped up its efforts to provide guidance to potential developers. In addition, on a case-by-case basis, FERC streamlined the permitting process for small, low-impact hydropower projects in ways that were allowed under the existing legislation, including waiving the three-stage consultation pre-filing requirement, combining multiple steps of the permitting process into a single step, and shortening comment periods (Wright 2010).

More recently, Congress has approved a suite of legislative measures with the objective of expanding the range of projects that can benefit from the most streamlined permitting pathways, while still ensuring adequate environmental protection. The Hydropower Regulatory Efficiency Act (HREA) of 2013 expanded the size range for projects (not located on conduits) that can apply for a FERC exemption from $5 \mathrm{MW}$ to $10 \mathrm{MW}$. Moreover, HREA introduced a new permitting pathway for certain nonfederal conduits that could accommodate hydropower facilities with capacities of up to $5 \mathrm{MW}$. Those projects that gain "qualifying conduit" status, a determination that is made within a 60-day period, do not require either an exemption or a license from FERC. For nonfederal hydropower development on conduit facilities owned

\footnotetext{
${ }^{37}$ https://www.ferc.gov/industries/hydropower/gen-info/licensing/small-low-impact/get-started/exemplicens/project-comparison.asp
} 
by Reclamation, the Bureau of Reclamation Small Conduit Hydropower Development and Rural Jobs Act of 2013 authorized extending the lease of power privilege (LOPP) process to projects with capacities of under 5 MW. In December 2014, the Carl Levin and Howard P. "Buck" McKeon National Defense Authorization Act extended the possibility of nonfederal hydropower development using LOPP to a subset of projects that had previously been prohibited. LOPP itself was revised in 2012 to make it more efficient and transparent.

The North American Energy Security and Infrastructure Act, passed by the House of Representatives in December 2015, proposes improvements to the federal permitting process that could particularly benefit hydropower development at NPDs owned by USACE. These projects currently require both a FERC license and a Section 408 permit from USACE. The new act promotes coordination between the various federal agencies to avoid duplication and inefficiencies in the permitting of these projects. It also encourages agencies to use existing studies whenever the information might be applicable, and to authorize studies at the basin or region level that can then be used by every project in that region or basin, instead of asking that each project performs every required study.

It is still too early to evaluate the effectiveness of the legislative measures approved in the 2013-2015 period. However, there is already some evidence of the difference in the predictability and length of the exemption versus license processes. A sample of 29 projects that started operation from 2005 through 2013, Uría-Martínez et al. (2015) show that the time spent obtaining required FERC permits was shorter and more predictable for projects pursuing exemptions than for those requiring licenses. For the 13 projects that received exemptions, the median time elapsed from exemption application to exemption issuance was 5 months; and this development step did not take more than 13 months in any of the projects in the sample. However, note that all 13 of those projects were conduit projects, which do not require the preparation of an environmental document for NEPA approval. On the other hand, for projects that required licenses, the median time spent in pre-licensing activities was 36 months and the median time elapsed from license application to license issuance was 21 months. The lengths of both stages of the licensing process spanned a wide range across the sample of projects considered.

\subsubsection{Standardization and Modularity in Nuclear Power}

As noted earlier, the regulatory requirements focus on the siting of the project, as well as the evaluation of some aspects of the technology to be installed (e.g., the potential for fish impingement). This situation is not unlike what is faced by the US Nuclear Regulatory Commission (NRC) when it licenses a new nuclear power reactor; that is, the NRC must approve both the safety-related aspects of the design/technology of the nuclear reactor and the location where the nuclear power plant would be licensed to operate. As discussed in the following paragraphs, the NRC has developed and is currently implementing a streamlined and efficient process for the review of license applications for new nuclear power plants, as well as applications for the relicensing and life extension of existing nuclear power plants. Many of the same principles used by the NRC may be applicable to FERC's future licensing actions regarding SMH projects.

In the mid-2000s, the NRC foresaw the need to ramp up its license review capabilities in anticipation of a flood of license applications for new nuclear reactors that would use next-generation nuclear technology; that is, an increased number of license applications was anticipated primarily as a result of funding and loan guarantees offered by DOE for the first six such new reactors.

Before that time, the NRC employed a two-phase strategy for licensing nuclear reactors as prescribed in Title 10 of the Code of Federal Regulations, Part 52 (10 CFR Part 52). The first phase involved the granting of a construction permit $(\mathrm{CP})$ that would authorize the permit holder to execute certain sitespecific actions related to building a new nuclear plant. The specific design of the plant was approved as 
part of this first phase; however, each type of reactor design was different from all others, in that sitespecific adaptations (such as specific cooling-water system designs) were necessary. The NRC's reviews focused on both the safety-related aspects (i.e., technology aspects) and the environmental-impact aspects (i.e., site-specific aspects) of the proposed nuclear power reactor. However, the $\mathrm{CP}$ review focused only on the licensee's proposed construction activities. The second phase of the NRC licensing process was implemented when the construction of the new nuclear plant had been completed. At that time, the applicant was expected to apply for an operating license (OL) for the new nuclear plant. The OL authorized the licensee to operate the nuclear plant under the conditions prescribed in the license granted by the NRC.

The existing 104 nuclear power plants in the United States were constructed and placed into operation under this previously used two-phase system of NRC licensing and approval.

The next generation of new nuclear plants in the United States is currently being licensed by the NRC under new regulations at 10 CFR Part 52, Subpart C. These new regulations eliminate the need for an applicant to go through a two-phase licensing review by streamlining the process into a single, combined $\mathrm{CP}$ and OL (or combined license, COL). This new process combines both phases of the NRC's previous two-step licensing process.

Furthermore, the suite of current next-generation nuclear power reactor designs is being reviewed by the NRC under regulations in 10 CFR Part 52, Subpart B, which pertains to the certification of standardized nuclear reactor designs. An application for a standard design certification undergoes an extensive safety review by the NRC. The result is a rulemaking that certifies the reactor design. These preapproved, certified reactor designs can then be included in a COL application to the NRC, and no further review of the reactor design by the NRC is required. The NRC's licensing review of nuclear reactors under the new system thus focuses on site-specific aspects, and not on the approval of the reactor design itself (which is granted through the design certification process).

In addition, an applicant for a new nuclear reactor may elect to pursue an Early Site Permit (ESP) from the NRC under 10 CFR Part 52, Subpart A. An ESP is an NRC approval of a site for one or more nuclear power facilities. Issuance of an ESP is a process that is separate from the issuance of a COL for such a facility. The ESP application and review process makes it possible to evaluate and resolve safety and environmental issues related to siting before the applicant makes a large commitment of resources. If an ESP is approved, the applicant can "bank" the site for up to 20 years for future reactor siting. An ESP does not, however, authorize construction and operation of a nuclear power plant. To construct and operate a nuclear power plant, an ESP holder must obtain a COL.

The applicant for an ESP is not required to provide a detailed design of a reactor or the associated facilities, but it must provide sufficient bounding parameters and characteristics of the reactor and the associated facilities so that an assessment of site suitability can be made. Therefore, one common technique incorporated into an ESP application is the use of a plant parameter envelope (PPE). A PPE defines a set of numerical values for plant design parameters or characteristics that an ESP applicant expects will bound the design of the reactor that might be constructed at the proposed site. The PPE values thus serve as a bounding surrogate for actual reactor design information during the NRC review. The NRC analysis of site-specific environmental impacts based on a PPE approach permits an ESP applicant to defer the selection of a reactor design until the $\mathrm{CP}$ or COL stage.

The NRC has successfully implemented the new regulatory review process described, and four new nuclear power reactors have been licensed with this new process and are currently under construction: 
- Two new reactors are under construction at the V. C. Summer plant in South Carolina, following licensing through the COL process with a certified reactor design.

- Two new reactors are under construction at the Vogtle plant in Georgia, following an ESP process using a PPE approach and a subsequent COL process with a certified reactor design.

Each of these four new reactors is scheduled to begin operation before 2021, whereas the previous NRC approval and licensing process (i.e., for the existing 104 operating reactors in the United States) sometimes took decades.

One additional technique used by the NRC involves the review of license renewal applications (i.e., lifeextension applications) for existing nuclear power reactors under 10 CFR Part 54. A nuclear power reactor is initially granted a 40 year operating license, and a license renewal application must be submitted to the NRC to continue operation beyond that period. Almost all of the operating nuclear reactors in the United States will approach the end of their initial 40-year license periods before 2030. To expedite the review and approval process, the NRC developed a generic environmental impact statement (GEIS) to evaluate the environmental aspects of license renewal. The GEIS assessed 92 separate environmental issues related to nuclear reactor relicensing. Sixty-eight of these issues were found not to be related to site-specific aspects and were thus identified as not requiring additional plant-specific analysis. Guidance was developed in the GEIS for the analyses that would be required for each of the other 24 issues (which were determined to have plant-specific aspects that can be evaluated only on a sitespecific basis). In its review of license renewal for a specific nuclear power plant, the NRC "tiers" to the GEIS and incorporates the GEIS analyses by reference in its relicensing review and decision. To date, 57 power plants have been relicensed by the NRC using this GEIS tiering method.

\subsubsection{Considerations for SMH}

In summary, and in regard to SMH facilities and the approval process that will be required by FERC and/or other agencies, the following analogies with the NRC's nuclear reactor approval and licensing processes are apparent:

- An examination of existing review, approval, and licensing processes can be conducted to identify any efficiencies that can be achieved by streamlining those processes. For example, can any multistep processes be combined into a single approval process, as in the NRC's COL process?

- Development and pre-approval of "certified" designs for hydropower facilities can expedite the approval process for locating such facilities at more than one location. The modular nature of SMH facilities would appear to be amenable to this "pre-certified" approach. Licensing and permit approvals could then focus on site-specific aspects, since the design/technology aspects would already have been evaluated during the design certification process.

- Consideration should be given to an ESP process in which a set of PPE characteristics can be used as bounding surrogates for a suite of previously or potentially certified SMH designs/technologies. Then the PPE can be used to evaluate a specific proposed location for the installation of an SMH project that fits within that same PPE.

- Development of GEIS approaches can identify those aspects of SMH projects that can readily be evaluated and given overarching closure, as well as those aspects that will require evaluation at the site-specific level. The use of GEIS approaches will aid the permit and licensing reviews of SMH projects by avoiding the need to repeat previous analyses that are of a generic nature. 
The recent trends in hydropower regulatory requirements suggest that regulatory authorities are acknowledging the push for small hydropower and the need for more streamlined licensing and permitting processes. Should SMH development accelerate, it is important that additional simplifications occur to support standardization in hydropower, thus minimizing short- and long-term risk, reducing development timelines, and decreasing cost.

\subsection{INTERCONNECTION REQUIREMENTS}

To supply power to a transmission system, hydropower facilities often use transformers or power electronics to convert the generator's low-voltage alternating current to high-voltage alternating current (typically $13.6 \mathrm{kVA}$ ) for distribution to a power system (see Section 3.6). Depending on the size of the project, small hydropower development may simply require a net metering and interconnection agreement with a local utility or may require an interconnection study to assess potential impacts resulting from the project. Load flow studies may be needed to determine the optimum voltage and conductor size (Leyland 2014). Typically, interconnection studies are carried out either by the utility or by a utility-approved engineer and are paid for by the project developer (Colorado 2010). Depending on project location and surrounding terrain, the cost of interconnection may present a significant challenge to project development, making an otherwise affordable project infeasible.

While it is not within the scope of currently funded SMH research, research into interconnection requirements, standards, and new technologies could provide advantages to SMH RD\&D.

\subsection{OPERATIONS AND MAINTENANCE CONSIDERATIONS}

Opportunities for improving the O\&M of SMH facilities are substantial, and proper design and implementation will play a huge role in their success. Improvement is facilitated through the ability to react to O\&M issues from a design and holistically coupled point of view. New module technology development enables the research to address, up-front, O\&M issues that historically were addressed from hindsight, and to address design issues proactively as opposed to reactively.

O\&M issues can be addressed much more easily and affordably as a result of the standardization and modularity aspects of SMH. The more predictable operational performance and easier maintenance of a standardized system will reduce the need for individual training and equipment and improve the logistics of replacing key components. Finally, the similarity of SMH systems streamlines efforts to improve knowledge and understanding of the system. Modularity improves the ability to easily swap out necessary components to minimize operational and production outages.

The well-known aspects of O\&M issues can be used to guide the design and implementation of the modules to help minimize issues and address them affordably. This approach can be realized by integrating embedded systems to monitor, predict, and facilitate operation of the systems' components. Appropriately incorporating sensors and integrating methods and techniques to allow the system to react and adjust according to performance, changing conditions, and predictive scenarios help in preventing surprise downtimes and scheduling appropriate and efficient maintenance. Telemetering of data and system status facilitates remote conditioning and assessment of the system as a whole, which saves costs. Systematic replacement planning can be performed in a manner similar to that used the Alstom PlantLife ${ }^{38}$ program, which is based on three modules. One module assesses O\&M status using scheduled diagnostics, a second acts to procure spare parts as it predicts a need for them, and a third assesses refurbishment or upgrade needs.

\footnotetext{
${ }^{38} \mathrm{http} / / /$ alstomenergy.gepower.com/Global/Power/Resources/Documents/Brochures/hydro-plantlife.pdf
} 


\section{SMH RESEARCH, DEVELOPMENT, AND TESTING ACTIVITIES}

New technologies for small hydropower development have been and are actively being developed. While the majority of these relate to generation technologies, a comprehensive approach addressing the integration of new generation technologies into a state-of-the-art hydropower facility has not been achieved through an accepted plant design. Standardization and modularity represent two new technology features that will be used to develop such a facility; they are described in more detail in this section.

\section{A New Paradigm for Hydropower Development}

The appearance of an SMH facility within the riverscape will be different from that of traditional dam and dam foundation designs. Envision a small modular passage or generation structure sitting on the bed of a stream. It extends vertically only to the water surface and is not a superstructure or dam. The modules are founded on a soil or rock foundation that has been disturbed only by the variations of low and high flows within the stream for hundreds of years. They may be supported on an underwater bedrock structure within the river, or they may be on a reef-like foundation structure visible only at low river flow periods. The modules regularly pass fish and small recreational craft. Perhaps the generation modules extend only partially across the width of the river, and the remaining portion consists of a natural fish pass module or a combined fish ladder and canoe chute module. They are easily removed for maintenance and rehabilitation, and they may even be interchanged with other modules based on seasonal variability.

This is not a visualization of a dam, but of a natural stream or river structure, a modular assembly designed to match the surrounding aesthetic. Perhaps the foundation simply levels the river bottom to allow modules to sit flat upon the river bed, as opposed to an extensive excavation that extends into the subsurface. A reservoir is not created to hold back flood waters, but rather water flows equitably between passage and generation modules that can withstand low flows and flood conditions. Water is partitioned between a turbine module(s) and PM(s) in a way that safely and consistently sustains the natural functions of the stream, including the passage of fish, sediment, and canoes and kayaks. Rather than a spacious powerhouse that sits above the water and requires an extensive manmade foundation, the turbine/generator assembly is underwater and requires no powerhouse structure and a minimal foundation.

The fundamental shift in hydropower thinking embodied by SMH is the assembly of an entire facility from interconnecting modules. By conceptually breaking a traditional hydropower plant into modules, the complexities that challenge the industry are identified along with the opportunities for improvement. The modular foundation approach strives for a completely replicable, invisible engineering and construction achievement. If a potential site has a foundation made up of a difficult soil type that is potentially unstable or pervious, perhaps the right solution is to choose a different site with a better foundation. The generation and passage approach strives for interdependent modules with known functionalities that together generate renewable power and maintain the environmental function of a stream reach. The need to achieve project feasibility and reliability, minimize environmental disturbance, and safely and consistently produce hydropower should guide the module design process; but above all, the SMH concept should be developed to work for a variety of sites while maintaining environmental compatibility and economic feasibility.

\section{New Research for Hydropower Development}

These concepts align with the DOE Hydropower Vision Roadmap's technology advancement actions (DOE 2016b) as outlined below:

- Action 4.1.1: Develop next-generation hydropower technologies 
- Action 4.1.2: Enhance environmental performance of new and existing hydropower technologies

- Action 4.1.3: Validate performance and reliability of new hydropower technologies

- Action 4.1.4: Ensure hydropower technology can support increased use of variable renewable generation resources

The SMH RD\&D is intended to reduce civil works needs and construction time, as well as minimize onsite installation and fabrication, thereby reducing cost. Though they are not specifically targeted in SMH $\mathrm{RD} \& \mathrm{D}$, it is expected that secondary benefits related to an improved regulatory and environmental approval process, along with reduced costs for supporting these functions, will emerge as a result of standardization and modularity. Primary and secondary benefits may be manifest throughout the project development, construction, and operation timeline as reductions in the burden of cost, time, and risk at critical stages of development (Figure 34). These perspectives have been actively discussed by industry but have not been put into practice because of their high-risk nature and unknown outcomes.

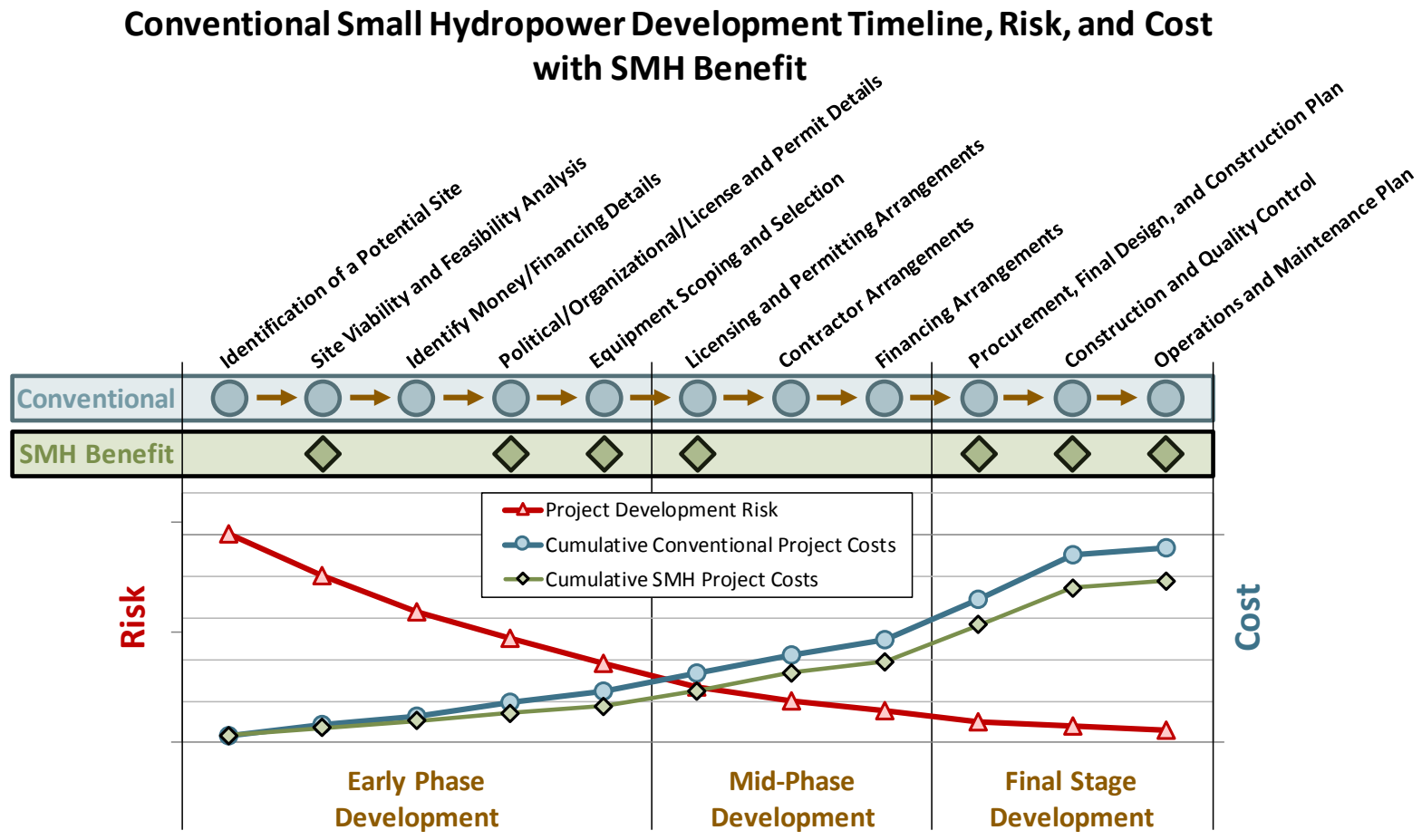

Figure 34. Conventional small hydropower development timeline showing project risk and costs throughout development and steps for which SMH development may offer benefits. Note that the figures presented are for demonstration purposes only and are not derived from analysis. Plots are not intended to suggest precise risk and cost comparison.

Ultimately, SMH research investigates whether a new conceptual approach (standardization and modularity) will have value for new hydropower development. Four key research pillars, outlined in detail in this section, define the SMH approach:

- Section 5.1. The Exemplary Design Envelope Specification (EDES) defines and explores the objectives, requirements, constraints, and performance of generation, passage and foundation modules under anticipated SMH deployment scenarios. Broadly, the EDES details the hypothesis that standardization, modularity, and ecological function as principal design concepts can enable 
hydropower technologies to deploy and operate with minimal environmental impact and greater public acceptance at reduced costs.

- Section 5.2. The Site Classification Scheme addresses the perception that hydropower development is predominantly site-specific by developing tools and methodologies that group potential sites or development regions into similar classes, for example, sites or river reaches that have similar stream gradients, hydrology, spawning habitats, and migratory fish species.

- Section 5.3. The Simulation and Modeling Capability supports and addresses two efforts: (1) to identify and assess currently unknown behaviors and module interdependencies that will be encountered in the design, operation, and assessment of SMH modules and facilities, and (2) to develop a simulation framework and guidance structure - which will be made available to designers, engineers, developers, and so on - that appropriately defines available modeling capabilities.

- Section 5.4. The Testing and Validation Capability identifies the testing needs, as well as physical and technical requirements, for establishing an SMH hydraulic testing facility that can accommodate modules defined in the EDES and new modular technologies offered by technology developers.

\subsection{SMH EXEMPLARY DESIGN ENVELOPE SPECIFICATION}

Through an intentionally holistic approach to system design, the SMH EDES defines a new class of hydropower technology capable of overcoming physical, environmental, economic, and social barriers to deployment. The EDES is so named because it will enable practitioners to identify designs that exemplify important concepts necessary for feasibility and acceptance. It is termed an "envelope" because it does not specify a single design, but rather a class of designs that meet the functional requirements and design constraints identified by the SMH stakeholder community. This new technology will be standardized, meaning its geometry, local hydraulics, aesthetics, cost structure, and other salient design features will be site-independent and its environmental performance well defined for a class of stream environments. It will also be modular, meaning that capacity and function can be scaled to a site through the deployment of multiple components that interface with minimum cost and maximum value.

The design features of standardization and modularity, concepts that will be defined and discussed in detail in this section, have garnered substantial international attention in R\&D proposals (EU TNSP), research pathways reports (Bishop et al. 2015), and industry analyses (HEA 2015) as two ideas that can positively disrupt the traditional hydropower development paradigm, reduce development costs, and increase deployment. Standardization of hydropower generating unit (turbine runner) designs has existed in many forms for decades, with a surge of interest in the 1970s following the development of preengineered tubular and rim type turbine concepts (Allis-Chalmers 1970). Although it has been effective at driving cost reductions in the design and fabrication stage, the turbine runner is generally a small portion of the overall cost of a hydropower facility. The procurement and installation of additional electromechanical equipment, civil works, and environmental mitigation technologies is a significant cost driver that is generally not approached in a standard way. The term "modular hydropower" has no universal definition, although a modular approach is currently being applied with success in many industries, from nuclear and fossil fuel generation to consumer electronic devices.

The goal of the EDES is to approach this paradigm in three distinct ways: (1) develop a comprehensive approach to the concept design of an SMH facility; (2) propose a conceptual assembly of an entire hydropower facility from independent and interdependent modules; and (3) provide a contextual, concrete, physical basis for the notions of standardization and modularity through specification of objectives, requirements, constraints, and performance of exemplary modules. The added value of SMH EDES research is twofold: to provide definition, form, and function to a fully integrated SMH concept, 
and to begin to quantify how this concept will improve small hydropower development. These two points are critical if SMH is to be considered, and adopted as, a game-changing technology.

This research is not intended to produce a specific, ideal power plant, turbine, generator, foundation, or passage facility design. The choice of an individual machine or arrangement might preclude consideration of novel, valid technologies and ideas that are currently being developed by manufacturers and small hydro innovators. Furthermore, the hydropower industry has invested significant time and expense in developing generation technologies and arrangements that optimize flow physics and fluid mechanics to produce high efficiencies. What the EDES intends to provide is a robust science-, physics-, and engineering-driven framework for modular hydropower that defines an SMH system as a set of integrated relationships that explicitly state what it should do and how it should perform under various conditions and deployment scenarios. Consequently, the EDES process will require a determination of all the relevant inputs and functional relationships that a modular type facility could expect to face. These inputs will be used to develop design constraints on each module, from which actual designs, configurations, and module functionalities can be explored. An assessment of module designs will identify how and where improvements in functionality, environmental impact, performance, and cost can be achieved. This iterative EDES process is illustrated in Figure 35.

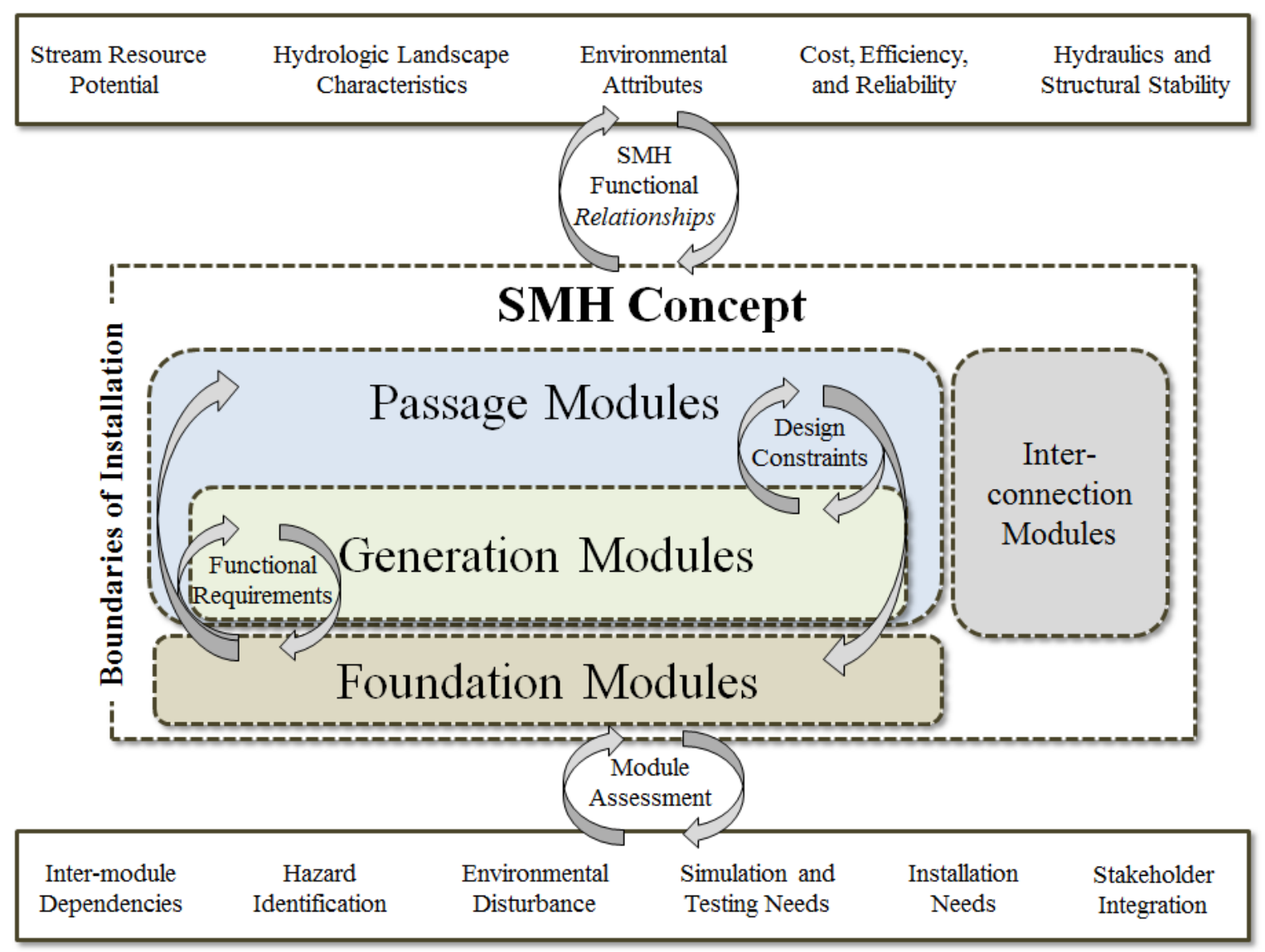

Figure 35. Conceptual diagram of SMH Exemplary Design Envelope Specification.

The SMH EDES initially considers three modules: GM, PM, and FM. Future research efforts will integrate both physical and virtual modules, including interconnection, installation, instrumentation and controls, and retrieval modules. The roles of each module are defined in the following sections. The individual and interrelated functional requirements, constraints, and design challenges are briefly outlined herein and are explored and defined in the EDES technical report (Witt et al. 2017). 


\subsubsection{SMH Terminology}

The maturity of hydropower technology has given rise to a broad understanding of basic conventional hydropower terminology. To build a common understanding of how SMH will be assessed and classified, several definitions relating to the notions of standardization and modularity are necessary. These are introduced below and referenced again throughout Section 5.1.

\section{Modules}

A module is a discrete functional unit or units with a dedicated purpose that, either independently or in combination with other modules, achieve a configuration appropriate for the scale and environmental context of the site selected for development. In the SMH context, five primary modules are considered:

Generation module. Generates hydroelectric power from flowing water under pressure.

Passage module. Adequately passes water, sediment, debris, aquatic life, and small recreational craft past an SMH facility.

Foundation module. Provides stability and support to SMH infrastructure by anchoring adjacent modules to the streambed and banks.

Interconnection module. Transmits electrical power from an SMH facility to a customer.

Installation module. A physical and virtual module that is used for placing SMH modules in a stream.

Standardization is a framework of guidelines, rules, and specifications (i.e., standards) implemented to maximize compatibility, acceptance, interoperability, safety, repeatability, or quality and minimize environmental disturbance. In a hydropower context, standardization of design, review, regulation, manufacturing, operations, and maintenance, and other features is intended to reduce site-specificity and project costs.

The modular interface is the mechanism through which SMH modules connect to other modules.

Modular plant scalability is the degree to which GMs, PMs, and FMs can be enlarged, reduced, or combined to meet the head and flow characteristic of a given stream-reach. Piecewise, in-parallel scaling of GMs is expected, in which numerous GMs will interface with PMs and FMs. Scaling relationships will be determined through functional assessments that quantify trade-offs in water throughput, size, power, and cost.

A modular trade-off is any situation in which the performance, cost, or functionality of a module has a correlated impact on another module. The EDES process must identify and quantify the trade-offs relevant to each module, of which many are expected. For example, both GMs and PMs have specific water quantity demands, and any discharge routed through the PM comes at the expense of generation and, ultimately, project revenues.

\subsubsection{Aspects of Holistic Hydropower System Design}

The holistic development of SMH modules entails up-front consideration of the trade-offs between functional requirements, design constraints, and performance expectations. Functional requirements state what modules must do within a given stream context to simultaneously achieve the stated objective of 
operation and maintain the ecological function of a given site. Design constraints must be developed from known functional and empirical relationships and interactions among GM, FM, and PM components and the characteristics of a particular stream resource. They must also be informed by socioeconomic limitations, market realities, and lessons learned in the worldwide development of small hydro. Performance expectations are driven by the stream resource, the project economics, and the specific market dynamics of the development location.

To begin the EDES process, a bounded envelope of resource potential must be defined. This includes, broadly, head and flow and, more specifically, hydrologic variability and site-specific topography, geology, and environmental attributes. The systematic variability of these attributes at the regional scale is integral to the design process. An identical average head and flow may exist in two distinct locations, but the environmental and ecosystem attributes that serve as pertinent input variables to the SMH modules and their functionalities may lead to a specific design decision in one case and not the other. Once the resource variability is defined at the regional scale, the functional requirements and goals of SMH can then be better defined in the context of ecosystem, infrastructure, market, and performance expectations for the targeted resource.

As part of the SMH holistic approach (Figure 36), the design of individual modules will require identification of the fundamental relationships that link physical resource variables to module performance. These fundamental linkage relationships (which are discussed in more detail in Sections 5.1.3 through 5.1.7 and are rigorously reviewed in the EDES report [Witt et al. 2017]) will capture the feedback interactions among the GM, PM, FM, and the suite of variables describing the watershed hydrology, topography, geomorphology, and aquatic species. By fluctuating these variables in a way that mimics known systematic variability, the responses of the watershed physical characteristics to different configurations of the SMH modules can be quantified through established indices. The introduction of these indices will enable researchers to pre-specify quantitative "success" criteria, which will be used to guide the design of the SMH modules within the envelope of known design constraints. These design constraints will involve not only the physics of how water interacts with machines and structures but also the expected cost and manufacturability of specific modules. Designs that reduce costs through standardization of components and modules will be conceptually assessed for installation needs, potential hazards, and performance against pre-specified success criteria. Similarly, design constraints will be introduced for mitigating environmental disturbance by the SMH facility to acceptable levels. 


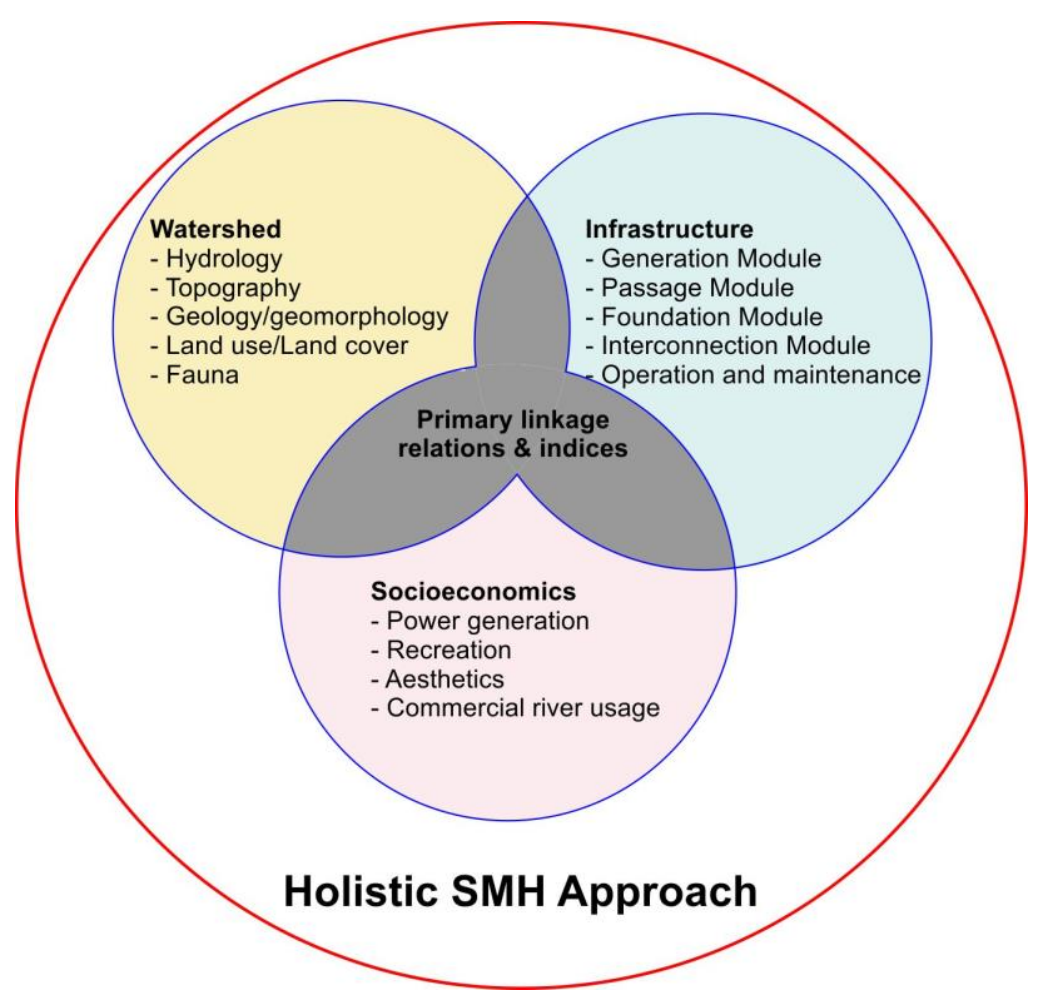

Figure 36. Holistic approach in SMH development.

\subsubsection{Resource Potential Addressed}

Reconnaissance-level resource assessments sponsored by DOE, discussed in detail in Section 2.1.1.3, have identified low-head and low-power hydro as the most likely future development opportunities. SMH must address this potential. In the New Pathways to Hydropower industry report (Bishop et al. 2015), effective site selection is cited as "perhaps the single most important aspect in development of a small hydropower project." Although the development of a single reference site specification for an SMH facility is premature at this time, the envelope of potential head and flow combinations that SMH should address can be bounded through an analysis of existing undeveloped stream-reach site characteristics. Once additional hydrologic resource characteristics have been determined (e.g., flow duration, stream classification, hydrologic landscape), the functional requirements of each module can be analyzed in greater detail.

The $65.5 \mathrm{GW}$ of NSD potential is distributed across 11,041 sites. A total of 10,121 of these sites, or $91.7 \%$ of all new stream-reach sites, could each support an estimated installed capacity of less than $10 \mathrm{MW}$; and 8,567 sites (77.5\% of the total) could each sustain less than $5 \mathrm{MW}$ of hydropower capacity. While no strict upper limit will be set for SMH technology, and strategic arrangements of GMs could potentially support a wide spectrum of power potential, an upper bound of $10 \mathrm{MW}$ will be set for SMH system design. This bound captures the majority of potential new development sites while roughly aligning with the limit at which equipment manufacturers begin to consider custom-made equipment and technology (HEA 2015).

The power potential of a given stream-reach could represent a spectrum of head and flow combinations. The 10,121 US sites with $10 \mathrm{MW}$ or less of hydropower potential are further screened to determine the average hydraulic head (gross) and the $\mathrm{Q}_{30}$, or the flow rate that is likely to be equaled or exceeded for $30 \%$ of the year (Figure 37). The $\mathrm{Q}_{30}$ is an approximate sizing flow for a typical low-head hydropower 
plant. Over $82 \%$ of these sites maintain an average gross head of less than $30 \mathrm{ft}$, with most falling between $10 \mathrm{ft}$ and $20 \mathrm{ft}$ range. In terms of flow, these sites generally exhibit a $\mathrm{Q}_{30}$ greater than 1,000 cfs that tends to decrease as head increases. Sites of less than $5 \mathrm{MW}$ capacity tend to have an average gross head of less than $20 \mathrm{ft}$, and sites between 5 and $10 \mathrm{MW}$ generally have an even distribution of average gross head between 5 and $50 \mathrm{ft}$.
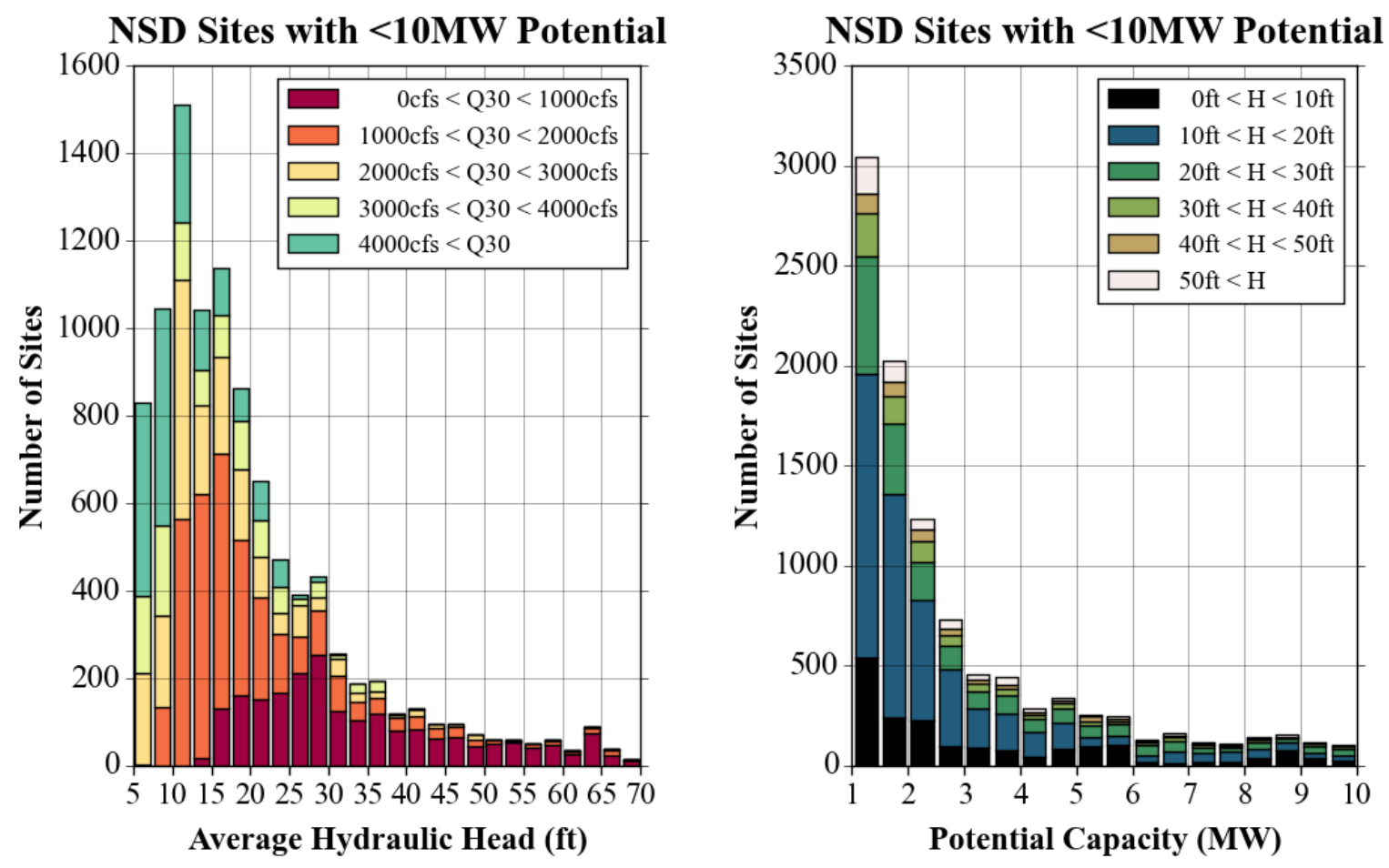

Figure 37. A distribution of the number of new stream-reach development sites for a given average gross head, colored by $\mathbf{Q}_{30}$ (left), and for a given potential capacity, colored by average gross head (right). Developed using data from the National Hydropower Asset Assessment Program.

While SMH configurations are expected to vary by region and stream geometry, there is no expectation that a one-size-fits-all solution can be developed. However, SMH technology development and design will be guided by the current resource, which demonstrates clear potential at sites with less than $30 \mathrm{ft}$ of gross head. The design flow to be passed by a combination of GMs and PMs will be at least 1,000 cfs and possibly no greater than $4,000 \mathrm{cfs}$. Specific details regarding the mechanism of flow passage and the relationship between generating and non-generating flow are explored in detail in the EDES technical report (Witt et al. 2017).

\subsubsection{Incorporating Stream Function into Module Design Standardization}

The function of a stream at a potential SMH development site is maintained by processes that act on numerous temporal and spatial scales. A watershed directs surface water into a stream, which carries water past an individual site. A watershed not only collects and channels water to a stream but also transports sediment and other organic matter from higher elevations to lower elevations. A stream sustains fish and other aquatic life that may migrate or travel upstream and downstream, and it is the medium for transporting recreational craft. A site may contain habitat critical to fish, or it may act as a point of sediment deposition within a watershed. In the context of EDES, stream function is defined as the flow and transfer of energy, water, sediment, fish, recreational craft, and water quality at an undeveloped 
location. The EDES operates under the assumption that an SMH facility that does not sustain or enhance overall stream functions is neither acceptable nor possible in modern regulatory contexts.

This idea is represented in Figure 38, which depicts a potential SMH site and a concept modular facility. A hierarchy of watershed, stream, and site-driven functionalities and processes are present at the site. These functionalities and processes are inputs to the module design process. The EDES will define the objectives, requirements, functional relationships, constraints, and performance metrics that exemplary modules must achieve. Multiple modules combine to create a holistically designed SMH facility that maintains stream function, i.e., the flow of energy, water, sediment, fish, recreational craft, and water quality.

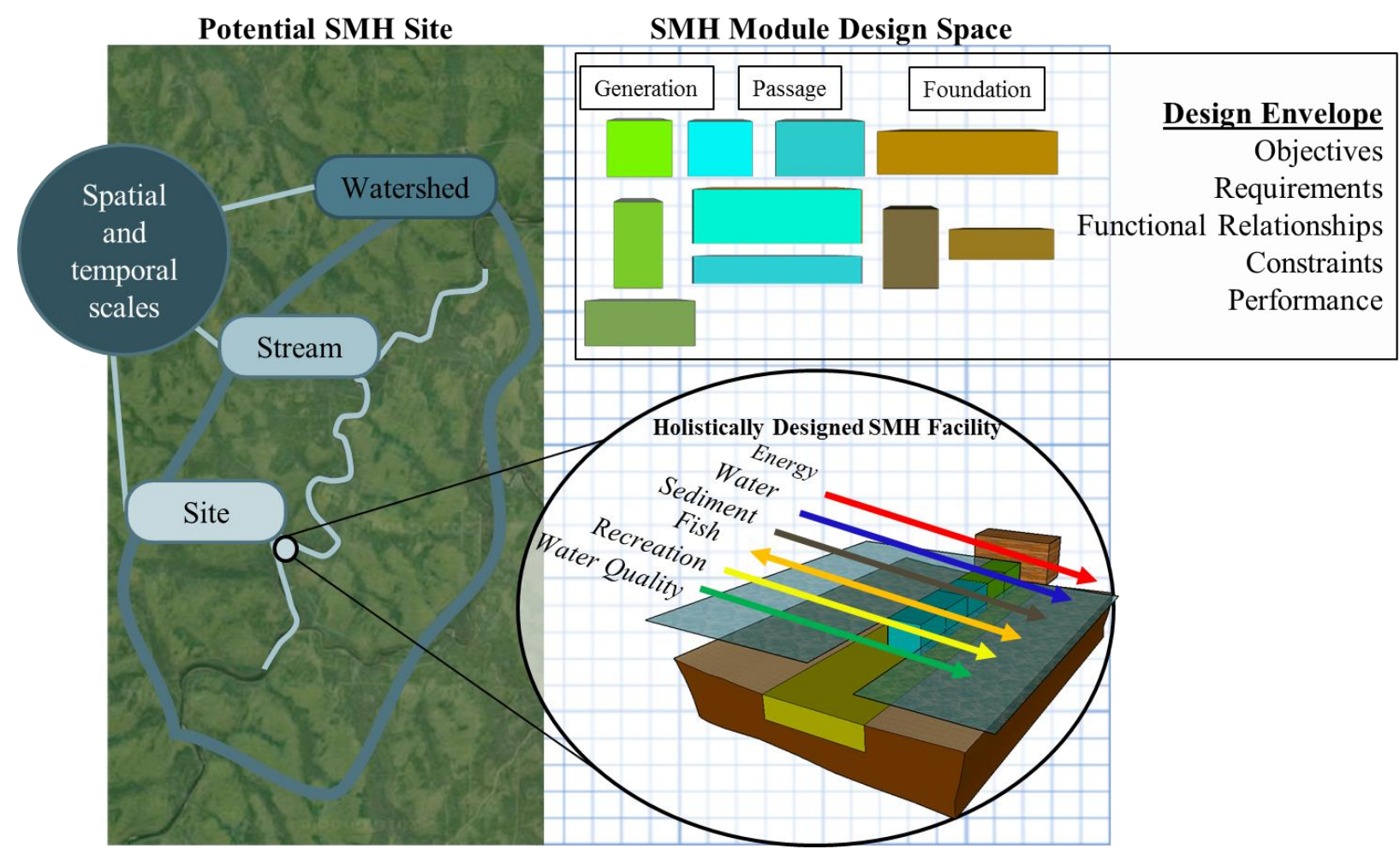

Figure 38. Holistic context of stream function, modularity, and standardization in modular design.

\subsubsection{Designing to Minimize Environmental Disturbance}

Mitigation of environmental impacts from hydropower projects has become a paramount development and design consideration. It has become increasingly apparent over the past few decades that disruptions of river connectivity can be detrimental to aquatic communities. Many hydropower projects do an acceptable job of meeting environmental criteria, and some have offered environmental enhancements for multiple competing stakeholders (Schwartz and Shahidehpour 2006). Many others have failed to mitigate disruptive environmental effects, or do not address legitimate environmental concerns until a significant investment has been made. The SMH EDES is not intended to find new ways of characterizing environmental disturbance. Rather, design thinking will be constrained by the known environmental disruptions that occur with small hydropower development. These constraints will be quantified, parameterized, and linked to stream characteristics to help develop a standardized approach to environmental mitigation. 
As a first cut to determine these constraints, the body of empirical data describing the known environmental attributes typical of NSD sites of $\leq 10 \mathrm{MW}$ capacity has been analyzed (Figure 39). More than $60 \%$ of all sites of $<10 \mathrm{MW}$ capacity have potadromous fish species (fish that migrate through fresh water), federally listed fish species, and fish species of concern. Clearly, the PM, or the GM and PM in concert, must address fish-related concerns, from passage to habitat to water quality and quantity. Whitewater runs are located within $500 \mathrm{~m}$ of nearly $50 \%$ of potential sites, and boat ramps are that close to a much smaller percentage. Accommodating small personal recreational craft must be a design consideration of the PM and of the SMH plant as a whole. The proximity of critical habitat and scenic rivers to approximately a third of potential sites is a strong indicator that SMH must seek to minimize disruptions to flow regimes. Advanced SMH PMs and GMs with biosensors and controls may be able to detect, alter, and mitigate flow conditions that lead to unfavorable habitats. This enabling capability may also be expanded to water quality concerns. If an SMH facility can detect that water quality is deteriorating, operational or mechanical techniques may be activated to mitigate and potentially improve local conditions.

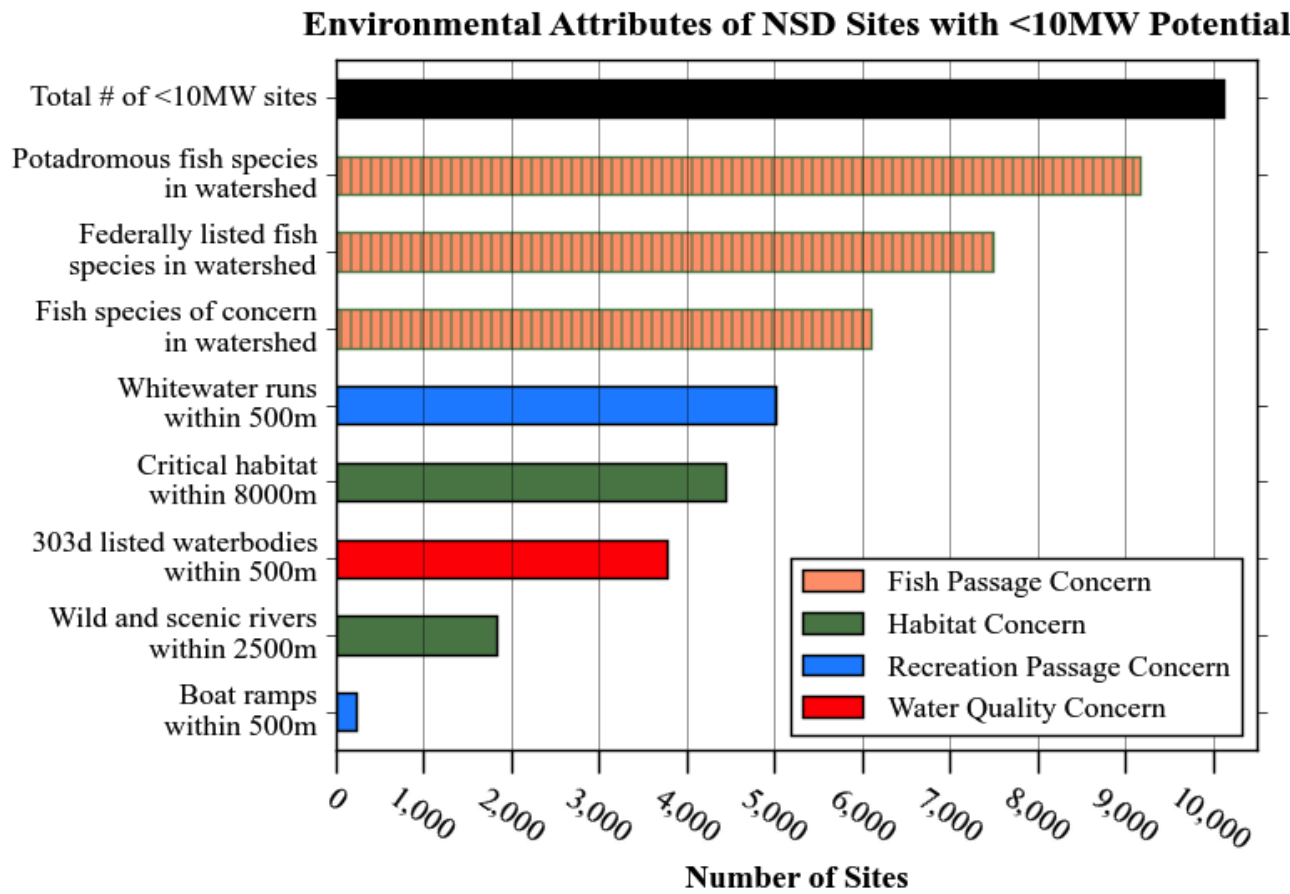

Figure 39. Number of <10 MW capacity NSD sites that exhibit known environmental attributes. Developed using data from the National Hydropower Asset Assessment Program database. ${ }^{39}$ Note that multiple species may be present in the same watershed.

\subsubsection{Functional Requirements of SMH}

Having defined the target size of an SMH facility, and upon identifying the mechanisms of environmental disturbance that must be mitigated with advanced module designs, the next critical step in holistic design is to specify the functional requirements of SMH technologies. The challenge of this task is that each constituent module must be designed both individually and interdependently. The GMs and PMs, for example, must work together to pass flow and maintain important river linkages throughout the watershed

${ }^{39}$ http://nhaap.ornl.gov/nsd\#Conterminous_NSD_Data 
where the SMH facility is located, while providing energy output that justifies the power plant investment. The GMs, PMs, and FMs must physically interface predictably; yet they should maintain the flexibility to operate under numerous spatial arrangements. The FM should minimize environmental disturbance while providing sufficient resistance to the forces acting upon and created by the GMs and PMs.

A thorough understanding of module interrelationships is critical to the design process. The EDES cannot account for every hypothetical SMH spatial arrangement and configuration, but it can be developed with the expectation that most SMH projects will share common characteristics, especially within the same regional setting. Modules must work together to exhibit the following characteristics:

- Match, within a given range of uncertainty, the efficiencies of existing hydropower technologies.

- Encompass the turbine runner, generator, and peripheral equipment in a single pre-assembled module.

- Provide standardized and scalable runner and generator configurations.

- Maintain a compact physical footprint that minimizes civil works and plant balance of equipment.

- Maintain a small environmental footprint that minimizes aquatic and terrestrial disruption.

- Retain river connectivity and minimize alterations to flow regimes.

- Keep modular interfaces predictable and simplified to the greatest extent possible.

- Minimize design to include only essential peripheral systems.

- Achieve reliable production using advanced/additive manufacturing and composite materials

- Minimize structural, public, and security hazards.

- Hold costs of materials, fabrication, and installation to pre-specified economic criteria.

These requirements are intended to guide design thinking to the greatest extent possible.

\subsubsection{Designing to Achieve Cost Reductions}

The EDES will seek to identify explicitly and implicitly how cost reductions may be achieved through standardized modules. Potential cost reductions may be achieved in the design, equipment procurement and fabrication, licensing and review, installation, and lifecycle management phases. The following are conceptual examples.

\section{Design}

- Module and plant design redundancies are reduced through design process standardization.

- A standardized module and SMH configuration for a given resource (head and flow) helps reduce feasibility study time and expense.

- Improved design approaches and equipment configurations help reduce typical O\&M burdens associated with current hydropower designs.

\section{Equipment procurement and fabrication}

- If predesigned modules are readily available, they reduce lead times, the need for customization, and design redundancies.

- Standard equipment specifications help accelerate the equipment procurement process during prefeasibility assessments and site design. 


\section{Licensing, review, and stakeholder acceptability}

- The known impacts, costs, and performance of specific modules and modular configurations accelerate the licensing and review processes by automatically satisfying licensing criteria.

- An accelerated licensing and review process reduces the costs of engineering and environmental impact studies.

- With time, standard design achieves a known level of performance and becomes a known and acceptable mitigation technology. This is not the case now, when specific environmental assessments are carried out and specific solutions and technologies created.

- Accelerated stakeholder acceptability of standard designs with known impacts could lower the cost of consultation and review throughout the permitting and licensing phases.

\section{Installation}

- Reliable and consistent installation cost estimates per module reduce project budgeting burdens.

- Reliable and consistent installation timelines per module reduce project scheduling and installation burdens.

- Off-site fabrication and on-site installation of modules help reduce labor costs for installation.

\section{Lifecycle management}

- Known module failure rates or component lifetimes simplify maintenance and lead to predictable rehabilitation or upgrade schedules.

- Simplified design minimizes O\&M requirements.

- Standard modules enable remote operation and reduce labor costs.

\subsubsection{Generation Module Specification}

As envisioned, a GM will encompass the entire powertrain, to include the turbine runner, generator, and governing mechanism, with consideration of inflow and outflow mechanisms. The EDES must specify the physical interactions that enable the machine to provide electrical energy from water flow; the boundaries of generating components; and the unknown input/output parameters, performance metrics, or specific designs that must be determined through simulation or testing. To be clear, this research is not intended to produce a specific, ideal machine design. Exemplary design of the GM will establish the criteria, formulae, and guidelines necessary for a GM to successfully and reliably generate hydroelectric power. This will include a rationalization of which design procedures should be standardized and which ones require variables that need to be individually resolved and optimized based on site-specific characteristics.

The first-order processes and inputs for the GM EDES and decision making environment ${ }^{40}$ are depicted in Figure 40. The general EDES methodology will build progressively and iteratively on five key processes: (1) establishment of the component hierarchy encapsulated by the GM; (2) identification of the functional and empirical relationships necessary to assess module performance, design, and operation; (3) functional decomposition, or the process of developing and analyzing module objectives, requirements, and constraints; (4) a discussion of exemplary module performance; and (5) module assessment. This section is intended to provide a brief overview of each process.

\footnotetext{
${ }^{40}$ Many of the concepts, fundamental relationships, and processes described in this section have been adapted from comprehensive resources on hydropower design and development. For more detailed information, please refer to USACE (1978); ASME (1996); ESHA (2004); and Leyland (2014).
} 
Although these categories appear to fall in line one after the other, GM design will likely not follow a linear approach. The functional requirements of a GM must be developed based on the best available engineering knowledge of electromechanical component dependencies. An assessment of anticipated module performance and the input from stakeholders will likely force a reevaluation and reapplication of the appropriate functional relationships and scaling analyses. During each iteration, emphasis will be placed on understanding, establishing, and documenting the trade-offs between module function, stream function, and performance variables.

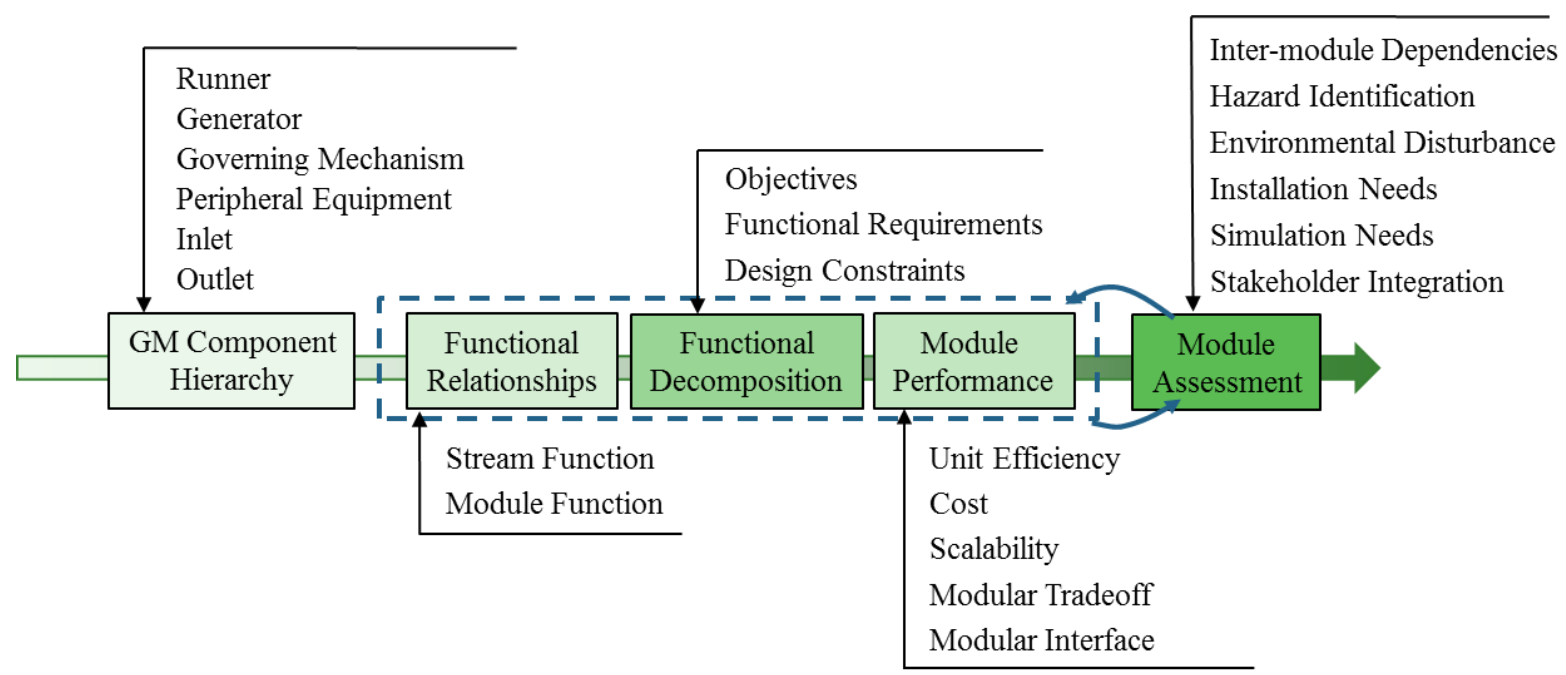

Figure 40. Methodology and inputs for generation module Exemplary Design Envelope Specification. Specific definitions of standardization and modularity are found in Section 5.1.1. This figure is intended to be conceptual and does not display all the particular inputs and subprocesses of the Exemplary Design Envelope Specification. Further detail and definition are found in the Exemplary Design Envelope Specification report (Source: Witt et al. 2017).

\subsubsection{GM Component Hierarchy}

Based on the resource potential outlined in Sections 2.1.1.3 and 4.2.1.1, the GM is expected to operate under low-head conditions, loosely defined as less than $30 \mathrm{ft}$ of gross head. Hydropower development conventions, informed by decades of developer, manufacturer, and engineering experience, would suggest the GM will incorporate an axial-flow type reaction turbine. This is a natural starting point in the EDES process; and initial considerations of component hierarchy, performance, speed, physical dimensions, and orientation will be born out of this assumption.

The hydropower industry outlines its vision of a predesigned, adaptable water-to-wire equipment package that incorporates a turbine-generator and pre-assembled electrical, control, and ancillary systems mounted on single skids (Bishop et al. 2015). With this in mind, the GM must encapsulate all necessary equipment for the conversion of the potential energy of water into electricity. The six fundamental components of the GM include the turbine runner, generator, governing mechanism, peripheral equipment, inlet, and outlet.

Turbine runner. The turbine runner is the prime mover of the GM, responsible for converting the pressure and kinetic energy of water into rotational motion. The turbine, fully submerged in water, is composed of blades that deflect the angular momentum of inflow to produce power. Power output is proportional to the rotational speed and torque created by the turbine runner.

Generator. The generator converts the mechanical power from the turbine runner into electrical power. It consists of two main components: the stator, a stationary component that transfers electrical power to a 
customer, and the rotor, a rotating component coupled to the runner that induces a voltage in the stator windings via magnetic fields produced by electromagnets or permanent magnets.

Governing mechanism. The governing mechanism ensures the generator is spinning at the correct speed by adjusting either the flow of water into the turbine or the load on the generator. The use of recently developed power electronics allows variable-speed systems to be used. The governing mechanism regulates voltage and power output.

Peripheral equipment. The peripheral equipment includes all necessary hydraulic, mechanical, electrical, or pneumatic systems used in the operation or control of the turbine runner, generator, and governing mechanism.

Inlet. The inlet is the mechanism, including gates and valves, that diverts water into the GM. The inlet must filter debris or pass it around the GM in combination with the PM.

Outlet. The outlet is the mechanism that returns water from the GM into the stream.

As it stands, the GM component hierarchy is loosely defined. Further refinements will be necessary to address component interrelationships, function, configurations, and cost, including these:

- Mechanical drive system. The mechanism that couples the generator and turbine runner must be defined. It may be a shaft that enables 1:1 coupling, it may be a rim-mounted generator rotor that also enables a 1:1 coupling, or it may require alternative configurations that require additional equipment.

- Turbine control. The turbine will be designed for optimum operation at a given head and flow. Turbine control at off-design conditions via a combination of single or double regulation and power electronics may be necessary.

- Speed increaser. In many low-head schemes, a speed increaser is necessary to match the low rotational speed of the turbine shaft to the (generally higher) requirements of the generator.

- Powerhouse. In a traditional small hydropower facility design, the powerhouse is responsible for protecting electromechanical equipment and its associated safety devices and controls (ESHA 2004). The goal of SMH is to reduce superstructures and incorporate the bulk of electromechanical equipment in a single pre-assembled package. Within GM design, the need for a reduced powerhouse must be reconciled with the need for exemplary safety characteristics.

\subsubsection{GM Functional Relationships}

A GM design must consider the forces and impacts of a control volume of water as it travels from upstream of the SMH plant into the tailrace, and how those forces and impacts relate to generation. It must also consider the responding forces of the GM components and their transmission into the foundation and appurtenant structures. While fundamental hydraulic engineering relationships are appropriate for exploring the functional relationships that dictate the design and performance of GM components, empirical relationships developed through trial and error of hydraulically tested model prototypes are also necessary, particularly with regard to component dimensions.

For ease of discussion, the functional relationships relevant to GM design are subdivided into two categories: stream function and module function 


\section{Stream (e.g., head, flow, flow duration, energy)}

As a starting point, representative head and flow estimates developed using the resource potential outlined in Section 5.1.2.1 will serve as initial conditions. The net head available generally determines the type of turbine appropriate for a given site, whereas the flow rate and flow duration dictate the capacity and availability of the turbine. From these variables, a range of annual energy production estimates for a given GM can be determined. Considering the environmental compatibility goal of SMH design, the modular nature of a GM, and the constraint of no significant impoundment, new relationships will be needed to characterize the energy potential of modular installations.

\section{Module (e.g., power, size, speed, specific speed, torque, setting, cost, efficiency, cavitation)}

Module functional relationships will provide the geometric limitations of a GM based on the expected head, flow, and power. The size and shape of the turbine will vary with turbine type, as will the weight of the unit, the location and orientation of the generator, the rotational speed of the turbine and generator, and the GM setting with respect to the tailwater elevation. To the extent possible, functional relationships must link component performance characteristics and costs to the resource potential to create a standardized approach to GM design.

Additional relationships to be determined include unit efficiency as a function of the friction and other losses throughout the GM. The operational limits of cavitation must be considered, which will largely be a function of tailwater setting and outlet velocity. Additional restrictions will be imposed that require a fundamental understanding of how resource variability affects performance (e.g., the effect of inflow velocity on inlet configuration).

\subsubsection{GM Functional Decomposition}

With functional relationships defined that link module and stream function, the functional decomposition of a GM exemplary configuration can begin. The goal of functional decomposition is not to develop or outline the shape and form of a specific machine, but to converge on a consensus of what each module should accomplish, outline how a GM must operate, identify and bound the design constraints, and identify which design constraints are most sensitive to GM feasibility. Functional decomposition will be used to rationalize, document, and recommend where and how standardization should take place.

GM functional requirements. The GM functional requirements describe what a module must do to generate hydroelectricity. For example, all GM components must be encapsulated in a single module. A module must exhibit a hydraulically smooth and aesthetically acceptable profile, designed to enable ease and simplicity of manufacturing and installation. The module must scale geometrically in a standard and predictable way, probably a function of head, flow, and power output.

GM design constraints. Parameterization of the GM design constraints serves to establish an upper and lower bound on the functional relationships (resource, component, and performance) within which the GM will be successful. Constraints will be developed with regard to, among other factors,

- cost

- performance

- $\quad$ survivability (e.g., flooding, extreme weather conditions)

- monitoring and self-adjusting capabilities

- environmental disturbance 


\subsubsection{GM Performance}

The performance of GMs must be parameterized to enable an evaluation of environmental, energy, and economic feasibility and acceptability. "Performance" in this sense refers to an array of variables, including unit efficiency curves, cost, scalability, reliability, and interactions with other modules. In theory, new modules should match or exceed the peak efficiencies of existing generation technologies. However, advanced feasibility modeling may indicate that lower peak efficiencies maintained over a wide range of head and flow may be acceptable if a GM exhibits low cost and a resilient design.

Individual module scaling. The individual GM will have a physical footprint that is dependent on functional relationships and the initial configuration of the GM components (i.e., turbine, generator, governing mechanism). Streams with larger discharges may require fewer large modules, whereas lowdischarge streams may be better accommodated with smaller modules. The geometric envelope for an individual module will be limited by economic, operational, and environmental constraints. Based on these design constraints, an upper and lower bound to the GM footprint will be defined.

Multi-module scaling. The flow characteristics of a given resource will dictate the full power potential of the SMH facility. When the flow is sufficiently large that it cannot be captured by an individual module, an array of several modules will be necessary. Additional considerations brought to bear include the shared electrical connections between multiple GMs, the role of the governing mechanism in controlling multiple GMs, the GM-GM modular interface, the instream configuration of GMs with respect to PMs, the flow output of GMs, the resulting impact on downstream habitat, and the multi-modular trade-off of cost and flow.

Modular trade-off. In a typical hydropower feasibility study, the power equipment arrangement, sizing, and selection are carried out through several stages of successive refinements to engineering details, costs, and benefits. The relationships and trade-offs among size, cost, power output, energy yield, and resource potential will be determined early in the design phase to conceptualize and parameterize the configuration of GMs. A single generating unit is often preferred in conventional SHPs because it simplifies design and poses fewer issues with intake placement and water availability (Leyland 2014). The simplest and lowestcost turbine arrangement is a turbine with fixed blades and gates that operates at a fixed speed for a given head, where plant power is adjusted by turning individual units on and off (ASME 1996). This strategy, a modular buildout of installed capacity with multiple smaller units, is being deployed worldwide at structures with existing civil works, although few instances of new development with this approach have been realized (see Section 3.1.1.2). The trade-off of cost versus potential energy production inherent to GM scaling must be understood with a standardized approach in the context of the existing resource potential.

An additional important modular trade-off is the partitioning of flows between GMs and PMs. The PM may span the stream, it may span a portion of the stream, or it may interface with the GM in currently unknown ways. Each of these configurations will have distinct impacts on the surrounding environment. It is known that water passage for numerous ecosystem needs is critical to operation, and that a run-ofriver scheme is the most likely to be developed where project inflows must match outflows. On the other hand, a minimum number of GMs will be required to meet energy generation targets, and these must be sized to handle a certain discharge for a given part of the year (Figure 41). This trade-off will be assessed and quantified early in the design phase to guide initial configurations. 

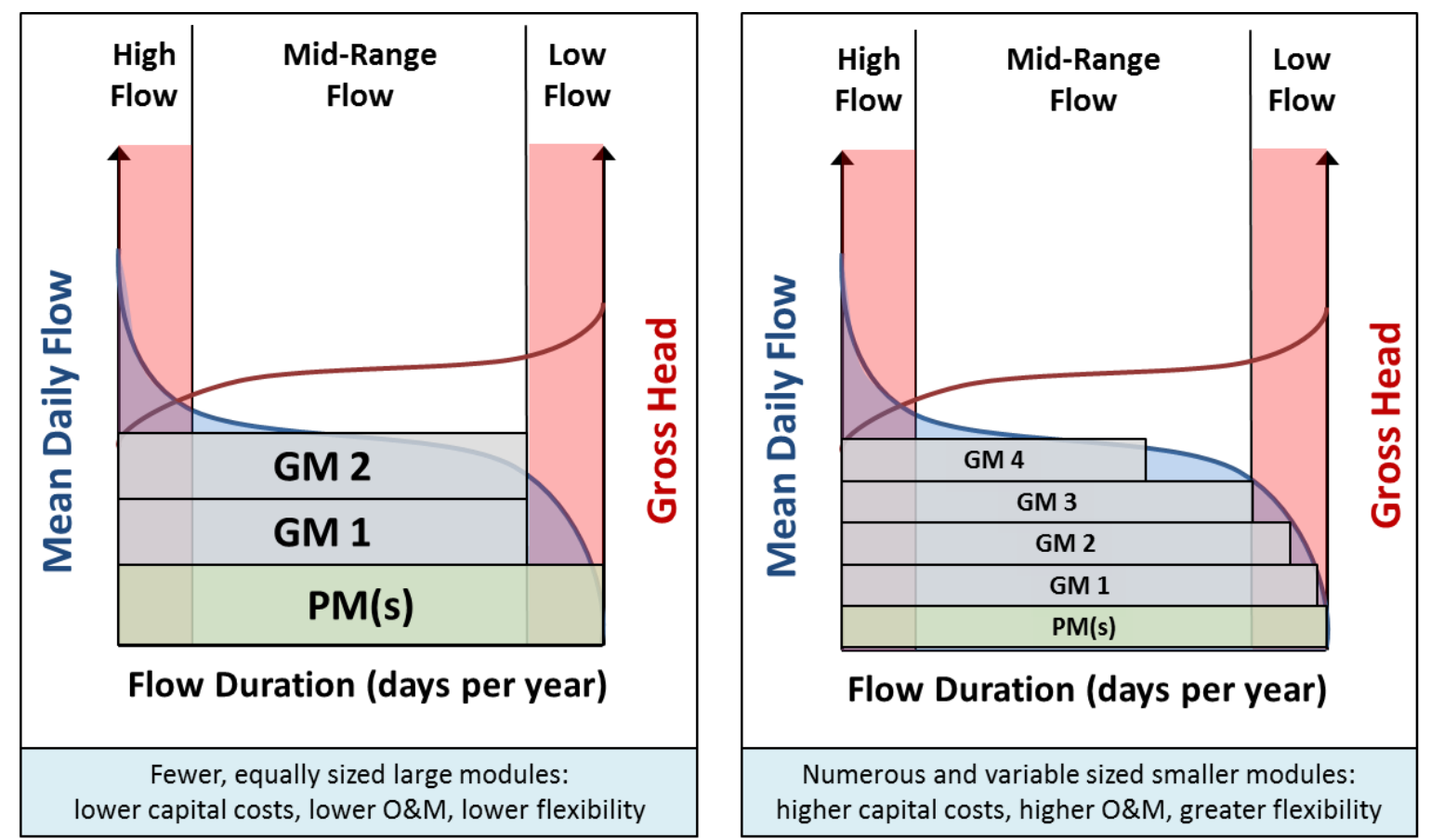

Figure 41. Determining the modular trade-off between passage and generation modules will balance optimization of capital expenditures and projected energy yield against passage needs and impacts. Adapted from Reich 2015

\subsubsection{Module Assessment}

It is expected that a high degree of cost and performance uncertainty will persist throughout the design concept stage. Module assessment represents a critical reevaluation step in the design process. It will be used to iteratively refine the SMH concept by identifying inter-module dependencies, potential hazards, concerns regarding environmental disturbance, and potential module-specific installation needs. Once a preliminary GM concept is developed, an assessment of the exemplary configuration must be carried out to identify design gaps, including the unknown parameters that must be determined through the SMH Simulation and Modeling Capability and Testing and Validation Capability. Feedback and criticism will be solicited from developers, equipment manufacturers, engineering consultants, environmental groups, and modeling experts to iteratively improve the design concept.

\subsubsection{Passage Module Specification}

As envisioned, the PM will interface with the GM to safely and consistently pass water, sediment, debris, aquatic life, and small recreational craft downstream. The PM must provide hydraulic resistance sufficient to direct a portion of streamflow to the GM, although it will be normally submerged and must accommodate fluctuating depth and velocities of stream flows.

The first-order processes and inputs for the PM EDES and decision making environment are depicted in Figure 42. The general methodology will build progressively and iteratively on five key processes: (1) establishment of primary stream linkage relationships; (2) identification of the functional relationships necessary to support stream connectivity and flow passage; (3) functional decomposition, or the process of developing and analyzing module objectives, requirements, and constraints; (4) a discussion of exemplary module performance; and (5) module assessment. This section is intended to provide a brief overview of each process. 


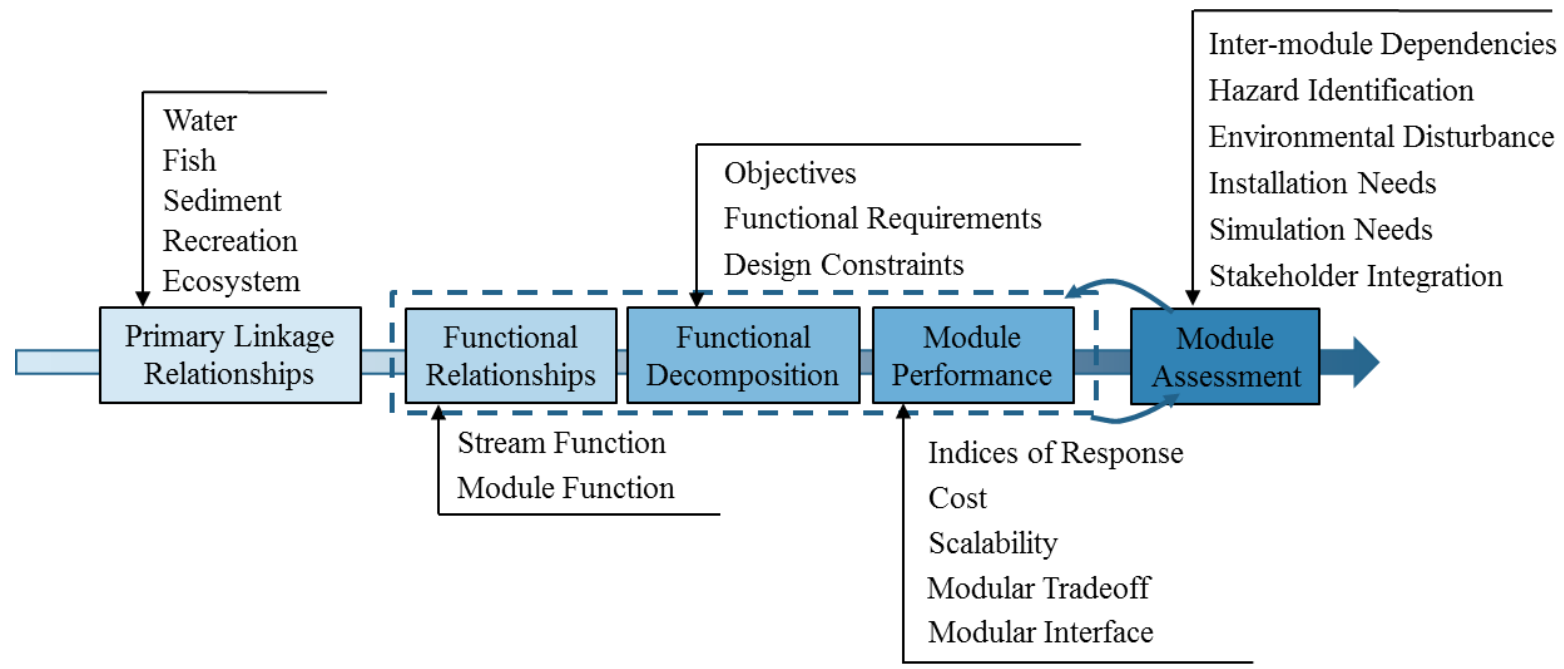

Figure 42. Methodology and inputs for passage module Exemplary Design Envelope Specification. Specific definitions of standardization and modularity are found in Section 5.1.1. This figure is intended to be conceptual and does not display all the particular inputs and subprocesses of the Exemplary Design Envelope Specification. Further detail and definition are found in the Exemplary Design Envelope Specification report (Source: Witt et al. 2017).

The traditional paradigm in small hydropower development is the construction of a dam, which has the potential to disrupt natural flow regimes and limit river connectivity, producing quantifiable impacts on aquatic ecosystems. Passage requirements are often determined on an as-needed basis or after a detailed environmental impact assessment has been carried out. The goal of PM design within the SMH framework is to bring passage requirements to the forefront of the design process by considering the SMH hydropower facilities as an integral part of the watershed in which they are situated. It is expected that by anticipating passage needs, setting quantifiable passage goals in advance, and accommodating them through a dedicated module, acceptance of SMH facilities will be improved; and licensing times, as well as $\mathrm{SMH}$ costs, will be reduced.

\subsubsection{Primary Linkage Relationships}

The need to establish ecological connectivity in river systems with hydropower facilities is a broadly recognized multi-objective problem, although practical mitigation strategies and the methodologies to evaluate their success are the subject of much research and discussion (Bratrich et al. 2004; Poff and Zimmerman 2010; LIHI 2014). PM design and function will be informed by primary ${ }^{41}$ relationships that have been shown to sustain upstream to downstream connectivity in fragmented river systems. These relationships must capture the interplay of the $\mathrm{SMH}$, flow, and watershed characteristics and then be translated into quantifiable technical and objective criteria so that the PM can respond accordingly. Contrary to past functionalities, these relationships will be dynamic to capture shifts in climate as well as abrupt changes in demand, ecosystem properties, and environmental limiting conditions. Examples of a single primary relationship for each category are given in the following paragraphs to guide the reader toward the PM design philosophy. Additional relationships, linkages, effects, and impacts are explored in the EDES report (Witt et al. 2017).

Water. A sustained and consistent flow downstream of a hydropower plant has become a standard and necessary operational practice over the past several decades. The ORNL mitigation database lists a run-

\footnotetext{
${ }^{41}$ Secondary and tertiary linkage relationships are analyzed and discussed in detail in the exemplary design technical document (Witt et al. 2016).
} 
of-river tailrace as the second most commonly required mitigation measure (required for $54 \%$ for projects) for projects with less than $10 \mathrm{MW}$ of installed capacity (Bevelhimer et al. 2015). This requirement states that project operation must ensure that the instantaneous sum of releases from the project equals the instantaneous sum of project inflows. In other words, the PM must ensure that flows are consistently and safely passed downstream when GMs are operating under no-flow and full-flow conditions.

Fish. The upstream and downstream movements of fish may be species-dependent and driven by various ecological causes (i.e., feeding and/or migration). In addition to addressing habitat concerns, the passage of fish around, through, or over a structure by use of a fishway is a common approach to maintain fish connectivity. A successful fishway is often designed with attraction flows, entrance designs, flow velocities, and pressures that are optimized for a given species (OTA 1995). Maintaining fish connectivity at an SMH will be based, as a first step, on the development of primary linkage relationships between fish passage and hydraulic parameters. These are relationships between variables that characterize fish populations - such as fish assemblage, mortality, and species - and hydraulic parameters, such as flow discharge, depth, and turbulence characteristics, which relate to fish passage (Dermisis and Papanicolaou 2009; Thomas et al. 2011; Noonan et al. 2012).

Sediment and debris. Hydropower facilities disrupt the continuity of sediment conveyance downstream, with important consequences in power generation, stream morphology, and fish habitat (Brandt 2000; Grant et al. 2003; Schmidt and Wilcock 2008; Wild et al. 2015). Overall, geomorphic changes after the placement of hydropower facilities result from an imbalance between the transport capacity and the flow competency, which are outcomes of disruptions in the connectivity of sediment and flow, respectively, within the riverine continuum. The EDES for SMH will consider primary linkage relationships that express this imbalance as a function of the changing watershed physical characteristics (e.g., hydrological, topographical, geological/geomorphological). The magnitude of the imbalance, and hence of the geomorphic change, will in turn be quantified by a suite of appropriate indices. For example, changes in transport capacity have been expressed by the ratio between the post-dam and pre-dam river depth, discharge, and riverbed slope. This ratio is an index that represents the percentage of the energy gradient that is needed to transport sediment of a given size, given a sediment supply from upstream. A unity value of this index represents a system at equilibrium, whereas values larger and smaller than unity express aggrading and degrading systems. Therefore, using such an index and knowing the functional relationship between transport capacity and flow, it is possible to quantify morphological change resulting from the placement of SMH facilities.

Additional indices may result from considering additional functional relationships. For instance, in systems that are prone to widening or narrowing, an index quantifying the change in river width would also need to be considered. In systems with prominent vegetation cover along the stream banks, an additional index considering the influence of vegetation could be the ratio of the vegetated river width to the top river width. Along the same lines, primary linkage relationships for sediment passage and indices need be developed to express the sediment deposition upstream of the SMH facilities that results from the decrease in transport capacity upstream of the dam.

Recreation. The instream use of water for recreation is prevalent throughout the United States. Connectivity for recreationists may take on an alternative form from that envisioned for ecological and biological needs. It has been reported that streamflow levels (flow quantity) have a measurable impact on the quality and availability of whitewater boating experiences, stream shoreline aesthetics, fishing opportunities, and the ability of a river to support multiple recreationists without congestion (Wilson and Carpenter 1999). When streamflow is not sufficient, or when a permanent barrier physically deters a recreationist from passing downstream, recreation opportunities are diminished. 
Ecosystem. The flow regime of a river is considered the fundamental variable that shapes the ecological features of a given riverine ecosystem. Attempts have been made to directly quantify aquatic ecosystem response to types of flow regime alterations. In general, consistent alterations of flow magnitude, frequency, and timing are correlated with a negative response in macroinvertebrate, fish, and riparian abundance and demographic parameters (Poff and Zimmerman 2010). In general, the functional relationships for the ecosystem involve relationships between fish habitat assessment indices and hydraulic and sediment indices, such as flow velocity and depth and suspended sediment concentration, respectively.

\section{Summary}

The primary linkage relationships for passage and a suite of necessary indices are identified in the EDES technical report (Witt et al. 2017). It will be critical to define limits in the values of the developed indices, so that changes in river morphology, fish habitat, generation, and water quality due to the placement of SMH structures remain within acceptable limits. These index value limits will subsequently be the determining factor for performance assessment of passage designs.

\subsubsection{PM Functional Relationships}

The goal of establishing PM functional relationships is to outline how a PM must operate in conjunction with a GM. To be successful, the PM must address connectivity barriers and strive to maintain primary linkage relationships while supporting the primary purpose of the facility, hydropower generation. As outlined earlier, "connectivity" is a broad term that encompasses a multitude of abiotic and biotic considerations. A single PM cannot provide the necessary functionality to address all connectivity issues. What can be established in the concept design stage are the relationships that describe natural stream functions and the explicit module functions that are necessary for a variety of passage needs.

Module function. The passage of flows around, over, and beside the GM will be a common characteristic of all PMs. The magnitude of flow to be passed by each PM must be linked to the specific objective of the module. For example, a recreation PM intended to pass kayaks must identify the depth and velocity of flow required to support the kayak and relate those values to the geometry of the module.

To sustain passage of flows, the resultant forces, stresses, strains, and vertical and horizontal loads per unit of depth associated with the potential combination of head and flow at a given resource must be determined along the entire vertical profile of a given stream-reach cross section. The design must consider the conditions that could lead to translation, sliding, or material failure of the module. Although the structural resistance and integrity of a static module must be understood, the assumption that the PM will be stationary is not a design restriction. The PM or its constituent components may require a certain degree of rotation to accommodate various magnitudes of flow passage. Of particular importance in this instance will be the behavior of critical points under stress, most notably the modular interface and the connections between mobile and stationary components.

Stream function. Flow passage is the primary function of the PM. The PM must exhibit the flexibility to pass a bounded range of discharge, from an environmental minimum flow to the full discharge of the river under normal and flood conditions. It is assumed the passage requirements necessary to address connectivity barriers will fall somewhere within this envelope; thus the PM must retain the ability to control the quantity, velocity, and frequency of flow releases. The precise vertical location and configuration of the flow release mechanism will require research and discussion, with consideration of the pressures, velocities, and quantity needs to support biological, sediment, and recreation passage. 
Flow passage must occur instream, and it is assumed the PM will have a certain depth of submergence at its crest that will be a function of fish, recreation, and water passage requirements. These requirements will provide a suite of constraints, which will be translated to well-defined limits in the values of indices. These limits will also need to account for the possibility that separate PMs may be necessary to accommodate different passage regimes, e.g., high flow variability for habitat needs and high flow magnitude for recreational passage. It is also possible that a dual-use PM that combines functions may satisfy the passage demands of multiple stakeholders. For example, a novel facility in the UK has gained acclaim by combining a fish pass with a canoe chute. ${ }^{42}$ Such additional constraints will be thoroughly investigated and incorporated in the limits for the indices describing the physical characteristics of the watersheds where SMH facilities will be placed.

\subsubsection{PM Functional Decomposition}

Each PM must be designed with a primary objective in mind. These objectives - to pass fish, to safely pass recreational craft across a facility, or to pass non-generating flows, for example - serve as the basis for identifying basic functional requirements and design constraints.

PM functional requirements. The PM functional requirements describe what each PM must do to achieve the primary objective. For example, an upstream fish PM must attract fish to the module inlet, allow fish to cross the facility, and allow fish to exit safely upstream. Each basic functional requirement can be further broken down into specific functionalities. To attract fish to the module inlet, a PM must maintain favorable flow conditions and patterns, guide fish to the inlet through behavioral or mechanical techniques, deter fish from entering the GM outlet, and accomplish predetermined fish attraction rates. These basic requirements can be met with a variety of specific designs; the burden of specific design decisions is left to the new technology innovator.

PM design constraints. Parameterization of the PM design constraints serves to establish an upper and lower bound on the functional relationships that describe how a PM maintains stream connectivity. Constraints will be developed with regard to, among other factors,

- cost

- performance

- $\quad$ survivability (e.g., flooding, extreme weather conditions)

- monitoring and self-adjusting capabilities

- environmental disturbance

- climate non-stationarity

- adjustable minimum flow requirements

- wet and dry elements downstream of the dam

- degree of fragmentation in connectivity

\subsubsection{PM Performance}

The performance of PMs must be parameterized to enable an evaluation of environmental, energy, and economic feasibility and acceptability. Performance in this sense is specific to PM type. For example, measures of fish passage performance may include the proportion of fish passing the module, fish survival rates, fish injury rates, proportion of fish entering the fish passage entrance, flow depth and velocity, and air bubble concentrations. By establishing a set of quantifiable indices for each performance measure, a standard evaluation procedure can be established for each module type.

${ }^{42}$ http://www.canoe-england.org.uk/facilities/weirs-fish-passes-and-canoe-chutes/ 
Individual module scalability. The individual PM or PMs must scale to meet a variety of passage requirements. It is anticipated that universal scaling of a single module will be appropriate for certain types of passage. The size of a module designed for recreation, for example, will be limited by the types of craft that are likely to encounter the facility. It may make economic sense to limit the span of this module to a pre-bounded cross-sectional area and to couple it to additional PMs that can pass smaller flows. Where possible, the scaling of a PM should be linked to flow quantities.

Multi-module scalability. When the flow is sufficiently large that it cannot be passed by an individual module, or if different locations require disparate passage arrangements, an array of several PMs will be necessary. Additional considerations brought to bear include the PM-PM interface; the instream configuration of PMs; the location of flow output from PMs with respect to GM(s) and the resultant impact on downstream habitat; and the multi-modular trade-off of cost, complexity, and targeted flow passage.

Modular trade-off. Understanding the modular trade-offs associated with flow through the PM will be fundamental to the SMH design process. PM trade-offs include the following, among others:

- Flow needs for passage and generation: Every cubic foot of water routed through the PM results in a reduction of generating (revenue) potential. If the PM varies the frequency or magnitude of releases, the effective response on GM operation needs to be understood and the impacts minimized.

- Flow needs for passage and minimization of environmental disturbance: The PM will need to pass flows while limiting scour and flow disruptions for downstream habitat.

- Flow needs and cost: It is anticipated that increased PM complexity may correlate with rising costs. It is also anticipated that increased PM complexity will correlate with decreased environmental disturbance and increased acceptance. These trade-offs must be optimized.

- Flow needs for passage and uncertainty in results (ecologic models): The models predicting habitat response to flow variations are generally associated with large uncertainties. There is no guarantee that strategies for PM operation or design will produce the intended results.

Modular interface. The modular interface will be the mechanism connecting the PM to the GM, the FM, and other PMs. The PM interface will be unique in that mobility is expected, and stiffness and strength are required when the PM is either stationary or in motion. A sealing mechanism may be required to isolate moving components from water damage. The PM will likely have several options for a modular interface, depending on the adjacent module.

\subsubsection{Module Assessment}

It is expected that a high degree of cost and performance uncertainty will persist throughout the design concept stage. Module assessment represents a critical reevaluation step in the design process. It will be used to iteratively refine the SMH concept by identifying inter-module dependencies, potential hazards, concerns regarding environmental disturbance, and potential module-specific installation needs. Once a preliminary PM concept is developed, an assessment of the exemplary configuration must be carried out to identify design gaps, including the unknown parameters that must be determined through the SMH Simulation and Modeling Capability and Testing and Validation Capability. Feedback and criticism will be solicited from developers, equipment manufacturers, engineering consultants, environmental groups, and modeling experts to iteratively improve the design concept. 


\subsubsection{Foundation Module Specification}

As envisioned, the FM will support the embedment, anchorage, or mooring of the GM and PM within streams. The FM must consider design challenges such as local intense scour, minimization of benthic habitat disturbance, structural support of GM and FM loads, and survival and stability during flood events.

The first-order processes and input for the FM EDES and decision making environment are depicted in Figure 43. The general methodology will build progressively and iteratively on five key processes: (1) establishment of primary foundation considerations; (2) identification of the functional relationships that link module and stream functions; (3) functional decomposition, or the process of developing and analyzing module objectives, requirements, and constraints; (4) a discussion of exemplary module performance; and (5) module assessment. This section is intended to provide a brief overview of each process.

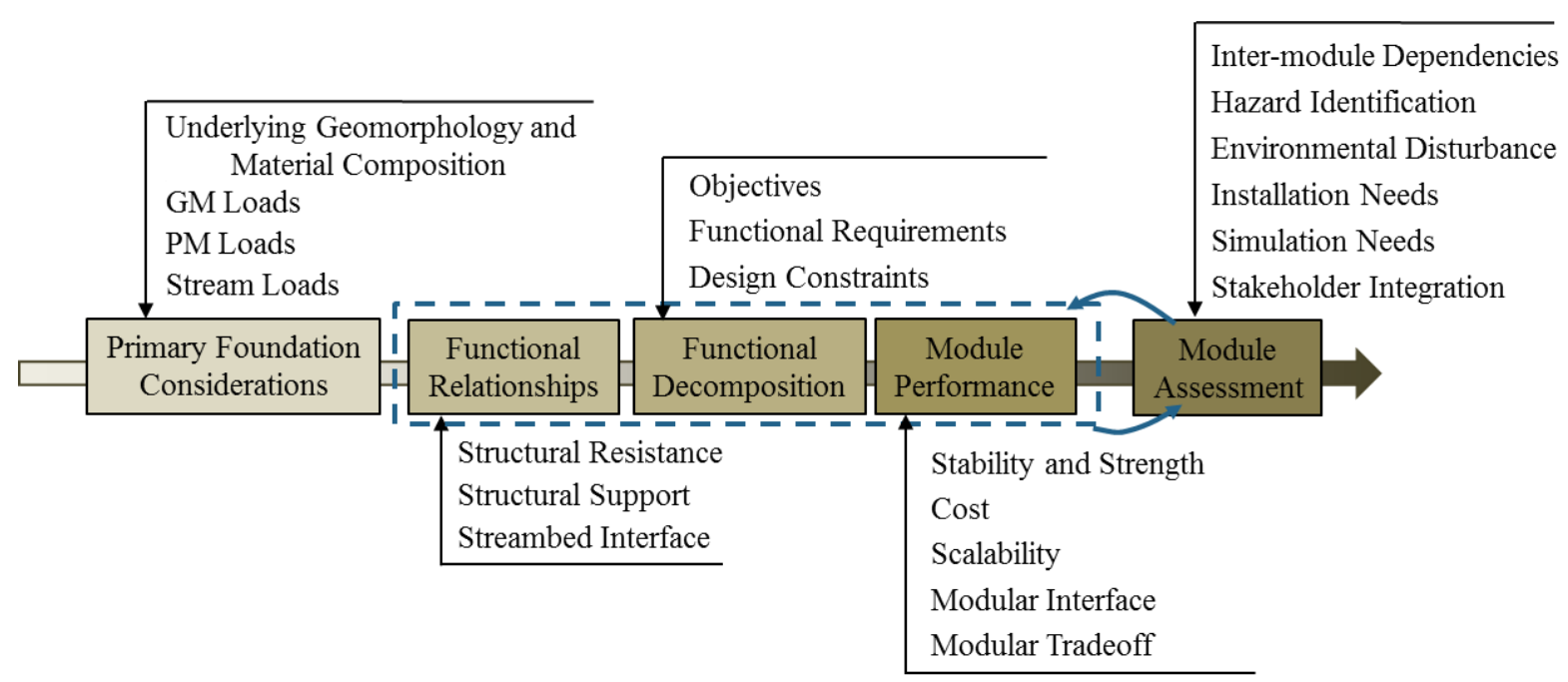

Figure 43. Methodology and inputs for foundation module Exemplary Design Envelope Specification. Specific definitions of "standardization" and "modularity" are found in Section 5.1.1. This figure is intended to be conceptual and does not display all the particular inputs and subprocesses of the Exemplary Design Envelope Specification. Further detail and definition can be found in the Exemplary Design Envelope Specification report (Source: Witt et al. 2017).

The design of the FM will be informed by the functionality and geometric attributes of the GM and PM. Although the process described above provides a framework for design thinking, the specific ideas in this section are subject to further refinement as the SMH concept evolves.

\subsubsection{Primary Foundation Considerations}

The primary function of the FM will be to safely and reliably support the operation of the FM and PM while minimizing environmental disturbance. The following primary considerations must be established early in the design process.

Underlying geomorphology and material composition. Traditional hydropower project foundations are designed for site-specific geology, bed material, topography, and bathymetry, with consideration of their evolution throughout the life of the project. These features must be identified and classified for the most common deployment scenarios, with emphasis placed on both streambeds and stream banks. 
The selection of foundation construction materials is also site- and project-specific and is largely a function of the proximity to local resources, the size and complexity of electromachinery, and the size and complexity of civil works. Following the standardization of the GM and PM, the latter two considerations can be quantified. The goal of the FM EDES is to reach a degree of standardization such that siteindependent material selection can be achieved. Fundamental input to materials selection may include the permeability of the material and its stability under dynamic loading.

GM loads. The envelope of loads (static and dynamic) resulting from normal operation of the GM must be quantified.

PM loads. The envelope of loads (static and dynamic) resulting from normal operation of the PM must be quantified. It is assumed that overtopping of the PM may be routine, and thus structural integrity within a range of flow exceedance probabilities is paramount.

Stream loads. The envelope of loads (static and dynamic) resulting from average flow and from changes in flow magnitude, frequency, and duration must be quantified. Similarly, the subsequent changes in head and the imposed loads they create must be quantified. Projected sediment accumulations in the reservoir over the dam life duration that increase the load on the structure and the FM should be identified.

\subsubsection{FM Functional Relationships}

Estimation of the required FM structural resistance, structural support, and adaptability of the streambed interface must be linked, via empirical or fundamental relationships, to the resource characteristics and the resulting forces from generation and PM operation.

Structural resistance and support. Structural resistance and support are largely tied to dynamic loading, or the forces imparted upon the FM by the stream, by the GM while generating, by the PM if and when the module is mobile, and the static loads of the individual modules. Functional relationships must be identified that link the loads applied to the FM to deformation, displacement, vibration, compression, and material failure; and these variables must be minimized. Because alternative materials may be a consideration in GM design, the trade-off between material permeability and structural integrity must be well understood.

Streambed interface. Functional relationships for the streambed interface must include depth of anchorage or embedment based on the underlying geomorphology or material composition, minimization of seepage through the foundation, and minimization of scour and benthic disturbance. Redirection and constriction of the flow by the foundation structures may lead to scouring, which could compromise FM stability. Scour mitigation countermeasures and a full understanding of the anchorage depth of placement will be necessary.

\subsubsection{FM Functional Decomposition}

The primary technical objective of the FM is to provide stability and support for SMH infrastructure (e.g., PMs and GMs) by anchoring the FM into the streambed and banks. To accommodate the variety of potential sites, subsurfaces, bathymetry, and stream geometry to be encountered, functional decomposition will focus only on the critical requirements and constraints that must be achieved or met by exemplary FM designs.

FM functional requirements. The primary FM functional requirements are to provide structural resistance against imposed loads, ensure the stability of the SMH facility, and minimize the mechanical impacts of moving water and sediment on the streambed. A good FM design will ensure these 
requirements are met by minimizing the possibility of failure from overturning, uplift, sliding, and tilting that might occur if the forces imposed upon the foundation exceed the module strength or the bearing capacity of the underlying subsurface.

FM design constraints. Initial research will seek to identify the concept-stage constraints that will most likely be encountered by an FM. The FM may have separate and distinct design constraints on the upper portion of the module at the modular interface, and at the lower portion of the module at the streambed interface, with a common central supporting mechanism. The types of underlying conditions will limit the anchorage mechanism; thus, a full parameterization of potential conditions, treatments, and solutions must be explored.

\subsubsection{Module Performance}

The performance measures of FMs must be parameterized to enable an evaluation of environmental, structural, and economic feasibility and acceptability. Structural feasibility in this sense refers to how well an FM provides structural resistance and stability against imposed static and dynamic loads in a safe and reliable manner. The lack of environmentally compatible, modular-type foundation concepts for small hydropower means this category retains a large degree of uncertainty and will require a significant research effort to fill knowledge gaps.

Modular interface. The FM interface will be the mechanism connecting the FM to the GM, the PMs, and the FMs between them. It must have a guiding type of mechanism so that the GM and PM can be installed with relative ease. The FM will likely have several options for a modular interface, depending on the adjacent module.

Modular trade-offs. Important modular trade-offs associated with FM function and design include the following:

- Excavation and stability: The method of anchoring the GM and PM to the streambed must provide sufficient stability. Traditionally, this is achieved through excavation and subsurface reinforcement, which carries significant cost.

- Stability and cost: Minimization of civil works is a goal of SMH, although a reduction in materials may trade off stability and support, while alternative materials with the appropriate strength characteristics may be too expensive.

- Standardization and site-specific needs: Foundation design and installation require the expertise of engineers with knowledge of techniques appropriate for subsurface exploration, sampling, and characterization. The ability to reduce this cost and need is unknown.

\subsubsection{Module Assessment}

It is expected that a high degree of cost and performance uncertainty will persist throughout the design concept stage. Module assessment represents a critical reevaluation step in the design process. It will be used to iteratively refine the SMH concept by identifying inter-module dependencies, potential hazards, concerns regarding environmental disturbance, and potential module-specific installation needs. Once a preliminary FM concept is developed, an assessment of the exemplary configuration must be carried out to identify design gaps, including the unknown parameters that must be determined through the SMH Simulation and Modeling Capability. Feedback and criticism will be solicited from developers, equipment manufacturers, engineering consultants, environmental groups, and modeling experts to iteratively improve the design concept. 


\subsubsection{Interconnection Module Specification}

As envisioned, the interconnection module will encapsulate the switchgears, transformers, cabling, monitoring and control equipment, and protection equipment necessary to interface with the GM or GMs and provide electricity to a customer. The interconnection module must provide a standard electrical arrangement with equipment voltage and current ratings that are appropriate for the requirements of the given customer power connection (i.e., transmission, distribution, or on-site use). Full development of the interconnection module is slated for Phase 2 of the MYRP. The initial research to be carried out includes the following.

\subsubsection{Identify Electrical Interconnection Equipment and Linkages}

A single line diagram representing the electrical distribution system is key to identifying the simplest and lowest-cost arrangement (Leyland 2014). This must be created following initial development of the GM, with a process as follows:

- Determine the arrangement and electrical connections between the generators, switchgear, and transformer.

- Standardize the equipment selection process based on GM output.

- Determine the electrical control philosophy (e.g., level of redundancy, remote vs. attended, communication medium).

- Prepare a diagram of the main control system components, linkages, and equipment.

- Standardize control system components based on GM output.

- Determine the protection facilities, equipment, and relays needed.

\subsubsection{Identify Monitoring and Control Equipment and Linkages}

The monitoring equipment will largely depend on whether the SMH will be attended, and to what extent the system should be automated. Some monitoring and automation equipment and control packages are already assembled and configured as submodules. According to ESHA (2004), "this modular system approach is well suited to the widely varying requirements encountered in hydropower control, and permits both hardware and software to be standardized. Cost reduction can be realized through the use of a standard system and modular software allows for easy maintenance" (ESHA 2004). To the extent possible, this configuration should be emulated:

- An analogue-to-digital conversion module for monitoring relevant operational data (e.g., headwater and tailwater elevation, gate position, power output)

- A digital-to-analogue converter module for controlling hydraulic valves and gates, governing mechanisms, pneumatic systems, chart recorders, and so on

- A counter module for counting pulses in $\mathrm{kWh}$, rain gauges, flow, and so on

- A telemetry module communicating system operational data and status to an off-site location

\subsubsection{Installation Module Specification}

As envisioned, the installation module will enable consistent, reliable, and cost-effective installation of SMH modules. Full development of the installation module would be premature without well-defined concepts for all other SMH modules. Therefore, much of the installation module development will occur during Phase 2 of the MYRP. The initial research to be carried out in Phase 1 includes the following. 


\subsubsection{Identify Installation Needs of the GM, FM, PM, and Interconnection Module}

Each individual SMH module will have module-specific installation needs that will be identified in the module assessment design process. Following completion of the EDES, an installation matrix outlining the needs, constraints, and assumptions for each module will be developed. Redundancies in installation needs will be combined for cost reduction opportunities. A major assumption of this work is that preassembly of most modules will occur off-site. The installation module must include a mechanism to assemble all SMH modules, as well as install them in the stream.

\subsubsection{Identify Potential Installation Methods}

A major goal of the SMH EDES is to reduce installation and construction times. Methods that enable this goal need to be identified and scoped for cost and for expected reductions in installation times. An additional and significant consideration for cost reduction and improved acceptance is the minimization of construction impacts on project lands, riverbank vegetation, aquatic species, and flow regimes.

\subsection{SMH SITE CLASSIFICATION SCHEME}

Site Classification, a key standardizing concept and component of SMH research, will address the perception that hydropower development is predominantly site-specific by classifying development entities (e.g., sites, stream reaches, or watersheds) into groups with similar module needs (e.g., fish passage or sediment transport) and functionalities. For example, sites or river reaches that have similar stream gradients, hydrology, spawning habitats, and migratory fish species would be expected to have similar fish passage needs and design requirements that are defined by the group characteristics.

Site Classification will leverage recent research into ecoregions, stream classification, and prediction of required mitigation to maximize the efficiencies that can result from systematically applying knowledge and rubrics for how environmental and ecological systems respond to disturbances. It is impossible to eliminate all site specificity from hydropower development, but future development efforts can include the judicious application of validated site classification principles to select technology modules most appropriate for a site class, providing greater transparency, clarity, and predictability of outcomes for stakeholders.

The specific objective of this concept is to develop a framework for classifying potential SMH sites in terms useful for informing SMH consideration, module need, and module design requirements using existing and new classification schemes.

Site Classification will include information on and incorporate issues related to considerations such as:

- $\quad$ presence of migratory fish species

- environmental flow needs

- existing water users in the basin

- sediment transport dynamics

- existing water quality issues

- potential and existing recreational services provided by the river

\subsubsection{Analytical Methodology}

Site Classification will incorporate multivariate statistical methods such as decision tree analysis and logistic regression to classify sites (or stream reaches) into groups of similar sites based on a simultaneous consideration of dozens of attributes of those sites. Site Classification will be conducted for each of the 
design modules previously identified (e.g., generation, fish passage, boat passage) to help determine which modules are needed by site classes and what specific design requirements should be considered.

In addition to using an existing database that provides extensive coverage of a variety of environmental attributes (National Hydropower Asset Assessment Program), this analysis will incorporate existing classification schemes, such as a hydrologic classification of streams (McManamay et al. 2014) and geomorphic stream classification (Rosgen 1994). Understanding hydrologic responses to instream disturbances will be a critical design constraint for SMH deployment to minimize environmental disruptions. However, the new site potential spans a wealth of streams with various streamflows and hydrologic character driven by regional differences in watershed attributes, climates, and landscapes. The geospatial distribution of known environmental attributes of NSD resources will serve as useful input in the design phase. For example, the distribution of certain hydrologic classes across the United States (McManamay et al. 2014) identifies groups of streams with similar hydrologic properties that may respond in predictively comparable ways to hydro development (Figure 44). Certain classifications may exhibit ecological patterns that span multiple potential hydropower sites, and a common PM would be of benefit. Similarly, certain regions may share similar watershed characteristics that can be used to identify potential sediment transport inputs and sediment passage needs. Table 5 shows examples of the types of information that can be used in site classification for determining whether a particular module is needed and if so, what types of design features might be required.

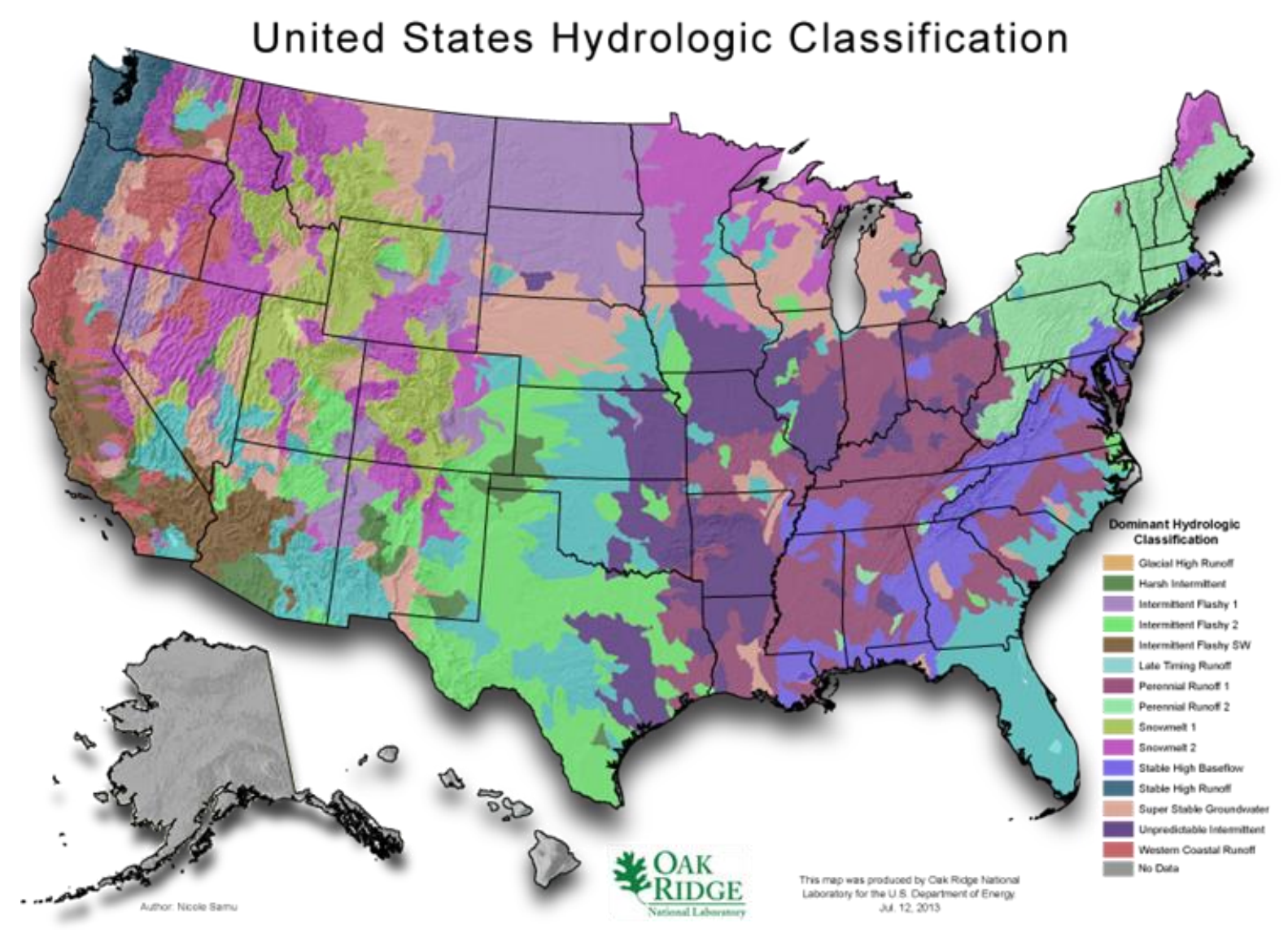

Figure 44. US map of hydrologic classes. (McManamay et al. 2014) 
Table 5. Types of information (indicated by X's) that can be used in site classification to inform module need and design

\begin{tabular}{|c|c|c|}
\hline Classification variable & Module need & $\begin{array}{c}\text { Design } \\
\text { requirements }\end{array}$ \\
\hline \multicolumn{3}{|c|}{ Downstream Fish Passage } \\
\hline Anadromous/catadromous migratory species present & $\mathrm{X}$ & $\mathrm{X}$ \\
\hline $\begin{array}{l}\text { - Timing of migrations/movements } \\
\text { - Size/life stage of migrants }\end{array}$ & $X$ & $X$ \\
\hline Resident migratory species present & $X$ & $\mathrm{X}$ \\
\hline $\begin{array}{l}\text { - Timing of migrations/movements } \\
\text { - Size/life stage of migrants }\end{array}$ & $\mathrm{X}$ & $\mathrm{X}$ \\
\hline Stream gradient & & $\mathrm{X}$ \\
\hline Flow metrics & & $\mathrm{X}$ \\
\hline \multicolumn{3}{|c|}{ Upstream Fish Passage } \\
\hline Migratory species presence & $\mathrm{X}$ & \\
\hline - Spatial and temporal & $\mathrm{X}$ & \\
\hline Resident species passage needs & $\mathrm{X}$ & \\
\hline - Spatial and temporal & $\mathrm{X}$ & \\
\hline Stream gradient & & $\mathrm{X}$ \\
\hline $\begin{array}{l}\text { Species' swimming abilities } \\
\text { - Prolonged velocity and duration } \\
\text { - Burst velocity and duration }\end{array}$ & & $\mathrm{X}$ \\
\hline Species’ jumping abilities & & $\mathrm{X}$ \\
\hline Flow metrics & & $\mathrm{X}$ \\
\hline \multicolumn{3}{|c|}{ Sediment Transport } \\
\hline Bedload characterization & $\mathrm{X}$ & \\
\hline Bedload movement & $\mathrm{X}$ & \\
\hline Stream gradient & & $\mathrm{X}$ \\
\hline Watershed contribution to sediment load & & $\mathrm{X}$ \\
\hline \multicolumn{3}{|l|}{$\begin{array}{l}\text { - Percent forested } \\
\text { - Percent agriculture (row crops) }\end{array}$} \\
\hline Flow & $\mathrm{X}$ & \\
\hline \multicolumn{3}{|l|}{$\begin{array}{l}\text { - Mean annual } \\
\text { - Flood frequency }\end{array}$} \\
\hline \multicolumn{3}{|c|}{ Recreational Boating } \\
\hline Existing use & $\mathrm{X}$ & \\
\hline - Public access / launches & $\mathrm{X}$ & \\
\hline Local recreational boating vendors & $\mathrm{X}$ & \\
\hline $\begin{array}{l}\text { Flow metrics } \\
\qquad \text { Seasonality }\end{array}$ & $\mathrm{X}$ & $\mathrm{X}$ \\
\hline Gradient & & $\mathrm{X}$ \\
\hline \multicolumn{3}{|c|}{ Water Quality } \\
\hline $\begin{array}{l}\text { Existing water quality issues } \\
\text { - 303d listings }\end{array}$ & $\mathrm{X}$ & \\
\hline \multicolumn{3}{|l|}{ Water quality metrics } \\
\hline - Nitrogen & $\mathrm{X}$ & $\mathrm{X}$ \\
\hline - Phosphorous & $\mathrm{X}$ & $X$ \\
\hline - Dissolved oxygen & $X$ & $X$ \\
\hline - Temperature & $\mathrm{X}$ & $\mathrm{X}$ \\
\hline - Turbidity & $\mathrm{X}$ & $\mathrm{X}$ \\
\hline
\end{tabular}


Table 5. (continued)

\begin{tabular}{lcc}
\hline \multicolumn{1}{c}{ Classification variable } & Module need & $\begin{array}{c}\text { Design } \\
\text { requirements }\end{array}$ \\
\hline $\begin{array}{l}\text { Watershed characteristics } \\
\text { - Percent agriculture (row crops) }\end{array}$ & $\mathrm{X}$ & $\mathrm{X}$ \\
& Environmental Flow & \\
Historic flow metrics & & \\
- Daily & $\mathrm{X}$ \\
- Monthly & $\mathrm{X}$ \\
- Annual & $\mathrm{X}$ & \\
Environmental flow needs & & \\
- Fish spawning & $\mathrm{X}$ & \\
- Fish migration & $\mathrm{X}$ & $\mathrm{X}$ \\
- Invertebrates & $\mathrm{X}$ & $\mathrm{X}$ \\
- Riparian plants & $\mathrm{X}$ & $\mathrm{X}$ \\
\hline
\end{tabular}

\subsubsection{Application to Module Selection and Design}

Results of the site classification will be used to inform module selection and exemplary design in a variety of ways. The characteristics that define various classes will provide an envelope or range of module design requirements. The number of sites or amount of stream reaches represented in various classes will be used to help identify which modules and design features should receive priority in design consideration. Site classification will also inform the testing and simulation pillars.

\subsection{SMH SIMULATION AND MODELING CAPABILITY}

The SMH Simulation and Modeling Capability will provide a framework that outlines and addresses the use of analytical and computational tools, approaches, and models for simulating the physical, operational, feasibility, and cost aspects of SMH. The tools will be used to assess SMH design and operational performance, reliability, manufacturability, and cost estimation for the system as a whole and on an individual module basis. The simulation and modeling capabilities will include strategies and methods to assess and prioritize the following:

- behaviors of fluid flow

- characteristics of materials strength and structural analysis subject to a variety of loading conditions

- hydroelastic response of the turbine

- hydroelectric performance and operation

- electrical generation and performance

- monitoring and control systems

- construction

- manufacturing

- installation

- cost estimation and systematic cost comparison and trending based on design, operation, type of manufacturing, construction, O\&M, and installation

- expert conceptual design flow (manufacturing for modularity) and planning (construction and installation) strategies

- feasibility of implementation and operation based on cost of design, manufacturing, construction and installation, and O\&M, as well as return on investment. 
The aim of the simulation component of this research is to identify the capabilities of simulation tools and modeling approaches; it is also to facilitate and advance the understanding of unknown and less understood physical relationships and phenomena that may be associated with implementation of a stateof-the art project like SMH. Simulations and analyses of the behaviors of physical processes and costs affecting SMH design and operation will be managed by ORNL, which will contract and work closely with experts in the respective fields to establish the basis, concept, and proofing of the simulation tasks.

The effort outlined herein will establish a framework that contains a prescribed holistic modeling approach to provide guidance for assessing the feasibility and applicability of a proposed small hydro design, installation, and operation with respect to defined performance criteria. Stakeholders (e.g., developers, designers, environmentalists, and biologists) can use the framework to facilitate advancement of the SMH concept toward structured analysis and preliminary design strategies to realize the TRL transition from design to testing and implementation.

The Simulation and Modeling Capability will assist SMH technology development through the aspects of design and testing. General design constraints and boundaries defined throughout the EDES phase will serve as a basis for using the Simulation and Modeling Capability to

- $\quad$ simulate specific engineering aspects of SMH modules, such as equipment and design performance (users: engineers, scientific professionals, designers)

- $\quad$ simulate the general engineering and operational aspects of the SMH system, such as systematic and holistic operation and performance (users: engineers, scientific professionals, designers, planners, construction and logistics installation professionals)

- conduct cost modeling and assess trade-off/benefit aspects of designs, configuration, and operation (users: engineers, scientific professionals, designers, planners, and manufacturers)

- conduct feasibility, logistical, and suitability assessments of various design, implementation, installation, and construction issues (users: all)

\subsubsection{Criteria for Simulation and Modeling Efficacy}

The simulation and modeling tools and approaches used to investigate SMH involve multiple aspects of physics, systems, and cost modeling. The analysis tools and approaches may include computational, analytical, empirical, conceptual, statistical, and physical modeling. The interconnectivity and coupling of processes within the system may require coupling models together so that certain models' output is used to inform other models' input. Therefore, it is important to correctly identify such processes and gain an understanding of the mechanisms and feedback processes involved so that the appropriate modeling and simulation approach is used.

In general, the SMH system consists of five integrated modules that collectively represent the facility or system of modules. Each of the five modules contains component-level design and operational physics specific to its function. Table 6 contains a preliminary list of SMH-related, high-level operational physics requiring simulation and modeling efforts. 
Table 6. Summary of high-level operational physics requiring simulation and modeling

\begin{tabular}{|l|l|l|}
\hline Module & Component & Operational physics \\
\hline Generation module & $\begin{array}{l}\text { Turbo and electromagnetic } \\
\text { machinery }\end{array}$ & $\begin{array}{l}\bullet \text { Water flow } \\
\bullet \text { Electrical production }\end{array}$ \\
\hline Passage module & Hydraulic structure & $\begin{array}{l}\bullet \text { Water flow } \\
\bullet \text { Environmental/recreation }\end{array}$ \\
\hline Foundation module & $\begin{array}{l}\text { Framework/foundation/system } \\
\text { structure }\end{array}$ & $\begin{array}{l}\bullet \text { Structural } \\
\bullet \text { Stability }\end{array}$ \\
\hline Interconnection module & $\begin{array}{l}\text { Generation/power system \& } \\
\text { logistics connectivity }\end{array}$ & $\begin{array}{l}\bullet \text { Power and electrical } \\
\text { connections }\end{array}$ \\
\hline Installation module & System and logistics installation & $\begin{array}{l}\bullet \text { Installation priorities, } \\
\text { conditions, and techniques }\end{array}$ \\
\hline
\end{tabular}

Modeling of the physics at the component level of the individual module is integral to system-level simulation, as the behaviors and conditions at the module level inform the modeling of the SMH system as a whole. Understanding the feasibilities and limitations associated with the modeling capabilities at each level is necessary for establishing expectations of the simulation's overall effectiveness.

The effectiveness of the simulation also depends on its capability to provide meaningful, useful results with respect to prescribed issues that must be addressed. The simulation of the system must address the following issues:

- Power production (various flow and situational conditions)

- Turbine/generator efficiency (various flow and situational conditions)

- Flow/power rating performance

- Site flow conditions and behavior (e.g., erosion/undercutting of foundation structures, structure loading conditions, recreational passage, safety)

- Site environmental conditions (e.g., fish passage, sediment loading and deposition, habitat conditions, water quality assessments)

- Overall system health (e.g., integrity of system structure and interconnection, systems working together)

- Installation logistics (e.g., flow conditions and loading during installation phases, priority and critical path deployment)

\subsubsection{Modeling Considerations}

SMH simulation will consist of several component-level modeling efforts, each of which should address various aspects of each of the modules. Prospective modeling issues for each of the modules are defined herein and represent the physical aspects of the module that might be addressed.

- GM: A significant element is the turbine machinery itself and its interaction with the moving water and the FM upon which it is installed. Modeling considerations to be assessed for the GM may include proper structural design of the turbomachinery with respect to material type, blade quantities and configurations, and modal analysis. They should also include overall attention to efficient operation with respect to the coupled nature of the hydraulic and electrical aspects. Design targets also include establishing the most effective connections and interactions with the FM and PM to 
minimize poor performance and damaging operation for each (i.e., minimizing machine and structure vibrations; minimizing operational wear and tear on turbine blades, inlet, and outlet flow structures to the turbomachinery; considering the integration of hydraulic and electromagnetic aspects of the turbomachinery with the FM).

- PM: Modeling considerations to be assessed may include and involve interdependent considerations of generation maximization; safe and reliable recreational passage; fish and sediment passage; maintaining dissolved oxygen, temperature, and other water quality standards; and minimization, control, and maintenance of bank and FM erosion. The modeling should include assessing flow behavior, velocity predictions, and sediment interactions across various module shapes and configurations.

- FM: Modeling considerations to be assessed for the FM include adequate structural and geotechnical design to maintain safe and reliable service. This will minimize the potential for strain and failure of the module, on local, module, and facility scales, so that interactions among modules and safe and proper operation of machinery are not jeopardized. This may entail performing structural and modal analysis in response to water flow past various module shapes and configurations. Aspects of sediment deposition and scour will be relevant modeling issues to resolve.

- Interconnection module: Modeling considerations to be assessed may include proper operational aspects of turbomachinery/electromagnetic integration and power maximization and delivery performance. This may include facilitating the optimum integration of module design to accommodate power delivery while effectively maintaining the module's own design considerations (e.g., for the GM).

- Installation module: Modeling considerations to be assessed may include considerations for and interactions of the modules from the aspects of feasibility and costs.

The prospective modeling issues identified here are the physical and operational aspects associated with establishing a successful SMH scheme. They provide a baseline for the modeling and simulation efforts.

\subsubsection{Simulation Performance and Metrics}

The simulation and modeling efforts used to investigate the various design and operational considerations of SMH systems are subject to model performance considerations. The conceptual modeling approaches, levels of detail, and various assumptions all affect the predictive performance of the models and simulations and involve various degrees of predictive accuracy as compared with realistic situations. Performance statistics and confidence margins are important metrics for assessing the integrity and usability of the results.

The modeling and simulation must be informed with a properly defined problem statement and wellposed approach for obtaining the most meaningful results. It follows that the models must be set up and executed properly, as well as calibrated and validated. Calibration and validation will help ensure that the models are accurately replicating the physical phenomena being analyzed. To remain cost effective,

model complexity and precision must be mindful of computational and development cost considerations.

\subsubsection{Scale and Structure of Simulation and Modeling}

Identification of the different scales associated with SMH is important for defining the structure and approach for modeling and simulation. Appropriate modeling techniques and sizing considerations are important for capturing behaviors corresponding to different aspects of SMH design and operation. The 
two primary physical scales of interest are the module and system (facility) levels. For each of these, respective length and temporal modeling scales can vary with respect to the degree of resolution required to accurately predict certain phenomena or processes of interest.

\subsubsection{System-Scale Simulation}

"System-scale" refers to the SMH system as a whole. This includes operation and interactions on the river system in which the system exists, such as locations at various distances upstream and downstream of the system. These areas of interest transition at the vicinity of the approach flows at the upstream sections and the exit flow at the downstream sections of the river, where flow behaviors in the river become increasingly more affected by the existence and operation of the SMH system in the river.

The SMH Simulation and Modeling Capability will consider the holistic connectivity of SMH with the environment by accounting for the interaction of the SMH facility with the watershed and riverine continuum. The primary linkage relationships will be modeled using a variety of modeling tools, e.g., hydrologic, sediment transport, morphodynamic, and biologic models. They will be used to assess the morphological, biological, and environmental responses of the riverine continuum to various configurations of the different SMH modules. System-scale modeling and module-level modeling may inform each other with passage of information and results through input and output boundary conditions.

\subsubsection{Module-Scale Modeling}

"Module-scale" refers to the component-level modules individually and the specific operational and interactive nature of the various modules. This level involves specific component-level systems (e.g., the interactions of turbomachinery and electromagnetic machinery with flow, sediment, and fish passage through the PMs) and the interactions of foundation vibrations with the turbomachinery. Each of these requires a separate model and very specific modeling techniques and assessments. Inputs to these models, such as flow and environmental constituents, can be derived from the simulation at the system scale.

Similarly, outputs from the module-scale models can serve as input to the system-scale simulation on the downstream side of the SMH structures. Transitions and overlap areas of system-scale and module-scale models may exist and should be handled appropriately.

\subsubsection{Concepts of Simulation and Modeling}

Performing simulations and modeling at these various scales requires various approaches and techniques to appropriately predict and assess the behaviors, conditions, and performance of SMH. As described earlier, a variety of modeling techniques and tools may be used, such as computational, analytical, empirical, conceptual, stochastic, and physical modeling. Identification of the most appropriate tool depends on the analysis and results needed. There are aspects of manufacturing, reliability, installation, logistics, and costs that must be considered, and appropriate modeling tools must be used to analyze the benefits and trade-offs associated with SMH design and operation. All of these aspects are in some fashion affected by physical behaviors intrinsic to SMH design and operation. Likewise, a majority of the modeling and simulation associated with SMH is physics based, i.e., quantifying and assessing the behavior of physical phenomena. Modeling at the module and system scales involves analyzing the interactions of different types of physics. The main areas of physics and subject areas that require modeling are

- structural/solid mechanics

- electromagnetic

- hydraulic/fluid mechanics

- controls/sensing 
- environment

The modeling will involve multi-physic interactions over various physical aspects of the SMH system (Figure 45). The interdisciplinary nature of modeling requires careful identification and planning among different subject matter experts, as well as the use of different modeling techniques and resources.

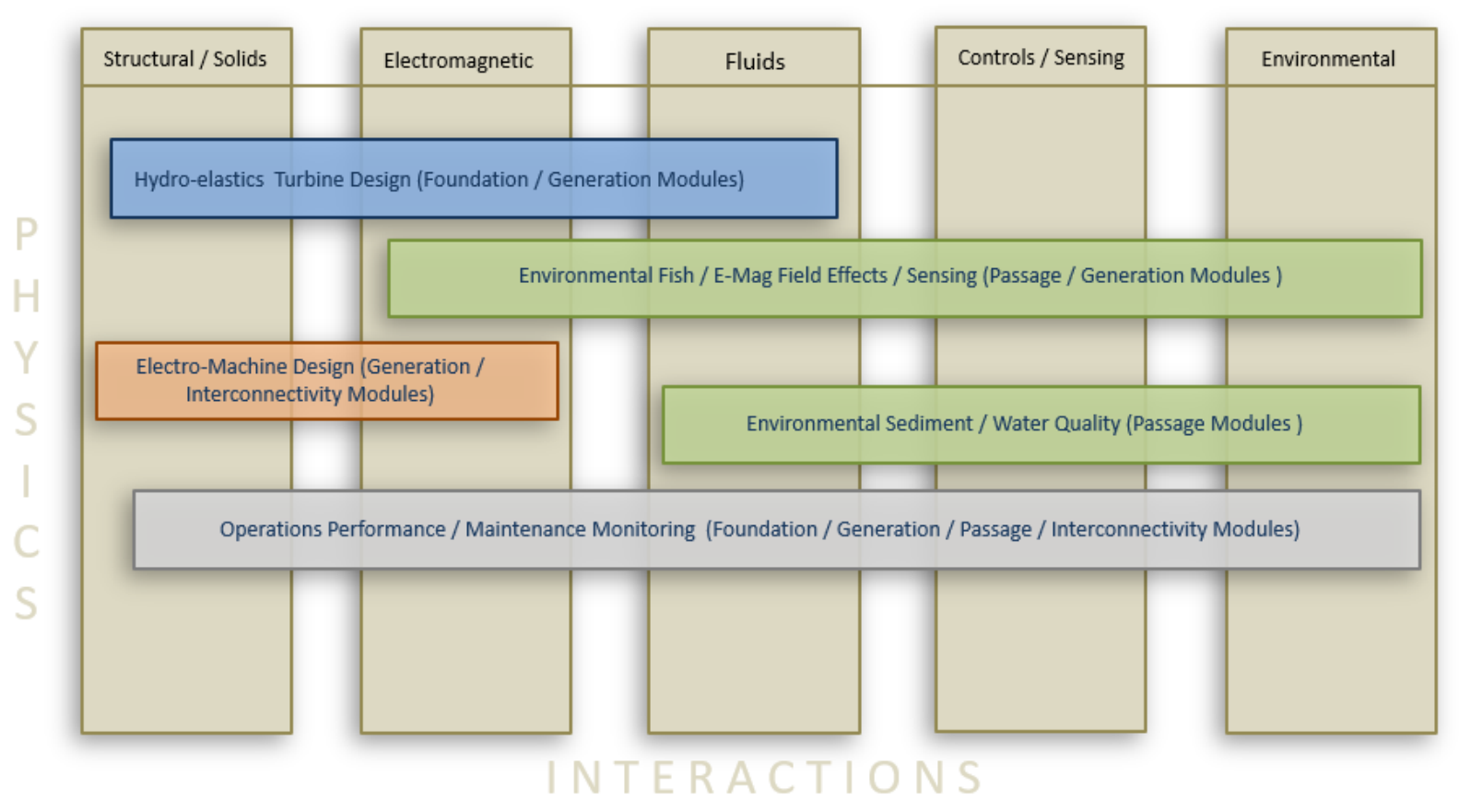

Figure 45. Physics and interaction schematic.

Each of the physical interactions identified in Figure 45 represents a separate item that will require some level of modeling and for which a "modeling concept" will be established that identifies the approach and specifics of the modeling effort. The modeling concept will, at minimum, include the following items of interest:

- Scale of the model (length and time): the extent of physical representation of the modules and river environment and the temporal consideration for processes, the extent of inclusion required for adjacent modules, and so on.

- Resolution of the model (length and time): identification of the characteristics and sizing of the physical behaviors, parameters, and time scales to be resolved within the model. This includes valueadded assessment of increasingly fine model grid resolutions and the respective benefits expected and required.

- Steady vs. unsteady: identification of the value of time-varying behaviors and characteristics of the modeled system.

- Modeling extent: identification of the benefits and characteristics to help define the extent of modeling, e.g., whole system vs. a sector of the system, entire time simulation vs. periodic period of time, and use of distributed or lumped parameters. 
- Modeling type: identification of the most informative and useful approach to modeling, to include physical-based modeling, stochastic approach, empirical, or conceptual.

Models for assessing performance and other aspects of manufacturing, reliability, installation, logistics, and costs will be conceptually tied into the development and use of physics modeling to make the cost assessments used to guide and facilitate the understanding and comparisons of impacts and trade-offs.

A Simulation and Modeling Capability schematic depicting the intricacy of the use of various models and various interactions is identified in Figure 46. In general, the process will use various computational, analytical, and perhaps statistical models to help predict the behaviors and performance associated with the SMH system components, equipment, and operation. A cost assessment model will be used to evaluate various cost metrics that will be used to guide design and operation with respect to performance and feasibility.

The various physics and interactions identified in Figure 45 serve as a basis for identifying first-cut relationships and expected model-type needs. The various aspects of the behaviors and the coupling of physics (identified in Figure 46 as groupings, e.g., "A and B," "C, D, and E") identified with module modeling and overall simulation can be addressed with various models. In some cases, multiple models may be required to reasonably assess the overall coupling of physical behaviors occurring in the SMH system or a subset of the SMH system. Figure 46 illustrates the requirement for model parameter and results transfers among various computational and/or analytical model platforms, identified as groupings of models "M1 and M2," M1 and M3," and "M4 and M5." In addition, to appropriately gauge SMH design and operational performance and feasibility, a precise, well-defined definition and relationship for "value and benefit" must be established as a basis for assessing trade-off analyses resulting from the feedback process between the physics and costs models.

Further identification, detailed specifications, and refined strategies for the processes will be provided in the technical documentation forthcoming on the Simulation and Modeling Capability. A suggested twotiered process for executing the Simulation and Modeling Capability component of the SMH project is identified in Figure 47. Category A items 1-6 represent those steps and thought processes that need to occur before the models are made available to end users such as designers, developers, and engineers (i.e., specified stakeholders and users of the end product). These steps ensure that key processes and interdependencies of functional relationships are identified and appropriate modeling techniques are assessed and established. Category B represents the component of the Simulation and Modeling Capability in which a refined, well-informed guidance structure emerges for using and identifying a suite of appropriate tools and methodologies that are presented to the users (i.e., designers, engineers, developers, environmentalists). 


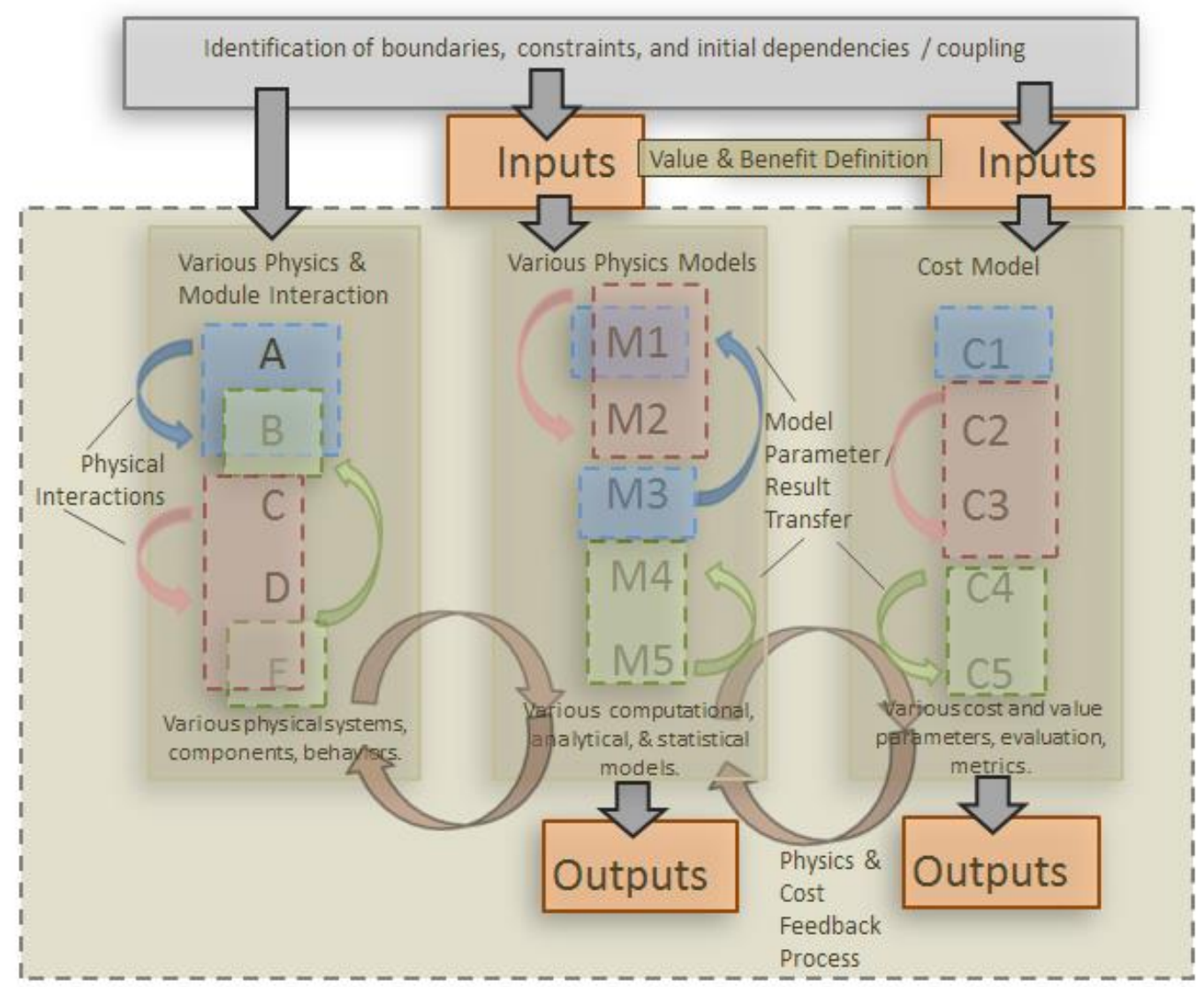

Figure 46. SMH Simulation and Modeling Capability structure of modeling aspects.

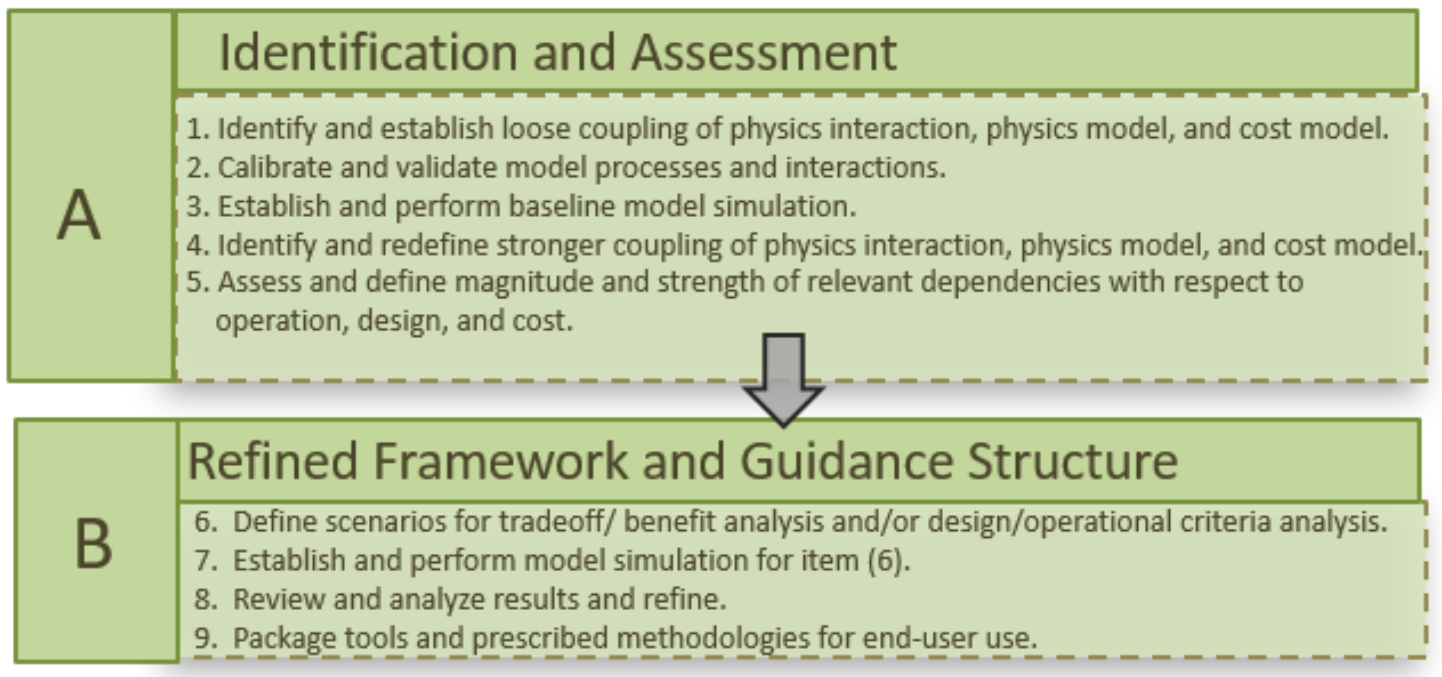

Figure 47. Two-tiered effort for the Simulation and Modeling Capability. 


\subsubsection{Integrated Simulation for Optimized Impacts and Trade-offs}

A goal of the Simulation and Modeling Capability effort is to assess the impacts and trade-offs of SMH for various configurations and operational scenarios within the context of an optimized system constrained by cost and other significant factors. Various combinations of design and operational considerations can be investigated to assess which are most appropriate, based on specified criteria. Since the design and operation of the system's modules is interdependent and integrated, there may exist several different design and operational combinations that are deemed appropriate. Identification and analysis of the impacts and trade-offs associated with design and operation will be used to guide and help make wellinformed model development decisions.

A conceptual identification of the possible impacts and trade-offs will be necessary to help guide the modeling and simulation approach, development, and structure, since the interactions among modules can be significant. Model development and use will incorporate appropriately defined integrated methods so that impacts and trade-offs can be assessed at the necessary steps. Cost modeling will be used to help establish a quantifiable means to assess the impacts of manufacturing, construction, installation, operation, and maintenance.

\subsubsection{Categorization and Transfer of Complex Information}

As described in Section 5.3.2.3, the integral nature of the modules and the interdependent effects are not trivial. Identification of the relationships and coupled effects is important for assessing impacts and tradeoffs. First, impacts and trade-offs will need to be identified for a general understanding of the system. Subsequent modeling will reveal finer-level details of interdependencies and will be used to categorize the cause-and-effect relationships of physical behaviors. These results can then be used in conjunction with cost modeling to begin prioritizing the range and combinations of design variable specifications and operational scenario specifications that have the most significant effects worth investigating.

A categorical relationship among the design, operation, and cost model parameters and results can be developed and can serve as a means of comparing and assessing tradeoffs and impacts. This process may involve extensive systematic model and simulation runs for varying parameters and/or scenarios to help define the system relationships with cost. Executing meaningful simulations of this magnitude containing coupled relationships and varying scales will require careful, well-designed methods for the tracking and transfer of the large amounts of information, model specifications, and results among all models and methodologies.

\subsubsection{Establishment of Baseline Simulation Scenarios}

To effectively use and compare any systematic model execution results, baseline simulation scenarios must be established and validated. The performance and limitations of a simulation scenario must be thoroughly understood and established to ensure that a model's construction, treatment of boundary conditions, integration with other nested models, execution order, and ability to produce realistic and valid results for a range of variables are adequate and defendable.

\subsubsection{Development of Simulation Component}

The development of the modeling and simulation effort for SMH has two significant purposes. The first purpose is to use modeling and simulation to guide researchers in identifying physical relationships and behaviors in SMH design and operation. This will help in identifying significant relationships and integrated modeling needs required for the development of a generalized framework within which to virtually test and assess systems. The second purpose is to develop a structured framework that contains 
specified guidance and a suite of modeling tools for analyzing and testing generalized designs, configurations, and operations of SMH systems.

\subsubsection{Chronological Priorities}

The development of a structured framework containing guidance and a suite of modeling tools requires prioritization on many levels. Specific modeling requirements, conceptual approaches, and the various uses and needs of model development must be well understood. Considering the various relationships and unknown characteristics of the integral nature and reactions of the system, as a whole and on a modular level, questions regarding the capabilities for using existing models, needs for new models and approaches, and innovative means to accomplish complex tasks need to be addressed. Modeling the SMH concept does involve several components that share overlapping and dependent roles, some of which are well understood and straightforward to model and some that are not. A thorough and systematic understanding of the modeling goals and approaches will be established. It will serve as a guide from which a hierarchical structure of modeling needs and priorities can be developed and used to establish a plan and timeline for model and simulation development.

\subsubsection{Identification of Pre-existing and Needed Simulation Components}

The final product of this effort will be a suite of tools, including models, guidance, and documentation, for virtually investigating an SMH system. The need to identify existing models, approaches, and tools, or the need to develop new products, will be addressed.

\subsection{SMH TESTING AND VALIDATION CAPABILITY}

Research outputs, primarily from the SMH EDES, will be used to identify testing needs and physical and technical requirements for establishing an SMH hydraulic testing facility. The SMH Simulation and Modeling Capability and SMH Site Classification Scheme will provide additional input by identifying gaps and challenges. An assessment of testing needs requires a basic understanding of the physical mechanisms and constraints associated with SMH design processes. Therefore, the evaluation of testing needs will be informed by the key processes (functional relationships), key variables, and functional requirements that are essential parts of the EDES investigation process. After understanding is gained of the interrelationships among the parameters involved, an actual range of parameter scales (e.g., hydraulic heads, flow rates, and physical dimensions of modules) that correspond to the scales of potential SMH products should be investigated so that a design scope for the test facility can properly be defined (i.e., parameter sizing process).

Additional testing needs can be identified during the process of identifying gaps and challenges imposed by the simulation and modeling process (e.g., initial and boundary condition needs), site-specific conditions (e.g., head and flow variations), and interactions with stakeholders. Once a comprehensive matrix of testing needs is developed, relevant testing methodologies and instrumentation can be identified. In parallel, a preliminary federal facility capability memo will be sent out to federal facility owners to initiate discussions through workshops and, subsequently, to identify test facility candidate sites. Further discussions will address potential technical, logistical, legal, and regulatory issues associated with those sites. Based on the information gathered, candidate sites will be evaluated using a capability criterion that will be investigated via a test facility capability requirements and assessment process. Based on the outcomes from these activities, a few potential test center locations will be proposed to aid decision making among DOE, federal hydropower agencies, and regulatory agencies. The next phase of the research will focus on developing plan details such as a blueprint and cost model for state-of-the-art hydraulic testing of the generation, passage, foundation, and interconnection modules. While housing a full scale test facility within federal hydropower fleets is being considered as the best 
choice at the moment, additional investigation will be needed to decide whether it is better to use multiple federal facilities, use a single facility, and/or leverage existing laboratories across the country. The test facility should be able to provide means for validation testing of individual and integrated SMH module design components while accommodating a wide range of testing needs from investors, regulators, and concerned stakeholders. The development of new SMH technologies will require an iterative testing process via a test facility for validation and improvement of the proposed technologies.

\subsubsection{Parameter Sizing}

To allow testing of various sizes of SMH module designs in the test facility, it is necessary to investigate a potential range of head and flow conditions across small hydropower sites, as well as the actual sizes of potential module products available in the United States. ORNL has estimated that $83 \%$ of potential development sites in US streams will have an aggregate turbine flow of 4,000 $\mathrm{ft}^{3}$ per second or less, and $83 \%$ of sites will be developed with a gross head of $30 \mathrm{ft}$ or less. Accordingly, these are the working upper limits of head and flow that DOE will use in scoping the test facility.

The full-scale test capability will also help refine and improve the overall SMH hydraulic, structural, and mechanical modular configuration, simplify the physical modular configurations, and refine module testing needs and test methodologies. However, if a module is designed beyond its range, scaled-down module designs may be needed for testing.

\subsubsection{Development of SMH Testing and Validation Capability Needs Matrix}

Based on parameter size considerations and gaps and challenges identified, a comprehensive Testing and Validation Capability needs matrix for each module component can be developed through stakeholder interactions. For Testing and Validation Capability development efforts, stakeholders will interact with ORNL staff to confirm product sizes, develop a complete list of testing needs, and review the methodologies and instrumentation that will enable the necessary testing. These stakeholders should be able to provide expertise in the fields of hydraulic, mechanical, electrical, structural and material, and environmental and biological testing. Table 7 provides a snapshot of a preliminary testing needs matrix. The needs matrix will be further vetted through interactions with investors, regulators, and concerned stakeholders during this process to accommodate a wide range of their needs.

Table 7. Preliminary testing needs matrix

\begin{tabular}{|c|c|c|c|c|}
\hline Types & Testing categories & $\begin{array}{l}\text { Testing } \\
\text { IDs }\end{array}$ & Testing needs & Relevant measurements \\
\hline \multirow{3}{*}{$\begin{array}{l}\text { GM testing } \\
\text { needs }\end{array}$} & Hydraulic & GM1 & $\begin{array}{l}\text { Performance testing of } \\
\text { turbine components }\end{array}$ & $\begin{array}{l}\text { Head, flow through a GM, pressure } \\
\text { differential, total energy loss, shear, } \\
\text { velocity, depth, and turbulence } \\
\text { under steady and unsteady flow } \\
\text { conditions }\end{array}$ \\
\hline & Mechanical & GM2 & $\begin{array}{l}\text { Performance testing of } \\
\text { generator components }\end{array}$ & $\begin{array}{l}\text { Speed of rotation, torque, and } \\
\text { temperature using dynamometer } \\
\text { and/or other measurement devices }\end{array}$ \\
\hline & Electrical & GM3 & $\begin{array}{l}\text { Performance testing of } \\
\text { electrical components }\end{array}$ & $\begin{array}{l}\text { Power quality measurements using } \\
\text { power analyzer, dynamometer, load } \\
\text { cell, and/or current/voltage } \\
\text { transducers }\end{array}$ \\
\hline
\end{tabular}


Table 7. (continued)

\begin{tabular}{|c|c|c|c|c|}
\hline Types & Testing categories & $\begin{array}{l}\text { Testing } \\
\text { IDs }\end{array}$ & Testing needs & Relevant measurements \\
\hline & $\begin{array}{l}\text { Structural and } \\
\text { material }\end{array}$ & GM4 & $\begin{array}{l}\text { Structural and material } \\
\text { performance and reliability } \\
\text { testing of turbine, generator, } \\
\text { electrical, and auxiliary } \\
\text { components }\end{array}$ & $\begin{array}{l}\text { Vibration, noise, modal analysis, } \\
\text { runaway, cavitation, and durability } \\
\text { under normal and abnormal } \\
\text { conditions }\end{array}$ \\
\hline & $\begin{array}{l}\text { Environmental and } \\
\text { biological }\end{array}$ & GM5 & $\begin{array}{l}\text { Environmental and } \\
\text { biological disturbance } \\
\text { testing }\end{array}$ & $\begin{array}{l}\text { Morphodynamic change monitoring } \\
\text { using a bathymetry scanner and } \\
\text { biological habitat change } \\
\text { monitoring in upstream and } \\
\text { downstream channels after placing } \\
\text { GMs or a combination of modules; } \\
\text { measurements of dissolved oxygen, } \\
\text { fish mortality, and injury through a } \\
\text { turbine; and so on }\end{array}$ \\
\hline \multirow[t]{2}{*}{$\begin{array}{l}\text { PM testing } \\
\text { needs }\end{array}$} & Hydraulic & PM1 & $\begin{array}{l}\text { Performance testing of } \\
\text { water, sediment, debris, } \\
\text { recreational craft, and fish } \\
\text { PM components }\end{array}$ & $\begin{array}{l}\text { Head, flow through a PM, total } \\
\text { energy loss, shear, velocity, depth, } \\
\text { turbulence under steady and } \\
\text { unsteady flow conditions, sediment } \\
\text { passage (transport rates, particle } \\
\text { movement pathway, resting times, } \\
\text { settling and self-weight consolidation } \\
\text { and scour), debris, small recreational } \\
\text { craft, and fish passage performance } \\
\text { evaluation }\end{array}$ \\
\hline & $\begin{array}{l}\text { Structural and } \\
\text { material testing }\end{array}$ & PM2 & $\begin{array}{l}\text { Structural and material } \\
\text { performance and reliability } \\
\text { testing of fish PM } \\
\text { components }\end{array}$ & $\begin{array}{l}\text { Cavitation, durability, wear, and } \\
\text { structural stability of the PM } \\
\text { structure during normal and extreme } \\
\text { conditions }\end{array}$ \\
\hline \multirow[t]{2}{*}{$\begin{array}{l}\text { FM testing } \\
\text { needs }\end{array}$} & $\begin{array}{l}\text { Environmental and } \\
\text { biological }\end{array}$ & PM3 & $\begin{array}{l}\text { Environmental and } \\
\text { biological disturbance } \\
\text { testing }\end{array}$ & $\begin{array}{l}\text { Morphodynamic change monitoring } \\
\text { using a bathymetry scanner and } \\
\text { biological habitat change } \\
\text { monitoring in upstream and } \\
\text { downstream channels after placing } \\
\text { GMs or a combination of modules; } \\
\text { disruption of fish migration, } \\
\text { biological, physical, and chemical } \\
\text { (e.g., phosphorous, nitrogen, carbon } \\
\text { dioxide) characteristics of water } \\
\text { quality, and water temperature }\end{array}$ \\
\hline & Hydraulic & FM1 & $\begin{array}{l}\text { Performance testing of FM } \\
\text { components }\end{array}$ & $\begin{array}{l}\text { Effects of shear, velocity, flow rates, } \\
\text { depth, and turbulence on local scour } \\
\text { intensity, sediment deposition, and } \\
\text { erosion }\end{array}$ \\
\hline
\end{tabular}


Table 7. (continued)

\begin{tabular}{|c|c|c|c|c|}
\hline Types & Testing categories & $\begin{array}{l}\text { Testing } \\
\text { IDs }\end{array}$ & Testing needs & Relevant measurements \\
\hline & $\begin{array}{l}\text { Structural and } \\
\text { material }\end{array}$ & FM2 & $\begin{array}{l}\text { Structural and material } \\
\text { performance and reliability } \\
\text { testing of FM components }\end{array}$ & $\begin{array}{l}\text { Measurements of stability effects of } \\
\text { dead and live loads acting on the } \\
\text { FMs (i.e., generation and passage } \\
\text { weights and hydrostatic and } \\
\text { hydrodynamic forces of water) } \\
\text { during normal and extreme } \\
\text { conditions, cavitation, durability, } \\
\text { wear, foundation material variables } \\
\text { (strain, strength, density, porosity, } \\
\text { and permeability), geometric } \\
\text { variables (module dimensions, } \\
\text { stream cross-section, excavation } \\
\text { depth, anchoring depth, anchor } \\
\text { dimensions), geomorphic variables } \\
\text { (river bed slope, bed topography, soil } \\
\text { properties, and structure of strata), } \\
\text { and sediment characteristic variables } \\
\text { (grain size distribution, size, shape) }\end{array}$ \\
\hline & $\begin{array}{l}\text { Environmental and } \\
\text { biological }\end{array}$ & FM3 & $\begin{array}{l}\text { Environmental and } \\
\text { biological disturbance testing }\end{array}$ & Benthic habitat disturbance \\
\hline
\end{tabular}

\subsubsection{Identification of Testing Methods and Instrumentation}

Based on the integrated testing needs matrix, existing test methodologies will be examined based on evaluation of journal articles, standards, and industry codes to identify the following:

- $\quad$ site-specific applicability

- advantages and disadvantages

- measurement challenges

- adaptability to variable operating conditions

- applicable range of head and flow rate

- head loss

- response to sediment and debris

- reliability for given environment

- maintenance requirements

A set of testing methods will be chosen according to their degree of feasibility, which includes, for example, ease of implementation, reliability, possibility of sensor integration with modular structure, public acceptance, costs, and benefits, and so on. Subsequently, physical and technical test facility capability and flexibility requirements will be formulated by developing rubrics, criteria, and protocols.

\subsubsection{Identification of Test Center Capability Requirements}

ORNL staff will coordinate discussions with DOE, FERC, USACE, Reclamation, and TVA staff as needed to ascertain and confirm the rules (e.g., those associated with NEPA and the FPA) that apply to validation testing of a non-federal prototype machine at a federal facility to deal with technical, logistical, legal, environmental, and regulatory issues. The test center capability requirements that enable testing of selected methodologies and instrumentation are outlined below. These requirements are preliminary, so they should be further vetted through interactions with federal utility owners. Although these can be considered basic requirements that must be accommodated, there are not clear answers for how to achieve 
those requirements. Therefore, further discussions with federal utility owners and concerned stakeholders are necessary to find solutions.

\subsubsection{Generation Module}

The GM test facility should be able to address the issues regarding hydraulic head and flow capacity, flow duration and water scheduling flexibility, flow control and modulation capability, electric power capacity and management, site access and crane capability, sediment handling capability, measurement system capabilities, and required levels of accuracy for useful test results, as documented in applicable model and prototype test standards for hydraulic turbines.

\subsubsection{Passage Module}

The PM test facility should be able to address the issues regarding direct/indirect accessibility to the PM for testing, safety issues due to possible worker activity in the water (e.g., sediment and debris measurements); temporary/permanent installation of testing equipment; biological testing capability (e.g., fish mortality, injury, attraction, and migration); physical testing capability (temperature measurement of vertical water column); and water quality testing capability. The PM test facility also should address the common hydraulic problems related to the GM, including hydraulic head and flow capacity, flow duration and water scheduling flexibility, flow control and modulation capability, and measurement system capabilities. While aforementioned capabilities in general demonstrate PM testing considerations in a fullscale test facility, PM studies may also effectively be supplemented by a scaled physical model. For example, fish behavior could be tested through full-scale field studies with real fish in a real environment. The scaled physical model could then be used to test new designs for the conditions that result in good passage conditions in the field.

For testing of the PM, new sensing technologies may be applied. For instance, radio frequency identification tracers could be used to track the pathways of sediment and fish movement through the facility (Tsakiris et al. 2015). Acoustic sensors and geophones could be used to provide autonomous and continuous monitoring of bedload transport through the PM. Doing so would follow the Reclamation practice for monitoring the sediment in the Elwha river upon the removal of the Elwha dam (Hilldale et al. 2014; Tsakiris et al. 2014).

\subsubsection{Foundation Module}

The test facility for the FM should be able to address the issues regarding the feasibility and ease of modifying or replacing FM designs, structural stability testing capability under various flow conditions (including overtopping of structures), safety issues due to possible civil works in the water (e.g., sediment deposition and local scour measurements, benthic habitat disturbance measurements) and the modulation capability of measurement systems. Direct stability testing of the FM in prototype test mode may not be possible because of safety concerns and costs, so a scaled model and/or the SMH Simulation and Modeling Capability may have to be used as alternatives.

\subsubsection{Interconnection Module}

The test facility for the interconnection module should be able to handle the linkages among structural components, electrical module components, and monitoring and control interconnections. Based on the testing aspects, doing so would require centralized control and monitoring capabilities including measurement systems, independence and interdependency of measurement systems when one module design specification is altered, and diagnostics to detect the performance quality of the interconnections. 


\subsubsection{Scale and Structure of Test Facility}

Since the SMH EDES may vary depending on the subjects of each design target (e.g., design specification for sediment transport vs. fish migration), test facility capability and flexibility requirements may need to be adjusted by prioritizing the importance of each design criterion. The feasibility of available testing methodologies should be considered in parallel. In addition, the following design criteria would need to be addressed at both the system and module levels.

\subsubsection{System-level Scale and Structure of Test Facility}

The proposed test center design at the system level should be able to address the following questions:

- What would be technical, operational, regulatory, environmental, financial, and legal issues and solutions associated with housing the test facility within the federal hydropower unit and/or modifying the existing infrastructure?

- Does housing a test facility at federal hydropower facilities significantly affect the performance of existing unit operations? Are there any complications and conflicts associated with using existing infrastructures (e.g., a bypass channel) and powertrain components for installation and testing of the SMH module components?

- Is a single test facility sufficient to accommodate various SMH testing needs?

- Is a separate powertrain testing facility needed?

- How can physical conditions such as hydraulic head and flow capacity be altered at a given facility?

- Is a scaled module testing lab (instead of prototype testing) more beneficial to test the scalability of modules and scaling constraints? Is a module-specific testing lab needed? Specific module components or even different designs of entire modules may need to be tested at a smaller scale in laboratory-controlled conditions to fine-tune their design characteristics, assess their scalability and performance, and provide insight into potential cause-and-effect relationships under well-controlled conditions.

- What are the testing methods and instrumentation that would best fit the potential candidate sites? Are different testing methods needed for varying module designs?

- How might a state-of-the-art test facility look if all of these questions are properly answered?

Opinions would be needed from concerned stakeholders, regulators, investors, industry experts, and academic researchers through multiple discussions at this design stage. Outcomes from these activities will establish a system-level picture of the test facility.

\subsubsection{Module-level Scale and Structure of Test Facility}

The testing center capability requirements will determine the testing specifications required at each module level. For example, the test center may need supporting structures/civil works that efficiently and easily interconnect the modules and provide a secure platform for testing when needed. The supporting structures/civil works should be flexible enough to accommodate various module designs for each test without additional modification and installation. This would be accomplished by standardization and modularization of interconnections between the module components. The test center also should be 
designed so that the selected testing methods can be conducted efficiently and effectively for the purposes of the respective facilities. The test center might include several test facilities, including run-of-river, tributary, model testing, and module-specific facilities. In designing these facilities, physical conditions such as head and flow can be chosen for the potential product ranges or through economic analysis of the products that are most popular or economical in the market. Further design specifications will be vetted through discussions with concerned stakeholders, regulators, investigators, industry experts, and academic researchers. A Full-Scale Testing and Validation Capability for Innovative Small Hydropower Technology (Personal communication from Brennan Smith of ORNL to Tim Welch, DOE Water Power Technologies Office), to be published separately from this report, will provide further in-depth information related to a small hydropower test facility capable of validating SMH technologies.

\subsubsection{Test Center Development Plan}

The outcomes of this research activity would provide an industry-accepted plan for an SMH field test facility. The facility must provide the means to validate the effectiveness of designs with respect to hydraulic, mechanical, electrical, structural and material, and environmental and biological testing at partial or full scale. The preferred plan for the test center, to the maximum extent possible, should attempt to leverage existing federal infrastructure in siting, rather than building, a new facility; doing so may minimize the need for regulatory processes (permitting and licensing) by FERC. Once the test center sites are decided, ORNL will coordinate with the relevant regulatory agencies and investing companies for discussions regarding a detailed test center development plan that would encompass specific layouts of facilities, construction schedules, collaboration needs, technical challenges, regulations, testing instrument (sensor) needs, funding and personnel needs, O\&M plans, and test center business model development and assessment. The test center business model, based on outcomes from these discussions, would primarily address initiation and long-term $\mathrm{O} \& \mathrm{M}$ and recognition of possible risks and uncertainties during the development of the test facility. SMH project validation testing will require a highly iterative process involving collaborative roles for a combination of government bodies, funding entities, scientific institutions, investors, and manufacturers with a keen vision for future environmentally compatible, costoptimized hydropower development.

\subsection{ENABLING R\&D ACTIVITIES}

Although they are not addressed in great detail as a part of this MYRP, additional research fields have high potential for improving SMH deployment. Targeted R\&D in each of these areas may be needed to fully leverage federal spending toward achieving more widespread SMH success.

\subsubsection{Advanced Materials and Manufacturing}

Approaches to investigate the design potential for the EDES will incorporate manufacturing and material considerations. Performance and cost metrics will be used to identify the feasibility of using particular materials and unique manufacturing techniques. The investigation of advanced material use will be closely incorporated into the simulation component to ascertain design performance metrics and feasibility. Unique manufacturing techniques, such as 3-dimensional additive printing, will be investigated with respect to influences on the cost and performance of design and installation.

The benefits arising from the use of advanced materials and manufacturing in SMH can be quantified with future R\&D upon development of the SMH EDES. The research must assess and address the following:

- Cost/benefit ratio for components and systems development versus traditional methods 
- Value-added with respect to the ease of accommodating various potential specific design elements (e.g., fine-tuned turbine blade geometries specific to site flow cases)

- Value-added for accommodating operation and maintenance issues and subtle design element changes (e.g., quick and easy replacement of worn-out components, inexpensive and easy replacement/adjustment of design elements based on observed in situ performance coupled with realized notable benefits)

- Availability of manufacturing processes and perceived expectations based on predicted increase in use for componentry and system development.

- Value-added or improvement in ease of transportation and installation of modules (based on lighter weight, improved structural integrity, timing, prefabricated sections, and embedded system components to prevent on-site complications in installation)

\subsubsection{Sensors, Control, Monitoring, and Telemetry Technology Research}

Monitoring the health of the river and its environment, the performance of the turbo and electromagnetic machinery, and the status and safety of the system are crucial for successful development of an SMH project. Ensuring that all elements are working properly is important in measuring the safety, performance, and health of the project, and hence the project's success. While various monitoring technologies have been applied to hydropower, systemic SMH design demands meeting monitoring needs in a new way to accommodate standard and modular design features.

Although various devices may serve specific sensor, control, monitoring, or telemetric purposes, they all serve a common purpose of monitoring the status of a hydropower system or component through electronic information transfer. Progress has been made in the use of wireless technology to efficiently and reliably transfer such information. Although traditional remediation often requires manual or semiautomated maintenance, monitoring the system status is often fully automated using SCADA or other technologies. In an SMH scheme, monitoring technology would ideally measure the following characteristics:

- Structural performance: structural integrity, foundation integrity, flexure, movement, and sediment and debris loading.

- Electromechanical performance: electromechanical machine efficiency, output, velocity, and acceleration, as well as component vibration, alignment, loading, temperature, and lubrication

- Flow measurements: turbine, passage, and other flow rates, along with water surface elevations at strategic locations upstream and downstream of the facility.

- O\&M: structural, electronic, or hydraulic degradation, mechanical cycling, machine flow obstruction

- Environmental status: dissolved oxygen concentration, water and air temperature, turbidity, bedload and suspended sediment transport rates at key locations upstream and downstream of the SMH facilities

- Biological status: algal growth and loading and fish presence, patterns, and passage 
Based on the various health indices identified by the monitoring process, smart and learning systems can be used to record and assess the data to make historical and benchmarked comparisons from which interventions can then be prescribed, if needed. Monitoring data may be used to identify the remaining or expected life of certain components or to identify issues or problems that require component repair or replacement. Using these data, adjustments to flow passage or turboelectrical machinery can be made to improve performance or react to particular events, and may be made via remote-controlled systems.

The integration of these monitoring capabilities into the SMH EDES can be accomplished through targeted research pathways that build on Phase I SMH development. Specifically, advancements in the application of embedded sensor, control and monitoring, and telemetry technology may be integral to SMH development.

- Embedded sensors: The ability to embed sensors into various facility components provides multiple benefits. Research into improving sensor accuracy and performance could yield beneficial results, while standardization and modularization of embedded sensors could reduce installation, operation, and maintenance costs. For instance, installing acoustic bedload measuring devices, known as geophones, could provide real-time, nonintrusive, autonomous information on sediment transport rates through the SMH facility. Furthermore, incorporation of embedded fiber Bragg grating sensors would allow real-time measurement of the displacement of components in the various SMH facility modules with high spatiotemporal resolution (Papanicolaou and Tsakiris 2012) These real-time data would, in turn, be used to inform the operation paradigm of the facility to achieve established and quantifiable passage goals.

- Control and monitoring: Further research into the integrated functionality and reduction in the size of control and monitoring devices could offer several advantages. Software development is needed to ensure connectivity among modules and functionality of control and monitoring.

- Telemetry: Research into mobile telemetry platform development (e.g., smartphones) could simplify monitoring processes by providing full access to the system in a remote, automated, unattended, costeffective, and efficient manner. Additional research may be needed to increase the reliability of communication systems. The development of smart, learning telemetry systems could prove invaluable in detecting faults, making adjustments, and enabling maintenance in a timely and accurate manner.

\subsubsection{Biological Design for Turbines and Structures}

In 1994, DOE partnered with EPRI and the Hydropower Research Foundation to establish the Advanced Hydropower Turbine Systems Program. This program supports the development of environmentally friendly turbine technologies by minimizing fish injury and mortality while maintaining adequate downstream water quality and efficient energy production. During a 4-year period in which the DOE Hydropower Program closed because of a lack of funding, development and testing continued through research conducted by Pacific Northwest National Laboratory, the USACE, and EPRI. These research efforts have continued through the DOE Water Power Program, and a variety of hydropower industry constituents have made progress in bringing environmentally friendly turbines to market (Hogan et al. 2014).

The current DOE BioDesign Project (BioDE) project can provide biological guidance for developing new lower-environmental-impact SMH facilities. Among the key outputs from that initiative is the Biological Performance Assessment (BioPA) Toolset that links physical forces fish may encounter during downstream turbine passage to fish injury and mortality. This toolset combines in-turbine hydraulic field data and CFD output with laboratory-derived stressor-fish response relationships to estimate the impact of 
turbine passage on fish species. In theory, the BioPA Toolset can enable simultaneous evaluation of the biological and operating performance of multiple turbine designs to allow for the necessary trade-offs among different performance metrics to minimize ecological impacts while maximizing generation. Stressor-fish response information being gathered as part of the BioDE initiative may also prove useful for evaluating the ecological impacts of other portions of SMH facilities, such as low-head spillways. The approach we are using in the BioDE project (i.e., linking physical stressors to fish response and health) may assist in evaluating and informing SMH design considerations related to fish bypasses, water quality, effective attraction flows, and designs for upstream PMs.

\subsection{MILESTONES AND SCHEDULE}

Proper RD\&D of SMH technologies will require coordinated efforts among numerous partners, stakeholders, and technology developers. This MYRP offers a preliminary roadmap for achieving RD\&D objectives and will be updated as the SMH project evolves. As envisioned, this MYRP and the EDES technical report (Witt et al. 2017) provide the framework for initial SMH conceptualization; and research efforts related to the SMH Research Pillars (EDES, Site Classification Scheme, Simulation and Modeling Capability, and Testing and Validation Capability) will further shape the SMH concept. These research efforts will require varying degrees of stakeholder feedback and may require modification as new considerations are made. Further development of exemplary design envelope specifications, site classifications, simulation and modeling capabilities, and testing and validation capabilities will pave the way for the procurement, construction, and commissioning of a hydropower test facility capable of testing and validating SMH designs that integrate stream functionality, standardization, and modularity. Successful application of SMH designs and design concepts through demonstration and deployment will enable broader acceptance and increased adoption. Where appropriate, collaborative mechanisms such as FOAs, CRADAs, MOUs, and IAAs may be sought to increase opportunities to demonstrate and advance SMH technologies. Figure 48 illustrates the phasing of the SMH RD\&D tasks as currently conceived for FYs 2016-2020. 


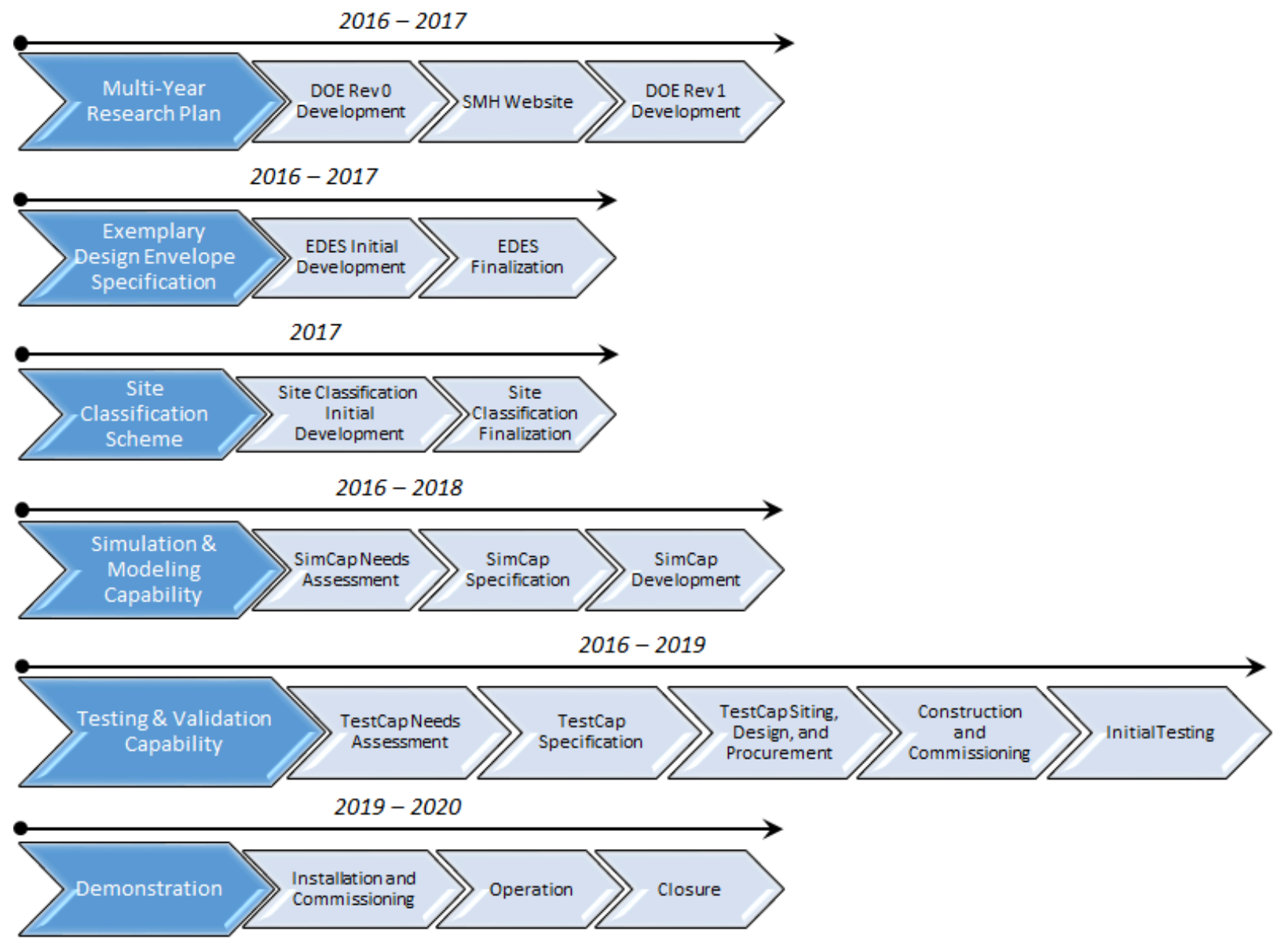

Figure 48. SMH RD\&D tasks for FY 2016-FY 2020. 


\section{REFERENCES}

AACE. 2013. Cost Estimate Classification System-As Applied in Engineering, Procurement, and Construction for the Hydropower Industry. AACE International Recommended Practice No. 69R12. January. http://www.aacei.org/toc/toc_69R-12.pdf. Accessed June 2016.

Aadland, Luther P. 2010. Reconnecting Rivers: Natural Channel Design in Dam Removals and Fish Passage. Minnesota Department of Natural Resources, St. Paul, Minnesota.

All-Energy. 2013. "StreamDiver aces a year of tests." reNEWS. http://renews.biz/48756/streamdiver-acesa-year-of-tests. Accessed June 2016.

Allis-Chalmers. 1970. Standardized Gated TUBE Turbine Generating Units. http://ycwua.org/wpcontent/uploads/2014/10/Allis-Chalmers-Brochure.pdf. Accessed June 2016.

Andaroodi, M. 2006. "Standardization of civil engineering works of small hydropower plants and development of an optimization tool." École Polytechnique Federale de Lausanne, Switzerland. https://infoscience.epfl.ch/record/116175/files/Comm_LCH_26.pdf\&version=1. Accessed June 2016.

ANDRITZ. 2014. "HydroMatrix: Innovative Hydropower Solutions.” http://www.andritz.com/hyhydromatrix-en.pdf. Accessed June 2016.

Annandale, G. W. 2013. Quenching the Thirst: Sustainable Water Supply and Climate Change. CreateSpace, North Charleston, S.C.

Applegate Group. 2011. "Section 2: Interconnection Issues." In Exploring the Viability of Low Head Hydropower in Colorado's Existing Irrigation Infrastructure. Applegate Group: Water Resource Advisors for the West, Denver, and Colorado State University, Fort Collins, Colorado. http://www.applegategroup.com/node/177. Accessed June 2016.

ASME (American Society of Mechanical Engineers). 1996. The Guide to Hydropower Mechanical Design. HCI Publications, Inc., Kansas City, MO.

Bard, J., H. Pirttiniemi, E. Goede, A. Mueller, D. Upadhyay, and M. Rothert. 2006. "Vasocompact —A European Project for the Development of a Commercial Concept for the Variable Speed Operation of Submersible Compact Turbines.” European Commission, DG TREN. http://www.esha.be/fileadmin/esha_files/documents/workshops/hidroenergia/ES2_Bard.pdf. Accessed June 2016.

Bates, K. and R. Johnson. 1986. A Prototype Machine for the Removal of Sediment from Gravel Streambeds. Technical report 96, Washington Department of Fisheries, Olympia, Wash.

Beaulieu, J. J., R. L. Smolenski, C. T. Nietch, A. Townsend-Small, and M. S. Elovitz. 2014. “High methane emissions from a midlatitude reservoir draining an agricultural watershed." Environmental Science and Technology 48(19), 11100-11108.

Berga, L. 2008. "Solving dam engineering challenges," HydroWorld.com. http://www.hydroworld.com/articles/print/volume-16/issue-1/articles/cover-story/solving-damengineering-challenges.html. Accessed June 2016. 
Bevelhimer, M. S., A. J. Stewart, A. M. Fortner, J. R. Phillips, and J. J. Mosher. 2016. " $\mathrm{CO}_{2}$ is dominant greenhouse gas emitted from six hydropower reservoirs in southeastern United States during peak summer emissions.” Water 8(1), 15.

Bevelhimer, M. S., M. P. Schramm, and C. R. DeRolph. 2015. Non-Federal Hydropower Mitigation Database. Oak Ridge National Laboratory. Available at: http://nhaap.ornl.gov/environmentalmitigation. (Accessed March 2016.)

Bishop, N., D. Linke, C. Alsberg, J. Anders, A. Grovue, S. Hill-Nelson, K. Johnson, B. Smith, D. Youlen, and K. Young. 2015. New Pathways for Hydropower: Getting Hydropower Built-What Does It Take? ORNL/TM-2015/48, Oak Ridge National Laboratory.

Boehlert, B., K. M. Strzepek, S. C. Chapra, C. Fant, Y. Gebretsadik, M. Lickley, R. Swanson, A. McCluskey, J. E. Neumann, and J. Martinich. 2015. "Climate change impacts and greenhouse gas mitigation effects on US water quality." Journal of Advances in Modeling Earth Systems 7(3), $1326-1338$.

Bonnet, M., A. Witt, K. Stewart, B. Hadjerioua, and M. Mobley. 2015. The Economic Benefits of Multipurpose Reservoirs in the United States-Federal Hydropower Fleet. ORNL/TM-2015/550, Oak Ridge National Laboratory. http://info.ornl.gov/sites/publications/Files/Pub59281.pdf. Accessed June 2016.

Brandt, S. A. 2000. "Classification of geomorphological effects downstream of dams," Catena 40(2000), 375-401. Elsevier Science B.V. https://www.wou.edu/las/physci/taylor/g407/brandt_2000.pdf. Accessed June 2016.

Bratrich, C., B. Truffer, K. Jorde, J. Markard, W. Meier, A. Peter, M. Schneider, and B. Wehrli. 2004. "Green hydropower: A new assessment procedure for river management." River Research and Applications 20(7), 865-882.

Brown, J. J., K. E. Limburg, J. R. Waldman, K. Stephenson, E. P. Glenn, F. Juanes, and A. Jordaan. 2013. "Fish and hydropower on the US Atlantic Coast: Failed fisheries policies from half-way technologies." Conservation Letters 6(4), 280-286.

Brownell, P., A. Haro, S. McDermott, A. Blott, and F. Rohde. 2012. Diadromous Fish Passage: A Primer on Technology, Planning, and Design for the Atlantic and Gulf Coasts. National Oceanic and Atmospheric Administration National Marine Fisheries Service and US Geological Survey Conte Anadromous Fish Research Center.

Bunn, S. E., and Arthington, A. H. 2002. "Basic principles and ecological consequences of altered flow regimes for aquatic biodiversity." Environmental management, 30(4), 492-507.

Bunt, C. M., T. Castro-Santos, and A. Haro. 2012. "Performance of fish passage structures at upstream barriers to migration." River Research and Applications 28(4), 457-478.

Cada, G. F. 2001. "The development of advanced hydroelectric turbines to improve fish passage survival." Fisheries 26(9), 14-23.

Caisley, M. E. and M. H. García. 1999. Canoe Chutes and Fishways for Low-Head Dams: Literature Review and Design Guidelines (HES 60). Hydraulic Engineering Series no. 60. 
Caisley, M. E., F. A. Bombardelli, and M. H. Garcia. 1999. Hydraulic Model Study of a Canoe Chute for Low-head Dams in Illinois (HES 63). Hydraulic Engineering Series no. 63.

Carlson, T. J. and M. Richmond. 2011. "Strategies for assessing the biological performance and design of hydroturbines." In T. Hogan, ed., Proceedings from Conference on Environmentally-Enhanced Hydropower Turbines, Electric Power Research Institute, Palo Alto, California.

CEA (Central Electric Authority) n.d. Best Practices and Bench Marks. http://www.cea.nic.in/best_practices_hydro.html. Central Electric Authority, Ministry of Power, Government of India, New Delhi, India.

Chatterjee, Bishu, Richard E. Howitt, and Richard J. Sexton. 1998. "The optimal joint provision of water for irrigation and hydropower." Journal of Environmental Economics and Management 36(3), 295-313.

CNRA (California Natural Resources Agency). 2013. Technologies for Passing Fish at Large Dams. California Natural Resources Agency Department of Water Resources. http://www.water.ca.gov/fishpassage/docs/lg_dam.pdf. Accessed June 2016.

Colorado. 2008. Floodplain Stormwater \& Criteria Manual, 2008. Chapter 13, Hydraulic Analysis and Design, Section 7, Recreational Structures. Colorado Water Conservation Board. Retrieved from http://cwcb.state.co.us/technical-resources/floodplain-stormwater-criteriamanual/Pages/main.aspx. Accessed July 2016.

Colorado. 2010. Colorado Small Hydropower Handbook. The Colorado Energy Office, Denver. http://extension.colostate.edu/docs/energy/hydro-handbook.pdf

Cooke, S., C. Hatry, C. Hasler, and K. Smokorowski. 2011. Literature Review, Synthesis and Proposed Guidelines Related to the Biological Evaluation of 'Fish Friendly' Very Low Head Turbine Technology in Canada. Canadian Technical Report of Fisheries and Aquatic Sciences 2931. Natural Resources Canada. http://www.nrcan.gc.ca/sites/www.nrcan.gc.ca/files/canmetenergy/files/Cooke\%20et\%20al\%202 011\%20VLH\%20TR\%202931.pdf (accessed March 8, 2016).

Coutant, C. 1998. Turbulent Attraction Flows for Juvenile Salmonid Passage at Dams. ORNL/TM13608. Oak Ridge: Oak Ridge National Laboratory.

Dale, V., R. Efroymson, K. Kline, H. Langhotz, P. Leiby, G. Oladosu,... M. Hilliard. 2013. “Indicators for assessing socioeconomic sustainability of bioenergy systems: A short list of practical measures.” Ecological Indicators 26, 87-102.

Debnath, D., T. Boyer, A. Stoecker, and L. Sanders. 2014. "Nonlinear reservoir optimization model with stochastic inflows: Case study of Lake Tenkiller." Journal of Water Resources Planning and Management 141(1).

Dermisis, D. and A. Papanicolaou. 2009. "Fish passage over hydraulic structures in Midwestern streams." International Journal of River Basin Management 7(4), 313-328.

DOE (Department of Energy). 2011. Technology Readiness Assessment Guide. DOE/G 413.3-4A. U.S. Department of Energy, Washington, DC http://www2.lbl.gov/DIR/assets/docs/TRL\%20guide.pdf 
DOE (Department of Energy). 2014. 2014 Water Power Peer Review Report. Office of Energy Efficiency and Renewable Energy Wind and Water Power Technologies Office.

http://energy.gov/eere/water/downloads/2014-water-power-peer-review-report

DOE (Department of Energy). 2016a. 2016-2020 Strategic Plan and Implementing Framework. Office of Energy Efficiency and Renewable Energy. http://energy.gov/eere/downloads/eere-strategic-plan

DOE (Department of Energy). 2016b. Hydropower Vision: A New Chapter for America's $1^{\text {st }}$ Renewable Electricity Source. Office of Energy Efficiency and Renewable Energy Wind and Water Power Technologies Office, Washington, DC http://energy.gov/eere/water/articles/hydropower-visionnew-chapter-america-s-1st-renewable-electricity-source.

Environment Agency. 2013. South East Annual Fisheries Report 2012/13. Environment Agency, Bristol, UK. https://www.gov.uk/government/uploads/system/uploads/attachment_data/file/288607/Environme nt_Agency_SE_Annual_Fisheries_Report_2012_2013_a9a4e4.pdf.

EPA (Environmental Protection Agency). 2015. Clean Power Plan. https://www.epa.gov/cleanpowerplan/clean-power-plan-existing-power-plants

EPRI (Electric Power Research Institute). 1985. Small Hydropower Development: The Process, Pitfalls, and Experience. Volume I: Feasibility Studies Summary and Analysis. EM-4036-V1. Electric Power Research Institute, Palo Alto, California.

EPRI (Electric Power Research Institute). 2011. Quantifying the Value of Hydropower in the Electric Grid: Plant Cost Elements. DE-EE0002666. Electric Power Research Institute, Palo Alto, California.

ESHA (European Small Hydropower Association). 2004. Guide on How to Develop a Small Hydropower Plant. http://www.esha.be/fileadmin/esha_files/documents/publications/GUIDES/GUIDE_SHP/GUIDE _SHP_EN.pdf.

FERC (Federal Energy Regulatory Commission). 1992. Guidelines for Public Safety at Hydropower Projects. Division of Dam Safety and Inspections. https://www.ferc.gov/industries/hydropower/safety/guidelines/public-safety.pdf

FERC (Federal Energy Regulatory Commission). 2004. Evaluation of Mitigation Effectiveness at Hydropower Projects: Fish Passage. Division of Hydropower Administration and Compliance. http://www.ferc.gov/EventCalendar/Files/20041018094218-fish-pass-final-report.pdf

FERC (Federal Energy Regulatory Commission). 2015a. Division of Hydropower Administration and Compliance Handbook. Office of Energy Projects. http://www.ferc.gov/industries/hydropower/gen-info/handbooks/compliance_handbook.pdf

FERC (Federal Energy Regulatory Commission). 2015b. Office of Energy Projects Infrastructure Update for October 2015. http://www.ferc.gov/legal/staff-reports/2015/oct-infrastructure.pdf

FHWA (Federal Highway Administration). 1999. Manual for Design and Construction Monitoring of Soil Nail Walls. FHW A-SA-96-069R. U.S. Department of Transportation. http://isddc.dot.gov/OLPFiles/FHWA/010571.pdf 
Fraser, R., C. Deschenes and M. Leclerc. 2007. "VLH: Development of a new turbine for very low head sites." Waterpower XV, Chattanooga, TN, USA, 2007.

French Development Enterprises LLC. 2015. http://fdepower.com/wpcontent/uploads/2015/09/FDE_PROFILE_Aug-2015.pdf

Gebler, I. 2012. "Near-nature water courses at hydropower plants as fishways and running water habitats." In Proceedings from 9th ISE 2012, Vienna.

https://restorerivers.eu/wiki/images/0/06/Gebler_near_nature_water_courses_2012.pdf

Gordon, J. L. 1983. "Powerhouse concrete quantity estimates." Canadian Journal of Civil Engineering 10(2), 271-286.

Gordon, J. L. 2003. "Turbine selection for small low-head hydro developments.” In Proceedings at Waterpower XIII, Buffalo. http://www.small-

hydro.com/pdf/workshops/cd/2003/technical/Turbine\%20selection\%20for\%20small\%20low\%20 head\%20hydro.pdf

Grant G. E., J. C. Schmidt, and S. L. Lewis. 2003. "A geological framework for interpreting downstream effects of dams on rivers." In A Unique River, Water Science and Application 7 American Geophysical Union, 209-225.

Gulliver, J. S. and R. Arndt. 1991. Hydropower Engineering Handbook. McGraw-Hill.

Hadjerioua, B., Y. Wei and S. C. Kao. 2012. An Assessment of Energy Potential at Non-powered Dams in the United States. GPO DOE/EE-0711. Department of Energy, Wind and Water Program, Washington, DC.

Hansen, K. D. 2008. "Design considerations for small RCC dams.” Hydropower \& Dams 3, 2-4. http://cement.org/water/hansen_article.pdf

Hatch. 2008. Low Head Hydro Market Assessment, Volume 1-Main Report. H-327842, Rev. 0. Hatch Energy, Ontario. Natural Resources Canada.

https://www.nrcan.gc.ca/sites/www.nrcan.gc.ca/files/canmetenergy/files/pubs/LowHeadMarketA ssessRptVol5E1MainReport.pdf

HEA (Hydro Equipment Association). 2015. Global Technology Roadmap. Hydro Equipment Association, Belgium. http://thehea.org/gtr_.pdf

Hilldale, R. C., W. O. Carpenter, B. Goodwiller, J. P. Chambers and T. J. Randle. 2014. "Installation of impact plates to continuously measure bed load: Elwha River, Washington, USA." Journal of Hydraulic Engineering 141(3).

Hogan, T. W., G. F. Cada, and S. V. Amaral. 2014. "The status of environmentally enhanced hydropower turbines." Fisheries 39(4), 164-172.

Hooker, M. 2014. "Recreation and aesthetics in the public interest: History and overview of hydropower license denials by the Federal Energy Regulatory Commission." Journal of Environmental Law. \& Litigation 29(87). 
HREA (Hydropower Regulatory Efficiency Act). 2013. Hydropower Regulatory Efficiency Act of 2013. http://www.ferc.gov/legal/fed-sta/bills-113hr267enr.pdf

ICPDR (International Commission for the Protection of the Danube River). 2013. Hydropower Case Studies and Good Practice Examples. International Commission for the Protection of the Danube River, Vienna. https://www.icpdr.org/main/sites/default/files/nodes/documents/annex__case_studies_and_good_practice_examples_final.pdf

IEA (International Energy Agency). Hydropower Agreement. 2000. IEA Assessment of Further Opportunities for R\&D-Summary Report: IEA Hydropower Agreement. International Energy Agency. http://www.ieahydro.org/media/2bf10d98/Assessment\%20of\%20Further\%20Opportunities\%20fo r\%20R\&D\%20-\%20Summary\%20Report.pdf

IEEE (Institute of Electrical and Electronics Engineers). 1988. IEEE Guide for Control of Small Hydroelectric Power Plants. IEEE Standard 1020-1988. The Institute of Electrical and Electronics Engineers, New York. http://ieeexplore.ieee.org/xpl/articleDetails.jsp?arnumber=29139\&filter=AND(p_Publication_Nu mber:2357)

IEEE (Institute of Electrical and Electronics Engineers). 2006. IEEE Guide for Control of Hydroelectric Power Plants. IEEE Standard 1010-2006. Institute of Electrical and Electronics Engineers Standards Association. https://standards.ieee.org/findstds/standard/1010-2006.html

INEL (Idaho National Engineering Laboratory). 1979. Feasibility Studies for Small Scale Hydropower Additions. Idaho National Engineering Laboratory. http://hydropower.inel.gov/techtransfer/index.shtml

INL (Idaho National Engineering and Environmental Laboratory). 2003. Estimation of Economic Parameters of U.S. Hydropower Resources (INEEL/EXT-03-00662). Idaho National Engineering and Environmental Laboratory. http://www1.eere.energy.gov/wind/pdfs/doewater-00662.pdf

Jager, H. I. and M.S. Bevelhimer. 2007. "How run-of-river operation affects hydropower generation and value.” Environmental Management 40(6), 1004-1015.

Jager, H. I. and B. T. Smith. 2008. "Sustainable reservoir operation: Can we generate hydropower and preserve ecosystem values?" River Research and Applications 24(3), 340.

Jager, H. I., R. A. Efroymson, J. J. Opperman, and M. R. Kelly. 2015. "Spatial design principles for sustainable hydropower development in river basins." Renewable and Sustainable Energy Reviews 45, 808-816.

Kao, S. C., R. A. McManamay, K. M. Stewart, N. M. Samu, B. Hadjerioua, S. T. DeNeale, D. Yeasmin, M.F.K. Pasha, A. A. Oubeidillah, and B. T. Smith. 2014. New Stream-reach Development: A Comprehensive Assessment of Hydropower Energy Potential in the United States, GPO DOE/EE1063. Department of Energy Wind and Water Power Program, Washington, D.C.

Katopodis, C. 1992. Introduction to Fishway Design. Freshwater Institute, Central and Arctic Region, Department of Fisheries and Oceans. 
Kenfack, J., F. P. Neirac, T. T. Tatietse, D. Mayer, M. Fogue, and A. Lejeune. 2009. "Microhydro-PVhybrid system: Sizing a small hydro-PV-hybrid system for rural electrification in developing countries." Renewable Energy, 2259-2263.

Kondolf, G. M., Y. Gao, G. W. Annandale, G. L. Morris, E. Jiang, J. Zhang, ... C. T. Yang. 2014. "Sustainable sediment management in reservoirs and regulated rivers: Experiences from five continents." Earth's Future 2(5), 256-280.

Leyland, B. 2014. Small Hydroelectric Engineering Practice. CRC Press Boca Raton, Florida. https://www.crcpress.com/Small-Hydroelectric-Engineering-Practice/Leyland/9781138000988

Ligon, F. K., W. E. Dietrich, and W. J. Trush. 1995. "Downstream ecological effects of dams." BioScience 45(3), 183-192.

LIHI (Low Impact Hydropower Institute). 2014. Revised LIHI Certification Criteria: A proposed new approach for 2014. Low Impact Hydropower Institute, Technical Committee. http://lowimpacthydro.org/assets/files/Criteria/Revised\%20LIHI\%20Criteria\%20$\% 20$ public\%20release\%20-\%2008192014\%20-\%20FINAL.pdf.

Linard, J. and E. Hansen. 2013. "Extreme dam building." Water Power and Dam Construction. January 18. http://www.waterpowermagazine.com/projectprofiles/projectprofilesextreme-dam-building/.

Marex Spectron. 2015. "Renewable energy certificates: REC prices.” The Green Power Network. US Department of Energy Office of Energy Efficiency and Renewable Energy. http://apps3.eere.energy.gov/greenpower/markets/certificates.shtml?page=5.

McManamay, R. A., M. S. Bevelhimer, and S-C. Kao. 2014. "Updating the US hydrologic classification: An approach to clustering and stratifying ecohydrologic data." Ecohydrology 7(3), 903-926.

McManamay, R.A., N. Samu, S-C. Kao, M. S. Bevelhimer, and S. C. Hetrick. 2015. “A multi-scale spatial approach to address environmental effects of small hydropower development." Environmental Management 55, 217-243. http://link.springer.com/article/10.1007/s00267-0140371-2

Mih, W. C. (1978). "A review of restoration of stream gravel for spawning and rearing of salmon species." Fisheries 3, 16-18.

Minott, D. and R. Delisser. 1983. “Cost reduction considerations in small hydropower development.” In Proceedings from the United Nations Industrial Development Organization: Third Workshop on Small Hydropower. Kuala Lumpur, Malaysia.

Newman D. and P. Munslow. 2010. "River Medway Canoe Trail: Projects to increase recreational use, and the ecological status, of the River Medway in Kent." UK Water Projects.

http://www.waterprojectsonline.com/case_studies/2010/EA_River_Medway_Canoe_2010.pdf

Noonan, M. J., J.W.A. Grant, and C. D. Jackson. 2012. "Quantitative assessment of fish passage efficiency." Fish and Fisheries 13, 450-464.

O’Connor, P. W., S. T. DeNeale, D. R. Chalise, E. Centurion, and A. Maloof. 2015. Hydropower Baseline Cost Modeling, Version 2. ORNL/TM 2015/471. Oak Ridge National Laboratory. 
Oregon. 2012. Oregon Small Hydropower Technology and Market Assessment. Summit Blue Consulting for Energy Trust of Oregon, Portland. http://www.oregon.gov/energy/P-

I/Hydro/docs/090126_Small_hydropower.pdf

OTA (Office of Technology Assessment). 1995. Fish Passage Technologies: Protection at Hydropower Facilities. OTA-ENV-641. US Government Printing Office, Washington, DC.

http://ota.fas.org/reports/9519.pdf

Paish, O. 2002. "Small hydro power: Technology and current status." Renewable and Sustainable Energy Reviews, 537-556.

Palit, D. and A. Chaurey. 2011. "Off-grid rural electrification experiences from South Asia: Status and best practices.” Energy for Sustainable Development, 266-276.

Papanicolaou, A.N.T. and A. Tsakiris. 2012. Use of Fiber Bragg Grating (FBG) Sensors for Performing Automated Bridge Pier Structural Damage Detection and Scour Monitoring. 25-1121-0001-472. University of Nebraska, Lincoln. http://ntl.bts.gov/lib/46000/46600/46671/Papanicolaou_472_Use_of_Fiber_Bragg_Grating_FIN AL_COMBINED.pdf

Peng, W. and J. Pan. 2006. "Rural electrification in China: History and institution." China \& World Economy 14, 71-84.

Poff, N. L., J. D. Allan, M. B. Bain, J. R. Carr, K. L. Prestegaard, B. D. Richter, R. E. Sparks, and J. C. Stromberg. 1997. "The natural flow regime: A new paradigm for riverine conservation and restoration." BioScience 47(11), 769-784.

Poff, N. L. and J.K.H. Zimmerman. 2010. "Ecological responses to altered flow regimes: A literature review to inform the science and management of environmental flows." Freshwater Biology 55(1), 194-205. http://www.wrb.state.ri.us/documents/Poff_Zimmerman_2009_FWB.pdf

Poindexter, G. B. 2015. "India's national mission on small hydro, rehabilitation and development of hydroelectric projects up to $25 \mathrm{MW}$." HydroWorld.com.

http://www.hydroworld.com/articles/2015/02/india-s-national-mission-on-small-hydrorehabilitation-and-development-of-hydroelectric-projects-up-to-25-mw.html (accessed March 7, 2016).

Pracheil, B. M., M. A. Pegg, and G. E. Mestl. 2009. "Tributaries influence recruitment of fish in large rivers." Ecology of Freshwater Fish 18, 603-609.

Pracheil, B. M., C. R. DeRolph, M. P. Schramm, and M. S. Bevelhimer. 2016. “A fish-eye view of riverine hydropower systems: The current understanding of the biological response to turbine passage." Reviews in Fish Biology and Fisheries, 1-15.

Reich, S. 2015. "StreamDiver: New plant concept for low head hydropower." Voith. http://www.britishhydro.org/downloads/4.2\%20Stefan\%20Reich\%20(Final).pdf.

REN21. 2015. REN21 Renewables 2015 Global Status Report: Renewable Energy Integration. Renewable Energy Policy Network for the 21st Century. https://cleanenergysolutions.org/training/ren21-renewables-2015-global-status-report-renewableenergy-integration 
Richter, B. D., J. V. Baumgartner, J. Powell, and D. P. Braun. 1996. "A method for assessing hydrologic alteration within ecosystems." Conservation Biology 10(4), 1163-1174.

Richter, B. D. and G. A. Thomas. 2007. "Restoring environmental flows by modifying dam operations." Ecology and Society 12(1), 12. http://www.ecologyandsociety.org/vol12/iss1/art12.

Rosgen, D. L. 1994. “A classification of natural rivers.” Catena 22, 169-199.

Sale, M. J., G. F. Cada, L. H. Chang, S. W. Christensen, S. F. Railsback, J. E. Francfort, B. N. Rinehart, and G. L. Sommers. 1991. Environmental Mitigation at Hydroelectric Projects. Volume 1. Current Practices for Instream Flow Needs, Dissolved Oxygen, and Fish Passage (DOE/ID10360). Department of Energy. http://www1.eere.energy.gov/water/pdfs/doewater-10360vol.1.pdf

Schilt, C. 2007. "Developing fish passage and protection at hydropower dams." Applied Animal Behaviour Science 104, 295-325.

Schmidt, J. C. and P. R. Wilcock. 2008. "Metrics for assessing the downstream effects of dams." Water Resources Research 44I. http://onlinelibrary.wiley.com/doi/10.1029/2006WR005092/abstract

Schwartz, F. H. and M. Shahidehpour. 2006. "Small hydro as green power." In 2006 IEEE EIC Climate Change Conference, pp. 1-6. Ottawa, Ontario, Canada, May 10-12, 2006.

Schweiger, P. G., L. Aadland, D. Roarabaugh, E. Neast, and C. Hoover. 2011. "Improving fish passage and public safety at low head dams," in 21st Century Dam Design-Advances and Adaptations, Proceedings from the 31st Annual USSD Conference, pp. 1299-1318. San Diego, California, April 11-15, 2011. United States Society on Dams.

Scott, M. B., P. J. Snyder, M. P. Walker, and P. H. Black. 2008. "Building RCC dams on sand foundations." International Water Power \& Dam Construction.

http://www.waterpowermagazine.com/features/featurebuilding-rcc-dams-on-sand-foundations/

Shen, W. S. 1999. "Flushing sediment through reservoirs." Journal of Hydraulic Research, 37(6), 743757.

Skalski, J. R., G. E. Johnson, C. M. Sullivan, E. Kudera, and M. W. Erho. 1996. "Statistical evaluation of turbine bypass efficiency at Wells Dam on the Columbia River, Washington." Canadian Journal of Fisheries and Aquatic Sciences 53(10), 2188-2198.

Smith, B. T., A. Witt, K. M. Stewart, K. Lee, S. DeNeale, and M. Bevelhimer. 2017. A Multi-Year Plan for Research, Development, and Prototype Testing of Standard Modular Hydropower Technology/RI ORNL/TM-2016/102, Oak Ridge National Laboratory.

Sobczyk, T., T. Wegiel, M. Grahl-Madsen, and M. Styrylski. 2010. "Integrated turbine with PM generator for small hydro-power plants.” Technical Transactions, 99-111.

Stranne, G., U. Nygren, L. Messing, M. Callavik, L. Balgard, B. Rothman,... M. Lindberg. 2005. "Integration of protection, control, monitoring, and remote communication into one intelligent electronic device for small hydro-power plants." ASEA Brown, Boveri \& Cie. https://library.e.abb.com/public/6ec0ea243f8e314bc12570110031ea3e/SA2005- 
000518_en_Integration_of_Protection_CControl_Monitoring_and_Remote_Communication_int o_One_Intelligent_Electron.pdf (accessed March 8, 2016).

Thomas, J. T., M. E. Culler, D. C. Dermisis, C. L. Pierce, A. N. Papanicolaou, T. W. Stewart, and C. J. Larson 2011. "Effects of grade control structures on fish passage, biological assemblages, and hydraulic environments in western Iowa streams: A multidisciplinary review." River Research and Applications. doi: 10.1002/rra.1600

TN SHP (Thematic Network on Small Hydropower). 2005. Proposals for a European Strategy of Research, Development and Demonstration $(R D \& D)$ for Renewable Energy from Small Hydropower. Thematic Network On Small Hydropower.

http://www.esha.be/fileadmin/esha_files/documents/publications/publications/Stra_doc_summary _2005.pdf

Tsakiris, A. G., A.T.N. Papanicolaou, and T. J. Lauth. 2014. "Signature of bedload particle transport mode in the acoustic signal of a geophone." Journal of Hydraulic Research 52(2), 185-204.

Tsakiris, A. G., A. N. Papanicolaou, I. V. Moustakidis, and B. K. Abban. 2015. "Identification of the burial depth of radio frequency identification transponders in Riverine applications." Journal of Hydraulic Engineering 141(6).

UNIDO and ICSHP (United Nations Industrial Development Organization). 2013. World Small Hydropower Development Report 2013: Executive Summary. United Nations Industrial Development Organization.

http://www.unido.org/fileadmin/user_media_upgrade/What_we_do/Topics/Energy_access/WSHP DR_2013_Executive_Summary.pdf.

Uría-Martinez, R., P. W. O’Connor, and M. M. Johnson. 2015. Hydropower Market Report. Wind and Water Power Technologies Office, US Department of Energy.

USACE (US Army Corps of Engineering). 1978. Feasibility Studies for Small Scale Hydropower Additions. US Army Corps of Engineering, Hydrologic Engineering Center. http://www.hec.usace.army.mil/publications/ProjectReports/PR-3.pdf

USACE (US Army Corps of Engineering). 2009. Technical Analysis of Pumped Storage and Integration with Wind Power in the Pacific Northwest. US Army Corps of Engineers Northwest Division Hydroelectric Design Center. http://www.hydro.org/wp-content/uploads/2011/07/PS-WindIntegration-Final-Report-without-Exhibits-MWH-3.pdf

USACE (US Army Corps of Engineering). 2013. Hydropower Resource Assessment at Non-powered USACE Sites. Final report. US Army Corps of Engineering Hydrologic Engineering Center. http://www.hydro.org/wp-content/uploads/2014/01/Army-Corps-NPD-Assessment.pdf

USBR (Bureau of Reclamation). 1987. Design of Small Damns (5th ed.). United States Department of the Interior. http://www.usbr.gov/tsc/techreferences/mands/mands-pdfs/SmallDams.pdf

USBR (Bureau of Reclamation). 2011. Hydropower Program: Hydropower Resource Assessment at Existing Reclamation Facilities. U.S. Department of the Interior, Denver, Colorado.

USBR (Bureau of Reclamation). 2012. Site Inventory and Hydropower Energy Assessment of Reclamation-owned Conduits. US Department of the Interior, Denver, Colorado. 
WAPA (Western Area Power Administration) and USBR (US Bureau of Reclamation. 2005. Replacements, Units, Service Lives, Factors. WAPA and USBR. December.

Ward, J. V. and Stanford, J. A. 1983. "The serial discontinuity concept of lotic ecosystems." Dynamics of Lotic Ecosystems 10, 29-42.

Whittaker, D., B. Shelby, and J. Gangemi. 2005. Flows and Recreation: A Guide to Studies for River Professionals. Whittaker, Shelby, \& Gangemi, and the Hydropower Reform Coalition, Washington, DC. https://www.nps.gov/hydro/flowrec.pdf

Wild, T., D. Loucks, G. Annandale, and P. Kaini. 2015. "Maintaining sediment flows through hydropower dams in the Mekong River Basin." J. Water Resour. Plann. Manage., 42(1). doi: 10.1061/(ASCE)WR.1943-5452.0000560.

Wilson, M. A. and S. R. Carpenter. 1999. "Economic valuation of freshwater ecosystem services in the United States: 1971-1997." Ecological Applications 9(3), 772-783.

Witt, A., B. T. Smith, A. Tsakiris, T. Papanicolaou, K. Lee, and K. M. Stewart. 2017. Exemplary Design Envelope Specification for Standard Modular Hydropower Technology/R1, ORNL/TM-2016/298, Oak Ridge National Laboratory.

WOU. 2004. "Salmonid spawning gravel cleaning and placement." https://www.wou.edu/las/physci/taylor/g407/restoration/WA_Dept_Forestory_2004_Spawning_ Gravel_Maintenance_Techniques.pdf

Wright, J. 2010. "Investment in Small Hydropower: Prospects of Expanding Low-Impact and Affordable Hydropower Generation in the West." Oversight Hearing before the Committee on Natural Resources, Subcommittee on Water and Power, United States House of Representatives. July 29, 2010. http://www.ferc.gov/EventCalendar/Files/20100729101535-7-29-10-Wright.pdf. Accessed July 2016.

Zhang, Q.F.K., B. Smith, and W. Zhang. 2012. Small Hydropower Cost Reference Model. ORNL/TM2012/501. Oak Ridge National Laboratory. http://info.ornl.gov/sites/publications/files/pub39663.pdf

Ziv, G., E. Baran, S. Nam, I. Rodriguez-Iturbe, and S. A. Levin. 2012. "Trading-off fish biodiversity, food security, and hydropower in the Mekong River Basin." Proceedings of the National Academy of Sciences 109(15), 5609-5614. 



\section{APPENDIX A. TERMINOLOGY}





\section{Key Terminology for Hydropower}

As a well-established industry dating to the 19th century, hydropower has been defined by many individuals, organizations, and federal agencies. For more information on commonly used terms and definitions, visit the following resources:

American Society of Civil Engineers' Guidelines for Design of Intakes for Hydroelectric Plants http://ascelibrary.org/doi/abs/10.1061/9780784400739.bm

Federal Emergency Management Agency's Federal Guidelines for Dam Safety: Glossary of Terms http://www.ferc.gov/industries/hydropower/safety/guidelines/fema-148.pdf

Federal Energy Regulatory Commission's Glossary http://www.ferc.gov/resources/glossary.asp

North American Electric Reliability Corporation's Glossary of Terms Used in NERC Reliability Standards http://www.nerc.com/files/glossary of terms.pdf

U.S. Bureau of Reclamation's Glossary of Hydropower Terms https://www.usbr.gov/power/edu/Glossary\%20of\%20Hydropower\%20Terms.pdf

U.S. Department of Energy's Glossary of Hydropower Terms http://energy.gov/eere/water/glossaryhydropower-terms

\section{Key Terminology for Standard Modular Hydropower}

Design Envelope. A conceptual collection of objectives, requirements, constraints, and measures of performance that collectively form a design environment.

Functional Decomposition. The process of developing and analyzing facility and module objectives, requirements, functional relationships, constraints, and measures of performance and determining how they are accounted for in facility design:

Objective: The function to be achieved as a result of deploying and operating a module or facility.

Requirement: A feature of a module or facility that (1) is essential to achieving the primary objective; (2) is verifiable through testing, measurement, or observation; and (3) in combination with other requirements, indicates that the module or facility is achieving its primary objective. Requirements are prescribed as functional, performance, interface, or a combination thereof. Functional requirements relate to the actions a module must perform; performance requirements are quantified by how well a module must perform a function; and interface requirements involve interactions with other modules. When prescribed in this way, requirements can be assessed on both an individual module scale and a holistic facility scale.

Functional relationship. A key physical, chemical, or biological interaction associated with the operation or performance of an SMH facility.

Constraint. A limitation on the value of a design parameter, requirement, or functional relationships, or a limitation on an effect of deployment or operation that must be satisfied and verifiable to ensure feasibility of a module or facility. 
Measures of Performance: A set of quantifiable indices or metrics that enable the evaluation of a module with respect to how well it accomplishes specific and primary technical objectives.

Holistic Design. A design philosophy that seeks to embed environmental, infrastructure, regulatory, and economic requirements and constraints into the technology design process.

Modularity. The physical or virtual organization of system components into discrete functional units, known as modules.

Module. A discrete functional unit or units with a dedicated purpose that, either independently or in combination with other modules, achieve a configuration appropriate for the scale and environmental context of the site selected for development. In the SMH context, five primary modules are considered:

Foundation module. A module situated between the streambed and passage and/or generation modules dedicated to resisting the forces of operation and supporting or bearing the loads imparted by modules and the environment.

Generation module. A module with dedicated functionality for hydroelectric power generation.

Installation module. A physical and virtual module that is used for placing SMH modules in a stream.

Interconnection module. A module with dedicated functionality for transmitting electrical power from an SMH facility to a customer.

Passage module. A module with dedicated functionality for the upstream to downstream passage of water, sediment, recreational craft, and fish, or the downstream to upstream passage of fish.

SMH Research Pillars. Coordinated research paths used to define and focus SMH research, development, and demonstration activities. The four SMH Research Pillars, as envisioned, are the Exemplary Design Envelope Specification, Simulation and Modeling Capability, Testing and Validation Capability, and Site Classification Scheme.

Exemplary Design Envelope Specification. An SMH Research Pillar associated with identifying and specifying the unique module and system characteristics needed for holistic SMH facility design, including the objectives, requirements, and constraints.

Simulation and Modeling Capability. An SMH Research Pillar associated with enabling SMH performance, reliability, manufacturability, and cost estimation and simulating design trade-offs.

Site Classification Scheme. An SMH Research Pillar associated with developing a set of attributes, potential impacts, and a classification scheme for determining which standardized assessment scheme components are needed for development and which technology modules are needed and compatible with development of a site.

Testing and Validation Capability. An SMH Research Pillar associated with enabling design testing and validation at partial or full scale.

Simulation and Modeling Scales. The categorization and extent of the physical domain for which length and temporal scale considerations are important for the simulation and modeling of processes associated with the SMH design and operation. 
System Scale. Pertaining to and/or associated with the general size and vicinity occupied by a collection of modules (facility) and the affected extents of the environment (e.g., river, watershed) containing the system. Module and component level references are generally contained within the system scale.

Module Scale. Pertaining to and/or associated with the general size and vicinity occupied by a module. Component level references are generally contained within the module scale.

Stakeholder. A person, entity, business, organization, or agency with an interest in hydropower. Key stakeholder categories identified in the SMH MYRP include Advocacy and Outreach, Electric Utilities, Hydropower Asset Owners, Project Development Interests, Regulatory and Standards Agencies, Resource Managers, Standards and Certification Entities, Technology Developers, and Water Management and Allocation.

Standard Modular Hydropower. A class of small hydropower employing technology standardization and modularity.

Standardization. A framework of guidelines, rules, and specifications (i.e., standards) implemented to maximize compatibility, acceptance, interoperability, safety, repeatability, or quality and minimize environmental disturbance. In a hydropower context, standardization of design, review, regulation, manufacturing, operations, and maintenance, and other features is intended to reduce site specificity and project costs. 

APPENDIX B. RECENT AND ONGOING DOE WATER POWER PROGRAM R\&D ACTIVITIES RELATED TO SMH 



\title{
Recent and Ongoing DOE-Water Power Program R\&D Activities Related to SMH
}

The following material lists hydropower awards granted from 2015 to 2016 by DOE which may be relevant to SMH technology acceleration. As these ventures progress, DOE and ORNL will assess how specific technologies and methods may be incorporated with or aligned to the SMH concept to advance SMH paradigms.

\section{DE-FOA-0001455: HydroNEXT: Innovative Technologies to Advance Non-Powered Dam and Pumped Storage Hydropower Development}

As a part of a 2017 funding opportunity, DOE awarded up to $\$ 9.8$ million for next-generation hydropower technologies. ${ }^{43}$ The funding targets development of

\begin{abstract}
"innovative technologies that will reduce capital costs and deployment timelines for pumpedstorage hydropower and non-powered dams...The non-powered dam (NPD) technology projects will help tap this resource by supporting the development of low-head, modular designs, which use separate, similar components that can be easily integrated and scaled to greater capacities. Modular designs can reduce infrastructure and construction costs and operate flexibly over a range of conditions at existing dams."
\end{abstract}

The following is an excerpt from the DOE webpage detailing the successful proposals related to nonpowered dam development.

- Natel Energy, Inc. of Alameda, California, will test a laboratory-scale Linear Pelton (LP) hydroEngine turbine. The aim of the technology is to increase the number of economically viable projects at non-powered dams by reducing the amount of civil works modifications as well as maintaining a high efficiency.

- Canyon Hydro of Deming, Washington, will optimize the design of the traditional Archimedes Screw for use in low-head, high-flow hydroelectric sites. The technology will reduce manufacturing and transportation costs through its innovative, fish-safe, modular turbine blade design.

- Rickly Hydrological Company of Columbus, Ohio, will design and laboratory-test advanced powertrain, modular infrastructure components, and design software to simplify small hydropower development at non-powered dams. The project focuses on a site development approach that can be applied to other hydropower technologies

\section{DE-FOA-0001286: Research and Development of Innovative Technologies for Low Impact Hydropower Development}

As a part of a 2015 funding opportunity, DOE awarded $\$ 6.5$ million for the advancement of hydropower technologies offering low environmental impact. ${ }^{44}$ Among the proposals awarded funding, a few have direct ties to hydropower foundation technology. The following is an excerpt from the DOE webpage detailing the successful proposals.

\footnotetext{
${ }^{43}$ https://energy.gov/eere/water/articles/energy-department-awards-98-million-next-generation-hydropowertechnologies

${ }^{44}$ http://energy.gov/eere/articles/energy-department-awards-65-million-advance-low-environmental-impacthydropower
} 


\section{Powertrain Component Innovations}

- Percheron Power, LLC, of Kennewick, Washington, in collaboration with Utah Water Resource Laboratory, Hertelendy Research Associates, and Pacific Northwest National Laboratory, will develop advanced components for use in Archimedes Hydrodynamic Screw (AHS) turbine systems. The advanced components will help improve the efficiency of AHS style turbines and could result in domestic manufacturing of a composite AHS turbine.

- Composite Technology Development, Inc., of Lafayette, Colorado, will develop composite turbine runners suitable for small hydropower systems. The use of composite materials can reduce the LCOE - a measure of the overall competiveness of different generating technologies — by improving fatigue, corrosion, and erosion resistance while reducing maintenance and transportation costs.

- Emergy Hydro ${ }^{45}$ of Atlanta, Georgia, in collaboration with Ricardo USA, Georgia Tech, and the City of Atlanta, will develop a platform magnetic gear technology to be used with commercial off-theshelf components in order to complete the most reliable and cost-effective low-impact hydropower drivetrain available. The technology will improve drivetrain reliability and significantly reduce overall maintenance. Rapidly Deployable Hydropower Civil Works Technologies

\section{Rapidly Deployable Hydropower Civil Works Technologies}

- Littoral Power Systems Inc. of Monmouth Junction, New Jersey, in collaboration with Alden Research Lab, University of Massachusetts-Dartmouth, and the National Renewable Energy Laboratory, will develop a proof-of-concept design of integrated modules for an integrated dam section. The full-size prototype will be tested for structural integrity, leak resistance, and ease of installation. The technology has the potential to lower construction and maintenance times and costs.

- French Development Enterprises LLC of Billerica, Massachusetts, in collaboration with Alden Labs and Oldcastle Precast, will develop a building-block style impoundment technology, which utilizes precast concrete segments with interlocking elements to provide rapid in-field installation and removal. Using prefabricated concrete panels in dam construction could significantly reduce construction time and costs.

\section{Innovative Methods and Materials for Hydropower Construction}

- Colorado School of Mines of Golden, Colorado, will conduct a study on the use of a cofferdam-a temporary enclosure built within a body of water to create a dry work environment - as a basis for the design and construction of permanent water-retaining structures to sustainably and cost-effectively harness hydropower. The research could significantly reduce dam construction time and cost.

- North Dakota State University of Fargo, North Dakota, in collaboration with the Institute for Transportation of Iowa State University, will develop a technique that uses basalt fiber impregnation to increase durability and reduce cracking and shrinkage of concrete. This product could reduce the cost and maintenance of concrete used in hydropower projects.

\footnotetext{
${ }^{45}$ Now called Emrgy, Inc.
} 


\section{Small Business Innovation Research (SBIR)}

From the SBIR website:

The Small Business Innovation Research (SBIR) program is a highly competitive program that encourages domestic small businesses to engage in Federal Research/Research and Development $(R / R \& D)$ that has the potential for commercialization. Through a competitive awards-based program, SBIR enables small businesses to explore their technological potential and provides the incentive to profit from its commercialization. By including qualified small businesses in the nation's $R \& D$ arena, high-tech innovation is stimulated and the United States gains entrepreneurial spirit as it meets its specific research and development needs.

2016 Awards (Phase I, Release 2)46

- Concepts NREC, LLC of White River Junction, Vermont - Because of costly infrastructure and environmental obstacles, the vast power of America's waterways is largely undeveloped. The proposed solution - a low-cost, modular, hydroelectric turbine generator unit — can be used in previously untapped locations. The proposed unit minimizes upfront costs and recurring maintenance costs, and reduces environmental impact.

- E-Motors Consulting, LLC of Menomonee Falls, Wisconsin - A team including two Wisconsin start-ups and the University of Wisconsin-Milwaukee is developing innovative technology solutions to harvest the vast energy resources available from water in smaller rivers and man-made channels, particularly where little height is available (less than 10'). Their proposed solution integrates an electric generator with a turbine and water conduit made from state-of-the-art, 3D printed elements.

- Magnetic Power-Motion, LLC of Floyds Knobs, Indiana - This project will focus on the development of an advanced hydroelectric generator for use in streams, rivers, and canals. This system is expected to be smaller, lighter, and more efficient than current technology and better able to exploit the energy production potential of our nation's river resources.

- Mechanical Solutions, Inc. of Whippany, Maine - Rivers have the potential to double current hydraulic electric power produced in the USA on a relatively non-intrusive and environmentally friendly basis. Developing a modular, compact, low cost, very low head (pressure) hydraulic turbine is needed to unlock this potential resource.

\section{Awards (Phase I, Release 2) ${ }^{47}$}

- Cadens, LLC of Sullivan, Wisconsin - The process of designing unique electricity-generating turbines for smaller rivers opens the door to using a largely untapped source of domestic renewable energy. A novel manufacturing technique, consisting of printing the material in three dimensions, together with advanced computing techniques, will provide a low cost, efficient and stream-specific solution.

\section{$\underline{\text { Small Business Vouchers (SBV) }}$}

\section{Round 1 Winners}

- Percheron Power ${ }^{48}$

\footnotetext{
${ }^{46} \mathrm{http}: / /$ science.energy.gov/sbir/awards/

47 http://science.energy.gov/sbir/awards/

48 https://www.sbv.org/a/pages/level3-water-round1-2
} 